
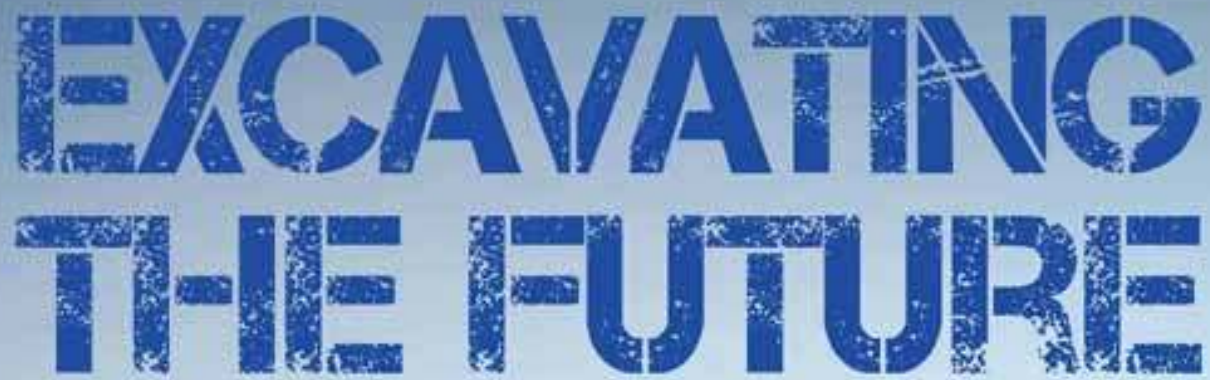

Archaeology and Geopolitics in Contemporary north American Science Fiction Film and Television

\title{
SH-IAW/N MAI_IIEY]
}

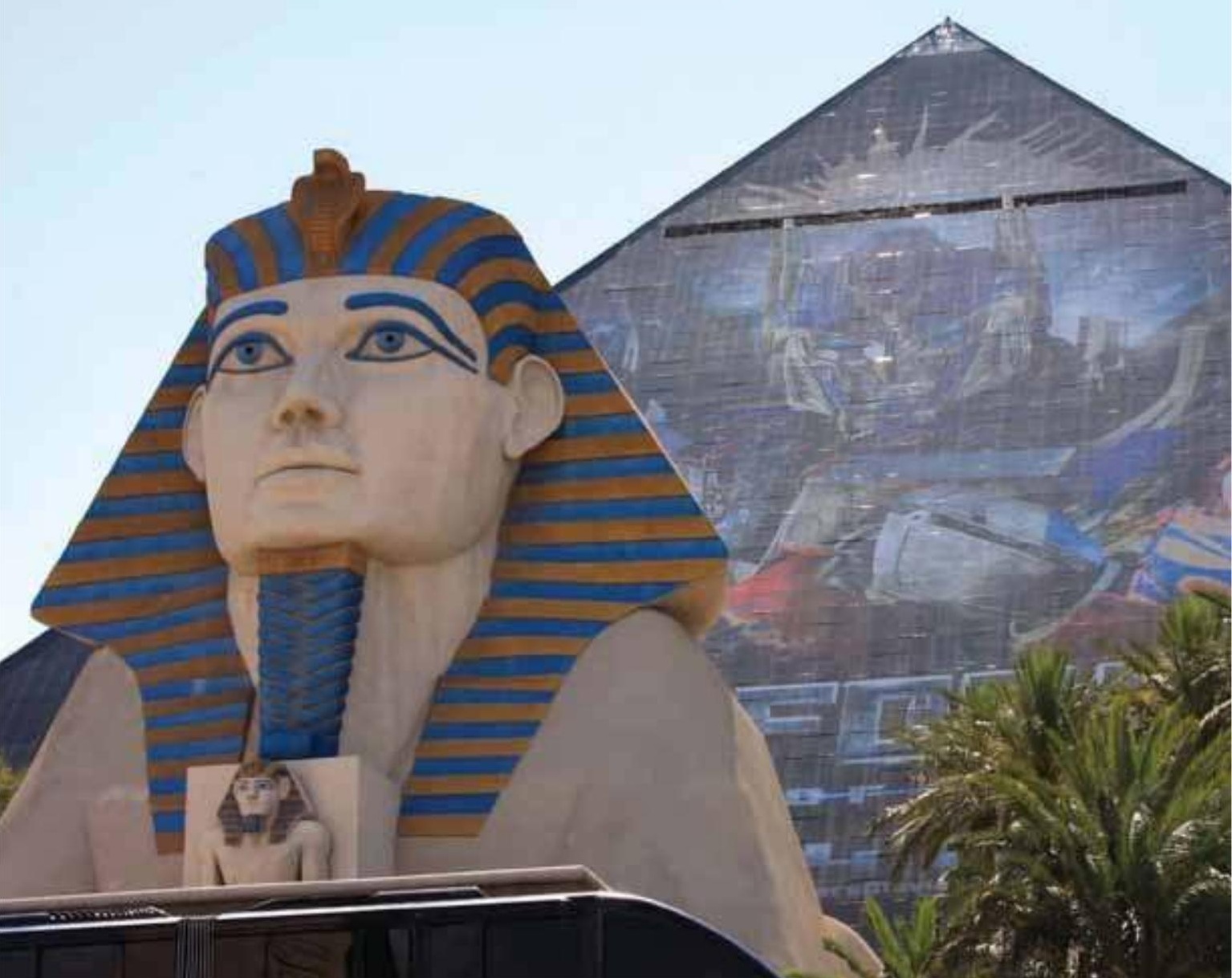




\title{
Liverpool Science Fiction Texts and Studies
}

\author{
Editor David Seed, University of Liverpool \\ Editorial Board \\ Mark Bould, University of the West of England \\ Veronica Hollinger, Trent University \\ Rob Latham, University of California \\ Roger Luckhurst, Birkbeck College, University of London \\ Patrick Parrinder, University of Reading \\ Andy Sawyer, University of Liverpool
}

\section{Recent titles in the series}

34. Mike Ashley Gateways to Forever: The Story of the Science-Fiction Magazine from 1970-1980

35. Patricia Kerslake Science Fiction and Empire

36. Keith Williams H. G. Wells, Modernity and the Movies

37. Wendy Gay Pearson, Veronica Hollinger and Joan Gordon (eds.) Queer Universes: Sexualities and Science Fiction

38. John Wyndham (eds. David Ketterer and Andy Sawyer) Plan for Chaos

39. Sherryl Vint Animal Alterity: Science Fiction and the Question of the Animal

40. Paul Williams Race, Ethnicity and Nuclear War: Representations of Nuclear Weapons and Post-Apocalyptic Worlds

41. Sara Wasson and Emily Alder, Gothic Science Fiction 1980-2010

42. David Seed (ed.), Future Wars: The Anticipations and the Fears

43. Andrew M. Butler, Solar Flares: Science Fiction in the $1970 \mathrm{~s}$

44. Andrew Milner, Locating Science Fiction

45. Joshua Raulerson, Singularities

46. Stanislaw Lem: Selected Letters to Michael Kandel (edited, translated and with an introduction by Peter Swirski)

47. Sonja Fritzsche, The Liverpool Companion to World Science Fiction Film 48. Jack Fennel: Irish Science Fiction

49. Peter Swirski and Waclaw M. Osadnik: Lemography: Stanislaw Lem in the Eyes of the World

50. Gavin Parkinson (ed.), Surrealism, Science Fiction and Comics

51. Peter Swirski, Stanislaw Lem: Philosopher of the Future

52. J. P. Telotte and Gerald Duchovnay, Science Fiction Double Feature:

The Science Fiction Film as Cult Text

53. Tom Shippey, Hard Reading: Learning from Science Fiction

54. Mike Ashley, Science Fiction Rebels: The Story of the Science-Fiction Magazines from 1981 to 1990

55. Chris Pak, Terraforming: Ecopolitical Transformations and Environmentalism in Science Fiction

56. Lars Schmeink, Biopunk Dystopias: Genetic Engineering, Society,

and Science Fiction 


\title{
EXCAVATING THE FUTURE
}

\author{
Archaeology and Geopolitics \\ in Contemporary North American \\ Science Fiction Film and Television
}

SHAWN MALLEY 
First published 2018 by Liverpool University Press

4 Cambridge Street

Liverpool

L69 7ZU

\section{Copyright () 2018 Shawn Malley}

The right of Shawn Malley to be identified as the author of this book has been asserted by him in accordance with the Copyright, Designs and Patents Act 1988.

All rights reserved. No part of this book may be reproduced, stored in a retrieval system, or transmitted, in any form or by any means, electronic, mechanical, photocopying, recording, or otherwise, without the prior written permission of the publisher.

British Library Cataloguing-in-Publication data

A British Library CIP record is available

print ISBN 978-1-78694-119-0

epdf ISBN 978-1-78694-873-1

Typeset by Carnegie Book Production, Lancaster 
To my feline companions past and present, Pringles, Tulip, Linus, Willow, Kizzie, Pompidou, Edgar and Biscuit, for teaching me so much about humanity. 



\section{Contents}

List of Figures $\quad$ xi

Acknowledgements $\quad$ XV

Introduction 1

Part 1: Battling Babylon: Military SFFTV and the War on Terror 19

1. Manticore 31

2. Stargate $S G-1 \quad 44$

3. Transformers 2: Revenge of the Fallen 59

Part 2: Of Artefacts and Ancient Aliens 73

4. Ancient Aliens $\quad 82$

5. Indiana Jones and the Kingdom of the Crystal Skull 95

6 Smallville $\quad 112$

Part 3: Cyborg Sites: The Case of A.I. Artificial Intelligence 135

$\begin{array}{ll}\text { 7. Battlestar Galactica } & 145\end{array}$

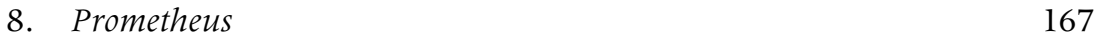

$\begin{array}{ll}\text { Envoi } & 191\end{array}$

$\begin{array}{lr}\text { Works Cited } & 198\end{array}$

$\begin{array}{ll}\text { Index } & 223\end{array}$ 

This reversal is a worldwide phenomenon. It is now becoming clear that everything we once thought dead and buried, everything we thought left behind for ever by the ineluctable march of universal progress, is not dead at all, but on the contrary likely to return-not as some archaic or nostalgic vestige (all our indefatigable museumification notwithstanding), but with a vehemence and a virulence that are modern in every sense-and to reach the very heart of our ultra-sophisticated but ultra-vulnerable systems, which will easily convulse from within without mounting a frontal attack. Such is the destiny of radical otherness-a destiny that no homily of reconciliation and no apologia for difference is going to alter.

Jean Baudrillard, from The Transparency of Evil (138) 



\section{List of Figures}

\section{Introduction}

1. 2001: A Space Odyssey. Stanley Kubrick, director, producer (MGM, 1968).

\section{Part 1: Battling Babylon:}

\section{Military SFFTV and the War on Terror}

2. Metropolis. Fritz Lang, director, Erich Pommer, producer (UFA, 1927).

3. Blade Runner. Ridley Scott, director, Michael Deeley, producer (Warner Bros., 1982).

4. Babylon 5. John Copeland, series producer (Babylonian Productions, 1994).

\section{Chapter 1: Manticore}

5. Manticore. Tripp Reed, director, Jeffery Beach, producer (UFO International Productions, 2005).

\section{Chapter 2: Stargate SG-1}

6. Stargate. Roland Emmerich, director, Dean Devlin and Oliver Eberle, producers (Canal+, 1994).

7. Stargate SG-1, 'The Tomb.' Peter DeLuise, director, Joseph Mallozzi and Paul Mullie, supervising producers (Sony

Pictures Television, 2001). 
8. Stargate SG-1, 'Babylon.' Peter DeLuise, director, John G. Lenic, producer (Sony Pictures Television, 2005).

\section{Chapter 3: Transformers 2: Revenge of the Fallen}

9. Transformers 2: Revenge of the Fallen. Michael Bay, director, Ian Bryce, Tom DeSanto, Lorenzo di Bonaventura and Don Murphy, producers (DreamWorks Pictures, 2009).

\section{Part 2: Of Artefacts and Ancient Aliens}

10. Planet of the Apes. Franklin J. Schaffner, director, Arthur P. Jacobs, producer (20th Century Fox, 1968).

\section{Chapter 4: Ancient Aliens}

11. Ancient Aliens, 'The Evidence.' Alex Chionetti and Brian Coughlin, producers (Prometheus Entertainment, 2010).

12. Ancient Aliens, 'The Mayan Conspiracy.' David Osper, producer (Prometheus Entertainment, 2012).

\section{Chapter 5: Indiana Jones and the Kingdom of the Crystal Skull}

13. Indiana Jones and the Kingdom of the Crystal Skull. Steven Spielberg, director, Frank Marshall, producer (Paramount Pictures, 2008).

\section{Chapter 6: Smallville}

14. Smallville, 'Skinwalker.' Marita Grabiak, director, Robert Hargrove, producer (Warner Bros. Television, 2002).

15. Smallville, 'Absolute Justice.' Tom Welling and Glen Winter, directors, Anne Cofell Saunders and Rob Maier, producers (Warner Bros. Television, 2010).

16. Smallville, 'Shield.' Glen Winter, director, Tom Flores, Holly Henderson and Don Whitehead, producers (Warner Bros. Television, 2010).

17. Smallville, 'Icarus.' Mairzee Almos, director, Tom Flores, Holly Henderson and Don Whitehead, producers (Warner Bros. Television, 2010). 
18. Smallville, 'Beacon.' Mike Rohl, director, Tom Flores, Holly Henderson and Don Whitehead, producers (Warner Bros. Television, 2010).

19. Smallville, 'Finale.' Greg Beeman and Kevin Fair, directors, Tom Flores and Scott Graham, producers (Warner Bros. Television, 2011).

\section{Part 3: Cyborg Sites: The Case of A.I. Artificial Intelligence}

20. A.I. Artificial Intelligence. Steven Spielberg, director, Bonnie Curtis, Kathleen Kennedy and Steven Spielberg, producers (Warner Bros., 2001).

\section{Chapter 7: Battlestar Galactica}

21. Battlestar Galactica, 'Flesh and Bone.' Brad Turner, director, Harvey Frand, producer (Universal Studios Home Entertainment, 2005).

22. Battlestar Galactica, 'Kobol's Last Gleaming: Part 1.' Michael Rymer, director, Harvey Frand, producer (Universal Studios Home Entertainment, 2005).

23. Battlestar Galactica, 'Kobol's Last Gleaming: Part 2.' Michael Rymer, director, Harvey Frand, producer (Universal Studios Home Entertainment, 2005).

24. Battlestar Galactica, 'Home: Part 2.' Jeff Woolnough, director, Harvey Frand, producer (Universal Studios Home Entertainment, 2006).

25. Battlestar Galactica, 'The Eye of Jupiter.' Michael Rymer, Bradley Thompson and David Weddle, producers (Universal Studios Home Entertainment, 2008).

26. Battlestar Galactica, 'Sometimes a Great Notion.' Michael Nankin, director, Harvey Frand, Ron French and Michael Rymer, producers (Universal Studios Home Entertainment, 2009).

27. Battlestar Galactica, 'Daybreak: Part 2, 3.' Michael Rymer, director, Harvey Frand, Ron French and Michael Rymer, producers (Universal Studios Home Entertainment, 2009). 


\section{Chapter 8: Prometheus}

28. Prometheus. Ridley Scott, director, David Giler, Walter Hill and Ridley Scott, producers (Twentieth Century Fox, 2012). 187 


\section{Acknowledgements}

For their generous financial support I thank Bishop's University and the Social Sciences and Humanities Research Council of Canada. Special thanks goes out to Sylvie Coté and Julie Frédette of Bishop's Office of Research, to Lee St. Onge and the staff at the John Bassett Library, to Nancy Robichaud and Monique Lafaille for their dedicated administrative assistance, and to my energetic and insightful research assistants Jeffrey Parent, Arian Fecteau and Jeanette Greven.

I would also like to express my appreciation to everyone at Liverpool University Press, especially for my editors, Anthony Cond and Jenny Howard, whose guidance was instrumental in bringing this project to completion, and to David Seed and the Editorial Advisory Board for their encouragement. Thanks too to the helpful and professional staff at Carnegie Book Production.

For their collaboration, discussions and companionship over the years, I wish to acknowledge the support of my friends and colleagues of the Science Fiction Research Association. For their help in seeing this manuscript through its various stages, warm thanks go out to Lisa Yaszek, Patrick Sharp, Sherryl Vint and Despina Kakoudaki, and for their various kindnesses and encouragement, to Peter Sands, Doug Davis, Ritch Calvin, Eric Otto, Craig Jacobsen, Amy Ransom, Joan Gordon, Veronica Hollinger, Steve Berman, Neil Easterbrook, Alfredo Suppia and Jason Ellis.

I also want to express my appreciation to Gregory Brophy, Andre Furlani, Sarah Fournier and the students with whom I have had the privilege of sharing my passion for SF.

My gratitude goes out most of all to my loving wife and companion, Grace Mazzocca, the coolest SF nerd in the galaxy. 



\section{Introduction}

The most characteristic SF does not seriously attempt to imagine the 'real' future of our social system. Rather, its multiple mock futures serve the quite different function of transforming our own present into the determinate past of something yet to come.

Fredric Jameson ${ }^{1}$

Casting a long shadow across the cinemagraphic landscape, the monolith in Stanley Kubrick's 2001: A Space Odyssey (1968) is arguably the most recognizable artefact in science fiction film. Simultaneously ancient and futuristic, this enigmatic signifier of the origin and evolution of homo technologus is an apropos 'site' to introduce the central concern of this book: digging up the past buried in the future of contemporary American science fiction film and television.

Two archaeological events are particularly germane: the appearance of the monolith in the 'Dawn of Man' sequence and the excavation of its lunar twin, Tycho Magnetic Anomaly-One. Each discovery imparts tremendous momentum to human evolution. When the monolith inspires 'Moon-Watcher' ${ }^{2}$ to wield a bone to hunt and then to defend territory and resources from competitors, we are confronted with an unflattering image of ourselves as agents of invention and progress. The famous match cut of the bone-which our progenitor euphorically hurls skyward after committing humanity's first murder-with the space station orbiting the Earth propels the audience on a jarring yet sensible evolutionary trajectory that renders inevitable the discovery of the second monolith

1 Jameson, 288.

2 For the purposes of this argument, I will use Arthur C. Clarke's nomenclature to refer to Kubrick's unnamed characters: i.e. Moon-Watcher and the Star Child. 
on the moon, astronaut David Bowman's discovery of the third monolith orbiting Jupiter, his psychedelic voyage 'into the infinite and beyond' and ultimate rebirth through the appearance of yet another monolith into the 'Star Child,' figured in the final sequence as the next phase of human development. Archaeology is a scientific touchstone and visual field for imagining humanity's progression from savages clubbing each other over the heads to sophisticated beings compelled to conquer outer space.

In 2001, archaeological 'discovery' conveys both the sense of finding something lost or hidden and of advancing scientific knowledge. But for artefacts that have no sensible historical referent outside the film text, they are, as film scholar Garry Leonard observes, 'unconcealed' in the epistemological structures erected around them. As intelligences motivated by the monoliths' evolutionary imperatives, Moon-Watcher and HAL describe a typology of consciousness that is decidedly violent and proprietary. The archaeological imagery offers a pointed critique of the film's SF premise. 'Buried, unburied, afloat in orbit, or in a dying man's bedroom,' relates Leonard, the monolith 'persists as an ineradicable progenitor and remainder, the inscrutable presence of which defamiliarizes the myth of origin most science fiction takes for granted' (45).

Itself an SF artefact, the film is also 'unconcealed' by the impenetrable figure of the monolith, which if laid on its side 'would have the dimensions of a movie screen' (49). As found object and source of technological wonder, the monolith is a metageneric image of SF film. ${ }^{3}$ In the Dawn of Man sequence, the monolith channels unmarked space into defined territory, fashioning the world in which Moon-Watcher becomes self-aware as a technological being into an environment he begins to measure and master. The cinematic mise-en-scene that recalls this originary moment unconceals the nature of progress latent in our own ritualistic ape-like gatherings before monolithic projection screens. The film's special effects, relates Carl Freedman, 'propose a continuity between the film itself, as a product of cinematic technology, and the characteristic technological content of the genre.' The monolith is not simply a special effect of the film, but, in the film's own mythology, the mother of special effects from which all other technological projections and their power to shape life are born and thematized as the alien intelligence that lies behind the obelisks' $(2002,101,110)$.

The archaeological content also shapes the geopolitical subtext. Moon-Watcher's discovery of the monolith is coeval with the dawn of

3 Marcia Landy observes that Kubrick dramatizes human evolution through cinematographic effects, conflating the history of consciousness with the history of cinema (88). 
material culture, unconcealing a version of deep time that is ideologically consistent with the present and, by implication, the imagined futures shaped by the discovery of subsequent monoliths. The camera remaps the heretofore 'free' extreme long shots of open savanna into quasicolonial spaces in which the hominids assume central focus. The province of archaeological and anthropological investigation themselves, these prehistoric figures reflect and project the particular historical moment of the film's making. At the conceptual core of a film released on the eve of the lunar landing - the extra-terrestrial stage for Cold War competitionKubrick's vision of space exploration raises important questions about the political and social ramifications of appropriating, like the ape-beings, the world for humanity's 'evolutionary imperative' (Freedman, 2002, 110). While the global tensions between the superpowers are fairly well resolved in the film-the Cold War space race has warmed to tepid discussions about Soviet and American zones of political and archaeological influence on the moon-the geopolitical moment is displaced into the SF fabula of the battle against an intelligent machine, whose own manner of unconcealing the meaning of the monolith reiterates the human drive to master new frontiers at any cost.

While I have more to say below about archaeological imagery in 2001, the salient point is that the monolith's visual, narrative and ideological properties cohere in a genre whose being resides, like archaeology itself, in speculations about change and technology. Gary Wolfe's chapter 'The Artifact as Icon in Science Fiction' is useful for aligning archaeological praxis and theory with SF poetics. Classifying the roll call of robots, intelligent machines and spaceships as artefacts is symptomatic of the way archaeological materials furnish 'evidence of some specific (usually remote) time and place, [that is] invested with some indeterminate value [...] to those who receive or discover it in some other time or place' (83-84). Like archaeological objects, the SF artefact accrues significance through acts of discovery and recovery; like the monolith, manufactured objects in SF assume their status as artefacts by virtue of being 'unconcealed' within the 'shifting and often counterintuitive visions of base reality that science itself reflects' (29). As material signifiers of time and difference, artefacts are thereby 'analogous to the function of the narrative itself' (96); as a source of objectified temporality in $\mathrm{SF}$, archaeology is a critical tool for unearthing the contradictions and fissures of historical discourse displaced into imagined futures.

The performative characteristics of science fiction film and television (hereafter SFFTV) are particularly suited to engaging these tensions. Susan Sontag's famous declaration about SF film that '[w] are merely spectators; we watch' (43) is an aesthetic distinction that also evokes 
SF's central occupation: the pleasures and politics of defamiliarization. In Science Fiction Film, Keith Johnston inverts Sontag's statement into a question about what 'audiences find spectacular' (42). For him, the material conditions of SF are inherently and necessarily spectacular. Ridley Scott's Blade Runner (1982) is exemplary, for its haunting archaeological mise-en-scene of ziggurats towering above twenty-first-century Los Angeles is a spectacular ideological marker of a capitalist empire indifferent to its own collapse. Freighted with historical significance, these futuristic temples share the skies with police hover cars and other simulated relics of the twentieth century. The ziggurats remain seats of power and human sacrifice; the cars, referents of a police state dedicated to enforcing naturalized expressions of power as spectacular manifestations culled from 'ancient mytho-history' (Johnson-Smith, 5). As evinced by 2001, SFFTV depends upon viewers' extra-diegetic experience of archaeology, even if such experience is informed by SF spectacle. Wolfe's artefact as icon thus opens SFFTV to the complex regimes of historical knowledge that archaeology also documents.

Fredric Jameson adroitly exploits the metafictive potential of SF archaeology in his monumental Archaeologies of the Future: The Desire Called Utopia. Like Foucault's genealogical analysis in The Archaeology of Knowledge of radical disruptions in the 'archive' of cultural history, Jameson addresses the central paradox of SF historicism dramatized in 2001. He relates, 'SF has concealed another, far more complex temporal structure: not to give us "images" of the future-whatever such images might mean for a reader who will necessarily predecease their "materialization" - but rather to defamiliarize and restructure our experience of our own present' (286). Like archaeology, SF teaches us 'that the present [...] is inaccessible directly' (287). A generative vehicle of material progress itself, SF registers what Jameson calls a 'symptom of a mutation in our relationship to historical time,' through 'our own experience of the object-world of the present' (284). The fantasies of the future, Jameson insists, are genetically dependent upon the fantasies of the past that we store and experience in places like museums and heritage sites and, moreover, in narrative histories circulating in popular culture. We can appreciate SF as a historicist genre because of its insistence on historicizing progress, of freighting the future with the past. In his chapter 'Progress Versus Utopia; or, Can We Imagine the Future?' Jameson is sceptical that this "concept" [...] can somehow be tested for [its] objective or even scientific validity' (282), and wonders what if the "idea" of progress were not an idea at all but rather the symptom of something else? This is the perspective suggested, not merely by the interrogation of cultural texts, such as SF, but by the contemporary discovery of the 
Symbolic in general' (281). As a symbolic medium grounded in the material record of progress, SF teaches us that we are enveloped in a paradox that is the genre's 'deepest vocation,' namely to 'bring home, in local and determinate ways and with a fullness of concrete detail, our constitutional inability to imagine Utopia itself' (289).

The paradox of Jameson's title is a touchstone for the present study: the manner in which archaeology exposes SFFTV to its political unconsciousness. This book investigates how contemporary SF televisual and cinematic representations of archaeology and their 'scientific' sense of the past and of cultural interaction contribute to socio-political investigation and understanding of geopolitics. The terrible events of September 11, 2001, have taught us that geopolitical crises are virtually indistinguishable from, and may even be anticipated by, media events. The apocalyptic vision of the Twin Towers vanishing from the New York skyline was impressed on the global imagination as if it were a cinematic event, like something 'from a movie' (King, 2005, 47; cf. Randell). On that fateful day, Slavoj Žižek relates, the 'fantasmatic screen apparition entered our reality.' This is 'what the compelling image of the collapse of the WTC was: an image, a semblance, an "effect," which, at the same time, delivered "the thing itself"' (16, 19). The obsessive, even fetishistic cycling of the attacks in the news and social media is itself an indictment of global power disseminating as a form of Hollywood spectacle. The cinematographic realm of SF not only framed the event for contemporary 'audiences' but transformed and rerouted it like the hijacked planes into a weapon of terror. The plethora of writing by film and media scholars on 9/11's indelible stamp on the ways security, invasion, threats to homeland and fears of mass destruction have since been represented in popular culture demands that we consider that if the attacks are mediatized weapons of retaliation on the West, they have been revitalized as potent images of threat and fear that have leant Western governments extraordinary powers of surveillance and control over their citizens in the name of freedom and security. ${ }^{4}$ If, as Roger Luckhurst observes, SF 'responds to the intensification and global extension of technological modernity not with new forms, but rather with ones lifted from the genre's venerable past' $(221)$, then SFFTV is

4 The literature on the cultural responses to the war on terror, $9 / 11$ and the Iraq War in film, TV, news media and the arts is extensive. Quay and Damico's September 11 in Popular Culture: A Guide is an impressive and fairly comprehensive overview of the subject. Individual representative studies include Berenger; Birkenstein et al.; Bragard et al.; Debrix; Dixon, 2004; Holloway; Izard and Perkins; King, 2005; Monahan; Morgan; Nacos et al.; and Prince. 
well suited to entertaining and documenting the ideological concerns of our era, wherein 'venerable' generic forms such as alien invasion have renewed cultural currency in the global war against terrorists.

SF has proven to be a flexible medium for responding to recent crises. J.P. Telotte explains that although

science fiction has, to some extent, always provided a stage for acting out cultural anxieties-as the cinema's tales of atomic holocaust and alien invasion at the height of the cold war attesttelevision's increased emphasis in this direction should be seen less as a problem or symptom of 'exhaustion' than as evidence of its growing importance as a tool of cultural deliberation and ideological exploration. (4-5)

But perhaps because of its close physical, temporal and cultural proximity, 9/11 presents new challenges for SF mediations of insecurity as much as it reenergized, like other TV and film genres, SF narratives of invasion, (in)security, war and conspiracy. As Lincoln Geraghty observes in his cultural history American Science Fiction Film and Television, post-9/11 SFFTV struggles with issues of representing what for many North Americans is a singular and hence fundamentally unrepresentable event outside of the spectacle of media itself. ${ }^{5}$ SF film has adapted to this lacuna between the event and its representation by situating ' $9 / 11$ and its fallout as narrative backdrop' $(2009,103)$. SF invasion and disaster films like Matt Reeves's Cloverfield (2008) and Roland Emmerich's The Day After Tomorrow (2004) are fairly transparent allegories of New York City under spectacular threat, a filmic tradition dating back to Merian Cooper and Ernest Schoedsack's King Kong (1933).

But SFFTV has also mined its own history for subtler alternative histories for 9/11. Steven Spielberg's remake of War of the Worlds (2005) is illuminating in this regard. Shifting H.G. Wells's Martian invasion narrative to post-9/11 New York (a point made clear by the bright-eyed Rachael Ferrier [Dakota Fanning] asking her ash-covered father, Ray [Tom Cruise], 'Is it the terrorists?'6), Spielberg displaces the novel's political questions into spectacular matter. Politics are re-injected into the film not through characters' reflections (they are for the most part concerned with survival), but through the imagery the film exploits as

5 Christine Cornea argues that the special effects of SF films like Independence Day have already manufactured a version of the events of 9/11 (264-65).

Cf. 'The Long Shadows of 9/11.'

6 Friedman, 158; Holloway, 92; and Jackson all make this point. 
a vehicle for terror. In Hollywood blockbuster fashion, the breakdown in American ideology is experienced as an external threat, in this case by conflating SF imagery with terrorist tactics: the ancient Martian war machines buried underground millions of years ago are artefacts hidden within the nation's own soil, awaiting activation like terrorist cells. The Martian war machines operate like artefacts both in Wolfe's sense of SF icons and as historical figures excavated from the substrata. The archaeological imagery offers an oblique means of reading global crises within the spectacular realm of SFFTV.

I have been arguing that archaeology is not simply an imaginative mine for SF's other worlds, but is an important critical medium for teasing out the ideological subtextures of historical representation within the genre. Treating SF as a form of future history is, moreover, endemic of perspectives by a group of archaeological theorists committed to interrogating the ways they also 'unconceal' the material past. It is to these discussions that I now briefly turn.

\section{Archaeology and the contemporary past}

A past that is not yet known is a form of the future.

Istvan Csicsery-Ronay ${ }^{7}$

In the popular imagination, archaeology is a form of science fiction.

Daniel Shoup 8

Excavating the Future is informed by a school of archaeological theory known as 'post-processual' or 'interpretive archaeology.' Embracing diverse theoretical positions from feminist, Marxist, post-structuralist and postcolonial criticism, and foregrounding the subjective nature of archaeological practice, post-processual archaeologists endeavour to understand how artefactual remains articulate cognitive and symbolic spheres of human action by considering how ideology operated in the production of material culture in the past and, moreover, in the hermeneutics of archaeological discourse in the present. Abandoning the notion of an archaeological 'record' and its implication of a direct imprint of the past on objects, post-processualists study artefacts like

7 Csicsery-Ronay, 1991, 388.

8 Shoup, 2009. 
texts, wherein material signifiers 'play' in and between the present and the imagined past (Chilton; Hodder; Hodder and Hudson; Preucel; Tilley, 1990, 1991, 1999). United in a postmodern scepticism of totalizing theoretical schema, meta-narratives and scientific positivism, these archaeologists locate archaeological discourse within broader cultural productions of the past in and for the present. This paradigmatic shift of archaeology as a broadly material science into an array of creative and culturally relative material practices is a crucial cipher for decoding geopolitics in SFFTV archaeology. ${ }^{9}$

Three important implications emerge for the present study. First, as a mode of 'unconcealment,' archaeology is a representational medium whose rhetorical tropes are, in the words of classical archaeologist Yannis Hamilakis, 'intricately implicated with processes of identity, politics, institutional power, disciplinary authority, and history.' Archaeologists 'do not just save and reconstruct,' he argues, they 'also ignore and destroy; they produce material realities, but they also tell stories; they too, like poets, are cultural producers working in the field of representation' (2004, 56; cf. Shanks, 1991). In this vein, Rodney Harrison is particularly suspicious of the meta-tropes of excavation and the depth metaphor for research and discovery.' He proposes an alternative metaphor: surface archaeology, an approach to 'assembling/reassembling' information in order to reorient 'archaeology away from the past and towards the present and future, which would see it forgo its search for origins to focus instead on the present and only subsequently on the circumstance in which the past intervenes within it' $(143-44,144) .{ }^{10}$ For post-processualists, archaeology is a creative intervention that challenges its practitioners to acknowledge and explore the ideological dimensions of their 'poetics.'

This raises a second point. Post-processualists are also interested in the relationship between amateur and professional interests in material remains. Stanford archaeologist, theorist, multimedia artist and blogger Michael Shanks contends '[w]e are all archaeologists today' $(2012,21)$, echoing a sentiment shared by many archaeologists that the everyday and amateur concerns with the material past play an integral part

9 For a concise study of these schools, see Johnson.

10 Thomas relates it 'could be argued that this disciplinary orientation towards depth, concealment, mystery and revelation is quite obstructive, for it enhances the belief that the past is entirely separate from the present: it is "somewhere else" that needs to be accessed in a particular way. [...] [It] is unhelpful to imagine that the past is a substance that is secreted away in dark places awaiting its recovery. The remains of the past are all around us, and we inhabit the past in important ways' (170). 
in the dialogic world of archaeological thinking. Practitioners like Shanks seriously consider the powerful influence popular media have in shaping conceptions about what archaeologists do as producers of historical knowledge and identities. In Archaeology Is a Brand! The Meaning of Archaeology in Contemporary Popular Culture, Swedish archaeologist Cornelius Holtorf invites scholars to take possession of the ways their profession has been 'branded' through its own topoi, like colonial adventure in exotic locations, detective work, treasure hunting/artefact rescue, scholarly expertise, and excavation as discovery. Holtorf's central and controversial argument (cf. G. Fagan and Feder) is that archaeologists should participate directly in the popular culture arena where so much interest in the discipline is itself generated. The implication for the present study is that popular cultural representations of the discipline are more than simple entertainment. They are critical sites for unpacking and confronting the politics of archaeological practice circulating in SFFTV.

While gauging what people actually think about archaeology is a difficult task, media analysis can provide clues about the means by which popular culture documents the work of archaeologists and, hence, its social value. Particularly germane for film and television is, thirdly, the performative nature of archaeology. This objective is perhaps best summed up by what Michael Shanks and performance artist Mike Pearson term 'theatre/archaeology,' the title of their collaborative effort to promote dialogue between the historically discrete disciplines of archaeology and drama. Their central premise is that archaeological knowledge is always contingent, because it is fashioned out of inherently performative encounters between bodies, objects and sites. Theatre/ archaeology looks for a composite authority through the living, tactile relationships we have with artefacts, investigating the ways contemporary interests in the past are articulated in popular culture and exert pressure on 'legitimate' forms of archaeological discussion. Shanks and Pearson challenge the assumption that if you mix up old artefacts and spectacle, entertainment, interests of the present, then that old artefact is supposed to be of less use to proper archaeological concerns such as producing knowledge of the past.' They consider, rather, '[w] hat use is an entertaining experience to archaeology?' Understanding archaeology as a cultural production that has always existed within a 'dramaturgical imagination,' they promote a new form of archaeological documentation in which the two disciplines

coexist within a blurred genre or a science/fiction, a mixture of narration and scientific practices, an integrated approach 
to recording, writing and illustrating the material past. Here archaeology and performance are jointly active in mobilizing the past, in making creative use of its various fragments in forging cultural memory out of varied interests and remains, in developing cultural ecologies (relating different fields of social and personal experience in the context of varied and contradictory interests) and in their joint address to particular sites and themes, a significant resource in constructing and energising contemporary identities, personal, communal and regional.

Ultimately, theatre/archaeology 'documents social practices' by sanctioning performance as knowledge within the archaeological project of 'piecing together fragments' (Pearson and Shanks, 114, 101, 131, 12).

While this short discussion does not presume to exhaust the breadth of issues being debated by post-processualists (and their detractors), its purpose is to offer their utopian dream of playful, democratic praxis and theory as an invitation to explore the material histories of our imagined futures in SFFTV. To illustrate how these archaeological 'science/fictions' are fertile territory for cultural study, I return briefly to 2001 to pose questions that are central to the present study. What kinds of futures can archaeology offer its audiences? How do archaeological practices shape cinematic storytelling? And, perhaps most importantly, how can archaeology expose SF futures to contemporary geopolitical discourse?

\section{1 redux}

$\mathrm{SF}$, then, is not a genre of literary entertainment only, but a mode of awareness, a complex hesitation about the relationship between imaginary conceptions and historical reality unfolding into the future.

Istvan Csicsery-Ronay ${ }^{11}$

In 2001 four monoliths preside over humanity's development. Produced by some unfathomable consciousness, these alien objects cached away in humanity's past and future accrue a priori significance by virtue of the activities that take place around them. At the beginning of the Dawn of Man sequence, material culture per se does not yet exist. Time is static, a cinematic effect produced by lingering long distance takes of neutral terrain and tedious shots of outcrops, bushes and scattered

11 Csicsery-Ronay, 1991, 388. 
bones that gesture towards a natural state before human agency. Except for a few diurnal cues, time is uncomfortably absent, a mise-en-abyme out of which Kubrick creates proleptic relief through the intervention of the monolith (cf. Landy, 89-91). But its sudden appearance and the reassurance of history and narrative progression it heralds introduces the film's central dilemma. The 'dawn of man' is not a historical event but a cinematic process by which the audience is confronted with discomforting images of Darwinian ascendancy over the environment of our progenitors, a 'defamiliarization of our need to generate a Myth of Origin, and, having once done so, our inability ever again to see the world except in terms of the "before" and "after" demarcated by this myth' (Leonard, 59).

The introduction of time and human agency presumed by this myth of origin are also products of 'camera consciousness' (Landy, 99), which after the appearance of the monolith focuses on the activities of our ancestors. In a genre where the 'privileged figure of alterity tends to be the machine' (Vint, 2009, 225), these hominids become mechanized through technological mastery of the natural world. 'The image of the ape,' Rebecca Bishop observes, 'serves as a mode of revealing' (243) tool-wielding humanity in contradistinction to the other animals. Ratiocination occurs for the first time when Moon-Watcher applies his experience of smashing skeletal remains with a femur to killing the animals with which he had lived in relative peace. The psychological poignancy of this moment is realized through the meta-filmic rendition of Moon-Watcher's thoughts, his awakening consciousness visualized for the audience as a slow motion cut scene of a falling tapir. We bear witness, furthermore, to the dawn of politics in the horrible image of the solitary Moon-Watcher gorging himself on entrails at a safe distance from the group.

2001 thus conflates the birth of human culture with the birth of archaeology, the invention of material culture with the advent of ideology. Archaeology affords tangible figures of historical action and a powerful critical vocabulary for deconstructing familiar paradigms of historical processes. This point is perhaps best illustrated by the caesura of Moon-Watcher hurling his bone/tool/weapon aloft to the triumphant chorus of Richard Strauss's Also sprach Zarathustra, his artefactual gift to the future, incarnate in the match cut to the bone-like space station. The skyward toss visually translates prehistoric ape-thinking into post-human AI-thinking. For the spectator, these early moments are, as Marcia Landy puts it, 'an invocation of the "dark dreams of the past" not as linear, immutable, and absolutely true but as exposing different presents and relations to the past, a past threatening ever to return' (90). The politics of space exploration implied by the match cut to the 


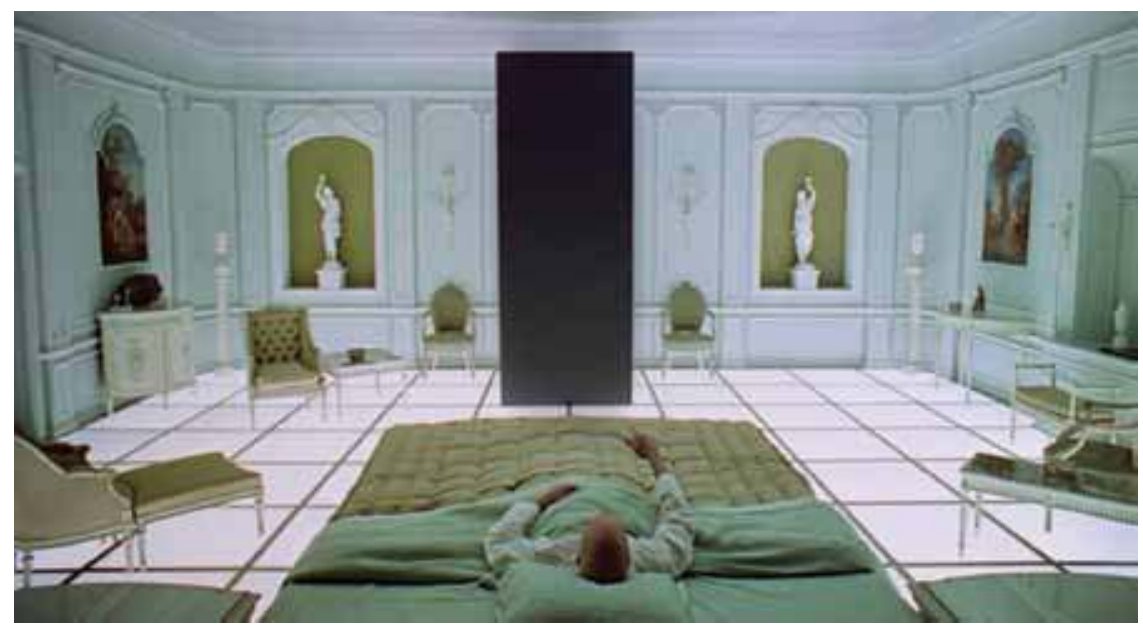

Figure 1. 2001: A Space Odyssey (MGM, 1968).

space station (which we know from Clarke's ancillary material is a nuclear weapons platform) recall the Cold War arms race and the war in Vietnam (Vint, 2009, 226), a chain of violence linking Moon-Watcher's pleasure in the destructive force of technology and the horrific sterility of the new millennium, when murder becomes a matter of computerized calculation.

The end of Bowman's voyage is likewise contained within the limitations of his own historical imagination, the 'temporal reservoir of memory' (Nelson, 130) spatialized in the eighteenth-century inspired hotel suite where he ekes out the remainder of his days. His last supper is a parodic reiteration of humanity's first. The steak he eats with a knife and fork politely echoes Moon-Watcher's first meal in the shadow of the monolith. The glass of wine that figuratively holds the measure of his life falls, inverting the evolutionary direction of Moon-Watcher's skyward bone toss. As Thomas Nelson relates, '2001 brings the human race to the limits of its growth, where, like the bone, it is converted into an artifact that turns to crystal and shatters from the weight of evolutionary gravity' (134). The monolith at the foot of the astronaut's deathbed represents a critical node in the journey from ape to human and from AI to cyborg with the cryptic appearance of the 'Star Child.' The allegory of evolution 'confronts the medium in which it is expressed' (Landy, 100), leaving the audience staring dumbfounded like Bowman at the monolith's shiny surface. Bowman apes Moon-Watcher. We ape them both.

This short analysis of 2001 suggests that Excavating the Future is not primarily concerned with the ways SFFTV employs 'real' archaeology 
for its scenarios, but rather how archaeological representation is subject to the kinds of cultural analysis that post-processualist archaeologists are undertaking in their evaluations of their disciplinary practices and communications. Specifically, this study examines how archaeology bequeaths to SFFTV a critical vocabulary with which to speak about the past, theorize our relationships with material culture, and excavate the discursive strata between cognition and estrangement.

\section{Excavating the Future}

Here we are far from the living-room and close to science fiction.

Jean Baudrillard ${ }^{12}$

Excavating the Future is structured on three classes of SF archaeology, each corresponding with a distinct phase of the monolith's 'unconcealment' in 2001: the relationship between material culture and war implied in the Dawn of Man sequence; the ancient astronaut topos represented by the excavation of the lunar monolith; and the post-human future imagined through Bowman's transformation into the Star Child.

Part 1, 'Battling Babylon: Military SFFTV and the War on Terror,' investigates the interplay between archaeology and militarism in the Middle Eastern mise-en-scenes of Roland Emmerich's feature film Stargate (1994), its television spin-off Stargate SG-1 (1997-2007), Tripp Reed's SF horror telefilm Manticore (2005) and Michael Bay's SF action film Transformers 2: Revenge of the Fallen (2009). Each text depicts Western political and military intervention in the Middle East through paradigms of archaeological stewardship over the region's cultural and natural resources, representations of archaeology that are symptomatic of sociopolitical reconfigurations of the Middle East circulating in the era of the Gulf Wars. I locate these tensions in a particular image, 'Babylon.' For the Mesopotamian city's complex mythical, historical and cultural associations-encompassing the biblical and imperial imagery of ancient Babylon, the embattled heritage site in contemporary Iraq, and the Rastafarian sense of global capitalism-is a deep-seated yet topical frame of reference to engage critically with our production and consumption of SF narratives of war and conflict set in the region.

The opening chapter examines an early popular cultural response to the U.S.-led invasion of Iraq: Tripp Reed's telefilm Manticore. Predicated

12 Baudrillard, 1998, 128. 
on the looting of the Baghdad Museum during the first week of the invasion in April 2003, Manticore is a 'Babylonian' text that reverses the events and politics upon which its scenario is based-the destruction of antiquities in wartime-into a liberation story. In the film, U.S. marines save Iraq from a legendary beast unleashed from the archaeological past by a megalomaniacal terrorist claiming Babylonian ancestry. Wedding the (neo)imperialist rhetoric of archaeological stewardship in the 'cradle of civilization' with military adventure, Manticore exemplifies how SF frequently capitalizes on and exposes archaeology's latent complicity with geopolitical activity. Yannis Hamilakis's notion of the 'Military-Archaeology Complex' (2009) - the absorption of archaeologists into military structures-provides an important critical context for examining how values like heritage and stewardship promote Western interventions in the Middle East, activities that in turn provide diegetic materials for SF narratives.

Chapter 2 develops the central thesis of Chapter 1, that paramilitary archaeology is a means of invoking and containing dangerous pasts as an imaginative extension of U.S. foreign policy in the Middle East. Whereas Stargate, which was released in the aftermath of Operation Desert Storm, is a fairly transparent liberation allegory, the shift to the televisual medium in which archaeological spectacle is normalized into a vehicle for episodic action (Vint, 2011, 72) is symptomatic of the deepening complexities of representing geopolitical activity in the Middle East after 9/11. Two Mesopotamian-themed episodes are particularly germane. Similar to the original film, 'The Tomb,' which was broadcast just three weeks before the 9/11 attacks (17 August 2001), offers confident displays of American sovereignty over the archaeological record of defeated enemies. In the episode 'Babylon' (9 September 2005), however, the mercurial figure of Babylon offers a counterpoint to the original film's overlay of archaeology and militarism, and indeed to the rhetoric of stewardship at the heart of the military-archaeology complex in post-invasion Iraq. The shifting representation of Mesopotamian antiquity in $S G-1$ 's ten-year run offers powerful cultural criticism of the show's own premise: that Babylon as a figure from ancient imperial history exposes the latent 'Babylon' of Western modernity.

The final chapter of 'Battling Babylon' investigates the archaeological cinematics of Michael Bay's Transformers 2: Revenge of the Fallen, a film predicated on artefacts transforming explosively into action. Like the monolith in 2001, the shape-shifting aliens satisfy the dual condition of artefact and meta-filmic technology. Engendered by stateof-the-art CGI technology, they are the progeny of the kinds of action sequences and cultural transformations that make sense of military 
activity for audiences. While trying to resolve or maintain within the Hollywood action blockbuster tradition the distinction between war and civilization, Bay's film ultimately collapses these oppositions through its visual rhetoric. I argue specifically that the militaristic, archaeological and geopolitical motifs in Transformers 2 coalesce in the framing techniques employed in the concluding action sequences. By figuratively compressing time into literally compressed spaces (here principal photography at Petra, Giza and Luxor into a single location), the set/setting is a chronotopic threshold that transforms antiquity into a battleground for military technocratic modernity.

Part 2, 'Of Artefacts and Ancient Aliens,' considers the premise of 'ancient astronaut' speculation-that monuments from antiquity are of extra-terrestrial origin or design-as an important, though critically neglected, historical trope in SFFTV. The proposition that human evolution has been shaped by mysterious agents who have left behind material evidence of their existence is, moreover, the master story of archaeology. This section begins with an analysis of the History Channel's popular (pseudo-)documentary series Ancient Aliens (2009-), a show that seeks legitimacy for its fantastic version of archaeological knowledge by exposing material culture study to its 'science/fictions.' Producing archaeological knowledge at the intersection of what archaeologist Cornelius Holtorf calls his discipline's ' $\mathrm{D}$ ' or 'detective theme' (2007, 75) with SF narratives of alien invasion, the series repeatedly articulates fringe archaeological claims in terms of insecurity discourses concurrently circulating in news, documentary and popular culture media. I argue that recurrent themes such as doomsday weapons, extra-terrestrial threats, government conspiracies, genetic tampering, the Mayan calendar, and the frequent focus on the Middle East as the origin of civilization and setting for the (generally imminent) apocalypse ground contemporary geopolitical anxieties in alternative archaeologies whose terms of reference are borrowed from the SF lexicon.

Chapter 5 examines Steven Spielberg's Indiana Jones and the Kingdom of the Crystal Skull (2008). Set in the post-war atomic era, the film follows the exploits of the middle-aged archaeologist in a race against the Red Army for possession of the eponymous Crystal Skull, an artefact left by an ancient race of inter-dimensional archaeologists seeking knowledge of primitive 'Terran' cultures (i.e. us). While the film's playful references to the cinematic antecedent of 1950s B SF movies and their connection to Cold War politics are fairly obvious, the ancient astronaut topos invites closer inspection of the nature of the aliens. As archaeologists and collectors-they have a massive collection of artefacts from Earth's early civilizations stowed aboard their spaceship/museum-they represent a 
version of colonial archaeology that Jones and even the audience may take for granted. The aliens function within the film's 1950s SF métier as symptomatic of communist anxiety, but they simultaneously sanction the civilizing activities of institutions like the British Museum, the Louvre and the Metropolitan Museum that lend credibility to Jones's adventures. The intrepid figure of colonial archaeology is resuscitated through the exotic adventures of technologically advanced beings from outer space. As in Manticore, Stargate and Transformers 2, archaeology is a device for manifesting threats that can be foiled by the conservative alliance of science and politics within the ostensibly depoliticized and entertaining medium of SF action and adventure cinema.

The final chapter of this section takes the ancient astronaut topos to the small screen with an examination of the teen drama Smallville (2001-11). That the pilot aired less than a month after $9 / 11$ and broke all WB viewership records suggests that the world was ready for a new Superman; that Smallville lasted a staggering ten seasons affirms that the production team succeeded in adapting Superman's image as defender of American idealism to new geopolitical paradigms for audiences growing up in an age perhaps uniquely defined by global terrorism. This chapter examines archaeology's role in retooling Superman's origin story for audiences of teen television melodrama. Two storylines are especially pertinent. The first is Clark's exploration of a series of caves claimed by the fictional First Nations 'Kawatche' as the birthplace of their people. Ancient petroglyphs in the caves foretell of the return of a messianic 'star being.' Locating the Kryptonian's origins at the intersection of ancient astronaut theory and the history of cultural violence attending indigenous land claims and cultural custodianship exposes the Superman mythos to distinctly colonial relationships with Native Americans. A lingering source of concern for Clark, these local tensions about the nature of his ancestry and mission on Earth intersect in storylines suggestive of contemporary anxieties about the legitimacy of the war on terror, the invasion of Iraq and Afghanistan, and the Patriot Act. The Egyptologist Carter Hall (aka Hawkman) emerges in the final two seasons (2009-10, 2010-11) as an important mentor to Clark, who is undertaking his final trials on the way to becoming Superman. Played by Stargate SG-1 archaeologist Michael Shanks, the character is an important meta-fictional figure of the new archaeological tropes sustaining the Superman mythos and, moreover, the shared geopolitical themes in these television programmes. Deconstructing the myth of Superman at its source, the teen television format offers a new generation of Superman fans a sophisticated and subtle interrogation of American idealism in the post-9/11 world. 
The concluding section, 'Cyborg Sites,' examines what archaeologist Michael Shanks terms the archaeological cyborg, the 'fusion of flesh and mechanism, person and artefact combined' (Pearson and Shanks, 70). For Shanks, the uneasy merging of body, culture, history and technology advances Donna Haraway's seminal claim that the main trouble with cyborgs, of course, is that they are the illegitimate offspring of militarism and patriarchal capitalism [...]. But illegitimate offspring are often exceedingly unfaithful to their origins' (151). By collapsing the biological and material into the ideological conditions of SF, the archaeological cyborg disrupts stable and discrete chronometric typologies of past, present and future, and the political regimes myths of origins often validate. The section introduction explores these relationships in Steven Spielberg's A.I. Artificial Intelligence (2001), whose story about an android boy's love for his 'mother' manifests for future alien archaeologists a vision of humanity centred on the nuclear family, an inference that completely counters the action of the film: the boy's alienation from the family unit in a world of bio-mechanical simulation. In $A I$, the archaeological record is literally a cyborg record that preserves an ironic past for the future. Released in June 2001, the film is itself a historical record of these ironies. Images of the Twin Towers rising out of a flooded and uninhabitable Eastern Seaboard are dystopic analogues of cyborg struggles for actualization in the global capitalist state of the fictitious near future. This critique is performed by the bio-mechanical archaeologists of the distant future, whose embodied form of cinematographic communication replicates the familial logic programmed into, but withheld from, the artificial boy. AI shows us that the cyborg is a powerful figure for contemplating the dangers of humancentrism by encouraging us to think and act in equitable and symbiotic ways within local, global and even temporal ecologies.

Chapter 7 focuses on the figure of the archaeological cyborg in Ronald Moore's Battlestar Galactica (2004-09). I argue that the central story arc of finding Earth after the Cylon decimation of the Twelve Colonies is structured as an extended archaeological expedition. Museums, artefacts, ruins and substrata give the fleet its bearings and also serve as genius loci for the ethical and philosophical question that fuels the voyage: how to understand and define humanity's purpose out of the ruins of the contemporary world? The show's answer is that the cycle of violence will rage until Colonial humanity accepts the Cylons' desire to transcend the status of historical objects and become historical agents. Finding a (co)habitable destination requires both sides to open the archaeological record to inclusive narratives of origin. I argue that Moore's plan to 'comment on things that are happening in today's society, from the war 
against terror to the question of what happens to people in the face of unimaginable catastrophe' (qtd. in Bassom, 12) stretches the mimetic role of antiquity in the original series into a dynamic interrogation of the geopolitical realities that the $B S G$ reboot documents.

The final chapter explores Ridley Scott's Prometheus (2012). As an 'archaeological' record of the Alien franchise, Prometheus provides ample material for cyborg criticism in the figure of its android protagonist, David. Modelling himself after the archaeologist, advocate of Arab nationalism and British spy T.E. Lawrence, David is a cultural artefact and agent of the starship Prometheus's expedition to retrace the origins of human life, an enterprise that, like the myth of Arab independence infusing Lawrence's The Seven Pillars of Wisdom, ultimately promotes the interests of the industrial-military-archaeology complex that David serves (in Lawrence's case, Britain's Foreign and Colonial Office). Within the genealogical imagery of the film (David is the 'son' the corporate tycoon Peter Weyland never had), David's cyborg being is also connected to the origin of humanity, the mythic 'Engineers' whom Weyland desperately seeks in the hope of extending his life. Ultimately, the archaeological dreams of discovering humanity's point of origin are dismantled along with the conservative political agendas such myths serve. As an unpredictable signifier of the archaeological project of gathering artefacts into partial typologies of origins and progress, Scott's cyborg archaeologist is a fitting coda to my investigation of the uneasy and ongoing alliance between archaeology and global politics circulating in the popular imaginary of SFFTV.

In sum, Excavating the Future demonstrates that the archaeological mise-en-scenes of these SF films and television programmes are constitutive of the dreams of progress sustaining globalist politics. Archaeology lends SF materials for recognizable futures, but it also injects challenging questions about the ideological motivations and assumptions such constructions hold for contemporary audiences. In a medium that, as J.P. Telotte claims for SF television, 'has established itself as one of the key mirrors of the contemporary cultural climate' $(2008,2)$, SFFTV documents historical experience and is itself a historical document of our era's imaginative responses to technological development and global crises. The present work addresses the lacuna of archaeology in SF criticism by demonstrating how this subspecies of SF historicism is much more than a source of visual imagery for SF fabula: a critical reading of archaeology in SFFTV 'unconceals' the medium's various ideological investments and interventions in future history. 


\section{Part 1 \\ Battling Babylon: Military SFFTV and the War on Terror}

These embodied contradictions form what I call Babylonian modernity, the ruins of the present lying amid pasts that are not yet past and paths to a future that is yet to come.

Nicholas Mirzoeff ${ }^{1}$

With Operation Iraqi Freedom officially over and coalition forces settling into Operation Enduring Freedom, the University of Colorado Press released in 2007 a revised edition of Brian Fagan's 1979 Return to Babylon: Travelers, Archaeologists, and Monuments in Mesopotamia. In the preface, the author relates that the publication is timely because 'recent archaeological catastrophes in Iraq have kindled renewed interest in the long history of Mesopotamian archaeology.' Fagan's justifications for the revised edition are symptomatic of widely held assumptions about the nature and history of archaeology circulating in the wake of the Second Gulf War. First, he defends the book's episodic format on the grounds that the work is a 'narrative of discovery, not of intellectual trends, which are of less interest to general audiences.' The second justification takes the form of a qualified apology, that Austen Henry Layard and Émile Botta, the first Europeans to begin large-scale digs in Mesopotamia in the mid-nineteenth century, 'were appalling excavators by today's standards, but they placed the Assyrians firmly on the stage of world history.' Continuing the dramatic metaphor, Fagan ends his prefatory remarks by declaring the adventure story is replete with interesting

1 Mirzoeff, 2005, 5-6. 
characters, at present with a tragic ending but surely with hope for the future. The stage is set. Let the play begin!' (ix, x, xi, xii).

That Fagan displaces the motives of his revision-the destruction of antiquities in wartime-into an 'adventure story' prompts an important question: can the notion of a 'return to Babylon' for readers in the post-Gulf War era be so easily harmonized with a romantic history of travel and excavation? ${ }^{2}$ Subordinating 'intellectual trends' to a 'narrative of discovery' is itself an ideological position that ignores the long and contentious history of colonial attitudes and structures under which Western archaeologists have practised their discipline in the region. His assertion in the concluding chapter that looters are 'selling Iraq's birthright and the cultural heritage of all humankind, which we all should collectively hold in trust for generations as yet unborn' (342), ignores underlying connections between looting and the global interest in and market for material remains from 'the cradle of civilization.'

The familiar tropes of discovery, adventure and global heritage Fagan employs are, furthermore, implicated in the discipline's 'other' history of geopolitical service. Sensitive questions about archaeologists' complicity with national and (neo)imperial agendas have proliferated since the invasion. ${ }^{3}$ Archaeologists Lynn Meskell and Robert Preucel, for example, argue that the Gulf Wars 'underscore the intensely political nature of the archaeological enterprise,' for the international outcry against the bombing and looting of archaeological sites reaffirms the entrenched view of the region as a precious repository of world heritage 'that requires control and management by Western experts and their respective governments' (315). ${ }^{4}$ In this vein, Yannis Hamilakis identifies the emergence of a 'military-archaeology complex' in Iraq, a phenomenon in which the problematic issue of culpability for destruction is redressed by 'embedded' archaeologists coordinating with military

2 For an analysis of the trope of archaeological heroism see Silberman, 1995.

3 For critical studies of stewardship in Iraq see Díaz-Andreu and Champion; Kohl and Fawcett; and Ucko. Comprehensive bibliographies on nationalism and archaeology may be found in Meskell and Preucel, 318, and in Kohl and Fawcett's introductory chapter 'Archaeology in the Service of the State: Theoretical Considerations,' 3-18.

4 Cf. Mourad; Shaw. For a short history of the state archaeology in Iraq since World War II see Bernhardsson, 211-21. For an extensive examination of the Ba'ath party's use of archaeology see Baram. For a concise study of the political uses of archaeology within the postcolonial Middle East see Bernbeck and Pollock. For studies on the lingering effects of colonialism in Middle Eastern archaeology see Goode; Silberman, 1989; and Steele. 
forces to 'rescue' antiquities. ${ }^{5}$ While the history of archaeology is 'replete with examples of scholars operating as part of military structures' dating back to Napoleon's invasion of Egypt, since 2003 this relationship has fundamentally changed with the equation of occupation with heritage protection (2009, 39, 42; cf. Emberling; Teijgeler). In U.S. Cultural Diplomacy and Archaeology: Soft Power, Hard Heritage, Christina Luke and Morag Kersel discuss the many 'soft power' initiatives designed by the U.S. government to cultivate 'democracy building' through appeals to 'common heritage of humankind' (7). Several initiatives overseen by the U.S. State Department's Bureau of Educational and Cultural Affairs exemplify this soft power approach, such as the Fulbright Commission, the Iraq Cultural Heritage Project, programmes of the Office of Citizen Exchanges, and special project funding through the Ambassador's Fund for Cultural Preservation (5). That ISIS has vehemently rejected these soft power initiatives by distributing footage of its own large-scale destruction of 'common' heritage at places like Nimrud (of which I have more to say in the envoi) illustrates that archaeology cannot be separated from politically motivated cultural claims by the West dating back to the nineteenth century. ${ }^{6}$

Constituted historically within geopolitical contestation over the 'cradle of civilization,' archaeological practice is entangled with the very image of Babylon that Fagan chooses for his title. It is in this sense that another book bearing the name of the ancient city in its title was also published during the occupation era: Nicholas Mirzoeff's Watching Babylon: The War in Iraq and Global Visual Culture (2005). An analysis of news coverage of the invasion and occupation of Iraq, Mirzoeff's book locates in the mercurial figure of Babylon the multiple and often contradictory manner in which North Americans consumed images of the exercise of power on a global scale' (3). Mirzoeff observes that

5 For surveys of the damage see Garen and Carleton; and Polk and Schuster. See also the bibliography of publications on these events and the response by the international community (Polk and Schuster, 226-27); Bernhardsson, 1-4, 222-23; and the special issue of the International Foundation for Art Research, 'Art Loss in Iraq,' 30-62. Among the many institutions tracking this developing story on their websites are UNESCO (http://www. portal.unesco.org), the University of Chicago (http://listhost.uchicago.idu/ pipermail/iraqcrisis), IFAR (http://www.ifar.org) and the Baghdad Museum (www.baghdadmuseum.org). For a defence of the military occupation and the damage to archaeological sites see Joffe. J.M. Russell covers losses during the First Gulf War.

6 For a largely positive treatment of archaeologists working in conflict zones see Stone. The essays are from mainly British perspectives. 
mainstream media have themselves become 'weaponized' expressions of a world order committed to securing tacit acceptance for the invasion. He begins his analysis from a particular domestic location, Babylon, Long Island, a suburb near the author's home. The town is evocative of the broader geopolitical tensions in the Middle East signalled in its name, for here ordinary cultural practices like driving military inspired Hummers and SUVs, going to gyms in camouflage exercise outfits, and tuning in to the war in 'hyperhouses' on enormous home theatres perform and replicate complicity for global power playing out in mainstream media.

For Mirzoeff, Babylon is a potent symbol of the war and its discontents because as an ambiguous sign of civilization and its corruption Babylon resists conscription into 'grand binary schemes' and is the 'irritating complication' that confounds any neat division of past and present, us and them, East and West $(5,4)$. The central image of Jacques Derrida's deconstruction project-the idea that meaning is endlessly deferred through the very binary systems of difference in which logocentrist meaning is created and policed-is the Tower of Babel, a structure that resists structure (Derrida, 2007). Born out of an impossible dream of completion, the building and the world order that conceived it were abandoned. In biblical-historical terms, the tower is both the origin of globalism and its inevitable demise, the place where meanings became literally different through multilingualism, and where new cultures began to compete rather than cooperate for God's secrets and authority. Since 9/11 Babylon's 'opposite' meaning emerges from the controls we try to place upon it: that as exporters and guardians of global culture, we in the West are also citizens of Babylon. Mirzoeff contends that as a 'physical and historical space that is [...] profoundly disjunctured and ambiguous,' Babylon intersperses 'the contemporary and the future it is trying to dream with the primal past,' thereby providing 'a frame within which differing methodologies and histories can be productively thought alongside each other to generate knowledges that might be [...] different to the received, disciplinary information that surrounds us' $(4,10)$.

A poignant illustration from the recent war is the U.S. military's decision to establish its base of operations for Southwest Command on the ruins of the ancient city. ${ }^{7}$ Notwithstanding the extensive and irreparable damage this caused, the placement of Camp Alpha on 'a famous and iconic site of local cultural mythology' is, in archaeologist Zainab Bahrani's words, a deliberate demonstration of the 'appropriation of historical consciousness for the west' $(2006,245 ; 2008,169)$. What

7 Bahrani $(2005,2006)$ also notes that Camp Alpha was only one of seven or eight such military emplacements. 
then could be a more fitting reprisal for the attack on the Twin Towers than the actual and symbolic destruction of the ancient city and its own tower? Both attacks have left gaping holes in the earth and on the cultural landscape. Both are terribly present in their absence. Each perfectly mirrors the other as an image of the inevitable collapse of centralized sites of knowledge and power, and the terrible destruction such dreams of totality inevitably unleash on others. Both towers seek completion and ruination at the same time, the raising and razing of monuments to power. Both are ground zero for the war against terror, the Twin Towers twinned in Babylon.

SFFTV is also critically engaged with Babylon. Exerting a monumental force in the dystopic futures of Fritz Lang's Metropolis (1927) and Ridley Scott's Blade Runner (1982), and serving as the governing metaphor for Babylon 5's five-year adventure in intergalactic diplomacy, Babylon has been reinvented many times over as a locus of geopolitical and cultural crises for SF audiences. What follows is a brief genealogy of Babylon in these works and their legacy for the post-9/11 SFFTV productions Manticore, Stargate SG-1 and Transformers 2: Revenge of the Fallen.

\section{Building Babel: from Metropolis to Babylon 5}

Scott apparently was concerned more with design-imaginative and obviously terribly costly sets and visual gimmicks-and allowed the script's ideas to be as confused as the Babel-like world of polyglots who roam the streets.

Rena Andrews ${ }^{8}$

It is not exclusively about androids, endangered animals, retrofitting, corporations, vision, world wars, or colonization. Instead, all of the things combine to form a cultural resonance that is ultimately shared with architecture.

David Fortin 9

With vertiginous office complexes and ethereal skyways soaring above cavernous factories, the spectacular architectonic mise-en-scene of Fritz Lang's Metropolis bristles with revolutionary energies threatening to shake the city to its foundations. The epicentre is the Fredersen Building.

8 Andrews, 6.

9 Fortin, 86. 
Referred to explicitly in the inter-titles as the 'Modern Tower of Babel,' the structure is an ironic monument of the indifference of centralized authority to the dialectic pressures of progress upon which such authority is constituted (Jacobs, 381). The factory girl Maria (Brigitte Helm) is the prophet and social consciousness of Babylon. In her sermon to the workers, Maria transfigures the biblical story of the Tower of Babel into a modern fable of alienation and exploitation. Her vision of a messianic 'mediator' who will lead the workers out of bondage is realized at the denouement on the cathedral stairs; but the awkward handshake of mutual understanding between Grot (Heinrich George) and Joh Fredersen (Alfred Abel) is an unsatisfying resolution to the film's complex evocations of social disparity and unrest. A powerful archetype of the unresolved social tensions of modernity, Babylon resists romantic endings.

Tom Gunning argues that the disparity between the film's 'powerful political critique' and its 'cartoon solutions' is not a sign of a 'work divided against itself' but is symptomatic of its allegorical structure, wherein visionary scenes form an ironic counterpoint to the film's narrative arc. He situates Babylon at the centre of this tension, for the 'retelling of the Tower of Babel parable involves [...] not a pietistic reference but an allegorical refashioning of the original meaning' (57). While Maria's sermon is part of the characters' diegetic experience, Babylon has an extra-diegetic dimension for the audience, for whom the narrative is experienced as a short feature spliced into the main story. The sequence is framed by Maria staring directly into the camera as a 'sign of authorship' (58). Shot through a halo-like matte, the narrative digression is layered cinematographically within the film, functioning as 'quotation marks, marking the images as being at a different level of reference from the images which surround them' (58). The subversive force of the allegory lies in the dehumanizing images of labour and the despair of shaven-headed gangs hauling an enormous stone block to the construction site. This image of actual work is further allegorized in the powerful composite shot of five columns of builders converging into the 'hand' that builds the tower. The montage undermines Maria's Christian message of remaining patient for salvation. Babylon cannot be so easily forgotten or forgiven with a handshake, for the hand forms into a rebellious fist that levels the tower to the ground. In this sequence, Babylon is both an allegorical story and an allegorical mode of delivering the film's central message: Babylon is a 'parable of ruin' from a mechanized future that is fundamentally at odds with Maria's naive medieval morality. In the action that unfolds, we see that the 'visionary scene of the tower has no mediator; the only thing that bridges that deep gulf between the speaker and the masses [...] is violence' (61). 


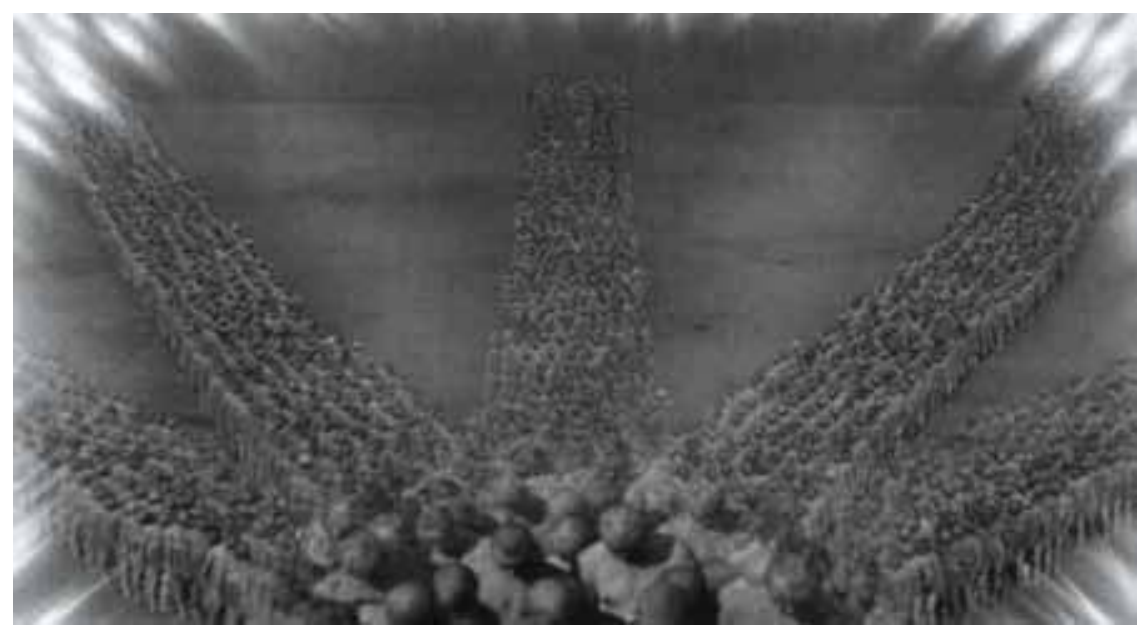

Figure 2. Metropolis (UFA, 1927).

Lang locates this future history in the SF trope of the cyborg. When Rotwang (Rudolph Klein-Rogge) steals Maria's image for his robot, he reproduces mechanically the contradictions of Babylon that inform the delivery and visualization of Maria's sermon. Transformed into the Whore of Babylon, she becomes a harbinger of Babylonian modernity. Babylon stands both for the class struggle-the subtext of Maria's messianic sermon-but also, as Gunning relates, for the 'true conflict in Metropolis, the one which actually produces and energises the film's system, [which] comes from the collision between the gothic and the modern' (64). The robot Maria performs these tensions at the 'exotic entertainment' arranged by Rotwang. The filming technique-through parallel editing and shot/ reverse shots of Freder (Gustav Fröhlich) in his sick bed witnessing robot Maria's sensuous Oriental dance before the salivating gentlemen of Metropolis-mirrors the cinematic form and allegorical content of her sermon in the catacombs. The Gothic and Babylonian elements fuse in the culminating tableau vivant of Maria as the Whore of Babylon, a modified realization of a woodcut that illustrates the Book of Revelation Freder keeps on his bedside table. 'Here Lang develops,' Gunning opines, 'the film's most complete apocalyptic vision, as Freder's gaze no longer links us to the events of the soirée but to entirely allegorical scenes' (73), which dissolve into the mechanical image of time, the steam whistle reporting shift changes at the heart of the city. The cyborg teaches us that the drunken march of progress cannot be stabilized by Christian teleology. A renascent figure of Babylon, the cyborg reveals that stable points of origin are always on the verge of collapse. 
Babylon is the flexible historical and architectural image that resists narrative closure, because it is a structure and social system that resists structure and systematization. The irony of the epitaph over Babel's ruins in Maria's sermon, 'Great is the world and its Creator! And great is Man!' manifests the cyborg conflict between human and machine. In the end, the crowd's attempt to burn the 'witch' Maria unveils the metallic mechanism beneath, a cyborg body that is impervious and indifferent to such Christian rites of purification, revealing that '[b]eneath the whore of Babylon runs the mechanism of modernity' (Gunning, 81). Born of history and industry, the cyborg cannot be conscripted into either the Madonna delivering a sermon or the whore manufactured by Rotwang. ${ }^{10}$ As a figure of materiality and modernity, the cyborg deconstructs the dialectical mode of historical reconciliation offered in the handshake between the factory owner and its mutinous worker. Maria's human flesh may burn, but her cyborg identity, and the historical and political agendas this monster subverts, cannot be cleansed by fire.

Ridley Scott's Blade Runner inherits and reworks the architectonic and cyborg imagery of Metropolis. In a film depicting the vast socioeconomic disparities of the industrialized world, the destruction of the natural order and the technological ability to replace humans with machines, power is measured stratigraphically in a dense mass of cultural referents ranging from the gritty criminal underworld to the soaring skyscrapers and sanctuaries of the elite, the fabulous ziggurats of the Tyrell Corporation and the Art Deco police headquarters modelled after the Chrysler Building. ${ }^{11}$ As in Metropolis, Babylon governs the future. The towers of corporate power are built upon the foundations of a morally and culturally bankrupt Orientalist slough, the natural habitat of Ridley Scott's own Whore of Babylon, the replicant Zhora (Joanna Cassidey), who plays Salome in Taffey's nightclub. In this freewheeling zone of 'commercial and cultural exchange and interracial contact' (Yu, 46; cf. Yuen) we also find Chew's (James Hogg) Eye Works. Like Tyrell's ziggurats, Chew's humble shop registers the 'globalized, transnational, borderless space of postmodernity, [which] remains racialized and marked [...] by history, exposing,' Timothy Yu relates, the 'degree to which Western conceptions of postmodernity are built upon continuing fantasies of-and anxieties about-the Orient' (46). The Babylon of the Tyrell Corporation looms over historical fantasies that, like the slave

10 For readings of the interplay of human and robot in the film see Dover and Huyssen.

11 The interior of the police station was filmed inside Los Angeles's Union Station. 


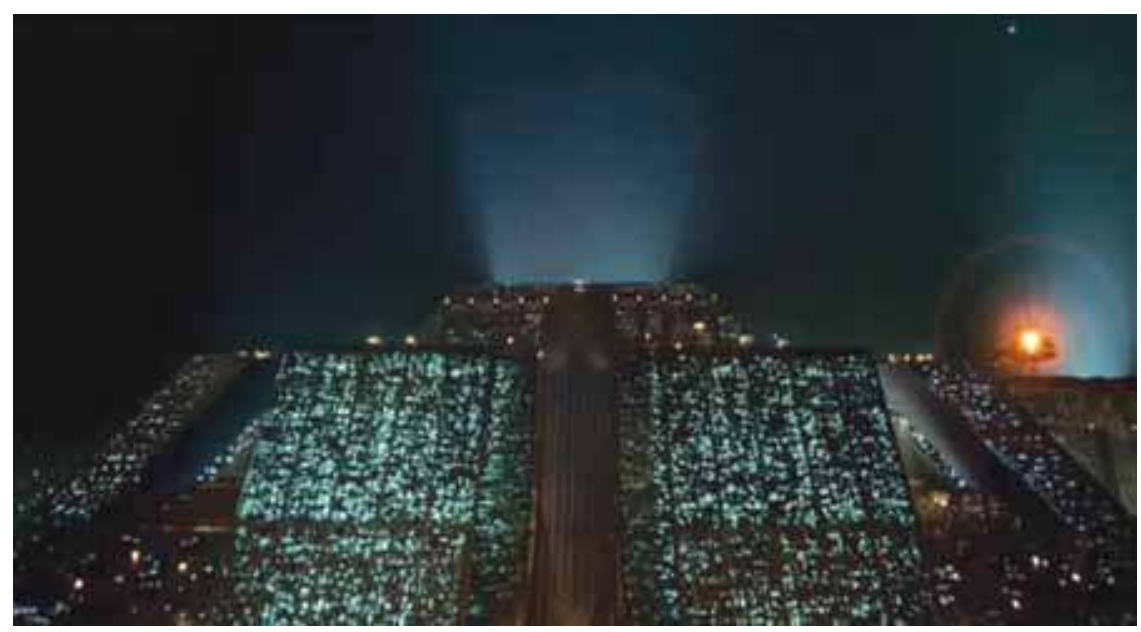

Figure 3. Blade Runner (Warner Bros., 1982).

sequences in Metropolis, critique teleologies of Western ascendancy envisioned as 'originating in, signified by, and literally built upon the Orient' (56). Scott's Orientalist clichés are retro-futurist anachronisms of industrial progress. In Blade Runner, Babylon colonizes and disrupts the future as a matter of style.

Similar to Metropolis, Ridley Scott's cyborgs embody the simulacral collapse of the human into the city's industrial processes. The opening shot of an iris-is it human? replicant?-reflecting the gas flares erupting over the city grafts ontological notions of self onto the artificial world being perceived. As the question mounts about who is and what it means to be human, the audience is uncannily implicated in this gaze. As Kaja Silverman observes, the opening 'shots of the blue eye [...] do not work to map out a spectatorial position for us on either side or other of the human/replicant divide, but to posit vision as the site of a certain collapse between these categories' $(1991,110)$. In this environment the protagonist-fresh from the exotic climes of Raiders of the Lost Ark-resists scopophilic fixation. Deckard (Harrison Ford) embodies the rather schizophrenic status of humanity within the city. As Richard Pope relates, the 'film is not primarily about whether or not Deckard is a replicant. He comes to seem like one through his position in the failure of the Symbolic, a failure that is given body through the setting of a city that increasingly seems to overwhelm him' (81). Contrary to the Denver Post review cited in the epigraph above, Babel is a coherent myth of cyborg materiality and identity. This is evidenced by Roy Batty's (Rutger Hauer) final words, his last testament couched in the 
inadequacies of the symbolic order to make intelligible his experiences for people absorbed by the city. 'I've seen things you people wouldn't believe' is Batty's injunction of the sacrifice of the humane to the indifferent gods of post-humanity dwelling in pyramids stretching into the overexposed heavens.

The subversive power of Roy's final words is manifest in his ability to make his own memories, ones that we 'people wouldn't believe' because they are too real: mixing the sight of attack ships on fire with tender recollections of C-beams (whatever they are) glittering on the Tannhäuser Gate. The film's denouement obscures as it critiques the power structures in which he perceives himself as an artificial person. The cyborg is the ultimate artefact, a product whose meaning is like memory itself, lost like tears in rain, pointing to 'a kind of subjectivity beyond them' (Pope, 84). Like Metropolis, Blade Runner exploits the historical image of Babylon to critique global capitalism and corporate power, but also to create a future history for the cyborg as a figure that elides like Maria's mechanized double the Christian imagery of Roy's soul passing into heaven. Instead, we have an open ending, at least in the director's cut (1992), in which the cyborg is a critical reminder of the inequities of a world that continues to direct human energy towards reorienting the past on a determinate path to the future.

The most exhaustive use of the Babylon myth in SFFTV is certainly J. Michael Straczynski's television space opera Babylon 5. The title refers to a Tower of Babel in space, a diplomatic space station where the various races of 'aligned' worlds-the Minbari, Narn, Centauri and humanmeet with the various 'non-aligned' worlds to work out disputes and interspecies affairs. This is the ruling fantasy with which the series is constantly at odds. The hopeful words uttered by Cdr. Jeffrey Sinclair (Michael $\mathrm{O}^{\prime} \mathrm{Hare}$ ) in the opening credits of the first season that at the 'dawn of the third age of mankind' Babylon 5 is 'the last best hope for peace' intimate a history of conflict that underlies the five-year story arc. The 'Babylon Project was a dream given form' about harmonizing difference; but Babylon is the staging area for a major conflict in each year of the series. Conflicts encompass wars of colonization (the Centauri want to rebuild their empire by destroying the Narns), wars of ideology between the so-called First Ones (the ancient races like the Shadows and Vorlons who vie to control the destinies of the younger races assembled on the station), a civil war in which Babylon 5 breaks from Earth after the assassination of President Luis Santiago (Douglas Netter) and the installation of Morgan Clark's (Gary McGurk) Shadow-backed totalitarian regime, an ensuing rebellion by the Mars colony, a Minbari civil war, and, in the final season, conflicts between the Centauri and 


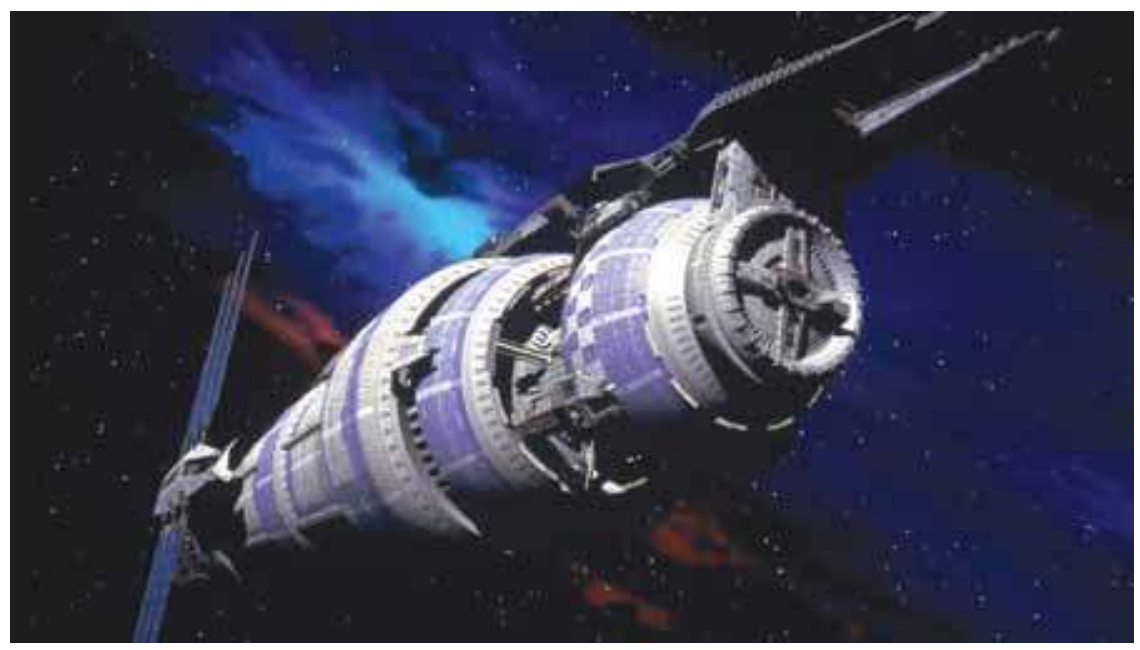

Figure 4. Babylon 5 (Babylonian Productions, 1994).

the new Interstellar Alliance orchestrated by the Drakh, former allies of the Shadows.

Sheathed in cobalt tiles evocative of the Ishtar Gate, Babylon 5 is a version of the Tower of Babel laid on its side, a five-mile-long metropolis in space. Internally the structure is a confused labyrinth of corridors, levels and forgotten spaces. Like the architectural milieu of Metropolis and Blade Runner, the station is the structural equivalent of the complex storylines and political issues with which the series grapples. The belly of the station is referred to as 'down below,' a sector in which a caste of grifters, refugees and homeless poor known collectively as 'lurkers' struggle for survival. The show is a potent reminder that, unlike Star Trek, the future cannot easily escape the class structure and social ills of capitalism. In the second season episode 'Acts of Sacrifice' (22 February 1995), for example, a technologically advanced race known as the Lumati visit the station to assess trade opportunities. They are delighted with 'down below,' which they interpret as an excellent mechanism for social control. Another episode focuses on the plight of the workers who operate the dock, the commercial soul of the station which doubles as a space port. Job action threatens the very future of the project ('By Any Means Necessary,' 11 May 1994). That the strike is resolved bureaucratically by moving funds from the military to the maintenance budget underscores 'that the series' conflicts are not only life-or-death confrontations with ancient forces but also familiar struggles with Senate subcommittees and resource allocation' (Vint, 2008, 249). 
What makes Babylon 5 such a compelling and forward-looking show is its exploration of the political unconsciousness of Babylon as a sign of Western progress. Wading through the ethical complexities attending democratic government (James and Mendlesohn, 8), liberal politics, terrorism, colonialism and commercialism, the show 'never reduces things to a binary of good and evil, instead offering a complex analysis of how the category of "right" can be constructed to serve any end' (Vint, 2008, 251). Babylon 5 invites its viewers into a third space of ideological meditation beyond myths of heroic triumph in which all victories are contingent and temporary.

The final episode, which features the decommissioning and demolition of the station ('Sleeping in Light,' 25 November 1998), does not resolve the Babylonian paradoxes and tensions explored in the series. It simply shifts galactic politics to a newly formed Alliance, whose headquarters reside on Minbar 20. Since commerce follows seats of power, the once vibrant centre of galactic affairs is regarded ultimately as a navigation hazard. Its physical destruction is an inevitable and logical completion of the diegetic world of Babylon 5: the myth of Babel is completed in this gesture. Babylon is the last hope for peace, because peace is always a catalyst for the kinds of geopolitical conflict to which SF has always responded. In real world terms, the idea of a futuristic UN and its honest failure in the show to complete its mandate lingers as a testament to recurrent geopolitical crises between the West and the East. Straczynski's Babylon floats in the space between the First and Second Gulf War, a fantasy of unity collapsing under its own weight. ${ }^{12}$

This brief foray into Metropolis, Blade Runner and Babylon 5 illustrates how SFFTV mines and transforms historical and mythological materials into futuristic tropes for geopolitical mediation. As a flexible signifier of future history, Babylon likewise opens Manticore, Stargate SG-1 and Transformers 2: Revenge of the Fallen to Mirzoeff's analysis of global images of war in the Middle East. Like their progenitors, these SFFTV artefacts offer a powerful critique of the ways historical narratives have become weaponized expressions of the military-archaeology complex for post-9/11 audiences.

12 According to Straczynski (1995), the conflicts in Babylon 5 were also influenced by the dissolution of the former Yugoslavia. 


\section{Chapter 1}

\section{Manticore}

The triumph of globalization is in no way guaranteed. Against its homogenizing and destabilizing effects, hostile forces are emerging everywhere [...] They are part of a painful revision that focuses on modernity and progress, processes that reject both the globalizing techno-structure and the ideology that seeks to make all cultures interchangeable.

Jean Baudrillard ${ }^{1}$

'... an irreparable violence towards all secrets, the violence of a civilization without secrets.' The desire to unmask Egypt's secrets is a link to the 'furious envy' of a global power faced with the symbolic order of Iraqi (and world) heritage that do not easily fit into the New Global Order.

Stephen Smith ${ }^{2}$

If Mesopotamia is the birthplace of civilization, it is also the terrain upon which its twin myths of democracy and freedom continue to be contested. Mainstream cinema is an important theatre of this struggle. While blockbuster military action films predating the 2003 invasion of Iraq such as Black Hawk Down (2001), Collateral Damage (2002), Behind Enemy Lines (2001) and We Were Soldiers (2002) evidence a huge appetite for narratives of conflict (Dalby), in response to growing suspicion that the Bush administration misinformed the American people and the international community about weapons of mass destruction, and to the haunting sense that the invasion was a misplaced reprisal for the 9/11 attacks, the 'military-entertainment complex' has been challenged

1 Baudrillard, 2006, 2.

2 Stephen Smith, 10. 
to develop new strategies for representing conflict in the Middle East. In this regard Robert Maltby has identified a trend in post-9/11 cinema that he calls 'allegory lite' (268-308), which

supplies Hollywood's principal narrative mode for films about controversial subjects [as] pure capitalist utilitarianism, performing the tricky commercial manoeuvre of appealing simultaneously to multiple audiences, alienating as few customers as possible, while transferring responsibility for any 'politicising' of films to viewers themselves. In Hollywood allegory lite, controversial issues can be safely addressed because they must be 'read off' other stories by the viewer; while the 'allegory' is sufficiently loose or 'lite,' and the other attractions on offer are sufficiently compelling or diverse, that viewers can enjoy the film without needing to engage at all with the risky 'other story' it tells. (Holloway, 83) ${ }^{3}$

Feature films tackling the war on terror are a case in point, for they typically direct audience attention away from politics by fostering sympathy with the travails and triumphs of the individual protagonists. ${ }^{4}$ For example, the cluster of Gulf War films released in 2007, including Lions for Lambs, The Kingdom, In the Valley of Elah and Rendition, are united in their 'war is hell' depictions of the conflict, and present serious issues of rendition, abuse and torture of prisoners, and the debilitating effects of PTSD on soldiers and their families. Yet each of these films evades direct geopolitical debate by privileging action-adventure, special effects, espionage narratives, melodramatic rendering of American values sabotaged by secret government agendas, and threats to masculine soldering in asymmetrical conflict. ${ }^{5}$

3 Mark Lacy likewise contends that while audiences are confronted with the 'moral anxiety' of fighting wars, mainstream cinema generally submerges geopolitical issues into myths of national identity. He says cinema has become a 'space where "commonsense" ideas about global politics and history are (re)produced and where stories about what is acceptable behavior from states and individuals are naturalized and legitimated. It is a space where myths about history and the origins of the state are told to a populist audience [...] Cinema is a space involved in the process of actively forgetting and actively producing history' (618).

4 The war has nonetheless furnished a plethora of direct responses by mostly independent documentary filmmakers. For filmographies see Quay and Damico, eds., and Prince. For a survey of SF responses to the war on terror see Charles.

5 See Dodds and Lacy for examinations of these themes. 
SF cinema affords an unlikely but illuminating example of this phenomenon in Tripp Reed's SF horror/military action telefilm Manticore, which aired on the SyFy channel in 2005. The fabula or 'allegory' is simplicity itself. During Operation Iraqi Freedom, soldiers from the U.S. Army 10th Mountain Division are sent on a mission to search for two missing journalists, who, under the guise of investigating a story on artefact looting, were secretly acting on intelligence that they would find a WMD at a small town in northern Iraq. The unit arrives to discover its residents massacred by the titular manticore, a 'living, breathing weapon of mass destruction' activated from an ancient statue by an insurgent leader and self-appointed descendant of Babylonian royalty who wants to deploy it against the Americans. The film ends predictably enough with the field littered with corpses, the beast vanquished and the heroes walking into the sunset.

Fabricating a metonymic substitute for the 'real' threat of Iraqi insurgency and WMDs in the figure of the artefact-cum-monster, the archaeological thematics upon which the surface allegory is constructed invite careful excavation of the film's 'other story,' the relationship between archaeological stewardship and the invasion of Iraq. Manticore takes as its premise the looting of the Baghdad Museum in April 2003 and the ensuing efforts by the occupation forces to arrest looters and recover stolen artefacts. The telefilm reconfigures events that were especially troubling for the international archaeological community, which had dispatched envoys to the U.S. Department of Defense prior to the war in an effort to persuade the invasion force to protect major museums and archaeological sites (Bernhardsson, 3). The military quickly mobilized to address the oversight: a tank was parked at the entrance of the museum and a military task force was struck to track down stolen artefacts and bring looters to justice. Its leader, Col. Matthew Bogdanos, even wrote a popular book about his experiences. Entitled The Thieves of Baghdad: One Marine's Passion for Ancient Civilizations and the Journey to Recover the World's Greatest Stolen Treasures (2005), the memoir is an action-packed, detectivestyle account of treasure hunting and meting out justice to untrustworthy Arabs selling off world heritage on the black market. In the absence of weapons of mass destruction and with serious questions being raised about the legality of the invasion, Bogdanos authored an 'allegory lite' victory for the military-archaeology complex.

But the 'other story' has also been 'read off' Bogdanos's compelling tale of military stewardship. Journalist Stephen Smith claims that the failure to safeguard the Baghdad Museum and other archaeological sites amounts to a political campaign as strategic as the bombing of military installations. Filtering the events of April 2003 through 
Jean Baudrillard's meditation on the $9 / 11$ attacks, 'Our Society's Judgment and Punishment,' Smith wonders 'to what extent did deliberate oversight by the US, as a possible manifestation of the 'furious envy' Baudrillard speaks of, typify the conduct of the war?' (3). By 'furious envy' Baudrillard means the 'envy' of the West as a 'low-definition mono-culture, confronted by high-definition cultures' (i.e. the capitalist West, which 'lost its own values long ago,' and Arab factions that resist its homogenizing influence [Baudrillard, 2006, 3]). For Smith, the bombing of Baghdad and the looting that ensued serve the same strategic goal. There is, he says,

a strong suspicion that the American failure to protect Iraqi heritage sites was more than mere negligence, but a deliberate oversightperhaps a kind of cultural 'shock and awe'-designed to devastate a sense of shared culture among Iraqis, leaving a blank page for the imprint of the US occupying forces and the reconstruction to follow. (1)

As a repository for Ba'ath nationalism, the archaeological record of Iraq, which had been cordoned off from Western archaeologists since Operation Desert Storm (Baram), manifested a potentially dangerous cultural and political 'singularity.' But under Bogdanos, destruction and reconstruction exchanged places. Putting antiquity back together again under the rubric of world heritage, the military-archaeology complex liberated ancient Mesopotamia from the machinations of the mad dictator and in the process fabricated a powerful alternative to figment WMDs.

Manticore displaces the paradox of military stewardship into an SF tale about saving Iraq from the triple threat of insurgents, looters and a legendary beast excavated from the very archaeological record soldiers are charged with protecting. In the film, hunting down the WMD is a symbolic response to the symbolic attack on the World Trade Center, but in the absence of any real WMDs a replacement is furnished from the material past in the form of the manticore, a monster that inhabits the Baghdad Museum, lingers in the anarchic psyche of the insurgents, and is unleashed against forces bringing democracy, freedom and order to Iraq. In 'allegory lite' fashion, then, the telefilm performs a 'Babylonian' inversion by coupling artefact destruction and the failure to find WMDs into a story in which the military and archaeological communities conspire to reconstruct global monoculture from the beleaguered cradle of civilization. ${ }^{6}$

6 For studies of archaeology and propaganda in the Gulf Wars see Pollock, 2005, and Pollock and Lutz. 
The news media plays an important role in situating the telefilm's action within real world geopolitical contestation. Manticore's title sequence comprises a montage of images and voices culled from CNN's coverage of the invasion. Reports of bombing, street fighting, rooting out terrorists and the tireless hunt for WMDs overlay images of military machinery, burning buildings and looting. The iconic shell-hole in the façade of the Baghdad Museum fades to a tumultuous interior scene of distraught museum officials roaming amongst broken artefacts and empty display cases. ${ }^{7}$ Assyriologist John Russell declares, 'This is probably the single event from the current Gulf War that will be remembered in the future. Long after all the other details are forgotten, the Iraqi people will remember this as the moment that their past disappeared' (ABC Good Morning America, 18 April 2003). Dismaying as this incident was for the archaeological community, Russell's response conflates the experiences of the anonymous Iraqi people with those of his profession. Broken statues stand in for actual violence to Arab bodies. The material past functions like simulacral flesh, whose destruction is lamented by a global order victimized by forces antagonistic to culture. Manticore thus creates verisimilitude for its SF horror scenario by performing a selective media archaeology of the invasion coverage and in the process raises an alternative monster for the military-archaeology-entertainment complex to combat.

The looting montage concludes with a lingering shot of a broken alabaster head-the haunting eyes of antiquity look deeply into our own-which dissolves into the opening sequence of two Iraqi men breaking into the basement of the Baghdad Museum. The continuity editing with CNN iterates the central theme of The Thieves of Baghdad, the conflation of terrorism and artefact destruction. Picking their way through a dark chamber crowded with packing cases and mummified remains, the robbers search for an amulet, the ancient key that will activate the manticore. Succumbing to the spooky atmosphere, one of the men baulks, begging his accomplice to turn back lest they fall victim to 'the curse of the sacred twins' (we later learn that there are two manticores, but one is destroyed during the bungled activation procedure). Overcoming their nerves, they find the amulet and seek their reward.

The stage is now set for the narrative of military salvation. In an homage to Apocalypse Now, the camera cuts to helicopters gliding over the twilight Baghdad skyline before settling on a group of soldiers arresting Iraqi civilians caught with looted artefacts bound for the black

7 The Baghdad Museum images are all excerpted from the Abu Dhabi TV broadcast of 16 April 2003, which were then rebroadcast on CNN. 
market. Tied and kneeling before the soldiers, families are interrogated and humiliated. A soldier passes through the crowd with an interesting artefact from the occupation: a special deck of cards issued in 2003 by the Department of Defense featuring head-shots of the 'most wanted' Iraqi regime officials. Predictably, Saddam Hussein is the ace of spades. The soldier compares the queen of diamonds (Air Defense Forces Commander Muzahim S'ab Hasan) to one of the prisoners, who happens to be a thief from the previous scene (Joro Zlatarev), convinced that he is big time.' By raising the issue of crimes against humanity in the context of artefact looting, the gesture is apropos of another archaeological initiative conducted during the war. In 2007, the Department of Defense's Legacy Resource Management Program issued its own deck of cards, this time representing archaeological sites in Iraq and Afghanistan. Wedding images with instructive slogans about the archaeologically rich terrain upon which soldiers are fighting and to which they should feel historically and culturally connected, the purpose of the deck is, 'to balance stewardship responsibility with mission support' (cf. Zeidler and Rush). ${ }^{8}$ The queen of hearts is the patron of this message: 'Ancient sites matter to the local community. Showing respect wins hearts and minds.' The appearance of the playing cards in the interrogation scene thus conflates the mission objectives of the 2003 and 2007 decks: hunting down two kinds of war criminals, Iraqi regime officials/terrorists and looters. ${ }^{9}$

The humanitarian mission of the 2007 deck is embodied by the unit's leader, Sgt. Baxter (Robert Beltran). A 'good cop' character, he recognizes the economic necessity behind the looting. In spite of his standing orders 'to arrest looters on sight,' he instructs his troops to hand out their rations and release the prisoners. The allegory of military liberation in Manticore backs the playing cards' gambit to save both artefacts and civilians. But in the very moment the soldiers are bathed in the light of good deeds and mutual understanding, they are attacked by

8 For information on the deck see the Baghdad Museum site at www. baghdadmuseum.org. Wikipedia carries the images of the most-wanted deck and the Legacy Resource Management cards: http://en.wikipedia.org/ wiki/Most-wanted_Iraqi_playing_cards and http://en.wikipedia.org/wiki/ Archaeology_awareness_playing_cards. See also Rush 2010, 2011, 2015.

9 Incidentally, Fort Drum is also the 10th Mountain Division Military Installation in upstate New York. Their stewardship role in Manticore extrapolates heritage initiatives developed at the base in response to the invasion. Fort Drum Cultural Resources Program also maintains heritage relationships with the Six Nation Haudenosaunee (Iroquois) Confederation of Mohawk, Oneida, Onondaga, Cayuga, Seneca and Tuscarora Nations, whose ancestors inhabited the land (Scardera, 152; Rush and Wagner). 
a mob of angry insurgents. Their kindness is rewarded with Iraqi hatred and violence (one soldier gripes, 'they don't appreciate all we've done for them'). Outnumbered, Baxter withdraws in defeat and the looters escape with the amulet. Stereotypically short-sighted with regard to the facts on the ground, the army brass exacerbates the unit's humiliation. Their commanding officer, Maj. Spencer Kramer (Jeff Fahey), greets Baxter with a stiff dressing down, the terms of which are couched in the ambiguous mission objectives themselves:

Kramer: 'Sergeant, you were sent there to stop further looting of the National Museum.'

Baxter: 'Yeah, we did that.'

Kramer: 'Once you'd identified and detained the looters you decided to give them all your supplies and send them on their merry way?' Baxter: 'There was a crowd of angry insurgents threatening our position. What the hell was I supposed to do?'

Kramer: 'Maybe if you'd done your job, Sergeant, instead of handing out party favours, you'd have been able to get out of there before the situation escalated and have your prisoners with you.'

Baxter: 'It was my understanding, Major, that we were here to liberate these people, and the only way this operation is going to succeed is if we show them that we're here to help.'

Kramer: 'That's exactly what we're doing.'

Baxter: 'By arresting a bunch of people that are trying to find a way to feed their families?'

Kramer: 'By maintaining order.'

Baxter: 'Oh, come on, Spence, you know this is crap! [...] Those people aren't criminals. They're living in a vacuum. No jobs, no electricity, no clean water. I did what I did because it was the right thing to do.'

Kramer: '[...] If you wanted to save the world, why didn't you join the Red Cross?'

Having established the 'allegory lite' narrative of military stewardshipand the conventional diegetic tension between real heroes and government bureaucrats- the fabula assumes its SF horror complexion, a horror rising from the 'furious envy' to which Baudrillard attributes terrorist reprisals on the West. We now rejoin the looters, who deliver the amulet to the insurgent leader, Sheik Umari (Faran Tahir). They enter the cave that holds the 'sacred twins.' For 'two thousand years they have slept,' intones Umari, 'waiting patiently to be called upon to rid us of our enemies. And now we have the power to restore this great nation 
to a land of believers.' Umari embodies the multiple threats of Islamic fundamentalism: he is at once a Hussein, ayatollah, terrorist, insurgent and looter. 'Never doubt,' he explains, 'that I am the rightful ruler of Babylon. With my sacred twins I will drive out the infidel and this will be our final victory for all to embrace. ${ }^{10}$ Umari begins the animation procedure, but the unnamed looter grows frightened and smashes one of the statues. Without the balancing influence of its twin, the solitary manticore runs amok, ripping everyone to shreds, except Umari, who escapes to die another day.

If in the context of the military fabula breaking down the balance of the twins is reminiscent of the fall of the Twin Towers and its reprisals, then pairing stewardship responsibility with mission support furnishes a compelling allegory for checking the destructive impulses of the Middle East. According to Baudrillard, however, the very architectural twinning of the WTC is iconic of the instability and unsustainability of such binary thinking. In a pre-9/11 essay, Baudrillard observes that whereas the other skyscrapers are each the original moment of a system continually surpassing itself in $[\ldots]$ crisis,' the 'two towers of the WTC are the visible signs of the closure of a system in the vertigo of redoubling' (1993a, 70; cf. Genosko, 2). Read against the U.S. military investment in artefacts, Manticore reveals that the towers' vertiginous collapse is also a visible sign of a world system desperate to find its own image in the cradle of civilization. In Manticore, the ultimate responsibility for artefact destruction-and thereby the ultimate justification for the invasionis deflected onto a singular monstrous force upsetting the balance of global order.

Representations of the news media in Manticore also raise difficult questions regarding the power of agencies like CNN to garner support for the war. In this regard, 'GNN' journalist Ashley Pierce (Chase Masterson) overhears soldiers speaking about a possible WMD in the northern border town of 'Al Kumar' and jumps at the opportunity to land the exclusive on the story. She must first convince her reluctant cameraman, Ryan (Ben Burdick), to accompany her. Ryan resists Pierce's admonition 'We could sit on our asses and do another puff

10 Saddam Hussein was himself obsessed with creating a version of Umari's legacy. To the horror of archaeologists, he built a modern palace on the foundations of the royal palace at Babylon. Visitors were greeted at the annual Festival of Babylon with images of Saddam posing with Nebuchadnezzar. He even had a stamp commemorating his likeness to the ancient monarch. For a thorough discussion see Baram. 
piece about stolen artefacts' by aligning his duties as a journalist with the mission objectives:

Ryan: 'It's not just about art, Ash, but about hearts and minds. It's about convincing the Iraqi people and the world that we care about preserving their culture and that we're not just some imperialist power bent on crushing their religion and controlling their oil.'

Pierce: 'Well hearts and minds ain't gonna put me on the anchor chair or get you a raise.'

The journalists' conflicted reactions to the war-Ryan's lip service to the ethical dimensions of the occupation and Pierce's blatant war-profiteering to advance her career-reflect a deep tension with the mission, which at the time of the film's release was hopelessly bogged down in the search for phantom WMDs (Kodrich and Law). Manticore furnishes a substitute: just as Pierce begins narrating a piece on recovering lost items from the Baghdad Museum (presumably to validate the unauthorized trip to the village), the manticore races past in the background. In an instant, the hunt for artefacts and the hunt for WMDs become one and the same. The town is soon ravaged, but the journalists are rescued by a village boy, Hani (Ram Bambani). The main narrative of finding the journalists and hunting the manticore commences.

The remainder of the telefilm is narrowly plotted and entirely predictable: carnage, American sacrifices, the death of the villain and the triumph of the heroes. The inevitable victory over the manticore/ WMD/terrorist is a transparent allegory of the U.S. mission to free the Iraqi people from the Hussein regime, root out insurgents and institute a legitimate government. The American military machine, localized in the characters of Sgt. Baxter and his brave band of brothers, resolves the tensions of the invasion set out in the title sequence by destroying/preserving the archaeological past by defeating the manticore. Allegorizing the threatening regime as a world heritage crisis, the military-archaeology complex in Manticore erects a 'New Babylon' that is ever-vigilant against Islamic fanaticism and indifferent to its own moral values of forced democracy and free-market fanaticism (Baudrillard, 1997, 133). Portraying the U.S. military as the balance of power-the archetypal good twin checking his evil brother-the nature of power levied in the cause of transplanting and enforcing global monoculture through shared heritage claims is buried in the telefilm's allegory lite portrayal of good versus evil.

The manner in which the battle against the beast is fought, moreover, 
invites consideration of the problematic nature of the 'other' battle to win hearts and minds introduced in the telefilm. Reminiscent of the Vietnamese orphan Ham Chuck (Craig Jue) in John Wayne's The Green Berets (1968), the pidgin-English speaking Hani is central to the telefilm's ethical resolution. An Americanophile with a penchant for shouting 'USA,' Hani is fascinated with American gear and technology, particularly a video camera belonging to one of the soldiers, Private Davis (Michael Cory Davis). Throughout the film Davis turns the camera onto himself, assuming the various personae of reporter, action hero, faithful husband and peace keeper. With his dying breath he entrusts Baxter with his camera, which contains his last message to his spouse. The soldier's recording forms another documentary layer, one that reiterates the kinds of stories in which he as a consumer of media culture as well as a soldier is immersed and defined.

But soldiers' filming habits during what has been termed the first 'YouTube War' (Andén-Papadopoulos, 25) have generated alternative perspectives to the Hollywood meta-narrative of liberation and sacrifice. ${ }^{11}$ The easily transmissible auto-documentary footage of the invasion and occupation presented the military with the problem of how to 'reconfigure professional standards of ethics and authenticity' (17; cf. Andén-Papadopoulos, 18) in an environment in which the kinds of tourist/peace-keeping activities featured on the Archaeological Awareness Playing Cards circulate alongside Abu Ghraib torture photography. In her commentary on Rory Kennedy's documentary The Ghosts of Abu Ghraib, Susan Carruthers argues that it is significant that the MPs of Abu Ghraib were 'reluctant to concede that photography may also be a form of abuse- $a$ "force multiplier" of other degrading violations to which the camera bears witness' (73). Sharing video recordings of prisoner humiliation, torture and sexual assault at the Abu Ghraib camp suggests that in modern warfare cameras are as fetishized as rifles (cf. Grajeda). Snapping photos of naked detainees forced into human pyramids is, moreover, a sadistic parody of Manticore's archaeological paratext. Nicholas Mirzoeff remarks that 'these human ziggurats' complement the 'many efforts by the occupying force to ensure that Saddam Hussein's glorification of the ancient Assyro-Babylonian past was neglected' $(2006,25) .{ }^{12}$

11 In the Valley of Elah typifies this trend through frequent reference to a soldier's mobile phone footage. The film's narrative simulates soldiers' documentary practices (especially of gratuitous degradation of corpses).

12 Mirzoeff further argues that forcing prisoners to 'enact same-sex erotic tableaux' was not simply a means of humiliation but an animation or 


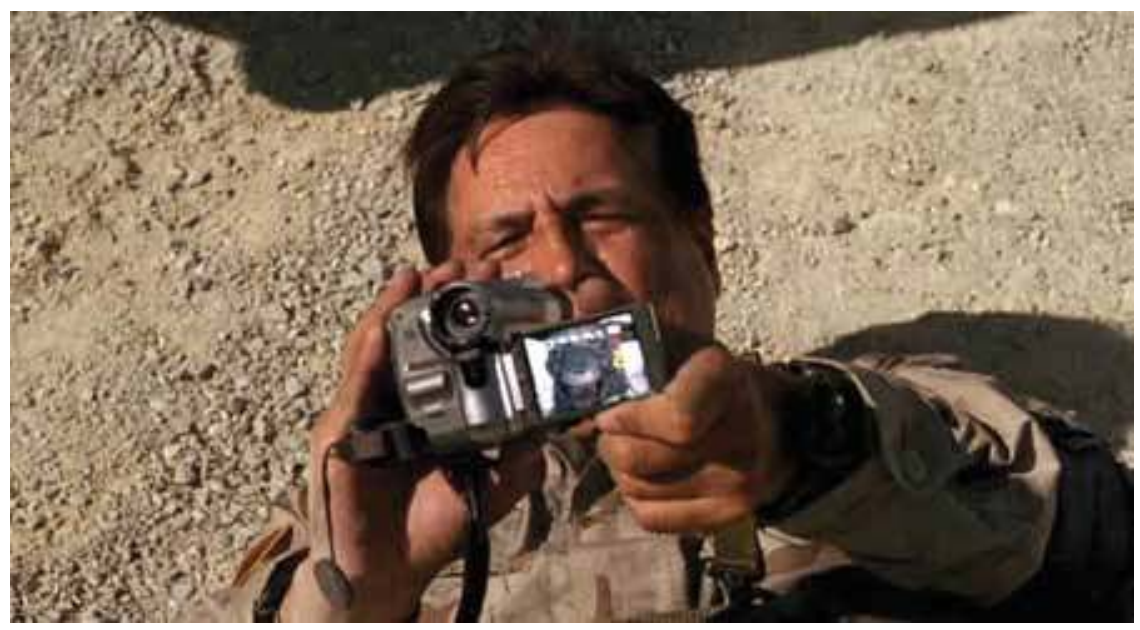

Figure 5. Manticore (UFO International Productions, 2005).

Through constant appeals to the viewers' relationship with news, cinema and military media, Manticore encourages its audience to accept as entertainment its allegory lite version of the invasion. While the telefilm comically derides its GNN representatives for cynical news mongering, it celebrates the culture of Hollywood action cinema and its long-standing relation with military structures through the self-referential manner in which Baxter kills the manticore. In the legend of the manticore, control of the creature requires balance with its twin: the manticores will shut down when they regard each other. Baxter coaxes the beast to gaze upon its own image captured by Davis's video camera. The manticore reverts to inert stone-is transformed back from weapon to artefact-and Corporal Kinks (Heather Donahue) shatters it with a sledgehammer. In a typical act of reversal, the film industry has created a monster out of the culture of a disenfranchised people, then saved them from it with the very technology that represents them as ignorant children and conniving terrorists in need of liberation, re-education and, in the broader documentary evidence of the war, even torture. The camera is itself the twin that mirrors and contains the symbolic destruction of the other. Hollywood is the balance of evil, whose inter-diegetic role in

'embodied spectacle' of the Orientalist trope of the sodomite. In 'adopting this strategy the global empire has reverted to the rhetoric of imperialism proper and the colonial expansion that preceded it' $(2006,25,30)$. Cf. Hagopian. 
destroying the artefact holds an ironic mirror to the CNN footage from which the telefilm garners authenticity for its resolution.

Considering film technology's power to create powerful and lasting images of others, what exactly is the camera mirroring? In Manticore, the soldier-filmmaker shoots enemies framed by his camera. While supplying a low-budget conclusion for the telefilm, the manner of victory nonetheless suggests that there is little room for alternative referents for the war on terror beyond those created by the military-entertainment complex itself. Baxter even rewards the orphaned Hani for his assistance and loyalty by making him a gift of Davis's camera. His home and family are gone, but he is ready and eager to shoot. 'I make picture! Spielberg!' he exclaims. The mainstream movie industry that Manticore references affirms the central role of Western technology in bringing Iraq back within the fold of civilization by reaffirming their place in a nativity story framed by archaeologists. The Iraqi child and by extension all the 'children' of Iraq can find security in watching themselves in paternalistic narratives of salvation exported to them in feature films. The child embraces the very technology that will destroy his own symbolic relationship with the past, the potentially dangerous singularity whose bombed and looted fragments can be endlessly resurrected and reconfigured in entertainment and news media. ${ }^{13}$

Covering a wide array of issues, from arresting looters and protecting archaeological remains to eliminating WMDs, Manticore supplies a happy ending to the tale of the Baghdad Museum by diverting attention away from the recent history upon which the telefilm constructs its allegory. The American military has purged Iraq of its bad element and secured the land for freedom-loving citizens eager to enjoy Spielberg blockbusters. Sanitizing the archaeological past of its association with dictatorship, the SF telefilm implicitly exonerates the destructive effects of Operation Iraqi Freedom and the West's invention of WMDs. Like the Iraqi extras in this film, the material remains of Mesopotamia play bit parts in cultural spectacles of propriety and control. In its rendition of the U.S. occupation, Manticore affirms the kinds of political and cultural claims Fagan attaches to the history of Mesopotamian archaeology in Return to Babylon. But if the looting of the Baghdad Museum has taught us anything, it is that if the stories we tell ourselves allow us to forget our role in the erasure, humiliation and domination of Arab peoples

13 Andén-Papadopoulos relates in her analysis of soldier-posted video material that a common motif is interaction with Iraqi children, both as images of liberation and victimhood (24-25). The Legacy Resource Management cards also employ images of children in their hearts and minds campaign. 
and their culture, they are as reversible and as unstable as the myth of world trade that collapsed on 11 September 2001.

Bearing the aesthetic hallmarks of the SF telefilm genre-narrow plotting, wooden acting, two-dimensional characters, cheap sets and cheesy special effects-Manticore circulates in the very limited niche market of the most dedicated SyFy channel subscribers. But with its ten-year marriage of archaeology and military adventure, Stargate SG-1 offers its viewers a more dynamic experience of watching Babylon. It is with the multiple and often contradictory views of the show's own premise that the next chapter is concerned. 


\title{
Chapter 2
}

\author{
Stargate $S G-1$
}

History, I've since come to believe, is the ultimate in speculative narrative, subject to ongoing and inevitable revision. Science fiction tends to behave like a species of history pointing in the opposite direction, up the timeline rather than back. But you can't draw imaginary future histories without a map of the past that your readers will accept as their own.

William Gibson ${ }^{1}$

At a question-and-answer session at the 2004 Creation Grand Slam Convention, Michael Shanks, who plays Stargate SG-l's intrepid archaeologist Daniel Jackson, was asked if he is related to Michael Shanks, the professor of archaeology at Stanford University. Shanks quipped, 'What you didn't know is, we're the same person!'2 While (arguably) funny, the idea of Michael Shanks as Michael Shanks does raise interesting questions about the shared investments an actor and an archaeologist have in representing the material past to their respective audiences. Having devoted much of his career to destabilizing entrenched divisions between academia and the public, the Stanford professor would be in all likelihood flattered by the comparison to his namesake in Stargate $S G-1$. For both Shankses, SF is a valid site for performing relationships with the artefactual past. That $S G-1$ thrived for ten seasons (1997-2007) attests to the power of archaeology to create credible and diverse worlds

A version of this chapter was originally published as 'Battling Babylon: The "Archaeology-Military Complex" in Stargate SG-1' in Genre: Forms of Discourse and Culture 46.3 (2013), 393-418.

1 Gibson, on Burning Chrome.

2 Http://www.stargate-sgl-solutions.com/interviews/ms/0403creation_ms_at. shtml; http://www.stargatefan.com/fandom/conventions/pasadenatranscript. htm (for transcript). 


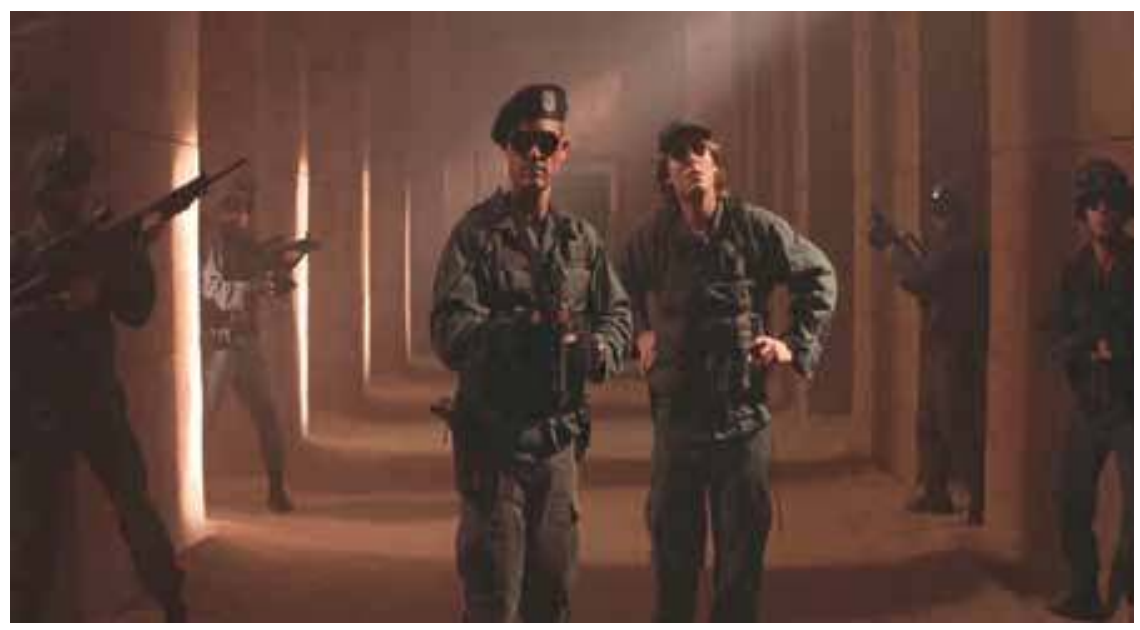

Figure 6. Stargate (Canal+, 1994).

for its characters to explore. Its longevity can also be attributed in part to the ways it adapts the premise of Roland Emmerich's feature film Stargate (1994) — the alliance of archaeological exploration with secret paramilitary operations by the U.S. government-to major geopolitical events in the Middle East.

A survey of Stargate's themes is necessary to contextualize the archaeopolitical thrust of its television offshoot. The stargate is the film's central novum, an artefact excavated near Giza in 1928 that present day scientists ascertain is a device of extra-terrestrial origin that allows inter-planetary travel through artificial worm holes. ${ }^{3}$ The army sends an expedition commanded by Col. Jack O'Neil (Kurt Russell) and accompanied by Egyptologist Daniel Jackson (James Spader) through the stargate to the distant planet Abydos. They encounter a race of primitive humans called Nagadians, who are forced to mine an energy-rich mineral for an alien overlord appearing to them as the god Ra. Jackson learns from hieroglyphs that the Nagadians are actually the descendants of ancient Egyptians, whom Ra had spirited away to Abydos to work his mine. Sympathetic to the plight of their 'living ancestors,' Jackson and O'Neil lead a successful revolt against Ra. Jackson marries the chief's daughter and teaches the people literacy and democracy. Awash with romantic images of big-scale

3 For analyses of the broad themes of the show see Beeler, 2008; Garcia and Phillips, 307-17; and Ndalianis, 2010. For studies of Stargate SG-1's production, see Beeler and Dickson. Linder-Linsley furnishes an uncritical examination of archaeology in the show. 
excavations, gangs of native diggers, desert landscapes and an underlying faith in Western technological and cultural superiority, Stargate offers the pleasures of archaeological adventure, military spectacle and the morally satisfying conclusion that the forces of reason and justice have brought liberty to the benighted peoples of Middle Eastern ancestry.

We can superficially appreciate Stargate as an innocent tale of good triumphing over evil-or even as a playful extrapolation of Erich von Däniken's notion in Chariots of the Gods that the pyramids were built by aliens ${ }^{4}$ _but such allegories of liberation are deeply rooted in the long history of Western political and cultural intervention in the Middle East. ${ }^{5}$ Displacing the colonial milieu of post-WWI Egypt to the SF terrain of Abydos and the battle against Ra, Stargate is the kind of cultural artefact that Edward Said asks us in Culture and Imperialism to interrogate. The mine at Abydos echoes the busy archaeological site where the stargate was found at Giza. Natural and cultural resources-artefacts and minerals-are valuable and virtually interchangeable commodities. In his essay 'Science Fiction and Empire' (2003) Istvan Csicsery-Ronay argues that political regimes and their literatures depend on technological difference as a quantifiable measure of progress that separates imperialists and subalterns. Imperialist archaeology bears this out as well, for artefacts are or once were technology, material points of difference that need to be acquired and relegated to narratives of change and progress that in turn fuel desires to explore and dislocate cultural and natural resources for the advantage of technologically advanced nations. ${ }^{6}$

Books such as Timothy Mitchell's now classic study of the cultural forms of appropriation of Egypt by European artists, archaeologists, collectors and diplomats, Colonising Egypt (1988), have challenged us to consider how popular and scholarly engagements with ancient Egypt contribute to Orientalist paradigms of cultural differentiation of local peoples from their history and the rewriting of Europeans as inheritors and benevolent purveyors of liberal institutions. ${ }^{7}$ Floyd Cheung blends

4 Cowan, 171-96, discusses this thesis.

5 Cf. Meskell, 2000, for an analysis of these lingering attitudes in postcolonial Egyptian archaeology and the Egyptian tourism industry.

6 For an application of Johannes Fabian's notion of the 'denial of coevalness' to indigenous peoples in imperial archaeological contexts see Gosden.

7 Brian Fagan's The Rape of the Nile: Tomb Robbers, Tourists, and Archaeologists in Egypt is also noteworthy, but its narrative format does not offer much in the way of postcolonial critique of Western Egyptology nor the role of Egyptians in this process. Cf. Reid, 1987, 2002; Gershoni and Jankowski; Hassan; and Wood. Bauer et al. and Nicholas and Hollowell also offer concise studies of the issues facing postcolonial archaeology in the Middle East. 
these issues into a more contemporary critique of the film's politics. He argues that Stargate typifies the kinds of cultural reconfigurations of the Middle East circulating in SF in the years following Operation Desert Storm. Reading ancient Egypt as a sign for contemporary Iraq, he contends that the movie's portrayal of liberating the Nagadians from Ra

alludes to a justification of the USA's action in the Persian Gulf War and toward a defense of US diplomatic and military intervention in general. To the skeptical eye, it might seem as if both Saddam Hussein and the USA merely coveted Kuwait's oil, but projects like Stargate help support the idea that the USA disseminates freedom [and] self-determination [...] while men like Hussein merely wish to exploit others for personal gain. (9)

The film is endemic of what Cheung considers Hollywood's tireless summoning of America's 'glorified, anticolonial history of independence from England in order to push forward its contemporary protectionist and neocolonial desires' (9). Stargate displaces these agendas into battles against forces hostile to the freedoms we believe we enjoy at home and feel obliged to defend abroad. ${ }^{8}$

Stargate SG-1 folds the rhetoric of archaeological stewardship into military contestation over foreign territory. In her analysis of the adaptation to television, 'Stargate $S G-1$ and the Visualization of the Imagination,' Sherryl Vint observes that while the series' budget could not accommodate the special effects of Emmerich's film, its 'real strength' is nevertheless 'its own ability to provide visual spectacle that rivals the big screen's.' With its insistent fetishization or 'visualization' of military technology, $S G-1$ is 'most emphatically not Star Trek. It is interested in military adventure, not diplomacy.' Like Manticore, SG-1 serves its audiences an 'allegory lite' diet of scientific exploration, spectacles of combat and a stock repertoire of military values like sacrifice, heroism and responsibility. In this regard, Vint makes a very important distinction: the 'series can tell us stories about the stories we tell ourselves [about warfare], but it falters when it tries to tell us stories about our material world' $(75,72,78)$ framed by these stories. Such faltering exposes the military-archaeology complex to the ideological connection between narratives of warfare and the material world. By encoding artefacts as weapons, Daniel Jackson's disciplinary impulse to preserve and study the remains of ancient Earth cultures

8 Studies of the political uses of the cradle of civilization argument include Hamilakis, 2005, and Meskell, 2005. 
spread throughout the galaxy is concomitant with geopolitical projects like keeping antiquity out of the wrong hands.

SG-1 also fosters archaeo-military adventure in dialogue with world mythology. A flexible and familiar storytelling medium, mythology allows the writers to expand Stargate's ancient astronaut premise into 'a coherent and internally consistent parallel universe' (Beeler, 2008, 272). In $S G-1, \mathrm{Ra}$ is only one of a number of tyrants known as 'Goa'uld.' A parasitic race that inhabits and controls the bodies of human hosts, they subjugate humanity throughout the galaxy by masquerading as their gods. In SG-1 nomenclature, the pantheons of Egyptian, Babylonian, Assyrian, Phoenician, Chinese, Hindu, Celtic and Greco-Roman deities are actually ancient Goa'uld. ${ }^{9}$ They command armies of 'Jaffah' warriors, humans who carry within them the infant form of the Goa'uld parasite known as a symbiote, which imparts strength and longevity to the host in exchange for loyal service. A major story arc in the series is unmaking these false gods and, like the Nagadians of the feature film, freeing the Jaffah from their Babylonian captivity.

Douglas Cowan observes that $S G-1$ 'reinforces the transcendent value of cosmographic myths. It highlights our collective need for myths of origin and questions the ability of technology, of science, and of modernity and postmodernity to corrode the power of those myths. Indeed, in science fiction, these myths are often reimagined, reinvigorated, and replayed' (183). I have been arguing, however, that the transcendent value Cowan ascribes to myths of origin is itself a myth born out of the 'corrosive power' of technology, science and modernity that SF artefacts like $S G-1$ document. In the show's own mythology, advanced technology was created by an extinct race known as the Ancients. Originating on Earth, they are the genesis of civilized humanity in the galaxy. Built into the series is the archaeo-imperial trope of searching through the remains of a lost civilization scripted as our progenitors, an echo of early Western travel and scientific accounts that insisted that local populations in places like Zimbabwe, Egypt, Mesopotamia and Mesoamerica have no historical or cultural connection to the wonders of the ancient world or the scientific or cultural wherewithal to appreciate them. ${ }^{10}$ Mythology is the narrative register through which 'technology becomes the driving force in globalization and cultural imperialism' (Simpson and Sheffield, 96). The racial and religious differences used to support these positions

9 The Norse gods are, however, benevolent beings called the Asgard, recognizable as 'grey aliens' from ufology.

10 For a concise history of archaeology's service to imperial and colonial paradigms in the nineteenth century, see Díaz-Andreu, 1-28. 
are also embedded in SG-1's image as liberators of enslaved peoples. As Simpson and Sheffield aver, 'through the various crises and conflicts the characters face, the shows construct for viewers an Earth-centric universe, in which Earth is collapsed into dominant U.S. American values in which science is the dominant paradigm, technology is the resolution to human problems, and a white masculine individualism is valued above all else' (97).

In this chapter I argue that Stargate SG-1's engagement with contemporary geopolitical contestations is particularly germane in the Mesopotamian-themed episodes 'The Tomb' (17 August 2001) and 'Babylon' (9 September 2005). Aired three weeks before the 9/11 attacks, 'The Tomb' offers a fairly straightforward victory over a Goa'uld resurrected from the cradle of civilization. Like Emmerich's feature film, the episode is a confident remediation of the First Gulf War. 'Babylon,' which aired two years after the invasion, is, however, deeply immured in the archaeological, historical and biblical troping of Babylon as a figure for the kind of despotic East whom the American-led coalition was trying to stabilize into a democratic trading partner. With troop casualties mounting, gas prices rising and the American public becoming increasingly suspicious that they were misled about weapons of mass destruction, the mercurial figure of Babylon in this episode resists the celebratory rhetoric of military stewardship characteristic of episodes like 'The Tomb.' While these two episodes certainly do not exhaust the Mesopotamian themes of the series, in concert they demonstrate that the Babylon mythos is not simply about a particular archaeological time or territory for SF military adventure: it is an ambivalent metaphor of the show's own commitment to protect the world against alien forces hostile to 'our' archaeological past and the consequences of such programmes.

\section{'The Tomb'}

A CGI panorama of a ziggurat situates the SG-1 team in the Mesopotamian milieu of the desert planet known in SGC nomenclature as P2X-338. Panning to the entrance we find O'Neill (now spelled with two l's) looming over Jackson, who is examining inscriptions on the door. 'It's Babylonian,' Jackson exclaims. 'Cuneiform. It's incredible.' The short exchange that follows typifies the often comically antagonistic nature of their roles and realms of authority and expertise:

O'Neill: 'Does it say how to open the pyramid?' Jackson: 'Ziggurat.' 
O'Neill: 'Huh?'

Jackson: 'You said pyramid. It's a ziggurat.'

O'Neill: 'Yeah, open the door'.

While Jackson is excited by the prospect of exploring this off-world version of Babylon, O'Neill just wants to break down the door. As in Emmerich's Stargate, archaeological and military goals are ultimately one and the same: in this case, getting into the ziggurat.

Jackson relates that the translation will take time. 'It's a dead language. I mean, I doubt if anyone's even stood here for 3,000 years.' At this point, Capt. Carter (Amanda Tapping) interjects, 'Oh, I wouldn't be so sure about that,' and holds up an empty pack of cigarettes. 'They're Russian.' The mystery of the alien Babylonians immediately dovetails with the discovery of an 'artefact' left by a rival superpower. This sets up a complex political dynamic. For the show references geopolitical tension in terms of both the Cold War and the 'warm' war in the Gulf. The episode plays out old atomic fear narratives via the Russian military presence on the mission, displaces them onto the galactic threat of the Goa'uld, and then transfers the fight for freedom and peace into a third space, the Arab milieu represented by the real world Goa'uld Saddam Hussein figured by the ziggurat. In $S G-1$, dramatic tension continually hinges on reanimating enemies from U.S. history for the military to defeat and, moreover, from a Western-centric archaeological record. Yet the SGC tries to transcend these antagonisms by operating as agents of global security, keeping the free world safe from Eastern despotism in its Russian and Babylonian incarnations.

As the episode unfolds we learn that the Russians are working in secret, despite a treaty to share knowledge. The Russians also have a stargate, but we learn that 'certain hard line elements in Russian Army Intelligence' commandeered it in order to 'steal alien technology at any cost.' SG-1's new mission is to return with a Russian team to P2X-338 and extract this rogue element. The SGC is, however, duped by their allies and drawn into helping the Russians secure an artefact the first team was searching for: the Eye of Tiamat, which was believed to endow the patron deity of Babylon, Marduk, with the power to defeat Tiamat, the god of chaos. The Russians wish to harness this mysterious power and keep it for themselves.

A time-honoured referent of imperial corruption, Babylon towers over the geopolitical tensions elicited by these old enemies. But aired on the eve of the WTC attacks, the show uncannily prefigures the decidedly Arab face of international terrorism emerging from the vacuum of the Cold War. In 'The Tomb,' Babylon is a recognizable archaeological place, 


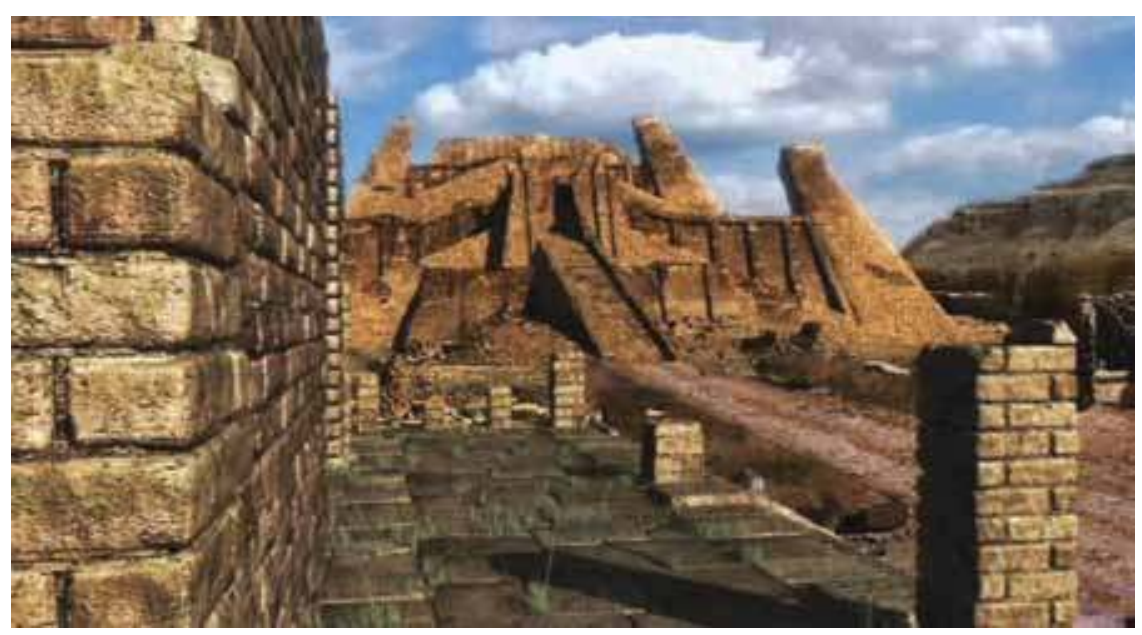

Figure 7. Stargate SG-1, 'The Tomb' (Sony Pictures Television, 2001).

a Scriptural and historical cautionary tale, and a metaphor for troubled international relations. Babylon is, in short, a potent (pre)figuration of 9/11 and the ensuing wars upon Ba'athist Mesopotamia.

The plot is straightforward but evocative of these tensions. The joint expedition returns to the ziggurat and discovers the grisly excarnated skeletons of the first Russian team. The plot thickens when they find the corporeal remains of Marduk. His fate is the subject of a nearby inscription. He was such an evil tyrant, Jackson relates, that his priests entombed him with a parasitic creature, to be continuously consumed and revived. At this point someone trips a booby trap and the expedition becomes entombed with the escaped creature, which the team realizes now plays host to Marduk. The Marduk monster picks off a couple of 'red shirts' and then transfers into another body. The question arises, whose? The inevitable standoff between $\mathrm{O}^{\prime}$ Neill and the Russian commander Zhukov ensues, each suspecting the other of hosting Marduk. The Goa'uld has, however, inhabited the body of another member of the Russian team, and the rest of the episode is devoted to Cold War enemies standing shoulder to shoulder to defeat a common enemy. Up to a point that is, for in the interim the Russian commander Zhukov locates and spirits away the Eye of Tiamat. 'The Tomb' offers a satisfactory conclusion to the monster hunt, but the threat the Babylonian Marduk represents simply reverts to the shifty Russian antagonists to American values. The cold and warm wars are interchangeable. Such substitutions provide the American military and entertainment industries with an endless supply of enemies to shoot. 
But we know from recent experience that enemies tend to shoot back. Imagining threats to global security in terms of Mesopotamia prefigures the escalation of the war against Western globalization. This is uncannily configured in the culminating scene, when SG-1 blows up the ziggurat. The military and archaeological establishments collaborate to destroy the alien menace to Western democracy in a spectacular show of force. In one fell swoop the team takes out Marduk and demolishes the antiquity Jackson defends as the guardian of global and galactic stewardship. The destruction of the temple is symbolic of the show's implicit contradiction that scientists and soldiers can collaborate to safeguard global peace. At the dawn of 9/11, destroying Babylon was an entertaining and confident reminder of the success of Desert Storm. With Hussein still in power, the ziggurat was a convenient and pointed ideological marker for U.S. vigilance against tyranny, a site that could be blown up over and over again. But the demolition of the ancient seat of imperial power in 'The Tomb' also portends the ghastly imagery of the retribution Mesopotamia unleashed on the West.

Destroying the ziggurat furnishes the episode with an aesthetic and even moral conclusion, but its very title is redolent with the history of violence to the archaeological past. SGC's standing order to scour the galaxy for artefact/weapons continuously compromises Jackson's professional ethics. The episode dramatizes both overtly in the explosion and more subtly in Jackson's expectations for learning the deeply contradictory nature of stewardship in the Middle East and elsewhere. As Yannis Hamilakis relates, stewardship plays

a dual political role: It counters the logic of private property which is at the basis of capitalist modernity, and it encourages archaeologists to oppose the destruction that results from the ceaseless race for profit. Nevertheless, the concept becomes hugely problematic when its effects 'on the ground' are taken into account. [...] [For instance] the concept of the archaeological 'record' has been shown to be problematic for archaeology, in that it is an entity not given but constructed[.] [...] For archaeologists, therefore, to declare that their primary responsibility is the care and preservation of and advocacy for the record sounds suspiciously self-serving[.] (2007, 26-27)

The 'effects on the ground' in this particular episode typify these epistemological and ideological tensions. The SG-1 team constructs in Hamilakis's sense the archaeological record by demolishing it. SGC is engaged in a deeply ambivalent programme of saving humanity from a dangerous past while maintaining the military-archaeological posture 
of defending the world against threats they themselves have unleashed through humanizing activities like archaeological exploration. The episode offers an oblique challenge to archaeologists today: for whom is the past retrieved or, in this popular culture reference, destroyed? Hamilakis implies that both impulses serve the same function when archaeologists conduct research in the service of globalist paradigms of world heritage and the kinds of soft power initiatives outlined by Luke and Kersel. ${ }^{11}$

The graphic demonstration of triumphalist politics in $S G-1$ was, however, downplayed dramatically after 9/11. Never again could the show so directly or neatly play out its own premise that antiquity is a free space to perform acts of heroism and individual sacrifice in the defence of freedom. The faith in a just cause or a happy ending-in this instance with an uncompromising attitude towards doing whatever needs to be done to archaeological sites to complete the mission-faded as the spectacle of bombings gave way to the dull, uncinematic reality of the occupation. Babylon would have to retrench for an audience struggling with the realities of pursuing an ethically suspect war. The penultimate season of $S G-1$ addresses these issues in an episode bearing the same name. In its post-invasion configuration, $S G-1$ 's Babylon is a flexible signifier for ethical debates about the war and homeland security and the ability and desire for occupying archaeologists to contain and control the past within paradigms of shared heritage. ${ }^{12}$

By the time 'Babylon' aired in 2005, SG-1 had introduced many serial plots to its mythological-episodic format. While still rooted in its ancient cultures premise, the show had become less interested in dramatizing triumphalist military adventure and more reflective about the complex public discourse attending issues of national security. The SGC itself comes under scrutiny from, and is increasingly accountable to, civilian oversight. Inter-agency conflicts for control of the stargate erupt as knowledge of the stargate programme is disclosed to the world's governments. The SGC perforce operates in an increasingly paranoid political environment. For example, the National Intelligence Department (NID), a secret civilian branch of the government monitoring extraterrestrial activity out of Area 51, has, like the Russian military, produced

11 The special issue of Archaeologies: Journal of the World Archaeological Congress 4.3 (2008) explores these questions in detail. Among the critical studies of funding structures for archaeological and heritage reconstruction are Arrighi; Hamilakis, 2003; and Scham.

12 Takacs examines SF televisual reactions to 9/11. Cf. D. Davis and Matthews for critical surveys of 9/11-inspired SF films dealing with themes of insecurity and invasion. 
rogue elements dedicated to consolidating U.S. power by sponsoring illegal missions to retrieve alien technology. Having normalized its mythological premise, the writers open the series to other sorts of villains (both foreign and domestic), broader and more intricate story arcs, and a wider SF scope (like the addition of the nanotechnology-based Replicators). Conflating archaeological discovery with national defence has engendered within the series complex regimes of insecurity. It is to these geopolitical concerns circulating in the early years of the war on terror that SG-1's 2005 version of Babylon responds.

\section{'Babylon'}

'Babylon' affords curious commentary on the politics of reconstruction in Iraq. Curious because of what is not there: material reference to the antiquity signalled in the title. For a show predicated on archaeology, the referent 'Babylon' is a haunting signifier without a material signified. The only archaeology in the episode is an off-camera mention of Jackson translating an inscription on an obelisk. In the context of the war to win hearts and minds through archaeological stewardship, this absence is even more disturbing when we consider that the 'Coalition of the Willing' was at that very moment occupying Babylon itself. Babylon is, in other words, not a place but an ambiguous signifier of globalization and its conflicts. The episode develops this theme in a quiet and intimate way through the experiences of four military men who, on two sides of a conflict, find common ground as soldiers fighting their separate yet complementary battles for freedom. Just as 'The Tomb' carries the history of the First Gulf War, 'Babylon' is born of the second. The episode invites us to reflect upon how our need to protect the world from terrorism implicates us in the West as citizens of Babylon.

Some background information about the series evolution between 2001 and 2005 is necessary to contextualize the episode. By the ninth season the SGC had prevailed in the war against the Goa'uld. But a more powerful enemy has taken their place, a race known as the Ori. In $S G-1$ mythology the Ori are known as 'ascended beings' who, like the original stargate builders, the Ancients, have evolved into powerful immortal beings of pure energy. The Ori are the Ancients' evil twin. Like the Goa'uld the Ori require human followers to do their bidding. Similar to the Western narrative of the 'rise of the West' from Mesopotamia, the Ori locate their ancestry and authority in 'Origin.' Their 'priors' travel through the galaxy spreading the Gospel of Origin and those who refuse the word are summarily put to death. As spiritual or energy beings they rule 
through ideological domination over the material world. In the context of war on terror, the Ori can be interpreted as projections of the West's fear of Islamic fanaticism, but they are also born out of similar antagonisms engendered by Western, Goa'uld-like materialism and imperialist politics.

In the episode, the SG-1 team gates to P9G-844, which the Jaffah team member Teal'c (Christopher Judge) believes is home to the reclusive Sodan, a lost Jaffah tribe that legend records had successfully rebelled against their Goa'uld overlords. Having located the Sodan, their leader, Lord Haikon (Tony Todd), relates their history:

Five thousand years ago my ancestors were one of the first of the Sodan. They were part of an elite command force under the Goa'uld Ishkur [the Assyrian-Babylonian storm god]. For years the Sodan pillaged and plundered under his name, driving fear into the hearts of all those that would oppose his rule. The further they ascended among the ranks, the more they were able to discern the truth. That he was not a god at all, but merely an imposter. Our true gods are those that came before us [i.e., the Ancients].

[...]

Ishkur branded my ancestors as traitors and ordered their deaths. They tried to fight, to show their brothers the faith. But the odds were too great, and they were forced to flee. They set out to find Kheb, hoping that their souls would find peace. Instead, their search led them to this world.

On the planet the Sodan ambush SG-1 and capture their new team leader, Col. Cameron Mitchell (Ben Browder). Believing that he killed the Sodan warrior Volnek (Jarvis W. George) in the ensuing firefight, the Sodan force Mitchell to train for a ritualistic battle to the death against Volnek's next of kin, Jolan (Jason George). It turns out, however, that Volnek was taken back to SGC headquarters and revived. Having developed a rapport during their training, Mitchell eventually convinces Jolan that the Ori, who have presented themselves as the Ancients of their faith, are simply determined to take away their freedom: that as former servants of the Babylonian Goa'uld Ishkur, they are falling into the Babylon of Origin.

Back at the SGC Teal'c (who led the Jaffah rebellion against the show's first villain, Apophis) and the convalescing Volnek have a parallel debate about the battles for freedom they share. But unlike his kinsman, Volnek will not accept Teal'c's claims that SGC is a galactic liberator. This discussion revolves around the nature of Volnek's injuries themselves. When Mitchell shot Volnek, he irreparably damaged his symbiote. He would have died but for an SGC drug formulated to replace 


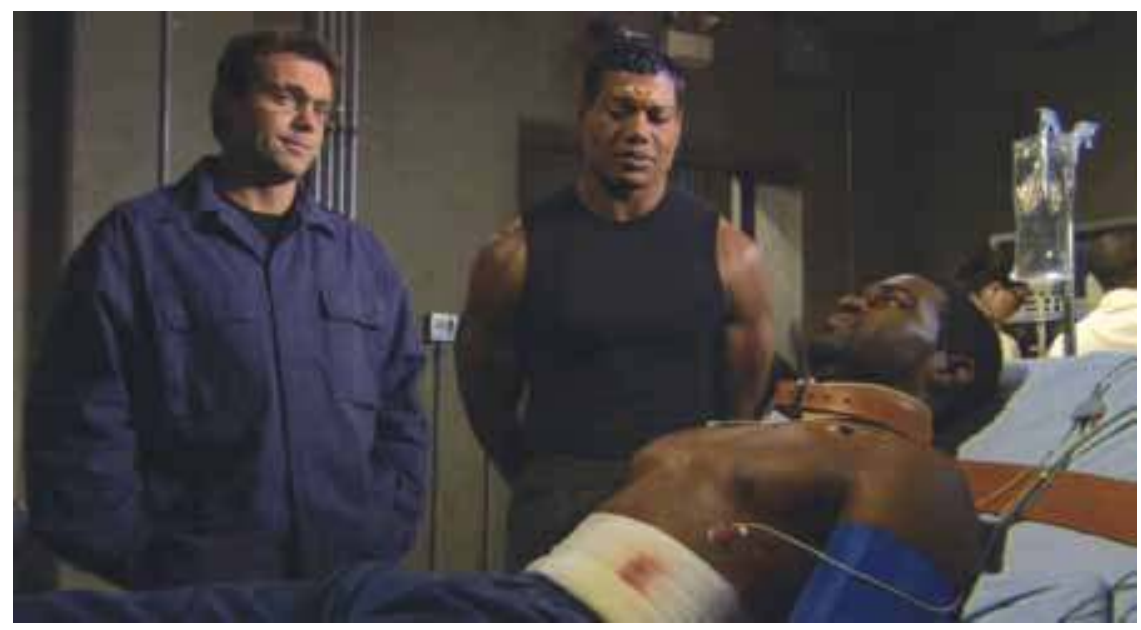

Figure 8. Stargate SG-1, 'Babylon' (Sony Pictures Television, 2005).

it called 'tretonine.' Teal'c, like all other free Jaffah, can thereby live without dependence on their former masters. Volnek however refuses to acknowledge its efficacy or Teal'c's motives.

Volnek insists that the tretonine has weakened him. Teal'c responds: 'On the contrary, brother. It has freed you.' Volnek counters that he cares nothing for this kind of freedom: 'Because of my failure as a warrior I languish here now. Prisoner to a former slave and his pitiful allies.' Teal'c replies that 'many Jaffah have fought and died for a cause that was started by the warriors of the Sodan.' Essentially, the free Jaffah, liberated by the SGC from their dependence on symbiotes, have resumed the ancient Sodan battle against the Goa'uld but have corrected their error of serving another master. The episode ends ambiguously with a prisoner exchange and the implied hope that the Sodan will join the right side of the battle for freedom.

On one level, the show reworks the biblical-historical story of the Babylonian captivity. Lord Haikon is the philosophical voice and guardian of the Sodan history of enslavement and deliverance. He speaks proudly of their struggles while in exile, wandering like the Israelites without a home, 'praying for the day when we could seek the path without recrimination.' Theirs is a longing for freedom from the sectarian violence that they have been forced to participate in, but which has become the very means of their survival and the defining feature of their culture. On another level, the episode is about delivering the Sodan warriors from the bondage of their own history. The SGC hijacks their belief systems by offering them liberty from both Goa'uld symbiotes and 
the Gospel of Origin. ${ }^{13}$ But the episode can only imply this, retreating to a morally superior position aligned with our sympathies for the members of SG-1. Unlike 'The Tomb,' with its clear mission objectives and neat conclusion, 'Babylon' only provides a contingent victory located in Mitchell and Jolan finding common ground. But even this is compromised by Teal'c and Volnek's mutual suspicion. The show takes us beyond the simple identification of the Ori with the Babylon of religious fanaticism or even its reverse, the Babylon of Western global capitalism. As a figure of power, Babylon is indeed an annoying complication that lies at the heart of the episode's message that our battles for freedom have opened the doors to reprisals.

Stargate SG-1 affords the kind of critical vantage point on the war in Iraq that Mirzoeff calls for in Watching Babylon. For 'Babylon' sounds out the problematic geopolitical climate of the post-9/11 world, in which globalism is itself under constant attack. The battles against intractable and eternal enemies like the Ori reflect our commitments to managing the global political theatre against forces that cannot be fought in the open. Enemies are disappearing into the need to produce antagonists against whom we can periodically mobilize. In his essay 'The Spirit of Terrorism,' Jean Baudrillard contends that the attacks on New York and the subsequent reprisals against Iraq and Afghanistan are emblematic of the crisis nature of globalism that Mirzoeff locates in the figure of Babylon. In Baudrillard's view, terrorism is itself a commodity created by and circulating within global capitalism. He calls this terroristic situational transfer,' whereby it is 'the system itself which created the objective conditions for this brutal retaliation [against the World Trade Center]. By seizing all the cards for itself, it forced the Other to change the rules.' He warns that 'all the singularities (species, individuals and cultures) that have paid with their deaths for the installation of a global circulation governed by a single power are taking their revenge today through this terroristic situational transfer' (9). 'Babylon' is a sensitive commentary on the geopolitical climate characterized by Baudrillard. The episode does not bask in instances of global (read galactic) triumph, nor does it offer any alternative or end to symbolic and actual violence. It considers through the character of Haikon, rather, the loss of singularity in global politics. The SGC offers protection of the Sodan way of life, but this is also illusory, because it is unimaginable for any agency to exist outside what Baudrillard terms the 'logic of relations of force' (15). Indeed, by the end of the 2005 SG-1 season the Sodan do in fact join

13 This is indicative of what John Rieder identifies as the 'ideological fantasy' of correcting indigenous beliefs; 30-31. 
the SGC in the fight against the Ori, an act that ensures their physical destruction, which began with the destruction of their 'singular' culture the moment they released Mitchell. In the end they are reduced to heroic casualties of the SGC narrative of freedom.

Ultimately the Babylon of $S G-1$ dramatizes the reversibility of all myths that try to naturalize power. 'Babylon' presents an incomplete victory, a failure of diplomacy and an affirmation of the potential for terrorist cells to strike. Unlike the crushing defeat of Marduk in his own Babylonian ziggurat, the Sodan brotherhood remains committed, if not unreservedly, to the Babylon of Origin. The episode may offer justifications for the military to protect us from the eternal threat of terrorism but it simultaneously unlocks through the personal bonds formed between Mitchell and Jolan the sinking feeling that the world cannot be corrected by democratic capitalism or individual heroism. This is all very reminiscent of ancient Babylon today, a site of global conflict over control of its meanings and legacy for the conquered and the conquerors alike. In 'The Tomb' we may find pleasure in bombing the ziggurat, but by 2005 laying waste to Babylon could no longer reassure us of the moral certainty or social justice of such acts. Instead, the show offers a considered appreciation of globalism in crisis for its viewers. The Tower of Babel cannot be destroyed, only continuously occupied and rebuilt until the global order no longer requires myths of Babylon or World Trade. Like the kind of military archaeology it is predicated on, $S G-1$ reminds us that Babylon refuses to remain buried and that occupying the past does not ensure control of the future.

What conclusions, then, can we draw from these performances of archaeology in Stargate SG-1? If we accept that archaeology and SF are both intensely political forms of representation, rather than strictly scientific and entertaining pursuits, then each field affords critique of the other. I have been arguing that the show is a symbolic medium for exploring contentious issues of stewardship that many archaeologists since the 2003 invasion have, at times begrudgingly, begun to recognize: that they are, and have always been, agents of the actual and symbolic destruction of the material past through excavation acts and the paradigms of ideological possession that make artefacts desirable commodities for governments, institutions and private collectors alike. These Mesopotamian episodes are hauntingly familiar in terms of the cultural and political determination that compels us to explore its ancient soil for traces of ourselves. In the wake of two Gulf Wars, archaeology is a powerful weapon in the battle against oppression, the Babylon of forces hostile to globalism and individual freedom as we conceive it. But $S G-1$ also shows that this weapon has the dangerous tendency to backfire. 


\section{Chapter 3}

\section{Transformers 2: Revenge of the Fallen}

It isn't the size of the blasts that 'sells' the movie; it's the iconography of the targets.

James Wolcott ${ }^{1}$

Pasts erupt into the present.

Derek Gregory²

In an interview with Judd Apatow at the 2011 Toronto International Film Festival, Transformers star Megan Fox revealed that had she not pursued acting she would 'want to be an archaeologist,' an avocational interest kindled by a particular television programme. 'I am obsessed with Ancient Aliens,' she relates; 'I Netflix that show like crazy.' This may be playful commentary on the History Channel's pseudo-documentary series, but Fox seems genuinely intrigued by its premise that archaeologists conspire to cover up material evidence of extra-terrestrial intervention in Earthly affairs. She states with animation, 'I would love to shadow someone on digs. I think it's amazing, and it holds all the answers. I want to go and see the real stuff that they're not willing to show the rest of the world, because they hide all the real stuff because humanity would panic' (Feinberg). However whimsical, Fox's endorsement of Ancient Aliens is an apposite commentary on her role in Transformers 2: Revenge of the Fallen (2009), the story about a secret paramilitary organization battling ancient aliens who have returned to Earth to activate a prehistoric doomsday weapon stashed inside the Great Pyramid at Giza.

Transformers 2 develops the basic themes of Michael Bay's first Transformer film (2007). Chronicling important rites of passage in the

1 Wolcott, 80.

2 Gregory, 1997, 228. 
life of high school sophomore Sam Witwicky (Shia LaBeouf)—buying his first car, attracting a mate with said car, and ultimately proving worthy of said mate in the crucible of battle alongside his transforming car, Bumblebee-the 2007 film affirms a Hasbro-centric version of childhood play, the 'scopic relation between male viewer and fetishized object: the car-man' (Wilson, 350). Set against the background of Sam entering university, Transformers 2 amplifies Sam's role as honorary Transformer through two ancient astronaut inspired adventures: an expedition to Petra to recover the 'Matrix of Leadership,' an artefact that fuels the weapon of mass destruction in the Great Pyramid, and a joint U.S.-Autobot clash with the Decepticons for possession of the Giza plateau. The colossal damage to World Heritage sites in the finale is a spectacular analogue of Sam's mutation into an action hero, a transformation that also embodies the contradictory tenets of stewardship in the military-archaeology complex.

This chapter examines relationships between the film's production history and its representation of historical remains within the milieu of SF action cinema. Collaborations with the Pentagon and with archaeological oversight organizations in Jordan and Egypt contribute to the film's 'realistic' portrayal of conflict in the Middle East. I argue that these relationships are indicative of 'structural violence,' a term coined by peace and conflict studies scholar Johan Galtung and adapted by archaeologist Reinhard Bernbeck to critique the mechanisms by which Western academics and institutions consciously and unconsciously perpetuate political and economic inequalities, often on a global scale. This concept assumes several complementary meanings in a contemporary SF action film that locates conflict at World Heritage sites. Violence to things in the film-the pyrotechnic spectacles of exploding military machinery, cyborg soldiers and ancient monuments-is a visceral correlative of the 'violent structures' inherent in the power of the military-archaeology establishment to secure consent for the questionable political worldview Transformers tacitly endorses as entertainment.

In the social sciences, the conceptualization of violence encompasses but is not restricted to its physical meaning. Johan Galtung's term 'structural violence' refers to the tendency of dominant social structures like capitalism and patriarchy to produce economic and political disparities, which are then naturalized in cultural systems that legitimize inequalities of gender, class, race and nationality. Structural and cultural violence are the subliminal ideological forces that inevitably lead to and are expressed physically in 'direct violence' like assault, police action and war. At the same time, physical or direct violence maintains systemic 
inequality often by posing as the solution to, rather than the product of, structural and cultural violence (Galtung, 1969, 1990; Galtung and Høivik). Structural, cultural and direct violence thus circulate in a hegemonic system that 'vehemently denies the connections between direct and structural violence' (Bernbeck, 395).

Applied to archaeology, Bernbeck's focus is not on violence to objects per se, but on the ways his discipline thrives within the 'violently unequal structures of our present world' (390). He illustrates this through several post-9/11 funding programmes and application procedures for international students at U.S. universities. These seem innocuous enough. Mandatory language testing (TOEFL) and Educational Testing Services, levying international student fees, complex entry and work visas, and security vetting are all realities in the post-9/11 English-speaking corporate and academic world. They are in place for our protection by screening for people 'pre-adapted to U.S. academic standards by indirectly ascertaining their financial background, class position, discipline, and willingness to submit to Western values' (400). These benchmarks of competency are deeply embedded in, Bernbeck argues, a system of inclusion and exclusion 'guaranteed to result in minimal impact of foreign ideas on institutions in the West' (401) by erecting intellectual and social barriers to knowledge transfer from non-Western countries (405). Positions of inferiority are perceived and interiorized by international students through structures that promote 'the superiority of others' (394) who are born into and/or have mastered 'internationally acceptable professional discourse' (398). '[B]iopolitics at the level of academics' have, he continues, 'such a deep history that they have become entrenched in our professional routines, on all sides of the structural divides [...] The main problem of Western imperialist archaeology is our inability to see our own practices as a facet of much larger economic, military and political structures of violent domination' (401, 405; cf. Starzmann).

Practising archaeology at sites of actual violence raises pertinent questions about the discipline's ongoing complicity with violent structures. The 'soft power' initiatives by the U.S. government outlined by Luke and Kersel are a case in point. Aggressive appeals to global heritage and the return of Western archaeologists to Iraq as global stewards are embedded in larger strategies of pacification and reconciliation (cf. Hamilakis, 2003, 2009; Rush, 2011, 2015). A recent essay collection by archaeologists Alfredo González-Ruibal and Gabriel Moshenska, Ethics and the Archaeology of Violence (2015), explores, as the title suggests, the ethical dimensions of research conducted at sites of past and contemporary conflict. Reflecting on theory and praxis at locations of ethnic violence 
and genocide, colonial and dictatorial oppression, and military conflict, ${ }^{3}$ the case studies consider how the discipline has been responsible for and profits from the kinds of violent structures outlined by Bernbeck (González-Ruibal and Moshenska, 5-6). Endeavouring to 'historicize [the discipline's] ethical principles' (Gnecco and Ireland, v), the volume's central message is the need for archaeologists to harmonize academic practices of fieldwork and publication with the goals and methodologies of social justice. Widening stakeholder inclusion to include the experiences and often silenced voices of people most directly affected by the violence under investigation is a fundamental step in this process.

Connections between Hollywood and contentious real-world issues by archaeologists working in conflict zones may seem tenuous or inconsequential, but a blockbuster like Transformers 2 not only represents global conflict but perpetuates through its corporate culture the violence it packages for global consumption. The interrogation of disciplinary habitus by archaeologists like Bernbeck, Luke and Kersel, and GonzálezRuibal and Moshenska helps expose ways in which archaeology is represented in a medium that is expressly about, profits from and perpetuates violent action. In the case of Transformers 2, popular representations of archaeology sublimate violent structures of inequality into powerful hegemonic images of salvation. By examining the effects such representations may have on an audience whose sympathies are aligned with the objectives of 'good guys' acting violently in global contexts, similar claims can be made for popular cultural representations of archaeology that naturalize the kinds of violent structures outlined by Bernbeck. Archaeology plays an important cultural role in maintaining the illusion that spectacular cinematic violence is self-contained on the screen and that its enthusiasts are merely spectators rather than sponsors of the action it references.

In this vein, film and media scholars have begun to appreciate action cinema as a vehicle of 'soft' power politics. Lisa Purse contends that the genre invites us to consider 'historically specific questions, prompted by contemporaneous and recent events, about the basis upon which it is right or necessary to take violent action, about what constitutes heroism, and more generally about what can and cannot be represented on screen in a cinematic fiction at this contemporary juncture' $(2011,5)$. In the Hollywood blockbuster era, violence circulates globally through high concept, protagonist-centred narratives that typically dramatize, in the words of media studies scholar Tanner Mirrlees, 'conflicts and crises of

3 See also Stone, passim, for considerations of ethical issues of archaeologists working with the military. 
world-historic proportions. They stage threats and challenges that tap into or resonate with the hopes and fears of the whole world' (188). Made-in-the-U.S.A. spectacles of violence for domestic audiences inured to 'watching Babylon' and exported to world markets assume particular kinds of global significance when, as in the case of Transformers 2, the strategic spaces for staging 'crises of world-historic proportions' are World Heritage sites.

Close collaborations between the military establishment and the production team are important for rendering historic space into spectacles of world-saving violence. The Pentagon has long been interested in what Georg Löfflmann characterizes as the 'production of cinematic narratives of military power and geopolitical identity' (280). Maintaining its entertainment liaison office in Los Angeles, each branch of the armed forces brokers deals with film producers willing to promote the 'global military role of the United States in the defense of national security' (282) in exchange for access to current military hardware and personnel. ${ }^{4}$ The cornerstone of this arrangement is 'accuracy' and 'realism' (283) in presenting positive images of the American military and U.S. foreign policy. The long-time chief of the Pentagon's liaison office, Phil Strub, is on record as stating that 'any film that portrays the military as negative is not realistic to us' (Robb, 143). Ties between the Transformers franchise and the Air Force Entertainment Liaison Office in Hollywood are illustrative. A short promotional video on the AFELO website replicates the transformational logic of war into spectacle and the spectacle of war into entertainment. Introduced through a montage of Air Force activities and assets, the video advertises AFELO's mandate to 'protect and project the Air Force and entertainment media: films, television, music videos, comics, video games.' Transformers military tech advisor Harry Humphries relates that the Air Force has been 'very very aggressive in recent years' in 'trying to be a part of the support function [of the film industry], showing the new assets that the Air Force has to offer' huge-budget SF projects like Armageddon (1998), the Ironman franchise $(2008,2010,2013)$, Battleship (2012) and of course Transformers. The Hollywood blockbuster is the perfect medium for military self-promotion, and directors and producers speak admiringly

4 Transformers 2 is a case in point. Involving cutting-edge military machines and hundreds of personnel from all five branches of the armed forces, the film is, in the words of Army liaison officer Lt. Col. Greg Bishop, the 'largest joint-military movie ever made' (Bell). Studies of the relationships between Hollywood and the Pentagon include Boggs and Pollard, 2007; Dodds; Power and Crampton; Robb; and Shapiro. 
and uncritically about the production value these partnerships bring to their films. ${ }^{5}$

Löfflmann further observes that the 'alien invasion' film is a particularly fruitful genre for representing 'authentic' military action (287-91). ${ }^{6}$ With its clear enemy, moral certainty of the cause and the inevitable victory of the besieged, the alien invader action film displaces geopolitical contestation into widely accessible narratives and spectacles of defence and domestic security. The paradox of rendering 'authentic' images of violence through the conventions of SF is easily resolved by considering the public values the Pentagon and directors like Bay share. As film scholars Carl Boggs and Tom Pollard observe, the deep patriotic and militaristic content of most combat pictures [...] is rarely determined by stringent Pentagon controls over the way producers, writers, and directors do their work; instead this content flows from the larger political and media culture that is the repository of imperialist ideology' $(2007,226)$. The Transformers franchise can disavow structural investments in military violence by accepting that 'real' and 'authentic' spectacles demanded by the Pentagon are divorced from political context in a film about cyborg soldiers saving the world from evil aliens. As SF, Transformers 2 supports AFELO's mission to 'protect and project' the contradictions of military culture by presenting, as producer Lorenze di Bonaventura relates, 'an extreme example of what the military does in everyday life' (Davidson). The spectacles of transformation in Bay's film-of vehicles into men and men into military machines-is the fantasy the military offers a theatregoing public desensitized to the political content latent in big-budget, high-tech productions of violent action.

The fantastic fabula of alien invaders who are actually war machines affords a broad canvas on which to mobilize military hardware. The plot reorients military commitments to homeland security and the war on terror through an all-or-nothing defence of the planet staged in the Middle East. The battle is spearheaded by Optimus Prime, who, after the defeat of his arch-nemesis Megatron in Transformers, leads a secret military organization of human soldiers and Autobots called NEST (Non-biological Extraterrestrial Species Treaty), which is tasked with

5 Cf. U.S. Department of Defense press release, 'Military Unites with Hollywood on Transformers' (23 June 2009). Archive.defense.gov/news/ newsarticle. aspx ?id=54875.

6 Mirrlees relates that with the exception of Titanic (1997), the top ten grossing films in each decade since the release of Jaws (1975) and Star Wars (1977) are fantasy, SF or their hybrid. Transformers 2 is counted among them. The economic reasons are fairly straightforward: fantasy and SF attract Hollywood's most targeted teen and young adult demographic (187). 
rooting out Decepticon terrorist cells. The planet's survival depends upon finding the 'Matrix of Leadership,' an artefact that activates a Sun Harvester, a device that drains stars of their energy. Megatron plots to harvest Earth's sun in order to recharge Cybertron's depleted Allspark and thereby declare victory in the age-old civil war against the Autobots. In the opening sequence we learn that in 17,000 BC such a device was created on Earth by an evil member of the first race of Transformers called the Dynasty of Primes, and sheathed by what we now recognize as the Great Pyramid. This 'Fallen' Prime was defeated by his benevolent brother Primes when they discovered that he wished to use the device on a planet inhabited by primitive humans. To ensure that the Sun Harvester could never be deployed they sealed the Matrix within what would become the Treasury of Petra. The return of the Fallen in Transformers 2 is thereby imagined in terms of a battle to monopolize energy and consolidate political power in the Middle East. In this sense, Transformers 2 is an imaginative realization of Dick Cheney's Project for the American New Century, which folded in 2006 when the first Transformer film was in post-production.

Violent structures linking Hollywood to the Pentagon also extend to archaeological agencies responsible for cultural oversight in Jordan and Egypt. Transformers 2 producers acquired approval from the Royal Film Commission of Jordon for a four-day shoot at Petra (Jafar). Fostering partnerships with Hollywood has become an important expression of Jordanian modernity (Ciecko). Acquainted with Steven Spielberg from the shoots at Petra for the concluding sequence of Indiana Jones and the Last Crusade (1989), King Abdullah II enlisted the director's help to establish in 2008 the Red Sea Institute of Cinematic Arts in Aqaba. Created in collaboration with the University of Southern California to train Jordanian students in the techniques and business of filmmaking, the institute is also endemic of the structural violence Bernbeck identifies in training programmes for foreign students of archaeology at American universities. $^{7}$ Bay likewise procured consent from the Egyptian Ministry of State for Antiquities to shoot principal photography at the Giza pyramid complex and at Luxor. Similar to the Pentagon liaison office, the official stewards of archaeological heritage in these countries tacitly acknowledge the power of Hollywood to mobilize and ennoble their 'assets' in the cinematic war on terror. Structural violence in archaeology assumes multiple meanings in a film that features direct violence to actual archaeological structures, violence that in turn promulgates unequal global structures typified by the desire for countries like

7 'Jordan Signs Cinema Pact with USC.' Cf. Ciecko. 
Jordan and Egypt to solidify cultural relationships with the West by tapping into the transnational power of the Hollywood film industry. Symbolic violence requires, Moshenska and González-Ruibal remind us, 'complicity of those who suffer the violence' (5), in this case by actively seeking economic and cultural relationships with an industry that, as Hani's dream in Manticore of 'making pictures' like Spielberg attests, has tremendous power in shaping perceptions of the Middle East, its peoples and history on 'all sides of the structural divides' (Bernbeck, 405).

Traces of these violent arrangements may be detected in Bay's transformation of world historic sites into a site of 'world historic' action. In a pre-release interview the director relates that the Egyptian set he recreated at the White Sands Missile Range in New Mexico imparts narrative coherence for the finale. He says,

I personally thought the ending of the first movie was pretty weak. For one thing, I had to shoot the city battle [in Chicago] on five separate blocks, which made it confusing and hard to follow. But the climax here is much clearer in terms of the landmarks and what the endgame is. And it's a really cool scene. You'll never have seen anything like it before. ${ }^{8}$

We certainly have not, because Bay repositions archaeological 'landmarks' separated by hundreds of kilometres into a single diegetic field. After helping Sam locate the Matrix of Leadership at the Royal Treasury at Petra, Agent Simmons (John Turturro) observes through binoculars Optimus parachuting with the army's Golden Knights demonstration team to the 'pillars' located at the base of the Great Pyramid; Sam then takes a short drive to regroup with the Autobot commander. There are of course no pillars at Giza (principal photography for these was taken at the Karnak temple complex at Luxor some 500 kilometres south), and it is impossible to see Giza from Petra, which is roughly 400 kilometres distant. ${ }^{9}$ On the New Mexico set Bay reorients archaeological space into action space, into what Martin Flanagan calls a 'chronotopic threshold,' the space where 'time is waiting to happen.' Like the tower in Die Hard (1988) or the bus in Speed (1994), defined spaces 'seem to wait for the inevitable burst of action which will activate their potential.' In action

8 Http://www.empireonline.com/movies/features/transformers-revengefallen-trailer-breakdown/19/jpg.

9 Spatial misprisions of Egypt have another domestic analogue in MGM's Luxor Palace Hotel in Los Vegas, which served as a projection screen to advertise the film's release. Cf. Malamud. 
cinema, the 'interaction of the hero with the spaces around him drives the narrative' and establishes dialogic engagement with 'the temporal and spatial environment of the spectator' $(113,107)$. Flanagan notes that the "unstable relation of what we might term "adventure-space" to its real geographical equivalent denotes a trend that, usually sanctioned by political or economic factors, has become embedded in film production' (108). At the levels of production, representation and reception, then, these chronotopic thresholds are embedded in the violent structures of an industry with the influence to sacrifice the geographical and cultural verisimilitude of its landmarks to the 'archetypicality' (108) of the endgame.

Flanagan observes that films in the blockbuster action tradition rarely engage with a "real" historical register, instead supplementing or conjoining historical allusion with self-conscious cinematic reference' (110). In Transformers 2, however, the chronotopic threshold Bay meticulously reassembles on an army base cannot entirely escape the violent histories that resonate in the spaces the film exploits for its story. In Filming the Modern Middle East: Politics in the Cinemas of Hollywood and the Arab World (2006), Lina Khatib contends that the association of the Middle East with violence is pandemic in Hollywood. She argues that since 9/11 the 'Middle East has been perceived globally as a place of conflict that is no longer confined to its geographical setting.' Instead, '[m]uch of the political debate on the Middle East revolves around space' (11). Blockbusters like Transformers 2 play a significant role in shifting perceptions of geopolitical violence to non-specific 'Middle Eastern' spaces like the empty desert, impoverished labyrinthine urban centres and rubble-strewn streets. Hollywood films, Khatib argues, 'attempt to use space as the stage upon which political conflicts are fought; i.e. space as background' (15). This is certainly true of Transformers 2, whose characters variously refer to the environment as 'a random' and 'god-forsaken desert'; they are appalled at being stranded 'in the middle of nowhere surrounded by donkeys.' Monuments of antiquity form a continuum with the desert and, indeed, with the Arabs who inhabit the fringes of the action space. Well-worn Orientalist images of poverty and backwardness divorce Arabic peoples from the military technology and car culture driving the principal narrative. Tongue-clacking goat herders, whooping Bedouins with their camels, and ubiquitous squawking chickens are atmospheric and anachronistic extensions of the pyramid, a monolithic Orientalist chronotopic threshold waiting activation by Sam, the Autobots and the U.S. military.

The final action sequences construct narrative causality between world heritage and the contemporary war on terror by sacrificing physical 
structures conscripted as 'background' in the military-archaeologyentertainment complex. ${ }^{10}$ The final sequence vacillates between two distinct chronotopic thresholds: the pyramid, where the battle between Agent Simmons and the Decepticon Devastator takes place, and the pillars, where Sam runs the gauntlet of Decepticon assassins with the Matrix of Leadership, which Optimus needs to recharge after a near-fatal encounter with Megatron earlier in the film. A high-angle establishing shot over the plateau emphasizes the sublimity of antiquity about to be disturbed by 'tightly framed explosive-montage-impact effects' on the ground (King, 2003, 117-18). From the apex of the pyramid, Megatron orders the assault on the U.S.-Autobot position at the pillars and for Devastator to advance on the pyramid itself. Composed of six other Transformers and over 2,000 parts (Robertson, 22), Devastator is the most imposing and costly Transformer in terms of digital imaging. ${ }^{11}$ His job is to climb the pyramid, suction away its stones and expose the Sun Harvester. With over 122,000 blocks simulated to fracture dynamically as they collided (Duncan, 115; Robertson, 25), the scene forms one of the most interesting archaeological action sequences in the film. Devastator vacuums everything in its path, including a Ministry of Antiquities van. Though a trifle ironic given the last-minute permission secured by the producers for access to film at Giza, the sight gag is nonetheless an apposite commentary on the archaeological themes of the film. The Ministry of Antiquities becomes at the level of narrative as well as production an extension of the military mission to restore the democratic ideals sustaining world heritage.

Bay also negotiated with the Ministry of Antiquities to film John Turturro climbing the pyramid. Aping the forbidden tourist practice, the display of privileged access is in this context a form of symbolic deterritorialization of antiquity for action space (Khatib, 26). Simmons follows the Decepticon up the structure and braves an avalanche of broken stone being torn from its crown. The harrowing scene of the pyramid's destruction warrants an equally spectacular military solution, an opportunity for the Pentagon to unveil a killing machine equal to the task: a prototype electromagnetic railgun. Still in development, and with plans to be integrated into battleships by $2025,{ }^{12}$ this space-age

10 On the 'last stand' trope see King, 2000, 138-41.

11 Conducted by Industrial Light \& Magic and Digital Domain (Duncan, 90).

12 For information on the railgun and its deployment see http://www.cnet. com/news/futuristic-navy-railgun-with-220-mile-range-closer-to-reality/; http://defensetech.org/2014/01/16/navy-rail-gun-showing-promise/; http:// www.defensenews.com/story/defense/naval/ships/2016/01/10/railgun-navyfanta-naval-zumwalt-ddg1000/78443016/. 


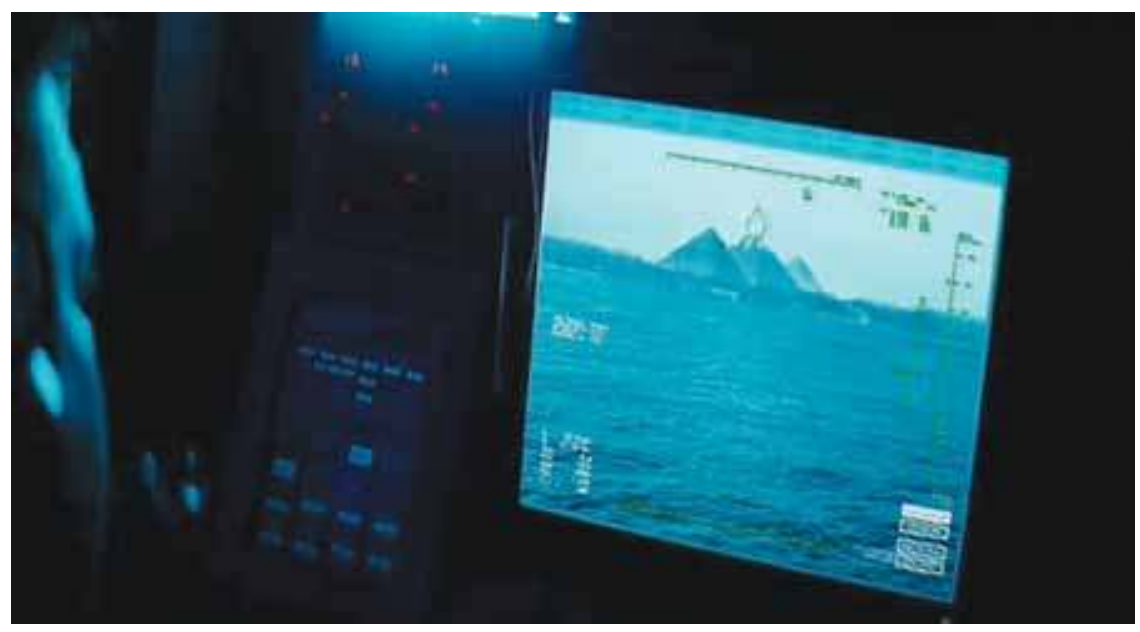

Figure 9. Transformers 2: Revenge of the Fallen (DreamWorks Pictures, 2009).

weapon fires steel projectiles to ranges three times further than conventional artillery. Improved 'lethality' and cheaper rounds are hallmarks of the weapon. Simmons calls in a strike mission to the navy positioned in the Gulf of Aqaba. The audience is invited into the CIC of the U.S.S. Kidd to monitor the counter-attack. The railgun is brought to bear, fires and Devastator is blown to smithereens. Introducing computer-assisted targeting systems into the diegetic frame equates the scopophilic experience of the viewer with the soldier's panoptic view of the battlefield. The audience shares the defenders' physical and moral purview through cuts to military extras operating their guidance systems and assault vehicles. Collective memories of recent engagements in the Middle East are thereby reframed in Transformers 2 through the kind of privileged visual complicity offered to viewers 'watching Babylon' on 'digitized battlefields' (Masters, 121).

Shifting to Sam's dash through the pillars, this phase of the missionand the demolition of cultural space it entails-mobilizes a huge arsenal of military assets to get Sam safely to Optimus. The Coast Guard establishes a beach-head, delivering Abrams tanks and troops to shore up the defence at the pillars. The navy scrambles F-18 Hornets from the U.S.S. Stennis. A squadron of F-16 fighters fly in attack formation. A-10 tank killers patrol the skies. An E-3 AWAC team gives a B-1B Lancer clearance to 'drop your 2,000 tonne payload.' Establishing air superiority reaffirms reigning images of U.S. possession of the skies and the euphemistic parlance of surgical strikes upon the '[o]ther space,' 
asserts Khatib, 'represented as a target' (21). The spectacular realism of military endorsed perspectives of the battlefield dovetails with the panoply of action cinematic special effects. Rapid cuts, movement towards the camera, shaky hand-held shots, jerky reframings, slow motion, stroboscopic lighting, speed-ramping, whiplash pans, crash zooms, multiple angles and wave after wave of fireballs create a frenetic effect of movement, danger and thrills for the spectator. Displays of military technology at this chronotopic threshold are constitutive of the cinematic technology through which Sam's evolution into manhood is configured.

A set piece in the midst of the action with the Witwicky family drives home this theme. Sam's parents are taken hostage by the Decepticons and used as leverage against their son to surrender the Matrix. Sam is forced to choose between saving the world or his parents. Bumblebee intervenes and whisks the parents to safety, but not before a crucial rite of passage takes place. Sam exhorts his father, 'You have to let me go.' The father reluctantly agrees, allowing the boy to become the kind of man the situation demands of him. The scene prepares Sam for his final test. On the verge of reaching Optimus, Sam finds himself in Megatron's crosshairs. Caught in an explosion, Sam is blown into the air and dies. Neither Army medics nor Mikaela's love can revive him. But at this point something magical happens. The entire diegetic field of action shifts to a dream vision. Sam's consciousness drifts into an overexposed after-life, where he is greeted by the spirits of the Primes who had entombed themselves with the Matrix of Leadership millennia ago. This quasi-mystical encounter is the film's final chronotopic threshold. The Primes reveal to Sam that they have been watching over him, and that the search for the Matrix that has taken him around the world is actually a voyage of self-discovery. The Matrix is not found, they insist, but earned. Sam literally is the Matrix and he alone can wield its power to revive Optimus and save the planet. Sam comes back to life and he plunges the Matrix into Optimus's chest. The anticipated fight with the Fallen can now begin. The Cybertronians duke it out mano a mano, the Fallen falls again, Megatron and Starscream fly off to fight another day, and the carnage ends with Optimus standing triumphant on the Sphinx, which comes to the film conveniently pre-stressed and battle-scarred.

But what does this enigmatic notion of becoming a thing signify? What does it mean for Sam's transformation into an action hero by becoming the Matrix of Leadership, by in a sense becoming an ancient artefact that holds the power to save or destroy the world? I have been arguing that as a global entertainment, Transformers 2 displaces the global reach of military power into outwardly depoliticized images 
culled from world heritage sites and SF alien invasion scenarios. The temporal tug-of-war between the deep past and far-flung cybernetic future describes a continuum of technological fetishism that is at the heart of Sam's evolution into the kinds of man desired by Hollywood and the Pentagon alike. In action cinema, violence frames as much as it defends freedom and progress. This is particularly poignant in the Transformers franchise, which, according to Harlan Wilson, harbours the promise of 'male capitalist "success,"' which is ideally carried out by means of aggression and violence, end-product representations of a cathexis applied by the gaze of the audience.' Wilson opines that the first 'film is itself a Transformer, extending and projecting itself as desiring-machine and phallus on to the body of its spectacular, scopophilic constituency' $(350,351)$. Transformers 2 squares artefact destruction with the diplomatic objectives of the military-archaeology complex. Maintaining traces of the human subject in these dramas of direct violence requires the reconstitution of peace and order through the humanistic imagery afforded by material archaeological attachments to culture while offering the promise of 'techno-masculinized' transformation (Masters, 115) of human bodies into terrible weapons and ancient monuments into weapons of terror.

The film ends with a voiceover by Optimus delivered from the bow of the aircraft carrier U.S.S. Stennis. Recalling George W. Bush's 'Mission Accomplished' speech from the deck of the U.S.S. Abraham Lincoln (1 May 2003), the address provides a logical, aesthetic and moral conclusion to the story of alien invasion by reconciling the destruction of heritage sites with the forever war in the Middle East: 'Our races are united by a history long forgotten and a future we shall face together. I am Optimus Prime and I send this message so that our past will always be remembered, for in those memories, we live on!' The feeble logic notwithstanding, the kind of memory Optimus advocates demands that the audience forget the political events and geopolitical tensions that the film references in its action sequences and in its action spaces. In its temporal, physical and cultural manifestations, antiquity is a vehicle for imagining a peaceful or at least secure future under military stewardship, as long as we ignore the ongoing history of direct and structural violence gathered around it.

In Transformers 2 'fantasies of empowerment' (Purse, 2011, 3) localized in the action hero are played out globally for audiences in its war on terror scenario. For Purse, 'the question remains whether the action film, with its reliance on simplistic notions of heroism and justice, its often conservative representational hierarchies and its inexorable progress towards a thrilling, spectacular expression of the hero's mastery over 
clearly identifiable foes, will ever be able to accommodate adequately the complexities of the post 9/11 world.' What is clear, she continues, 'is that action cinema bears the traces of that world, whether through contextual references, direct engagement $[\ldots]$ or the concomitant and persistent popularity of explicitly fantastical films' (168). With its exercise of military assisted violence on terrain redolent with recent contestation, Transformers 2 reframes the troubling partnership between archaeologists and soldiers-imagined in the geopolitical and cinematic need to save the world through spectacular destruction of antiquity-through SF action, wherein the diegetic world seems to lie outside of the immediate social order. Yet, the film's dissimulation of war in the Middle East reminds us how we 'watched Babylon' and 'all the weaponry, gear and technology of the cyborg being set up in and around the borders, boundaries and bodies of Iraq for Operation Iraqi Freedom' (Masters, 125). Like Hal in 2001, the Cybertronians at once incarnate and displace anxieties about the violent complexion of our own technological determinism. They are the ultimate artefacts of Hollywood's techno-military fetishistic culture.

Evoking Kubrick's film is an appropriate way to shift consideration from military SF to the figure of the ancient astronaut as source of geopolitical meditation and mediation in SFFTV. The ancient astronaut is a central trope in SF archaeology, and is, with the exception of Manticore and A.I. Artificial Intelligence, the plot-triggering device of each text under investigation in the present study. As a revisionist figure of human history, the ancient astronaut is another futuristic model for imagining present configurations of global security and insecurity through archaeology. In Part 2, 'Of Artefacts and Ancient Aliens,' I argue that like military SF this figure from fringe archaeology is an important means of charting cultural anxieties circulating in post-9/11 SFFTV entertainments. 


\section{Part 2 \\ Of Artefacts and Ancient Aliens}

The cinematic history of [ancient astronaut] narratives is long, demonstrating that cinema does not merely reproduce popular pseudoarchaeological research, it has also contributed to the growth of these stories.

Peter Hiscock ${ }^{1}$

We've watched it a thousand times. Earthrise over the pock-marked lunar landscape. The Eagle gliding over the Sea of Tranquillity. Armstrong's clumsy descent. One small step for man. The teaser of the Ancient Aliens pilot episode makes one giant leap further:

July 20th, 1969. Astronauts Neil Armstrong and Buzz Aldrin became the first men to land on the moon. Just like aliens visiting from another world, it had been the stuff of science fiction. Now everything that could be imagined seemed possible. If mankind could travel the skies and go to other planets, why couldn't beings from other planets visit the Earth? Amidst a wave of modern UFO sightings a new theory emerged: that aliens visited Earth in antiquity, and were regarded as gods. But if that were true, wouldn't there be proof? Perhaps there was. All we needed to do was open our eyes and our imaginations. The proof perhaps was all around us. ('Chariots, Gods, and Beyond,' 8 March 2009)

1 Hiscock, 156. 
If the historic moon-landing consummated the SF imagination for audiences gathered around their television sets, then for ancient astronaut advocates archaeological traces are manifestations of the same imagination in antiquity. As Stanley Kubrick's 2001: A Space Odyssey attests, however, SF is not always eager to celebrate the technological achievements of NASA. In the introductory chapter I argued that Kubrick clouds the dawn of space exploration by 'unconcealing' the monolith. The violent competition that its discovery instilled in our hominid forebears and in their space-faring progeny is the sine qua non of an evolutionary path hurtling towards self-destruction. Introducing a controversial nexus of ideas about human evolution and extra-terrestrial life through the familiar iconography of the Apollo 11 mission, Ancient Aliens similarly invites its viewers to reconsider the potentially apocalyptic future of a people catching up to its literary imagination.

These relationships are manifest in that other SF wonder of 1968, Franklin J. Schaffner's Planet of the Apes, but with the ironic twist that the ancient astronauts turn out to be us, the human progenitors of ape ascendancy. In 'Simians, Subjectivity and Sociality: 2001: A Space Odyssey and Two Versions of Planet of the Apes,' Sherryl Vint observes that both films critique the trajectory of a human civilisation-developed from a once-shared culture with simians-that has produced the threat of nuclear annihilation' (226). Engaging problematically with the ideology of past, present and future, the human/simian binary is a version of the ancient astronaut topos in a film that is explicitly preoccupied with the archaeology of an apocalyptic future, the suppression of information, and the legacy of artefacts. Two archaeological moments underpin this reading: the excavation of what Cornelius (Roddy McDowall) correctly deduces is a proto-simian human settlement, and NASA astronaut George Taylor's (Charlton Heston) shocking discovery of the Statue of Liberty in the Forbidden Zone at the film's conclusion. For Cornelius, Taylor is a living artefact, the 'missing link' in ape evolution. This is a dangerous hypothesis because this link is an ancient astronaut returned through a relativistic voyage from the prehistory of ape culture, a world whose physical remains prove that simian origins lie amongst the shards of the Anthropocene. In the strata of the Forbidden Zone, Taylor finds a child's talking doll, the visible (and audible) chink in the armature of singular simian evolution espoused by Dr. Zaius (Maurice Evans), who ultimately confesses that he hid this data to protect apes from the knowledge of common ancestry. Exhumed from the past, Taylor manifests a simian fate bound to the social injustices and paranoia that the Cold War era film critiques. 


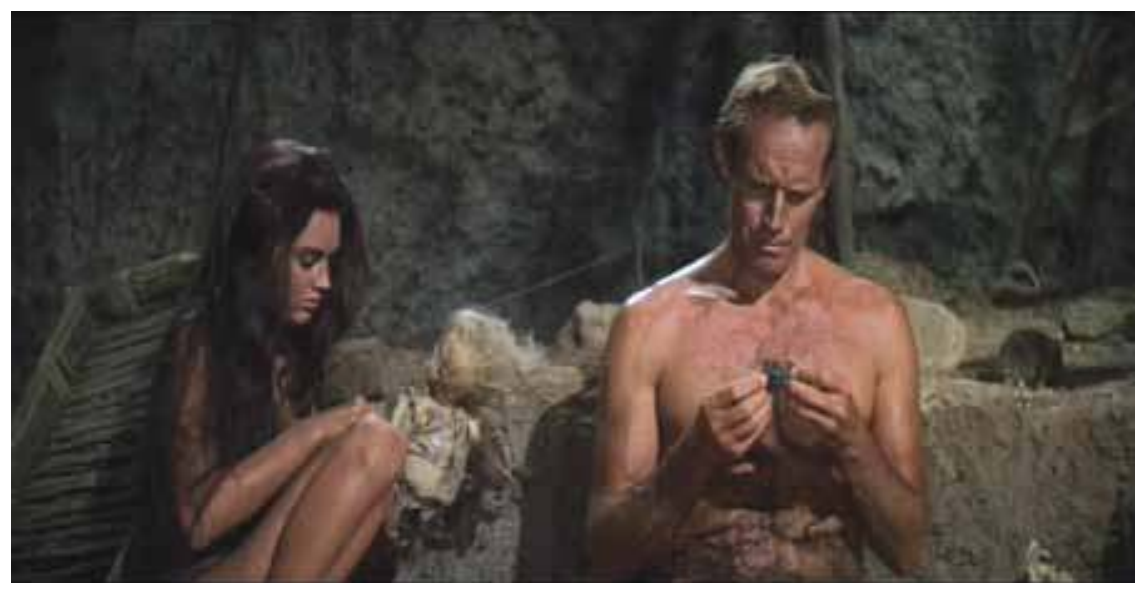

Figure 10. Planet of the Apes (20th Century Fox, 1968).

The conclusion recalls the opening sequence aboard Taylor's command module, NASA's version of a time capsule launched into the future. Taylor hopes to be welcomed on his return by a more ethical humanity. He wonders, 'does man, that marvel of the universe, that glorious paradox who sent me to the stars, still make war against his brother? Still keep his neighbour's children starving?' But the experiment in time exploration is ultimately symptomatic of the social injustices he hopes to leave behind. The ancient astronaut finds the answer to his musings in the image of the Statue of Liberty listing in the sand at the end of Planet of the Apes' (Vint, 226). Space travel, the epitome of progress, leads not to liberty but apocalypse. Prefiguring the rise of apes in a new cycle of violence triggered by his arrival, the beach-wrecked past forecloses futurity in a palpable indictment of 'patriarchal and military values' (228).

2001 and Planet of the Apes sound out the troubling cultural and political zeitgeist of the burgeoning Space Age, an era in which, as the narrator of the Ancient Aliens pilot avers, science and its fictions seemed conjoined. Indeed, speculations about the possibilities of encountering alien life emanated from within the ranks of NASA itself, perhaps none more famously than by astrophysicist and SF author Carl Sagan. As host of the Emmy Award winning television miniseries Cosmos (1980), Sagan's advocacy of the Search for Extraterrestrial Intelligence programme for a generation immersed in the wonders of space flight helped open a serious dialogue about alien visitation. ${ }^{2}$ In his 1973 book The Cosmic Connection: An

2 Davies furnishes a history of the project and its failure to produce proof of extra-terrestrial intelligence. 
Extraterrestrial Perspective, Sagan observes that there is today-in a time when old beliefs are withering - a kind of philosophical hunger, a need to know who we are and how we got here. There is an ongoing search, often unconscious, for a cosmic perspective for humanity' (59). Sagan did not exclude the possibility of looking backward for this 'cosmic perspective.' In his co-authored book with Soviet astrophysicist I.S. Shklovskiǔ, Intelligent Life in the Universe (1966), Sagan entertains the idea that mythological and religious texts might record extra-terrestrial visitation. He devotes several pages to the Sumerians, a group that interests him precisely because of the prevailing genetic fallacy that their civilization is the ancestor of our own' (456). Sagan cites the myth of Oannes, a sky god attributed with endowing his worshippers with knowledge of agriculture, mathematics and astronomy. Sagan argues that if Sumerian civilization is depicted by the descendants of the Sumerians themselves to be of non-human origin, the relevant legends should be examined carefully.' To this he adds an important rider: 'I do not claim that the [legend] is necessarily an example of extraterrestrial contact, but it is the type of legend that deserves more careful study' (456). Myths from 'the earliest civilizations on Earth,' he explains, 'deserve much more critical studies [...] with the possibility of direct contact with an extraterrestrial civilization as one of many possible alternative interpretations' (461). According to film scholar Mark Brake, Intelligent Life in the Universe was Kubrick's 'bible' (252): 2001 is predicated on Sagan's 'thesis' that some 'extraterrestrial society or federation' could have constructed a base on the dark side of the moon in order to monitor and facilitate contact with 'an emerging technical civilization [...] perhaps to head off a nuclear annihilation' (462). ${ }^{3}$

Though abstracted from a single chapter in a largely speculative work (i.e. Chapter 33, 'Possible Consequences of Direct Contact'), ideas

3 In 1963 Sagan wrote: 'We assume that there exists in the Galaxy a loosely integrated community of diverse civilizations, cooperating in the exploration and sampling of astronomical objects and their inhabitants. If each such advanced civilization launches one interstellar vehicle per year, the mean time interval between samplings of an average star would be $10^{5}$ years, that between samplings of a planetary system with intelligent life would be $10^{4}$ years, and that between sampling of another advanced civilization would be $10^{3}$ years. It follows that there is the statistical likelihood that Earth was visited by an advanced extraterrestrial civilization at least once during historical times. There are serious difficulties in demonstrating such a contact by ancient writings and iconography alone. Nevertheless, there are legends which might profitably be studied in this context. Bases or other artifacts of interstellar spacefaring civilizations might also exist elsewhere in the solar system. The conclusions of the present paper are clearly provisional' (485). 
amplified by Kubrick took root in the fringe archaeological community and essentially laid the scientific groundwork for ancient astronaut deductive research. Suggesting possible connections between present and past civilizations, Sagan's publications lent credence to the kinds of 'sensational books' $(1973,206)$ like Erich von Däniken's Chariots of the Gods? (1970) that he would vehemently disavow in later writings. Concerning the Oannes legend, for example, Sagan categorically asserts that provocative as this and similar legends were, I concluded that it was impossible to demonstrate extraterrestrial contact from such legends: There are plausible alternative explanations' $(1973,205)$. Appealing to scientific reasoning to ameliorate the problem he helped create, he states that '[p]ondering wall paintings, for this purpose, like looking for UFOs, remains an unprofitable investment of terrestrial intelligence-if we are truly interested in the quest for extraterrestrial intelligence' (207). ${ }^{4}$ These animadversions notwithstanding, the scientific romanticism underpinning Sagan's quest for extra-terrestrial life opened space exploration to a science fictional imagination that propelled Paleo-SETI's own voyage into the outer reaches of the archaeological past.

While it is not my intention to detail the history of ancient astronaut thinking-which is itself a subspecies of alternative archaeological thought encompassing anthropologist Marcel Griaule's investigations in the 1930s of the astrological religions of Mali's Dogon people, the rise of ufology in the late 1940s, and New Age religions, cults and even popular entertainments today-no investigation of the cultural currency of ancient astronaut speculation would be complete without mentioning Erich von Däniken. With his Chariots of the Gods? Unsolved Mysteries of the Past selling over 60 million copies, having nearly 30 other books and a box-office smash documentary film of Chariots to his credit, ${ }^{5}$ designing the UFO themed Mystery Park in Interlaken, Switzerland (2003-06), and founding the Archaeology, Astronauts, and SETI Research Association, von Däniken is unquestionably the most famous and energetic promoter of ancient astronaut speculation. In broad strokes, von Däniken claims that extra-terrestrials visited the Earth thousands of years ago, engineered humanity by manipulating the DNA of our hominid forebears (and/or mating with them),

4 Sagan makes similar comments about von Däniken and his associates in The Cosmic Connection (199-207) and Boca's Brain (43-80).

5 Chariots of the Gods? was adapted for television in 1973 by Alan Landsburg under the new title In Search of Ancient Astronauts. It is narrated by Rod Serling, the iconic voice of The Twilight Zone and screenwriter of Planet of the Apes. 
bequeathed the skills necessary to build cities and civilizations, and then mysteriously vanished. Archaeological sites all over the world offer proof of this radical idea. The Nazca geoglyphs in Peru are remains of an extra-terrestrial landing strip; the Egyptian pyramids are architectural texts of advanced alien mathematical principles; the moai of Easter Island are signalling devices built by alien castaways; Stonehenge is an astronomical clock constructed with anti-gravitational technology; the Palenque sarcophagus lid is a blueprint for a rocket ship (fig. 12). Religious and mythological texts like the Hebrew and Christian bibles, the Quran and the Mahabharata, as well as the oral legends of the Hopi also document extra-terrestrial activities and interventions of gods and angels whose power is neither divine nor magical but technological. Ezekiel's fiery chariot is a spaceship. The battles in the sky described in the Mahabharata are chronicles of aliens unleashing atomic weapons from flying machines. A resilient and flexible monomyth of the extraterrestrial legacy to humanity, the ancient astronaut premise offers the pleasures of archaeological mystery through an impression of scientific plausibility.

Needless to say, many archaeologists are unconvinced. Among the most active and vocal 'sceptics' are Kenneth Feder and Garrett Fagan. ${ }^{6}$ Having run to eight editions since 1990, Feder's provocative Frauds, Myths, and Mysteries: Science and Pseudoscience in Archaeology defends the scientific method against the popular theories of archaeology that attract many of his students to the discipline. In a chapter devoted to ancient astronauts, Feder identifies typical rhetorical fallacies. ${ }^{7}$ The most pervasive is what he terms the 'inkblot hypothesis,' the projection of a priori desires onto objects. Similar to devout Christians gazing upon the face of Christ in the Shroud of Turin, believers in ancient astronauts find their imprint throughout the archaeological record. Inkblot thinking accords faith its visible correlatives.

Garrett Fagan's essay collection Archaeological Fantasies: How Pseudoarchaeology Misrepresents the Past and Misleads the Public is a collaborative effort by professional archaeologists to redress claims made by alternative archaeological communities such as Druid worshippers, occultists and Atlantis hunters. Peter Kosso's introductory chapter 'The Epistemology of Archaeology' is a text-book lesson in scientific reasoning, beginning with objective, neutral, detached observation of

6 Fritze provides a comprehensive bibliography of von Däniken detractors (283-84; cf. note 79).

7 Schadla-Hall outlines the recurrent themes and rhetorical tropes of alternative archaeology. 
facts. The 'chain of logic,' N.C. Flemming adds, 'from the field data through to social deductions is very clear, and even if the results may be disputed, the methodology is constrained by academic conventions' (69). Fagan's own chapter 'Diagnosing Pseudoarchaeology' is a kind of DSM chart for categorizing a host of symptoms ranging across disregard for context, rigid a priori deductions, and fundamentally polemical and even dangerous appeals to 'religious belief, nationalist or political ideology, or race consciousness' (28). Commercial motives of the ancient astronaut industry, moreover, cannot be discounted (Flemming, 47). Flemming further locates, to cite the title of his contribution, 'The Attraction of Non-Rational Archaeological Hypotheses' in a hybrid rhetoric of science and religion. Like Agent Fox Mulder (David Duchovny) on The $X$-Files who 'Wants to Believe,' faith will find the truth of its premises and ignore or rationalize contradictions in a totalizing theory once it has taken root in the imagination. The psychology of pseudoscience engenders the 'contrivance of an all-or-nothing religious leap of faith to attract the true converts' (62). Ancient astronaut adherents experience a cult or subcultural sense of initiation into mysteries beyond the veil of mundane historical reality. Pseudoarchaeologies, Flemming argues, 'ruthlessly exploit the self-critical caution of science and academic reasoning [...] and they attract and seduce the punters with age-old stories of danger and conspiracy, combined with requiring the true convert to make a commitment of faith, against reason' (66; cf. Harrold and Eve; and Lovata, 2007). ${ }^{8}$ Scientists warn the public to beware of hucksters masquerading as enlightened sages; the 'pseudos' alternatively decry a jealous scientific cabal for hiding the truth that an unknown and largely unknowable force has directed our evolution and will one day return.

Between these poles other voices have recently emerged. Kenneth Feder contends that pseudoarchaeology flourishes in part because archaeologists have not adequately assumed responsibility of 'sharing with their students, as well as with the general public, archaeological knowledge and the results of the scientific investigation of our shared human past' $(2006,95)$. This challenge has been answered by scholars not primarily concerned with debunking or disparaging popular cultural responses to archaeology, but with opening the media communications in which it thrives to cultural study. In these contexts, the term 'alternative archaeology' is preferred to 'pseudoarchaeology,' and is a growing field of academic study by scholars interested in examining the flow of archaeological discourse between scholarly and popular audiences.

8 See Holtorf, 2005, for a bibliography of other detractors. 
Swedish archaeologist Cornelius Holtorf best sums up this position in 'Beyond Crusades: How (Not) to Engage with Alternative Archaeologies.' He asks archaeologists to examine seriously the overlapping 'social and cultural needs that both scientific and alternative archaeologies address.' Shifting the dialogue from results to processes, Holtorf advocates for more 'epistemological relativism' in order to draw non-academic discourses into the post-processual project of questioning the status of scientific knowledge and the orientation of 'the present with larger historical perspectives and narratives' $(544,550,547){ }^{9}$

In his article 'The Comforts of Unreason: The Importance and Relevance of Alternative Archaeology,' Tim Schadla-Hall treats alternative archaeology as a fundamentally rhetorical field. Like Feder and Fagan, he is wary of the support for 'racist, ultranationalist [...] [and] fundamentalist beliefs' (255) attending so much of alternative archaeology's recurrent tropes of hyperdiffusionism, conspiracy and occultism. But like Holtorf, Schadla-Hall considers the phenomenon as an active and bona fide mythology or belief system worthy of study alongside religions that claim to derive divine knowledge from superior intelligences. Published in 2012, a special issue of Numen: International Review for the History of Religions likewise treats alternative archaeology as, to cite editor Pia Andersson, 'an important part of modern religious history' (135). Particularly relevant is Jonas Richter's 'Traces of the Gods: Ancient Astronauts as a Vision of Our Future,' which examines the religious undertones of the phenomenon. Ancient astronaut principles have their objective correlative in a rhetorical gesture that Richter calls interpretatio technologica, wherein '[t]raditional theological, spiritual, or psychic explanations of [numinous] phenomena are replaced by profoundly physical, material explanations: changing angels into aliens' (225). Religion collapses into politics: the promise of divine power is available (at least imaginatively) to people dedicated to understanding technological mysteries hidden in archaeological remains. Ancient astronaut discourse holds the promise that '[h] umankind will travel to outer space and spread intelligence, becoming the creators of another civilization. History will repeat itself, and we ourselves will become astronaut gods' (243). Ancient astronaut narratives thereby present, according to Andreas Grünschloss, 'a new mythic foundation for modern man and his scientific and technological mode of being in the world' (16), a promise that accords with Sagan's own hopes and fears at the dawn of space travel.

9 Cf. Lovata, 2005, an interview with Preston Peet, the author and publisher of alternative archaeology texts. 
Feder's contention that the 'mistakes and misrepresentations of human antiquity found in [Chariots of the Gods?] are so egregious [...] [they] have led some [...] to suggest that, far from being a writer of alternative human histories, von Däniken is instead a writer of fantasy and science fiction' $(2010,60)$ opens alternative archaeology to the same regimes of knowledge that SF also documents. The twin themes of ancient astronaut narratives-esoteric knowledge and conspiracyresonate with the themes of insecurity and fear of the unknown that have been staple tension-making devices of the SF genre and its hybridizations with horror, disaster and invasion. The purpose of the following chapters is not to assess the credibility of ancient astronaut lore, but to examine its thematic context as a science fiction of our ongoing relationships with the material past. To begin I turn to an analysis of the documentary practices of the History Channel's Ancient Aliens, a television series that considers, like the appeal to the moon-landing with which it begins, the nature of origins and evolution within the polemics of contemporary SFFTV. 


\section{Chapter 4}

\section{Ancient Aliens}

'I'm not saying it was aliens ... but it was aliens.'

Meme attributed to Giorgio Tsoukalos

[S]pecial effects in mainstream SF have been transformed from signs of a rational and objective science and technology to representations of a joyous, and 'sublime' intensitythematically linking postmodern culture's new 'detached,' 'free-floating,' and 'liberated' sense of emotional transcendence with the transcendental.

Vivian Sobchack ${ }^{1}$

Star Trek: Into Darkness (2013) opens in medias res with James T. Kirk (Chris Pine) and Leonard 'Bones' McCoy (Karl Urban) fleeing the very small indigenous population of a crimson forested planet. In an effort to lure them from their temple, which is about to be destroyed by a volcanic eruption, Kirk steals their sacred scroll. When the natives are out of danger, Kirk abandons the scroll and returns to the U.S.S. Enterprise, which is concealed underwater. In violation of the Prime Directive (non-interference in the development of pre-warp civilizations ${ }^{2}$ ), Kirk is forced to reveal the ship when it leaves the planet. The natives immediately toss aside their scroll and kneel in worship before the rapidly ascending Enterprise. When the ship warps away, the group's elder scrapes an outline of the Enterprise in the soil as the rest of the tribe looks on in excitement. The crew of the Enterprise save the planet from certain destruction, but in the process steer its inhabitants toward

1 Sobchack, 1997, 287-88.

2 Cf. McGeough's examination of the imperial logic of the Prime Directive. 
a potentially dangerous evolutionary path. For the descendants of this world, Kirk and McCoy will be ancient aliens.

The scene in fact makes an overt reference to a famous chapter in ancient astronaut lore. The planet is question is known as Nibiru, named after the world Zecharia Sitchin describes in his best-selling book, The Twelfth Planet (1976). A self-taught Sumerian scholar, Sitchin created from his reading of Sumerian mythological texts an alternate history of the solar system, in which a 'twelfth planet' on a vast elliptical orbit around the sun intersects with Earth's orbit every 3,600 years. The film inverts Sitchin's theory that the technologically advanced inhabitants of Nibiru, known to the ancient Sumerians as 'Annunaki,' were responsible for kick-starting human evolution. Purported to be on a collision course with Earth, the 'wandering planet' Nibiru (Fritze, 211) was one of the most popular doomsday conspiracies coinciding with the 'end' of the Mayan long-count calendar in 2012. As evidenced in films like 2001: A Space Odyssey, Planet of the Apes and Transformers 2, ancient astronauts afford a broad canvas for imagining world-ending scenarios. The opening scene of Star Trek: Into Darkness illustrates, furthermore, that the digital special effects that leave the awestruck natives of Nibiru gaping in wonder are constitutive of the ancient astronaut topos of technologically superior beings interfering in human affairs. As a technological medium, the History Channel's pseudo-documentary Ancient Aliens (2009-) likewise inundates the viewer with spectacular images that blend venerable SF tropes of extra-terrestrial intervention and invasion with the visual conventions and rhetorical strategies of documentary television. This chapter examines the cinematographic methods through which Ancient Aliens produces alternative archaeological knowledge at the intersection of digital effects, documentary rhetoric and SF storytelling.

Elana Gomel's Postmodern Science Fiction and Temporal Imagination (2010) is useful for considering the cultural concerns to which this hybrid form responds. Her work is founded on the bold premise that SF is the realism of postmodernism. ${ }^{3}$ Unshackled by the 'chrono-logic' constraints of realist fiction, SF 'documents,' she says, the 'explosive growth' (3) of postmodern temporalities through particular narrative figures she terms 'timeshapes.' A special case of Mikhail Bakhtin's chronotope and reminiscent of Gary Wolfe's SF icon, timeshapes are flexible metaphors that accommodate 'new forms of time' generated by a broad array of

3 Gomel echoes Brian McHale's Postmodernist Fiction (1987): 'Science fiction, like postmodernist fiction, is governed by the ontological dominant. Indeed, it is perhaps the ontological genre par excellence. We can think of science fiction as postmodernism's noncanonized or "low art" double' (59). 
contemporary scientific and cultural discourses, including 'evolutionary theory, quantum mechanics, cosmology, cyberspace, globalization, and resurgent religious fundamentalism' (3). Gomel identifies three distinct timeshapes, each corresponding with a particular SF narrative. The first and most recognizable is time travel, a conceptualization of time as space that forecloses against temporal interference at the risk of invoking the dreaded time paradox or 'chronoclasm.' The second, alternative history, opens existence to the many-worlds interpretation of quantum physics. Both time travel and alternative history refute chrono-logic realism, because time and space are conflated in the former and multiply in a web-like multiverse in the latter.

Gomel's third timeshape is the most compelling for the present reading of Ancient Aliens: that is, apocalypse, a complex rendering of the end of time with the 'advent of the millennium' (18), a time beyond time itself. Apocalypse, she states, is 'a one-way road to eternity which is the salvation of the chosen few and the damnation of the discarded many. It is perhaps the most ideologically potent and dangerous timeshapeand the most popular' (18). A postmodern shield against time's arrow, apocalypse accords SF a coherent vision of ideological affairs that makes the end of time inevitable and even desirable in a world of global conflict: a world in which, she says, 'apocalypse has become mega-entertainment and mega-war' (21). Though entirely suspect epistemologically, Ancient Aliens is in Gomel's sense a 'realist' postmodern fiction of the end of time within the cultural paratext of post-9/11 SFFTV.

Ancient Aliens disrupts narrative space-time by investing static artefactual markers of the past with the kind of futuristic agency Wolfe attributes to the 'venerable' icons of SF. The programme outwardly imitates familiar documentaries of archaeological discovery, wherein objects are 'unconcealed' as pro-filmic images in a visual field saturated with similar images emerging into the light of day: as Timothy Clack and Marcus Brittain state in Archaeology and the Media, of 'presenting a fiction [of discovery] through an unsteady camera, a crouching trench level shot, the scraping of the trowel' (49). Ancient Aliens takes a step further by 'science fictionalizing' these discovered object/images into figures of alternative archaeology. The modus operandi of revelation (of exposing hidden messages about the future buried in the past) is the series' central thematic concern: timeshaping material remains into an alternative archaeology of the future, a documentary of the possible or even inevitable return of our extra-terrestrial ancestors. The show's 'revelatory' apparatus for uncovering secret knowledge, moreover, persistently aligns archaeology with Scriptural revelation of the signs of the end of days. 
Ancient Aliens emplots discovery as apocalypse through a distinct televisual style developed in the series' inaugural season. Over the course of five two-hour episodes, the show methodically erects an eschatological framework around archaeological referents. The first episode 'The Evidence' (20 April 2010) establishes the claim that the material imprint of ancient peoples is actually an arcane blueprint of modern and futuristic technologies. The teaser opens with a 'cosmic perspective' of the Earth from outer space then plunges into a kinetic montage of heavy construction equipment and transportation and power systems girding the planet. Ancient sites and artefacts are then introduced: dynamic framing and lighting effects invest the inanimate past with the contemporary purpose of machines. Sound effects accentuate the visual comparison. Camera zooms 'swoosh' towards artefacts. Drums beat out tension. A series of minor crescendos anticipate bold narrative statements. 'Are these examples of modern technology, or is there evidence that these incredible achievements existed on Earth thousands of years ago?' Time for expert testimony. The prolific lost Atlantis author Graham Hancock avers, 'You begin to ask yourself, "Are we missing part of the story?"' The drums surrender to spooky piano and vocal phrasing reminiscent of The Omen or X-Files themes. The narrator wonders, 'Could ancient man have possessed knowledge far beyond that of our own century? And if so, where did it come from?' The tempo surges to the fully orchestrated main theme as two-dimensional panels of artefacts crash towards us from the cosmos-all very reminiscent of Richard Donner's rendition of the Phantom Zone in Superman (1978) - then settle into the main title. Multiple levels of sound-drums, piano, synthesized voice, orchestra-build tension and a palpable sense of threat.

While old objects and expert testimonials impart documentary perspicuity for the ancient astronaut premise, the kaleidoscopic visual and tonal fields transform objects into 'the evidence' of an otherworldly past through low-budget special effects culled from the repertoire of 'B' SF. The teaser displaces artefacts into an epistemological register that is not museological but decidedly cinematographic. Special effects have a crucial function. They do not merely supplement the documentary narrative, they carry 'truth' in familiar and unsettling images and storylines cobbled together from disaster and invasion films. Spectacle is not a substitute for narrative; rather, it is a form of storytelling that bridges logical gaps in ancient astronaut rhetoric. The privileged form of narrative is the montage, the loose connection of images culled from science fictional claims on the 'real' world. Archaeological objects engender multisemic forms of address that resist narrative closure (McClean, 164) by consigning them to the spectacular plausibility (and 
circular reasoning) of ancient astronaut thinking. The viewer is accorded momentarily the privileged perspective of the extra-terrestrial, then is bombarded from space with a meteoric revelation of an unsettling truth.

The episode chapters themselves develop at a slower pace the argument introduced in the teaser. The narrator invites us to consider the evidence, in the first instance of an unpresuming bird figurine discovered at Sakaara, Egypt, in the nineteenth century. The opening shot tracks a scorpion skittering across a burning rock, then pans up to a soft focus of the step pyramid of King Joser in the distance. The camera pans around the pyramid and tombs at its base, then dissolves to a display case at the Cairo Museum. A close-up of a simple wooden bird carving on a stick is juxtaposed to an animation of a papyrus manuscript unfurling. Purportedly discovered alongside the carving, the scroll bears the phrase 'I want to fly.' Having established an archaeological gaze and museological context, the object undergoes several transformations. The shape of the wings suggests to researchers that the figurine represents a flying machine. The artefact is measured, digitized on CAD/CAM software, replicated in a scale model, tested in a wind tunnel, then 'flown' in a flight simulator. Physical modelling and digital imaging hold the archaeological and the technological in suspension. Watching the model of the bird actually fly (with the minor addition of an elevator) is quite compelling evidence of our own mastery of the skies. The object becomes a sign of the very technology to which it is subjected.

While simulations suggest aerodynamic integrity for gliding, there is however no obvious means of propulsion. The documentary apparatus furnishes evidence through exclusively cinematic techniques: a short animated scene of the bird-plane and its pilot being catapulted into the air. While the integration of animation into the documentary matrix is a common practice in history and science programming in order 'to bring to life objects and events that are impossible to capture with the live-action camera' (Roe, 9), the rather anticlimactic cartoon of what is strangely evocative of a children's carnival ride is a rather bizarre opening salvo in the campaign to uncover extra-terrestrial influence in human affairs. Far-flung examples of sculpted flying-saucer-like turtles from Guatemala and tales of magic carpets from Persia bear witness to the extensive grasp of ancient alien activity-and the tautology of the Paleo-SETI imagination. The quiet corner of the Cairo Museum is made to bear witness to an integrated global network of airports (including the Nazca 'runways'), power plants (the Giza pyramids harness microwave radiation) and wireless electrical grids (obelisks around the world broadcast energy like Tesla towers). Disparate remains of an 'Ancient Airlines' coalesce in an animation of a spaceship collecting energy from 


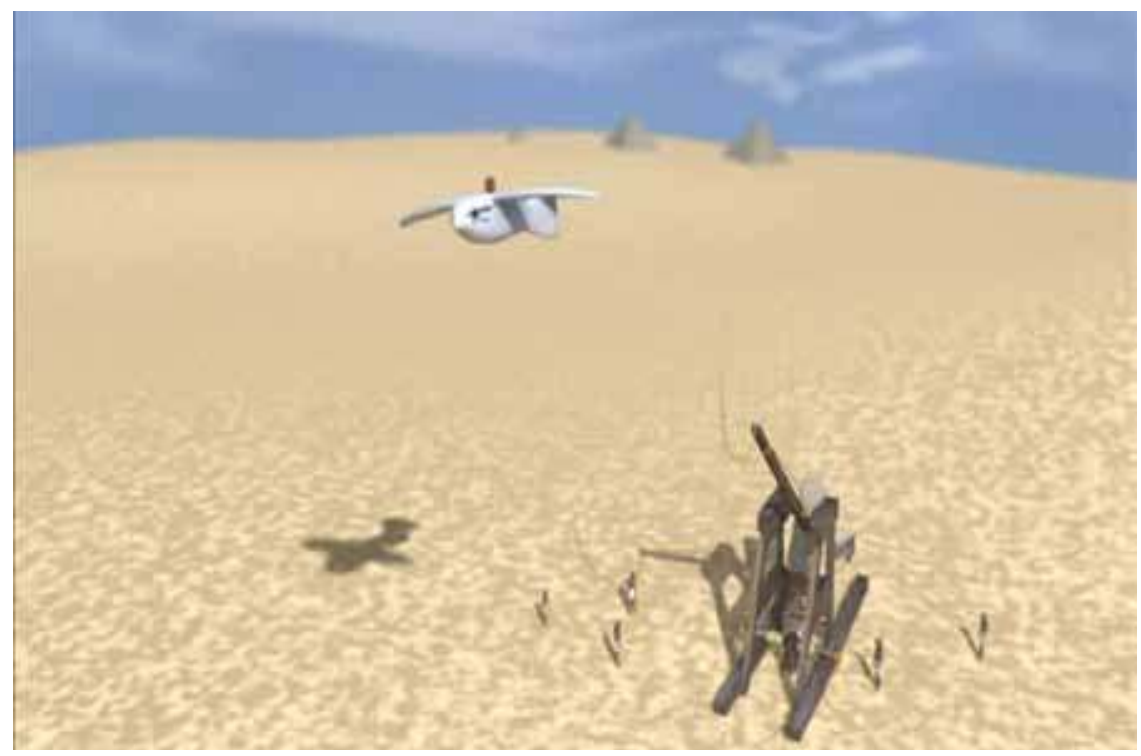

Figure 11. Ancient Aliens, 'The Evidence' (Prometheus Entertainment, 2010).

the surface. While an extreme example of the techniques by which documentaries 'aid and supplement our vision,' the spacecraft hovering over Giza clearly demonstrates that the 'world shown in the actuality or documentary film is presented as knowable, and the terms of its knowability are organized by the film, not by reality' (Cowie, 2, 13). In the case of Ancient Aliens, actuality is self-consciously allied with SF cinema, whose narrative commitments are both discovered in and shaped by special effects technologies (cf. Landon).

A palpable sense of threat builds over the course of the season. By episode 3, 'The Mission' (4 May 2010), the audience is prepared to learn about a sinister extra-terrestrial agenda. The authoritative index of the (male) voice-of-God narrator commonly folds the a priori conclusions of ancient astronaut researchers into either/or hypotheses that impart an air of scientific scepticism. 'According to the ancient astronaut theory, aliens may have come for many reasons: to excavate, to breed, to conquer or simply to explore.' Sumerian sky-gods known as the 'Anunnaki' genetically modified early humans into a slave labour force for mining operations. Rapacious aliens were also responsible for mass extinction events recorded in Scripture: 'Was the intent to clear the way for colonization or invasion, and if so what sort of technology would be needed to effect such a widespread change?' Are crop circles 
'futuristic clues guiding us to our ultimate destiny or ancient symbols paving the way to our ultimate destruction?' Ancient Aliens regular David Childress speculates that traces of a continuous extra-terrestrial presence are all around us. Indeed, aliens may be watching us from the moon, which he postulates could be a 'Death Star ... capable of destroying a planet.' Episode 4, 'Closer Encounters' (11 May 2010), transfigures the central conceit of alien visitation in Spielberg's 1977 film into an apocalyptic alternative history of human civilization. Medieval painting and literature record UFO sightings around the time of the Black Death. Post-war atomic weapons testing reiterates biblical accounts of doomed cities. The deluge was engineered by aliens dissatisfied with their genetic experiments. Ancient Aliens elicits an emotional response to the investigation by investing aliens with the terrible power of God recorded in Scripture.

The final episode of the first season, 'The Return' (25 May 2010), closes the circle on ancient ET speculation: 'But what if extra-terrestrial beings came to Earth tomorrow? Would they signal the birth of a new age of peace and prosperity, or trigger a war of the worlds?' The first season emplots ancient astronaut research within a mythic version of history, in which we can anticipate after a time of tribulation the promise of unification with the creator. Joseph Campbell Center archivist Jonathan Young, who is a frequent visitor on the show, considers ancient astronaut lore as a bone fide manifestation of Campbell's monomyth of the eternal return. The most 'ancient and most durable' version of temporality, myth is a deterministic 'image of time that denies temporality,' a space-time pattern that is, like Christian fundamentalism or the Mayan calendar, often 'giving birth to apocalypse' to complete its cycle (Gomel, 19, 20). The teaser highlights apocalyptic overtures of the return through direct reference to SF: 'Spaceships over Los Angeles. Body-snatchers controlling our minds. ETs making contact. These and other alien-based scenarios have been the plot-lines of countless science fiction movies and television shows.' Orson Welles's radio production of The War of the Worlds (30 October 1938) is cited as a possible invasion scenario. 'The Return' explores in essence the central issue occupying the protagonist of The War of the Worlds, who at the time of the Martian invasion was 'busy upon a series of papers discussing the probable developments of moral ideas as civilization progressed' (9). In the novel, morality is judged wanting and humanity escapes extinction only by accident. But treating SF media productions of alien invasion, nuclear annihilation and body-snatching as inevitable future histories of the return, Ancient Aliens insistently filters reality through the determinate lens of apocalypse, a worldview in which H.G. Wells's nightmarish vision of uncontrolled 
evolution was uncannily affirmed by a neurotic nation tuned into the Columbia Broadcasting System in the autumn of 1938.

Another culturally expedient manifestation of the apocalyptic imagination in Ancient Aliens is its participation in the cultural frisson of the so-called end of the Mayan long-count calendar. The subject of at least 18 individual shows on the History Channel, including Mayan Doomsday Prophecy (5 August 2006), Decoding the Past: The Other Nostradamus (28 November 2005), The Lost Book of Nostradamus (28 October 2007), Nostradamus 2012 (4 January 2009), Apocalypse Island (3 January 2010) and the six part miniseries Countdown to Apocalypse (2012), ${ }^{4}$ the 'overall emphasis of the 2012 phenomenon as portrayed on television,' Kevin Whitesides relates, 'is clearly on apocalypse rather than utopia' $(2013,90)$. In his article 'The Mystique of the Ancient Maya,' anthropologist David Webster wonders, 'Why do [the Maya] exert such a powerful hold on the imagination of the public, as well of some archaeologists?' The basic reason, he argues, is the commonplace human impulse to appropriate ancient cultures as the repositories of our hopes, or fears, or fantasies. But why the Maya?' (129). Whitesides and Mayan archaeologist John Hoopes suggest that as a 'polythetic set of romantic beliefs that derive from eclectic assertions about the ancient Maya calendar,' the 2012 phenomenon offers 'a new mythology for our time to allay the angst that accompanies rapid technological, social, political, and environmental change' (50). The Mayan end of days is a flexible myth that accommodates the kinds of technocratic anxieties normally reserved for SF and dystopian literature. Accredited scholars have themselves contributed to the millennial mythology of 2012.5 In his influential book The Maya (1966), archaeologist Michael Coe calculated a long-count date, 'associating it with the concept of universal annihilation' (Hoopes, 2011a, 190). Coe associated warfare themes in Mayan inscriptions with the Christian concept of 'Armageddon' from his reading of the post-conquest creation myth, the Popol Vuh. According to John Carlson, Coe essentially 'planted the "meme" in global popular culture of a destructive "apocalyptic" 2012 completion of the Long Count' (2001la, 5).

Carlson also notes that the Dresden Codex, the oldest and best-preserved Mayan manuscript, is often cited as the source of an apocalyptic promise that a great flood will engulf the world (Carlson himself contends this is simply a fable about the annual return of the spring rains)(Carlson

4 Discovery Channel likewise offered 2012-themed disaster programmes such as Decoding the Past: Doomsday 2012-The End of Days (2007) and Apocalypse How? (2008).

5 For studies of the development of 2012 mythology see Hoopes 2011a, $201 \mathrm{lb}$. 
$2011 b, 171-76)$. Likewise, the theory of a 'rare' and life-altering galactic alignment on 21 December 2012 proposed by New Age groups like Harmonic Convergence stems from a fundamental misunderstanding of the Mayan biannual observation of the alignment of the Earth, sun and galactic equator (Hoopes, $2011 \mathrm{a}, 195$; cf. Hoopes, $201 \mathrm{lb}$; Sitler; Webster). The '2012 phenomenon is,' Hoopes asserts, 'an astrological and cultural event, not an astronomical one' (2011b, 245), whose associations with Armageddon, Whitesides adds, 'arose amid Cold War fears of nuclear annihilation in the 1960s, becoming firmly rooted in the countercultural milieu of the 1970s and 1980s predominantly as a hybrid apocalyptic/ utopian narrative representing hopes of great change as a result of some radical disruption of the norms of modernity' (74). Firmly located in the context of fundamentalist Christian and countercultural New Age millenarian ideology, ${ }^{6}$ the 2012 apocalypse was alien to the Maya. Rather, ancient disaster scenarios like 'the biblical deluge, the destruction of legendary Atlantis, the Old Norse Ragnarök myth, and even [those of] extraterrestrial and UFO cults' form a 'solid backdrop to popular mythology about 2012' (Carlson, 2011b, 5).

Given their exposure to world ending events in popular and even academic discourse, the Maya are easy pickings for Ancient Aliens's brand of syncretic millenarianism. Season four opens with a special two-episode tribute to 2012, 'The Mayan Conspiracy' and 'Doomsday Prophecies' (20 February 2012). The episodes uncover evidence of extra-terrestrial visitation encoded in Mayan calendrics. 'The Mayan Conspiracy' opens with a pastiche of archaeologists, astronomers and astrophysicists speaking admiringly about a people who developed sophisticated means for charting long periods of time and the complex reasons for so doing. Enter David Childress, who directs us to the smoking gun of the Mayan conspiracy: the sarcophagus lid of King Pacal discovered in the Temple of Inscriptions at Palenque. While the consensus among Mayan scholars is that the artefact depicts the king's journey to the after-life, Childress furnishes the von Däniken reading of Pacal operating a space capsule. The monarch, Childress observes, was the 'original rocket man.' Similar to the Saqqara bird, the Palenque artefact undergoes no less than three stages of semiotic abstraction. We are presented with a replica of the sarcophagus lid in situ, revealed after a performance of discovery by Childress who, sporting an Indiana Jonesesque fedora and khaki safari shirt, descends in wonder to the burial chamber. The lid is digitally enhanced to reveal the basic workings

6 Cf. Campion, and Restall and Solari for studies of the role of religion and myth in the 2012 phenomenon. 


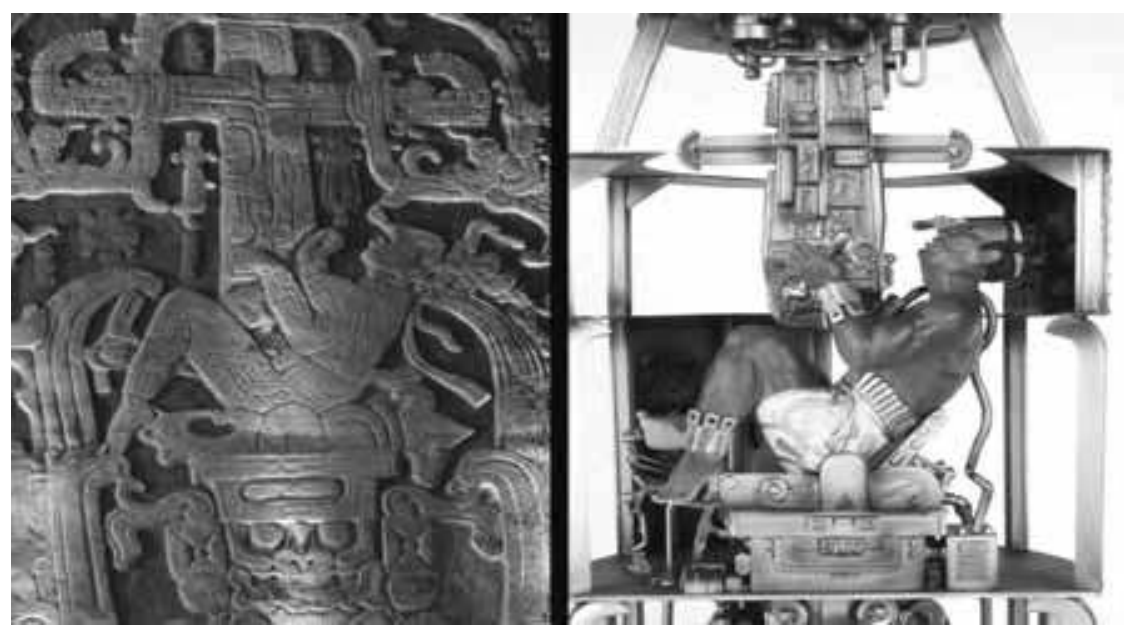

Figure 12. Ancient Aliens, 'The Mayan Conspiracy' (Prometheus Entertainment, 2012).

of the cockpit controls, breathing apparatus and exhaust system. Giorgio Tsoukalos, the much-memed spokesperson and consulting producer of the programme, brings us to the workshop of a U.S.-based model-maker, who constructed a scale version of the loin-clothed rocket man at the helm. Tsoukalos is very pleased with the result. A 'dream come true,' he especially 'loves' the addition of NASA-inspired engine bells to the bottom of the module. The artefact retains an indexical relationship to the archaeological world while functioning as a classic icon of SF. Tsoukalos's haptic play with the model invites the viewer to 'explore the past, present and future of the world out there of shared experience and the world in here of subjective experience' (Roe, 40).

The episode follows with 'inkblot' or prima facie correlations between NASA technology and Mayan glyphs and sculptures. The serpent god Kukulkan (or Quetzalcoatl), who is often depicted emerging from the mouth of a snake, is an astronaut in a cockpit. The false dichotomy sets up the 'Mayan conspiracy': the alien kings and priests used their technology to control the human population. While archaeology may provide insights into ostensibly sinister relationships between temporal and secular power, there is little physical evidence of a Mayan conspiracy at work. Rather, the episode advances its arguments within, as Ian Reyes and Jason Smith put it, an 'aesthetics of conspiracy rhetoric.' They argue that '[c]onspiracy theory is a genre unto itself' (400), a paranoid style emanating from an 'epistemic lacunae' wherein conspiracy is 'premised on the leap from identifying/constructing a 
mysterious absence to assuming that absence is actively produced by governments, scientists, media, or a different powerful other' (404). Typically, in conspiracy thinking 'leaps unwarranted by the evidence' are 'enthymemes consistent with conspiratorial tropes' that promote 'entelechial formations' (401) within the genre (i.e. they are self-evident). In this way, ancient astronaut advocates argue that their investigations expose forbidden knowledge withheld from the public, a rhetorical gesture that simultaneously refutes while appealing to orthodox scientific discourse to authenticate its doomsday predictions.

As the title suggests, 'Doomsday Prophecies' amplifies the apocalyptic interpretation of the 2012 meme introduced in 'The Mayan Conspiracy.' The teaser weaves dire predictions with CGI disasters. 'Ancient calendars forecasting a deadly countdown' (giant cogs of the Mayan time machine grind inexorably to the fateful end). 'A galactic alignment triggering a wave of natural disasters' (seas flood inland and buildings topple in mega-earthquakes). 'Could our planet really be headed for extinction?' (meteors bombard the Earth and glaciers crumble into the ocean). 'Or is there another agenda, one even more profound?' Animation supplements the testimony from a battery of academic experts who speak about Mayan conceptions of cyclic time; testimony that is truncated and fed back into the entelechial formation of the Mayan conspiracy supported by the visual and aural rhetoric of apocalypse. In the opening chapter a throbbing rhythm of bass and drums accompanies a montage of highand low-angle shots of Mayan temples, evoking sensations of mystery, danger and a whiff of melancholia for a vanished world. Tension mounts as an intricate set of animated cogs churn out calendar rounds. Pan flutes transport us back in time to historical re-enactments of the Maya making astronomical observations and chiselling their secret wisdom in stone tablets. The aural establishes aura in the televisual appropriation of the Maya's astronomical achievements into the alien conspiracy to decimate human civilization.

'Doomsday Prophecies' revisits the serpent god-cum-ancient astronaut Kukulkan. The narrator posits, 'Was it possible, as some ancient astronaut theorists suggest, that Kukulkan was in fact a flying spacecraft engineered and piloted by otherworldly visitors?' The answer comes in the form of an animated snake-like spaceship landing on a ziggurat. Corroborative evidence may be found at Chicenitza in the Yucatán Peninsula, a site with direct links to Kukulkan's celestial being. Tourists and pilgrims gather each solstice to witness a shadow play cast on the temple steps of the 'serpent' descending to Earth and then returning to the heavens. For Giorgio Tsoukalos, his fixation with flying deities impels him to conclude that the solar event commemorates the ancient 
Maya observing the contrails snaking behind their gods' flying machines. Again, animation manufactures ocular proof relative to postmodern rather than Mayan questions about the nature of time and progress.

The final chapter of the episode, 'The Return,' affords viewers through a series of flyover shots of mountains, streams, forests and cities the global perspective enjoyed by extra-terrestrials like Kukulkan. 'Planet Earth [...] Mankind's existence on its surface is relatively recent and fragile.' A montage of the tsunamis, hurricanes and earthquakes that have recently racked the southern U.S. and Asia are marshalled into illustrations of the imminent fulfilment of the Mayan prophecy. The apocalyptic timeshape is rhetorically powerful because, as Jeannie Chapman relates, allusions to natural disasters [are] embedded in a general perception that the current historical moment is one characterized by crisis and disorder.' Re-contextualized as the work of ancient astronauts, these documentary events and images nourish the threatening diegetic environment Ancient Aliens promotes by naturalizing 'signs of the times' as 'common knowledge' (49) available to ancient astronaut researchers and to anyone persuaded by their claims. The televisual documents of the real are never far from the SF imagination of the possible. Reminiscent of the conclusion of the Stargate SG-1 episode 'The Tomb,' 'The Return' ends with a meteor obliterating the Temple of Kukulkan. The world so carefully constructed in the opening scene is razed to the ground as a spectacular testament to the arcane knowledge hidden within the ziggurat.

A final voiceover affirms the veracity of a Mayan conspiracy in the form of pointed questions:

Will December 21st, 2012, signal the end of civilization as we know it? Or are the dire predictions nothing more than a myth, a misinterpretation of an even greater truth? Perhaps what awaits us is not the end of our world, but a new beginning. What if it would reveal the celestial origins of man?

While the question simply circles back to the premise that the Maya predicted the end of life as we know it, the aesthetics of doomsday articulate an enigmatic 'greater truth,' a Sphinxian riddle whose referents lead us into the maze of ancient astronaut lore where SF is the privileged sense-making apparatus for a neurotic and fragile world. While many archaeological documentaries celebrate the recovery of objects of historical value, Ancient Aliens addresses broader human concerns that, while unquestionably subcultural, are, as their constant reference to mainstream SF film suggests, connected to problematic issues and debates 
about the nature of time and civilization in an age whose information technologies are themselves symptomatic of heightened global crisis. Just as Ancient Aliens is careful to couch its conclusions in questions, the History Channel was evidently careful to foreclose against the possibility of the very truth it purported to uncover. The network did not air any 2012-themed programmes on 21 December 2012. Perhaps the producers feared the lesson of Orson Welles's radio play. Yet the decision not to broadcast this kind of material re-inscribes its potential truth-like the suspicion that high-rise hotels have a 13th floor-through erasure. Absence of 2012 material on that potentially fateful day testifies to the power of television to shape beliefs, in this case by bearing silent witness to a Mayan conspiracy. 'What if it were true?' was possible, but only for a day.

The next two chapters examine relationships between ancient astronaut lore, alternative archaeology and apocalypse in Indiana Jones and the Kingdom of the Crystal Skull and Smallville. Though very different incarnations of SFFTV, the film and television series share certain concerns with the History's Channel's commentary on global affairs through the figure of the ancient astronaut. The fourth instalment of the Indiana Jones saga conflates tensions of the Cold War epoch with Mayan apocalypse and shapes them into a commentary on contemporary global insecurity. Steeped in storied history of comics, television and film, Smallville also excavates a new, culturally vibrant myth for its hero. From the archaeological genius loci of the 'Kawatche' Caves, Clark Kent emerges to save the world from the multiple threats of extra-terrestrials and the dark forces lurking within Homeland Security. It is this nexus of concerns that the following chapters address. 


\section{Chapter 5}

\section{Indiana Jones \\ and the Kingdom of the Crystal Skull}

It was sci-fi, more than any other genre, that caught the hysteria behind the picture window.

Peter Biskind ${ }^{1}$

The fictions of the covert sphere at once make the secret work of the state visible and consign it to the realm of fantasy.

Timothy Melley ${ }^{2}$

Nearly two decades after riding into the sunset at the end of The Last Crusade, Indiana Jones dusted off his whip for a markedly different kind of adventure. Titles of early drafts for a fourth instalment of the Raiders saga reflect George Lucas's desire to lure Jones from the jungle film and into the cinematic purview of its SF cousin. In 1994 Lucas commissioned Jeb Stuart to write the screenplay for Indiana Jones and the Saucermen from Mars. ${ }^{3}$ Later versions of the project bear titles like Indiana Jones and the Atomic Ants and Indiana Jones and the Destroyer of Worlds (Rinzler, 231, 237). In Indiana Jones and the Kingdom of the Crystal Skull (2008), the archaeologist has a close encounter with Luke Skywalker, a moment anticipated at the Well of Souls in Raiders of the Lost Ark (1981), when Jones passes a fresco depicting an Egyptian genuflecting before R2D2 and C3P0. Once a playful nod to Lucas and Spielberg's collaboration, the graffito is now an artefactual reminder of a future in which Indy raids the material remains of a race of ancient astronauts.

While the ancient astronaut theme, which entered mainstream

1 Biskind, 103.

2 Melley, 2011, 35.

3 The script can be found at https://www.wattpad.com/76531-indiana-jones4-script. 
popular culture in the late 1960s with Erich von Däniken's Chariots of the Gods?, is slightly anachronistic for a film set in 1957, the SF scenario introduces Jones to a new generation of movie goers more familiar with Mayan calendrics than the atomic ants and little green men from the Saturday matinees of Lucas and Spielberg's childhood. Kingdom of the Crystal Skull does have killer flesh-eating ants, but they are 'natural' features of the jungle imaginary rather than atomic genomes of 1950s SF film. The film also features aliens, but they are largely incidental to the quest to secure the eponymous crystal skull. Decidedly not the kind of 1950s SF movie that Lucas envisioned in Saucermen from Mars, it is instead a quasi-historical drama of the era that produced them. Steeped in meta-textual references to Jones's acclimatization to a new world order in which jackbooted Nazis bent on world domination have been supplanted by aggressive American foreign policies and ideological contestation with the U.S.S.R., the twenty-first century Indiana Jones is a media archaeologist of an age whose SF tropes of invasion, contagion and mutation-and the allegories of anti-communism, anti-McCarthyism and nuclear annihilation they variously engaged-are constitutive of the apocalyptic overtones of contemporary ancient astronaut discourse.

This chapter examines the manner in which the film organizes relationships between geopolitics, archaeology and SF around the theme of 'the return.' In the first instance, the return of Indiana Jones to the big screen reconfigures the swashbuckling adventurer within the cinematic traditions of post-war SF film. The franchise catches up to its new past by recalibrating raider mythology with geopolitical crises that are age-appropriate for the 65-year-old Harrison Ford. Secondly, the implicit conflation of 1950s SF tropes of alien invasion with the apocalyptic return of ancient astronauts links the cultural brio of Cold War action/ adventure cinema with versions of post-9/11 security circulating in contemporary SFFTV. The narrative, thirdly, hinges on returning the crystal skull to its place of origin. Joseph McBride observes that the 'racism that marred the first two films is replaced in Indy $I V$ by an almost apologetic treatment of Jones's former activities-he protests that he is not (any longer) a "grave robber," and his quest is to put back a stolen artifact' (525-26). ${ }^{4}$ While there is still plenty of racism in the film, the archaeological past is no longer available for plunder. But overtures of

4 This aspect of the Indiana Jones films has garnered considerable critical attention. Cf. Morris, 102-12; Shohat and Stam, 124; Tomasulo, 333; Weaver-Hightower; and Zimmerman, 37. For an argument for Jones's liberal values see Friedman, 112-18. See also Aronstein and Biber for analyses of the franchise's political alignment with Reagan era neoimperialism. 
shared heritage are reminiscent of the problematic nature of stewardship exemplified by the American return to Babylon and, moreover, by recent formulations of what Erik Nemeth calls 'cultural security,' in which historical materials in contested territories like Iraq and Syria remain targets for cultural terrorism and sources of funding for jihadist groups like ISIS (2015). The updated myth of archaeological heroism in Kingdom of the Crystal Skull offers an oblique commentary on transnational security strategies being formulated in concert between academic and governmental stakeholders, and the challenges of geopolitical security in a global economy that remains invested in trafficking artefacts between 'collecting nations' and emerging 'source nations.'

Before undertaking the mission to recover the crystal skull, Jones must adapt to the particular social and ideological tensions of post-war America. The title sequence injects the archaeologist into the Cold War arms and space races in the form of a literal drag race in the Nevada desert between teenagers in a roadster blaring Elvis Presley's 1956 hit song 'Hound Dog' and a convoy of Soviet spies disguised as American soldiers. The music fades as the trucks turn at an intersection marked with a forlorn neon sign directing motorists to 'Nevada's Famous Atomic Cafe.' ${ }^{5}$ Signs of doom shadow the post-war confidence typified by America's youth cavorting in hotrods. The convoy churns up a deserted gravel road and stops at another sign, 'Hanger 51 Main Gate.' A chromakeyed title 'Nevada 1957' in the upper portion of the frame completes the scene. Abducted by the Soviets, Jones is forced to locate a particular artefact from Area 51, the remains of a 'saucerman,' which the archaeologist helped recover from the Roswell crash site in 1947. The raid on Area 51 is part of a larger Soviet operation to secure the legendary crystal skull, whose purported mind-control properties are of interest to Stalin's crack psychic weapons scientist, Col. Dr. Irina Spalko (Cate Blanchett). While the race to recover the crystal skull tests Jones's wits and skills as a raiding archaeologist, the film's intra-text is concerned with updating the raider legend in a popular cultural milieu better suited to the exploits of James Bond. Escaping the Soviets on a rocket sledge, Jones is propelled into the space age-within the year the Soviets would launch Sputnik and successfully test the world's first ICBM - an era in which the dusty archaeologist is himself a vivid alien.

Threats to Jones's agency are also framed by prevailing domestic fictions of the Cold War, particularly the generalized fear of communist

5 The sign is a thinly veiled reference to the famous Little A'Le'Inn Café in Rachel, near Area 51, a gathering place for UFO conspiracy theorists (cf. Lepselter). 
infiltration. He is jettisoned into what historically is known as 'Operation Plumbbob,' the code name for a series of 29 nuclear detonations at the Nevada Test Facility in 1957. Disoriented from the rocket sledge, Jones stumbles into a 'doom town' constructed for an imminent test shot. The archaeologist finds himself the unwitting cicerone of a museal world inhabited by plastic mannequins nestled before black and white console television sets twittering 'It's Howdy Doody Time,' tableaux that epitomize idyllic communities like Los Alamos, New Mexico, which were built around the atomic energy industry but shielded from its fallout by the culture of the residential community itself (Hunner, 37). Jones breaks into a house and rummages through the artefacts of the 'nuclear' family, a kitchen stocked with household cleaners, chrome toaster ovens and electric can openers, an uncanny product-placement of the ascendant post-war American middle class. He wanders among the arrested routines of ecstatic mothers in print dresses strolling along pavements populated with children pulling Radio Flyer wagons, a Good Humor Man distributing Creamsicles, and the paperboy and postman on their rounds. Dad washes his Buick sedan in the driveway while the kids frolic on their Slip 'n Slide. Across the street, a cherry-red '57 Chevy glistens in the Nevada sun.

This eerie yet strangely wistful set piece of 1950s Americana offers a meta-filmic reference of staged threats to suburban prosperity in the survival television broadcasts and films made by the Federal Civil Defense Administration. ${ }^{6}$ Exemplary is a short feature produced in 1955 for 'Operation Cue,' whose detonation of 'Apple II' simulated a Soviet attack on property and civil defences at the purpose-built 'Survival City' (Matthews, 87-88). ${ }^{7}$ One of the narrators is a housewife whose interest in the effects of radiation on food and fabrics testifies to the stiff gender codes required to survive the atomic age. She acknowledges the generous sponsorship of the various domestic industries for donating appliances, foodstuffs, clothing and furniture. ${ }^{8}$ The nuclear test is both an assault

6 See Matthews for an extensive study of the relationship between civil defence authorities and the television and film industries. Scheibach, 2009, provides facsimiles of government publications related to civil defence.

7 Https://www.youtube.com/watch? $\mathrm{v}=\mathrm{yRK}$ Kstl62-c. Operation Cue's nuclear test 'Apple-2-Survival Town' was broadcast on 5 May 1955.

8 Lisa Yaszek, 2011, discusses the trope of nuclear domesticity in her analysis of the Motorola Television Hour episode 'Atomic Attack' (1954), which deals with a family's response to nuclear bombs obliterating New York City. The show references Los Alamos in that the men in the suburban neighbourhood work in the nearby rocket programme installation. Cf. George on gendering of SF films, particularly Chapter 4, 'Invasion from Within: Mom, the 


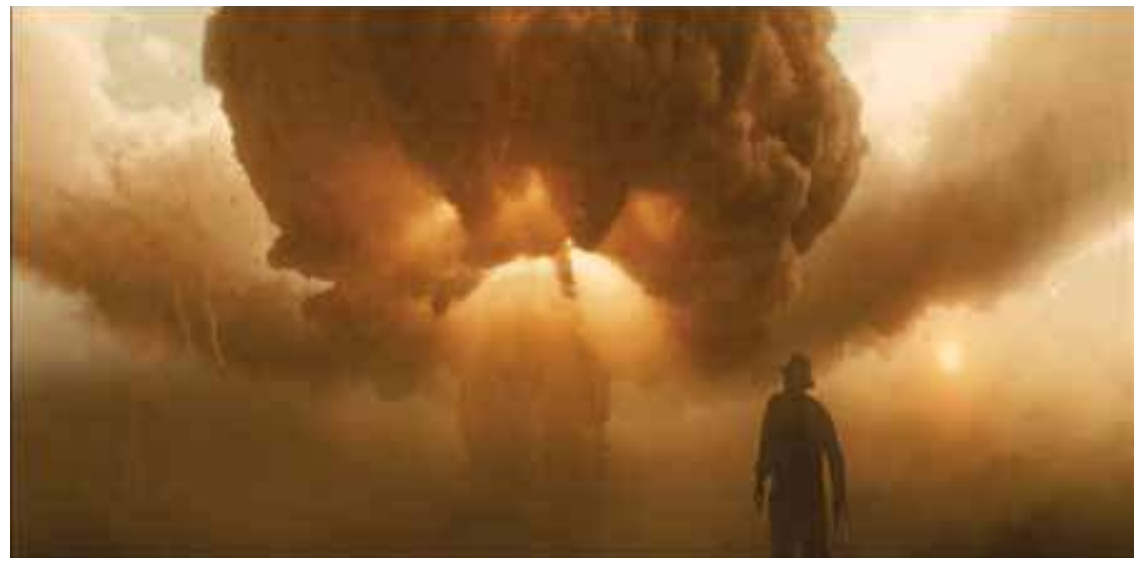

Figure 13. Indiana Jones and the Kingdom of the Crystal Skull

(Paramount Pictures, 2008).

on and an advertisement for the latest labour-saving conveniences. After the test, the technicians feasted on irradiated tinned goods salvaged from demolished larders, a kind of 'reverse last supper, where any signs of life after the nuclear explosion were celebrated as an absolute victory' (Masco, 29). ${ }^{9}$ The tensions between 1950s nostalgia and the apocalyptic nightmare evoked by such FCDA films is parodied in Kingdom of the Crystal Skull when Jones takes refuge in a legendary domestic terror of the age, the lead-lined refrigerator. The plastic world is momentarily back lit by the blast. Close-ups of melting family members and their pets dissolve into hallmark long shots of shock waves rippling through the neighbourhood. Thrown clear of this Levittownesque suburban nightmare, Jones is silhouetted in a low-angle shot of the mushroom cloud billowing skywards, momentarily revealing the hollow eye sockets of a skull. In a flash the 1950s atomic age foreshadows post-nuclear threats represented by the talismanic crystal skull.

Lucas ultimately got his 'Indiana Jones and the Destroyer of Worlds,' but the arresting image of the ochre fireball does little if anything to advance the narrative. Instead, atmospheric tensions between nostalgia and horror in Doom Town epitomize the fragility of the utopian

Nuclear Family, and Suburban Masculinity,' 85-106. Cf. Hendershot, 97-107. Matthews, 95-100, provides a reading of 'Atomic Attacks' as exemplary of television's collaboration with civil defence exercises.

9 A similar test at Yucca Flats was broadcast live on 17 March 1953 (Matthews, 84-85). 
dreams born out of the atomic age. Jones's haunting tour exposes the audience to the ambiguities inherent in what Costandina Titus terms 'Atomic Kitsch,' whose central symbol is the mushroom cloud. Kingdom of the Crystal Skull reworks and reproduces through the aesthetics of kitsch-with its 'simple message, mass distribution, emotional response, beautiful imagery, and stylized form' - the ideological landscape in which the 'awesome beauty of the fireball' helped divert 'the public's attention from asking substantive questions about possible negative consequences and costs.' Over time the mushroom cloud has become the central image of the 'atomabilia' phenomenon of the 1980s and 90s, whose influence ranges across films such as The Atomic Cafe (1982), Peter Bacon Hales's coffee table book Atomic Spaces: Living on the Manhattan Project (1997), and collecting Cold War paraphernalia like toy uranium waste railway cars and Miss Atom Bomb pin-ups. The mushroom cloud, she says, lingers as 'a nostalgic icon reminiscent of simpler, safer times' $(105,107,110,102)$.

But the mushroom cloud is also a cultural fossil of an age that celebrated freedom purchased by dangerous technology and at the expense of actual security. By 1957 McCarthyism was in full swing and the U.S. was saturated in FCDA doomsday propaganda. The ambivalent image of the mushroom cloud is symptomatic of what Charles Gannon calls 'silo psychosis' (146-72), ${ }^{10}$ the psychological impact rendered on those wielding the atomic bomb as a tool to expand 'hegemony across previously impermeable cultural and national borders.' The dark side of atomic kitsch, he states, 'reaches its grim zenith in the action/sf film genre' (146, 147). Citing films like The Day After (1983) and Terminator 2: Judgment Day (1991), Gannon observes that the 'obsessive nature of these visuals - the attention to detail, the dilation of time to permit an almost clinical assessment of the annihilating effects of the bomb-additionally suggests a sensual, almost erotic fascination with the spectacle of destruction.' Kingdom of the Crystal Skull captures a historical moment that was itself confronting a futuristic cinematic world in which atomic-age audiences were at once exposed to the innocent pleasures of Howdy Doody and the 'collage of nuclear test footage showing the horrific (and often bizarre) effects of the bombs.' At ground zero, Jones is likewise positioned between 'potency and vulnerability,' a relic of silo psychosis reanimated for our contemplation $(147,149,165)$.

While in Hollywood allegory lite fashion Jones will ultimately be 'cured,' the side effects of the experience linger in the uncanny resemblance to contemporary nuclear anxieties. A poignant reminder of 
Hiroshima and Nagasaki, the detonation is a semblance of world-altering images like the fall of the WTC. In his article 'September 11 and Cold War Nostalgia,' Aaron DeRosa's assertion that 'September 11 registered, in part, as a traumatic repetition of the atomic blasts in America's cultural consciousness, a trauma from which America can never fully recover until it recognizes the true relationship of these events to one another' (59) invites speculation on the potential for popular cultural artefacts like Kingdom of the Crystal Skull to harness this dynamic. The cinematic nature of the collapse of the WTC furnishes a visual framework for contemplating the mushroom cloud rising over American soil: like the bomb, the twin towers are an ambiguous symbol of global power and the (self-)destructive potential of that power. If in the moment the audience confuses Jones staring in awe at the detonation with our mediated ground-level views of the towers collapsing in inverted mushroom clouds, the ghostly apparition of the crystal skull is a crystal ball for a post-9/11 America experiencing resurgent Cold War anxieties in the form of nuclear brinksmanship with terrorist states like Iran, Pakistan and North Korea.

These tensions are manifest in the following scene, in which Jones is detained and interrogated by the FBI on suspicion that he is working for the Soviets. Nuclear psychosis is parodied in the anti-communist hysterics of the FBI agents. Jones demands, 'What am I being accused of, except surviving a nuclear blast?' Disoriented from the ordeal, Jones is marginalized and isolated by what Timothy Melley calls the 'culture of paranoia' (2000, 1-46), the 'paradox in which a supposedly individualist culture conserves its individualism by continually imagining it to be in imminent peril' (6). The agents cast doubt upon Jones's illustrious war record (it is revealed that he served as a spy for the Allies in the Pacific for the Office of Strategic Services, the agency that became the CIA in 1947) and raid his Marshall College office. The university, fearing a scandal, suspends him, an action sanctioned socially right outside Jones's classroom, where students gather for an anti-communist rally. Brandishing 'Better Dead than Red' placards, their protest is symptomatic of the film's atomic kitsch but also the insidious paranoia of a world in which politicians and public servants threaten the agency of the campus's beloved professor. The interrogation scene concludes with a high-angle shot of Jones from the perspective of the FBI agents. Sitting forlorn from his scolding (cue the John Williams theme, slowed and melancholic), Jones becomes a version of The Incredible Shrinking Man (1957), 'in its representation of males' suburban nightmare, with their masculinity being symbolically stifled by work, family responsibilities and domestic conformity' (Geraghty, 2009, 26). A scapegoat of the conservative culture 
staged in Doom Town and policed by the FBI, having survived a nuclear blast is all the evidence the FBI needs to clip the professor's wings.

With specific references to rock ' $\mathrm{n}$ ' roll, UFOs, Good Humor trucks, mushroom clouds and Hoover's G-men, the opening sequences take the cultural pulse of the world that gave rise to the distinct 1950s complexion of SF film and literature. The manner of positioning viewers towards the multiple traumatic threats of state-sponsored paranoia about alien invasion and global war reminds us that the '1950s in America,' as Keith Booker relates, 'were informed by a radical doubleness,' an era widely remembered as a 'Golden Age of nuclear fear,' a decade of prosperity haunted by the dual spectres of communism and the 'witch-hunting forces of anti-communism' $(4,5,5)$ : anxieties that inspired classic $1950 \mathrm{~s}$ films like The War of the Worlds (1953), Invaders from Mars (1953), Earth vs. the Flying Saucers (1956) and Invasion of the Body Snatchers (1956), as well as the unease about nuclear weapons represented in The Day the Earth Stood Still (1951) and the counterpoint to invasion in the 1953 film It Came from Outer Space (Vizzini, 31), an allegory of cultural relativism in which marooned ETs just want to go home. Epitomized by the protagonist's discomfort in this environment, Kingdom of the Crystal Skull evokes the spectrum of political positions that have, in Steffen Hantke's words, 'become the basis for the current critical discussion on 1950s science fiction' $(2010,147) .{ }^{11}$ But specific questions about the nature of the other, criticisms of domestic policy and ambivalent feelings about the nuclear future are displaced simultaneously into a more contemporary cultural gestalt signalled by the alien artefact. As an homage to the SF cinema of the atomic era, the film also circulates with a host of post-9/11 SF invasion films and television shows exemplified by recent remakes of War of the Worlds (2005) and The Day the Earth Stood Still (2008), which stamp old invasion stories into new cultural currency. ${ }^{12}$ Jones is rehabilitated for the modern world through the aesthetics and politics of atomic crises that, as Wheeler Winston Dixon avers, have

11 Jeff Smith, 1-16, provides a historical overview of the critical attention to Cold War subtexts in cinema. Chapter 7, 'Loving the Alien: Science Fiction Cinema as Cold War Allegory,' is a history of this critical trend (239-71). Among the many studies of the socio-political dynamics in 1950s SF film are Biskind; Booker; Dixon, 2005, 103-33; Hendershot; Jancovich; Luckhurst, 92-119; Scheibach, 2003; and Seed, 1999a.

12 Stacey Takacs and Steffen Hantke, 2010, explicitly connect 1950s invasion and paranoia tropes with several television series that emerged for single season runs in 2005-06, Surface, Threshold and Invasion. Battlestar Galactica (2004-09) also fits these criteria, as does the more recent show Colony (2016-). 
returned with a vengeance. He asserts, perhaps hyperbolically, that '[i] n many respects we are living the 1950s right now: repressed, obsessed with "terror alerts," eagerly seeking phantom security in ever-increasing hypersurveillance, reverting to the patriarchal order for a measure of safety and reassurance, retreating to our new digital home entertainment centers to experience the world as filtered through a variety of "news" filters' $(2005,184)$. Adam Piette similarly observes that the Cold War 'continues to live and thrive within our collective imaginations as a security state hysteria,' a 'paranoid field of fantasies' (2) characterized by wars against mythologized enemies, the threats of WMDs and stealth weaponry, and, in the words of Fabienne Collignon, 'pod-people hiding, waiting, in sleeper cells' (2).

While it is too simplistic to graft wholesale these distinct geopolitical environments onto one another, it is nonetheless useful to consider to what extent a nostalgic Hollywood blockbuster can translate the paradoxes of the atomic age into 'nuclear criticism' of the present world. I suggest that the Nevada desert is itself a proving ground to test this question. As the chronotopic threshold into a cultural milieu that provides the basic vocabulary for the Golden Age of SF film, Nevada 1957 remains available to the modern imagination in the form of, as Joseph Masco puts it, a 'dream space for a spectacular idea of progress,' a 'desert island within a military-industrial crypto-state, a place where secret military machines are designed, where atomic bombs are detonated, and where chemical weapons and nuclear waste are stored: it is a home, in other words, to all the "national security" technoscience supporting a superpowered military state.' At the same time, the desert is also a 'pristine tabula rasa,' an 'endlessly renewable frontier' in which desires for freedom incarnated in the oasis city of Las Vegas remain powered by the utopian energies that gave birth to the nuclear age itself $(24,23,24)$. In the American southwest freedom and orthodoxy vacillate endlessly between conceptualizations of the natural and social. Masco contends that the Nevada desert is a dreamland where 'both citizens and officials have come to rely on tactical amnesia and temporal sutures to enable a precarious [...] cosmology of progress, one fueled by high-octane combinations of risk, secrecy, utopian expectation, and paranoid anxiety in everyday life' (24). The crystal skull in this sense is a cryptogram of this 'cosmology,' for its image cast upon the doomsday cloud 'sutures' the 1950s story world to the post-9/11 environment where questions of progress are reimagined through the myths of ancient astronauts, Mayan doomsday prophecies and the eternal return of the West to the desert cradle of civilization.

Like Masco's symbology of the Nevada desert, the crystal skull is an ambivalent signifier of a cultural landscape rooted in myths of pristine 
origin. The artefact transports Jones across the threshold of the nuclear age to the primal action spaces of raider legend, in this case to the jungles and ancient cities of South America. The invitation comes in the next sequence when Jones encounters a young greaser named 'Mutt' (Shia LaBeouf), who needs help finding a mutual friend, Professor Harold Oxley (John Hurt), who was abducted in the Amazon while searching for the crystal skull. Mutt's mother, who turns out to be Jones's amoureuse from Raiders of the Lost Ark, Marion Ravenwood (Karen Allen), is also missing. Over the course of the adventure Jones discovers that Mutt is his son. Jones does right by the boy and marries Marion at the end of the film. Having rescued his first love and old friend, the marriage reaffirms the stability of the nuclear family parodied in the decimation of Doom Town.

Nuclear controversies in both their political and domestic fashioning merge into contestations over the crystal skull, which is treated in the film as a bona fide Mesoamerican artefact. That the British Museum acquired one in 1856 and the 1867 Exposition Universelle in Paris featured them in their Mesoamerican display suggests that the skulls do have a scientific pedigree. But acquired mainly from antiquities markets and dealers, lacking proper archaeological context and showing clear evidence of modern lapidary tooling (Feder, 2010, 67-69), their archaeological value is limited to curiosities of nineteenth-century manufacture. Jones, however, understands them as 'deity carvings,' furnishing plausible authenticity for Spalko's alternative archaeological researches. The Ancient Aliens episode 'Crystal Skulls' (7 October 2013) expounds upon the kinds of extra-terrestrial properties that Spielberg attributes to the McGuffin via Spalko: their ability to channel the psychic energy of advanced intelligences, store ancient knowledge, facilitate inter-dimensional travel and communication, and even trigger Armageddon. It is also purported in the episode that when the 13 'original' skulls (presumably corresponding with the 13 rounds or baktuns of the Mayan long-count calendar) are gathered together their powers will be amplified. Reuniting the skulls for this purpose forms the basis of the narrative that follows.

Mutt relates that Oxley disappeared trying to take the artefact to a place called Akator. Jones fills in the details:

It's a mythical lost city in the Amazon. Conquistadors called it El Dorado. Supposedly the Ugha tribe was chosen by the gods 7,000 years ago to build a giant city out of solid gold [...] It had technology that wouldn't be seen again for 5,000 years. Francisco de Orellana disappeared into the Amazon looking for it in 1546. I 
almost died of typhus looking for it myself. I don't think it exists $[\ldots]$ The legend says that a crystal skull was stolen from Akator in the fifteenth or sixteenth century, and that whoever returns the skull to the city temple will be given control over its power.

Mutt furnishes a map in the form of a letter from Oxley in which is written a riddle: 'Follow the lines in the earth only gods can read, which lead to Orellana's Cradle guarded by the living dead.' The solution is the ancient astronaut mecca, the Nazca lines, which point the way to Orellana's grave where Oxley hid the skull from the Soviets. The treasure hunt begins in earnest: Jones and Mutt retrace the footsteps of the conquistadors, and in the process save Marion and Oxley and foil the Soviet plot to harness the power of the skull to infect the free world with communist ideology.

The riddle leads Jones and Mutt to a Catholic missionary sanatorium in Nazca where Oxley, having been driven mad by the crystal skull, was committed. The walls are covered in chalk sketches of an elongated skull, a map of an 'Aztec' graveyard, and the word 'return' written in many languages. The theme of return advances the plot by directing Jones to Orellana's grave and then to Akator. The return satisfies the ancient astronaut tenet of reuniting the skulls, an outwardly liberal gesture that updates the raiding ethos for viewers uncomfortable with white men taking things from natives. Yet the action spaces available to Jones remain decidedly colonial in nature. Similar to Michael Bay's compression of Egyptian archaeological sites into a single shooting location in Transformers 2, the protagonist adventures in an imperial geography that plays 'fast and loose with [...] Latin American history and myth, placing the Iguazu waterfalls in the Peruvian jungle, mixing in the Nazca lines with El Dorado, [and] fusing Mayan and Aztec and transporting them from Mesoamerica to South America' (Scorer, 106). When the party lands at Nazca, Jones speaks Quechua with the indigenous people, a language, he relates to Mutt, that he learned while riding as a youth with Pancho Villa. While participating in a populist Mexican revolution may give Jones street credibility with the Peruvian natives, this historically revisionist gesture also naturalizes within the diegetic environment the kinds of aggressive post-war policies designed by the U.S. to counteract the ostensible expansion of Soviet influence in the western hemisphere (cf. Booker, 8). Jones's nostalgic reminiscences are thereby coeval with the shifting neoimperial landscape wherein coveted non-Western territory is characterized by ideological contestation and covert influence rather than the kinds of physical occupation endemic of the colonial era that gave birth to the raider legend. 
As John Rieder argues in Colonialism and the Emergence of Science Fiction (2008), the colonial environment of the jungle and the postcolonial world of the Cold War are not easily distinguishable in the SF imaginary. Especially pertinent to the present study is his concluding chapter, 'Visions of Catastrophe,' which examines the genre's problematic fascination with disaster and the critique of progress it implies. As evidenced by Kingdom of the Crystal Skull's nostalgic relationship with 1950s SF, the narrative of contagion and/or infiltration of the homeland by a malevolent foreign entity 'achieves striking, symptomatic popularity in post-World War II American science fiction,' reflecting 'anxieties concerning America's economic and cultural inundation of the postcolonial world, about the invisible but ever more pervasive power of new forms of multinational capitalism, or about the hybridization of the postimperial homelands' $(124,148)$. Unlike nuclear fictions, these variants on the catastrophe theme work subtly to annihilate the fascinating differences that make any utopian sense of progress in SF possible. Rieder conjectures,

Might not the sense of America's overwhelming cultural and economic ubiquity, taking the place of an older global economy's reliance on colonial expropriation and imperial control, have lent considerable power to a type of science fiction story that we find repeated during the same years, in which [...] a surreptitious or invisible foreign presence transforms signs and values, empties out older cultural artifacts and rituals, and refills them with fundamentally different motives and assumptions? (148)

If Jones is a victim of a shifting Cold War landscape that features alien Soviet scientists seeking to transform colonial freedom into postcolonial communist orthodoxy, the international race for the crystal skull also implicates the U.S. as authors of the kind of paranoid discourse used to rationalize the version of neoimperial expansion and indirect control Rieder describes. Purportedly a mind control device, the crystal skull is the ultimate SF touchstone for 'transforming signs and values' of 'older cultural artifacts' like Indiana Jones into a Cold War hero.

After securing the skull from the graveyard, Jones is captured promptly by Spalko. Strapped into a kind of dentist chair, he is positioned as a victim rather than perpetrator of the imperial contestation that drove him back into the jungle. Spalko forces him to gaze into the crystalline eye sockets, a procedure that she believes will establish a psychic bridge to the deranged Oxley, who knows the secret location of Akator. Jones stares hypnotically at the artefact. The camera slowly 
zooms into the glowing sockets, then cuts to Spalko's wide, penetrating eyes as she reveals her sinister plan:

Imagine, to appear across the world and know the enemy's secrets. To place our thoughts into the minds of your leaders. Make your teachers teach the true version of history. Your soldiers attack on our command. We will be everywhere at once, no more powerful than a whisper, invading your dreams, thinking your thoughts for you as you sleep. We will change you, Dr. Jones, all of you, from the inside. We will turn you into us. And the best part? You won't even know it's happening.

A virtual compendium of the excesses of Cold War paranoia, Spalko's dreamy monologue transforms the heretofore colonial artefact into an SF icon of Cold War cinema, an object of burgeoning American global hegemony mirrored in fears of Soviet mind control. As objective correlative of shifting generic and geopolitical registers, the crystal skull represents what is perhaps the most irrational yet fascinating strategic fiction of the Cold War era, brainwashing. According to Timothy Melley, brainwashing 'became a meaningful cultural fantasy [...] because it combines the thematics of secret agency and ideological conversion at the heart of cold warfare.' Corresponding with the 'growth of mass society at midcentury,' which 'created the need for a theory of social influence-a way of understanding how messages and institutions affect individual behavior and identity' in an environment with a 'profoundly different worldview of Communist peoples'-mind control was a self-fulfilling prophecy that rationalized covert warfare and counterterrorism by propagating widespread fear of an unseen enemy (2011, 23, 27).

From declassified CIA documents, Melley details a version of brainwashing that bears remarkable similarities to the contagion themes in Spielberg's film. In broad strokes, mind control was invented by the CIA and 'reported' by Edward Hunter, a CIA propaganda specialist posing as a journalist. His book Brain-Washing in Red China: The Calculated Destruction of Men's Minds (1951) popularized the idea that the psychological warfare purportedly waged by the communists in North Korea was 'a deadly threat to the rugged individual autonomy that would win the Cold War.' The 'public concept of brainwashing was from the beginning a creation of the CIA' for a propaganda campaign that deflected attention away from the secret development of 'a real mind control weapon of its own.' The CIA's failure to find a 'truth serum' reveals that 'Hunter's vision of total control was itself a fiction designed to stir public fear,' which was then leveraged to sanction CIA experiments 
with new methods of physical torture and 'enhanced interrogation,' research that would later be employed in the war on terror $(2011,25$, $28,29)$. Melley's short history of brainwashing goes like this:

the concept began as an orientalist propaganda fiction created by the CIA to mobilize domestic support for a massive military build-up. This fiction proved so effective that the CIA's operations directorate believed it and began a furious search for a real mind-control weapon. The search resulted not in a miraculous new weapon but a program of simulated brainwashing designed as a prophylactic against enemy mistreatment. This simulation in turn became the real basis for interrogating detainees in the war on terror. In this way, the demonology of the Cold War took a surreal and bodily turn, as the institutions of the United States first imagined, then simulated, then projected onto a new enemy, their worst fears of Cold War Communism. $(2011,30-31)^{13}$

Circulating in an unacknowledged pact between popular culture and the CIA, brainwashing injected into the Cold War a "certain "postmodern" quality - a confusion of what is real and what is merely a strategic fiction.' The 'security state,' he continues, 'transformed the conditions of social knowledge [...] in texts invested in demonstrating their own artifice and raising doubts about the nature of the real, the authentic, and the natural' $(2011,32)$. Kingdom of the Crystal Skull capitalizes on this 'postmodern quality' of the Cold War. Pretexts for returning Jones to the jungle, the fictions of Cold War paranoia and governmentality that are so carefully foregrounded in the first half of the film are largely abandoned in the second. The film thus performs a mind control experiment on the audience, whereby the apocalyptic implications of ancient technology are deflected entirely into the minds of mad Soviets, and the struggles for world domination devolve into a treasure hunt for a mythical artefact.

At Akator the colonialist logic that underscores the ancient astronaut premise is represented by a fresco depicting the 5,000-year-old story of sky gods with elongated skulls imparting the skills of civilization to the native 'Ugha.' Solving various archaeological riddles and booby traps-and staving off a band of hybrid Mesoamerican Ugha guardians emerging as living incarnations of the carvings-the party finally enters a temple complex inspired by Mayan cities like Chichen Itza and Copan. They stumble onto an amazing site, a vast storehouse of

13 For a thorough history of this phenomenon in literature see Seed, 2004. 
archaeological artefacts gathered from ancient civilizations all around the globe. 'Collectors,' Jones reverently observes. 'They were archaeologists.' In this extra-terrestrial museum, Jones meets his own past and future in the pursuits of beings responsible for kick-starting humanity's evolution. In an inner sanctum they find the crystalline skeletons of 13 aliens awaiting the return of their comrade. The crowning moment of the return of the crystal skull is upstaged by Spalko, who beholds in these beings the perfect incarnation of Soviet ideology, a 'hive mind' with a 'collective consciousness, more powerful together than they could ever be apart.'

The notion of the return carries two distinct meanings in this scene. What for Jones is an issue of repatriation is for Spalko a hubristic desire to want to 'know everything.' But what is the nature of this knowledge, and is it so distinct from Jones's own worldview as an adventuring scholar? These questions are answered cinemagraphically through the apocalyptic spectacle with which the film concludes. Spalko is hypnotized by the skull. Her mind and body are destroyed, overloaded by the knowledge/ power she seeks to imbibe from this holy grail of communist ideology. The temple itself has been built around an inter-dimensional spaceship that takes off in a cataclysm that destroys the Soviets, the archaeological treasure and the temple complex itself. Jones looks up at the spaceship mushrooming up from the ground, a dark mirror of the atomic test shot. As in Manticore, Stargate SG-1 and Transformers 2, threats to national security are deflected onto an archaeological record that hides doomsday weapons attractive to rogue powers, a material past that must be demolished in spectacular-and spectacularly ironic-demonstrations of control and ownership.

I suggest, moreover, that the apocalyptic associations attached to the ancient astronauts assume a distinctly contemporary complexion in the finale. Regaining his wits, Oxley reveals that the beings are not heading into outer space, but 'the space between spaces.' This enigmatic utterance sustains the mystery of the McGuffin/artefact, but it is also an oblique testament to the age of global terrorism, in which threats are no longer imaged spatially as exterior. Like the Cold War era Soviets, the aliens are evocative of a geopolitical environment in which, as Markus Kienscherf argues, insecurities and threats are [...] problematized as circulating below, across and beyond state borders' in a world where 'violence in general, and the threat of terrorism in particular' is 'increasingly held to emanate from fluid, mobile and networked organizations that operate across different spatial scales. These insecurities are, moreover, deemed to cut across the traditional division between domestic public safety and foreign defense' $(3,5)$. The 
porous borders between outer and inner space accommodate internal threats of Soviets looting the military warehouse at Area 51, colonial adventuring in politically borderless ancient territories, and the vertical 'raiding' imagery of underground descents and ascents. After the ship saucers away to the 'space between spaces,' Jones remarks, 'knowledge was their treasure.' An affirmation of the ancient astronaut premise of gifts of knowledge from superior beings, such knowledge also coincides with the particular anxieties associated with this second mushroom cloud erupting out of the Peruvian jungle. Jones readily identifies with beings who take things from primitive peoples in exchange for foreign wisdom. But so does Spalko. The treasure hoard of knowledge is thereby constitutive of the scientific practices that accommodate the 'gift' of archaeological knowledge in a geopolitical climate in which intelligence is also framed by paranoid agencies like the FBI, CIA and KGB. Through the SF thematics of invasion and apocalypse, control of archaeological knowledge remains immured in a remarkably imperialist worldview governed by strategic fictions of security and insecurity.

Refracted through the lens of 1950s SF cinema and post-9/11 ancient astronaut discourse, faith in the potentially redemptive nature of archaeology is also a strategic fiction in the war on terror. In its many incarnations in the film, the notion of the return-to sites of former colonial influence, of repatriating artefacts and reuniting with supreme beings-brings us full circle to the problematic 'return to Babylon' outlined in Part 1 of the present study, in which Western archaeologists have returned to wield new forms of global power through reinvigorated symbolic claims on the cradle of civilization. Collapsing dangerous intelligence into benign forms of academic knowledge at the film's conclusion reaffirms the colonial premise of a franchise whose flirtations with SF in the figure of ancient astronauts also circulate as a contemporary sign of the end of times visualized spatially as an exploding museum and an exploding mind. Erasure of the past is the future predicted in Kingdom of the Crystal Skull, whose spectacles of violence deflect terror onto dangerous others hidden among us.

Reminiscent of Reinhard Bernbeck's discussion of 'structural violence' in academic archaeology in the U.S. and Christina Luke and Morag Kersel's discussion of archaeological diplomacy in Soft Power, Hard Heritage, Erik Nemeth's article 'Collecting Cultural Intelligence: The Tactical Value of Cultural Property' (2011) examines the strategic role artefacts play in the field of international security. Because cultural property is targeted for looting and funding politically motivated violence, he argues that developing security programmes in conjunction with cultural heritage preservation is now of significant interest to 
policy makers. ${ }^{14}$ But considering neither the historical nor regional sources of violence in the Middle East, Nemeth's formulation of cultural intelligence replicates the paranoid relationship between national security and material remains dramatized in Kingdom of the Crystal Skull. Security in this sense is potentially hazardous to both history and people when used to extend and naturalize globalization under the pretext of promoting, as Luke and Kersel relate, a 'positive image of the United States, especially in a charged climate of objects and sites under threat, sometimes as a result of U.S. actions.' By 'exploiting threat and emphasizing security protection in order to justify U.S. programs' (81), artefact preservation has become a cultural weapon in the arsenal against terrorism. Baudrillard (2006) likewise reminds us that the gift of global security can always be returned, as demonstrated by ISIS's demolition of the UNESCO World Heritage Sites at Palmyra and Nimrud. ISIS has shown us our own death not entirely in terms of the spread of religious fundamentalism and radicalization, but as our own murder of heritage in mad parodies of material consumerist progress in places like Survival City.

At the close of the film Jones leaves the jungle to be with his new family. He is reinstated at Marshall College and promoted to Associate Dean. His first love and only son are returned to him just as he returned the crystal skull to its kind. A question remains, however: does this simulation of repatriation offer adequate compensation for a history of raiding rationalized now by superior beings who destroy the material past in displays of superior wisdom? While we wait for the aliens to return for a definitive answer, we can consider how the issues of control over historical narrative, ownership of cultural property and popular representations of geopolitics converge in the return of another iconic American hero to post-9/11 SFFTV, Superman. The nature of material history in Smallville's timely excavation of the Superman myth is the subject of the next chapter.

14 Cf. Nemeth, 2015. 


\title{
Chapter 6
}

\author{
Smallville
}

I stand for truth, justice and ... other stuff.

Clark Kent, Class President candidacy speech ${ }^{1}$

At least hypothetically, Smallville is a likely location of new initiatives for criminally circumventing law enforcement's existing intelligence network. Smallville represents one of the best places to hide for terrorists and other criminal entrepreneurs. For that reason, Smallville needs to be incorporated into the planning effort, but the planning effort, in turn, must understand and incorporate the special character of the nation's Smallvilles and their police.

Futures Working Group White Paper ${ }^{2}$

In the penultimate, ninth season of Smallville several retirees from the Justice Society of America converge on Metropolis to encourage Clark Kent (Tom Welling) to embrace his destiny. Among these Golden Age superheroes is Dr. Fate (Brent Stait), who presents the young man with a tantalizing glimpse of the future:

Clark: 'When you saw my fate, what did you see?'

Dr. Fate: 'You will lead this generation as Hawkman once led ours.' Clark: 'You sound like a group I met from the future [i.e. the Legion of Superheroes]. They hinted at my destiny, but they were as vague as you are.'

Dr. Fate: 'Then let me be specific. Although Lex Luthor is your ultimate opponent, you will triumph over him [...] And when you

1 'Drone' (30 April 2002).

2 Buerger et al. 
show yourself to the world, it will be a different age than ours, Clark, a silver age of heroism that will start when they look up into the sky at you with hope for tomorrow. You will help everyone to embrace it.' ('Absolute Justice,' 5 February 2010)

Couched in well-worn allusions to the 'man of tomorrow,' 'looking up to the sky' and DC Comics' 'silver age' of superheroes, Dr. Fate's prediction is an echo of Superman past. Déjà vu haunts the entire series. With running in-jokes about leaping tall buildings and outrunning speeding bullets, Clark's penchant for blue T-shirt and red jacket ensembles, and the prevalent primary colour palettes in set and lighting design, dramatic irony is the dramatic motor propelling Smallville's decade-long deferral of Clark's transformation into Superman.

Smallville's longevity is attributable in part to the creative interplay between the basic signs or syntactic structures that comprise the myth of Superman' (Ndalianis, 2011, 86) and the conventions of serial melodrama. Guided by the 'no flights, no tights' injunction established by creators Alfred Gough and Miles Millar, Smallville remakes Clark Kent for a niche audience that was not necessarily Superman familiar or friendly. Choosing the lead from the cast of Judging Amy (Denison, 169) was a deliberate strategy to draw the female viewership of WB programmes like Dawson's Creek and 7th Heaven (Jones, 1) to a series whose subject matter would also be of interest to the 12- to 34-year-old male demographic. Similar to the 'melodramatically motivated television action series' Buffy the Vampire Slayer (Denison, 164), which migrated from WB to UPN in 2001, Smallville moulds Clark Kent into 'an archetypal WB teen[,] [...] a conflicted hero who could singularly embody the coalition of identities the netlet hoped to attract as its audience' (Shimpach, 100; cf. Wee). ${ }^{3}$

As fate would have it, the WB's timing was perfect. Airing on 16 October 2001, the pilot episode's delivery of the infant Kryptonian to the American heartland in a cataclysmic meteor shower registered as both an aftershock of the WTC attacks and the SF point of difference. ${ }^{4}$ A 'revisionist gesture' that 'brings the series into alignment with post-9/11 responses' (Hantke, 2012, 378), the fallout from the destruction of Krypton establishes the basic thematic and ideological context for a series that configures threatening differences to the body politic in terms of the kryptonite-enhanced abilities of 'meteor freaks' populating

3 Smallville migrated for its final two seasons to the new CW network, the product of a merger between WB and its rival UPN in 2006.

4 Having an estimated 8.4 million viewers, the pilot earned the highest ratings of any WB series debut to date (Shimpach, 97, 100). 
Smallville. For a show whose protagonist is himself an alien and an alienated teen, Smallville allows, as Daniel Kulle relates, Superman's traditional 'conservative containment strategies' to clash with 'subversive body strategies' (159). By collapsing Clark's outsider status into the 'inherently contradictory, transgressive experience' of adolescence (Ross and Stein, 7), Smallville exposes Superman's history of geopolitical mediation to the particular domestic fictions and cultural practices of post-9/11 American teenagers. ${ }^{5}$

In a television text that repeatedly refers to the material world of the Superman franchise, archaeology is a conspicuous medium for 'recovering the memory of what Superman eventually came to $b e^{\prime}$ (jagodzinski, 173). Two archaeological storylines are particularly relevant for investing Clark's intra-narrative destiny with the extra-diegetic concerns of viewers. The first is Clark's discovery of the Kawatche Caves in season two (2002-03), the site from which the incipient superhero first gathers hard evidence about his identity from material remains left by a Kryptonian ancestor in the physical and cultural matrix of the indigenous 'Kawatche' nation. Tackling issues of heritage conservation and aboriginal land claims, the episode troubles the Superman telos by grounding Clark's origin story in both the colonial imagery and eschatology of ancient astronaut discourse. The second storyline features Dr. Fate and the Justice Society of America, whose tutelage of Clark coincides with one of Smallville's most direct engagements with contemporary politics, a story arc about balancing civil liberty and national security in a world threatened by global terrorism. At the centre of this debate is the aging Egyptologist-superhero Carter Hall (aka Hawkman, played by Michael Shanks), who mentors Clark in his final trial against the supervillain Darkseid, an ancient alien entity who has infected humanity with xenophobia, infiltrated the government, and created a secret police force to prosecute superheroes. Clark's final battle before donning his signature cape and tights resolves the riddle of Clark's destiny inscribed on the walls of the Kawatche Caves, and represents the culmination of a decade-long journey in which his messianic origins as a superior white being are deconstructed and methodically reconstructed in concert with post-9/11 anxieties of (ancient) alien invasion.

5 Davis and Dickinson argue that the audience for teen dramas also include adults (3). Cf. Ross and Stein, 5. As Wee puts it, since the 1990s the term "teen" had less to do with biological age and increasingly more to do with lifestyle and shared cultural tastes and interests' (47). jagodzinski argues that Smallville's version of Superman responds to the embodied mutation in X-Men as a trope for disaffected youth culture and broader concerns about the invasion of national borders (174). Cf. Bukatman, 2003, 48-78. 
The second-season episode 'Skinwalker' (26 November 2002) introduces a novel element to the Superman myth, a series of caves from which the fictional Kawatche First Nation claims ancestry. Meaning 'skinwalker,' the moniker 'Kawatche' denotes the secret ability to transform into wolves, an intergenerational mutation caused by exposure to kryptonite left by a Kryptonian astronaut five centuries beforehand. The discovery of the caves triggers a series of moral dilemmas for the nascent hero, who is disconcerted by the mysterious and potentially malevolent origin of his own superpowers. To further complicate matters for Clark, the site is a lightning rod for Kawatche 'terrorism' against powerful corporate interests infiltrating Smallville's idyllic rural community. 'Skinwalker' thus establishes Clark's early civic engagement within the problematic materio-political conditions of his own origin story.

The episode teaser opens with Kawatche professor of languages and activist Joseph Willowbrook (Gordon Tootoosis) confronting the foreman (Rob Morton) of a LuthorCorp office tower being constructed directly above the caves. Protesting his right to pass freely on ancestral land, Willowbrook is summarily removed and threatened with legal action. Night descends and the foreman finds himself being stalked by a white wolf. Extra-diegetic chanting intimates that the wolf is Willowbrook. Frightened, the employee accidentally fires a flare into a fuel depot and is killed in the explosion. Vacillating between the wolf's grainy low-angle hand-held camera view of the incident and the guard's terrified perspective, the editing invites the audience to consider conflicting points of view in what the police assume is a politically motivated murder. In an episode that typically mixes, as Cary Jones relates, 'entertaining mystery-solving and crime-busting with regard to the conspiracies and corporate greed surrounding the Luthor Corporation' and 'monster-ofthe-week-type phenomena' (1), balancing perspectives is part of Clark's weekly lesson in the vicissitudes of justice.

Drawn to the scene, Clark inadvertently triggers a cave-in and exposes an unexplored section of the complex. This attracts Willowbrook's granddaughter, Kyla (Tamara Feldman), who is desperately cataloguing petroglyphs imperilled by the construction project. She is delighted to find a hoard of glyphs depicting the legend of 'Naman,' the mythical father of the Kawatche, a celestial being said to possess the strength of ten men and the ability to light fires with his eyes. The story foretells, she informs Clark, of Naman's return to the Kawatche in their hour of need. Clark is caught in the precarious position of reconciling the decidedly colonial myth of a celestial saviour with his desire to understand his personal connection to the site, and, moreover, his superheroic moral duty to protect fragile Kawatche history while investigating the 
suspicious death of the LuthorCorp employee. Falling into his heritage provides no revelatory satisfaction for Clark, for he must continue to undergo a constellation of trials to define himself within and against the ambivalent iconography of his ancient astronaut forebear. Moreover, the episode advances Clark's narrative of becoming as a matter of negotiating what Shahriar Fouladi calls his 'monstrous puberty' the conflation of socio-biological changes with the potential 'corruption by internal or external forces' that threaten to 'overturn his traditional role as a protector' (161). The petroglyphs corroborate his fear that he might inadvertently or uncontrollably unleash his superhuman powers on his adoptive home. Smallville re-historicizes the visual iconography of the superhero's body through dramas of disaffected teenage mutants who redefine the borders of normalcy to which Clark, growing up with acute anxieties of his own difference, struggles to conform. ${ }^{6}$

In 'Skinwalker,' these concerns jostle in the televisual apparatus of teen melodrama. What follows is a shot-by-shot analysis of a one-minute-forty-second scene in 'Skinwalker.' Evocative of what television scholar John Caldwell terms the 'zero-degree style' of soap opera melodrama, the fixed thematic sets, minimal character movement, excessive acting and extra-diegetic mood music delineate the characters' conflicting emotional and ideological stakes in the Kawatche crisis. ${ }^{7}$ The frequency of cuts ( 39 in total), the fixed and mobile framing, and the multiple camera angles emphasize political tension by fostering discrete axes of intimacy between the characters. The scene follows a conversation between Clark and Jonathan Kent (John Schneider), who is fearful that his adopted son, who is infatuated with Kyla and eager to learn more about Naman from Joseph, has misplaced his trust in strangers who seem to hold the key to his extra-terrestrial identity. To Jonathan's surprise, Clark has invited Kyla and Joseph, who has just been released from custody, to dinner.

Shot 1 [opens from the commercial break with a close-up of Joseph Willowbrook speaking at the dinner table in the Kent farmhouse. Camera tracks out to reveal the assembled company while Joseph speaks; Martha Kent (Annette O'Toole) collects the plates]

Joseph: 'According to the legend, a man came from the

6 Cf. Beeler, 2011, who equates Clark's development in the television serial narrative with the bildungsroman tradition.

7 For studies of acting conventions in soap opera see Brunsdon; Butler, 1986; and Klinger, 1991. 
stars and fell in love with the mother of our people. Out of that forbidden affair, the Kawatche people were born.' Clark: 'Do you know which star he came from?'

Shot 2 [close-up of Kyla, smiling knowingly at Clark, then turns gaze to Joseph]

Shot 3 [medium close-up of Joseph, low angle as he speaks] Joseph: 'The legend only tells that he left one day and flew back into the sky ...'

Shots 4 and 5 [in mid-sentence, medium close-up of Jonathan, who looks disconcertedly at Clark; close-up of Clark, who returns Jonathan's glance]

'... promising he would send another.'

Shot 6 [medium close-up of Jonathan; Martha is out of focus in background taking plates into the kitchen]

Jonathan: 'And that would be this Naman person you've been talking about, right?'

Shot 7 [close-up of Clark over Joseph's shoulder as Jonathan speaks; Clark looks at Jonathan with a worried expression]

Shot 8 [close-up of Joseph over Clark's shoulder]

Joseph: 'Yes. Of course, that was 500 years ago. He's a little late.'

Shot 9 [close-up of Kyla, who coquettishly bites her lip while looking at Clark]

Shot 10 [close-up of Clark, who returns her gaze, smiles, then sheepishly looks down]

Shot 11 [close-up of Joseph, sensing sexual tension] Joseph: 'You're not from around here, are you Clark?'

Shot 12 [close-up of a surprised Clark, who raises eyebrows and opens eyes wide]

Shot 13 [medium close-up of Jonathan, who looks to Martha for help; rack to medium long shot of Martha in the kitchen] Martha: 'Um, actually Clark is adopted.'

Shot 14 [close-up of Joseph, who shifts gaze to Clark]

Shot 15 [close-up of Clark over Joseph's shoulder]

Clark: 'These, uh, these symbols seem to make up some sort of alphabet.'

Shot 16 [close-up of Kyla]

Kyla: 'That's the really weird part.'

Shot 17 [close-up of Clark, smiling at Kyla]

Shot 18 [medium long shot of Martha serving Jonathan pie while Joseph speaks; Jonathan acknowledges Martha with a smile] Joseph: 'Our people don't have a written language ...' 
Shot 19 [close-up of Joseph from low angle]

'... I've seen a symbol here or there on artefacts, but never in a pattern before.'

Shot 20 [close-up of Clark]

Clark: 'So you don't know what they mean?'

Shot 21 [close-up of Joseph over Kyla's shoulder as Kyla responds] Kyla: 'Grandpa's studied a lot of ancient languages ...'

Shot 22 [close-up of Kyla]

'... I'm sure with some time he can decipher what the symbols are.'

Shot 23 [close-up of Joseph over Clark's shoulder]

Joseph: 'If Luthor doesn't get at them before we do.'

Shot 24 [close-up of Jonathan looking up from his pie with furrowed brow]

Shot 25 [Martha passes in the background out of focus behind a close-up of Clark, who turns his head to follow her movement around the table]

Clark: 'Mom, maybe you can talk to Mr. Luthor.'

Shot 26 [medium close-up of Martha surprised and caught out by Clark]

Shot 27 [close-up of Joseph]

Joseph: 'You know Lionel Luthor?'

Shot 28 [medium close-up of Martha, embarrassed]

Shot 29 [close-up of Clark smiling gleefully as he speaks]

Clark: 'Know him? Mom is his executive assistant!'

Shot 30 [close-up of Joseph, who looks away incredulously as Martha responds]

Martha: 'I'll do what I can, but ...'

Shot 31 [close-up of Jonathan, who looks up under furrowed brow to Martha]

'... it isn't that easy ...'

Shot 32 [close-up of Martha shifting gaze between Joseph and Clark]

'... The situation isn't that black and white ...'

Shot 33 [close-up of a shocked Clark over Kyla's shoulder while Martha speaks]

'... That complex will create ...'

Shot 34 [close-up of a shocked Kyla over Clark's shoulder while Martha speaks]

Martha: '... a thousand ...'

Shot 35 [close-up of Martha]

'... desperately needed jobs.' 
Shot 36 [close-up of Clark]

Clark: 'And you think that's more important than these caves?'

Shot 37 [close-up of Martha shrugging her shoulders and looking to Joseph]

Shot 38 [close-up of Joseph, looking away and shifting uncomfortably in his chair]

Shot 39 [close-up of Jonathan]

Jonathan: 'So, um, does anyone want coffee with their pie?'

Shot 40 [close-up of Clark, glancing at Joseph, Kyla, then down. Scene ends, cutting to establishing shot of a sunset on the barn where Clark and Kyla retire. Their first kiss is interrupted by the unexpected arrival of Lana Lang (Kristin Kreuk)]

The rapid framing and focal length variation convey a wealth of paratextual information. Part of the conversation, the camera discloses meaningful, though partial information to each character. Repeated close-ups and reaction shots foster intimacy between Clark and Kyla within the hospitable old-time aura of the Kent family farm. By the end of the scene, however, the framing alters register, turning in on itself to foster mistrust, disappointment and the kind of indignation and embarrassment that cannot be washed down with coffee and apple pie. The tonal shift accentuates the 'forbidden affair' between the American boy and the Kawatche girl-forbidden too because the audience knows that Clark's romantic destiny in his teenage years lies with Lana Lang, who dutifully obstructs Clark's new love interest in the next scene-and advances the uber-plot of the Luthor family's corporate hold on Smallville life. In addition, the frequent shot/reverse shots and over-shoulder shots engender in real time the emotional tensions simmering within the dialogue, techniques that flirt with Clark's secret playing out in his attraction to Kyla. Moreover, the frenetic cuts triangulate and complicate romantic and familial alliances, and threaten to expose Clark through his burgeoning attachment to the Kawatche and their cause. The result is a ripple effect of clashing confidences and secrets between Clark and his parents, between Kyla and Joseph, and between the star-crossed lovers. The scene exemplifies how the 'excess' of serial melodrama ${ }^{8}$ invites, as Jason Mittell observes, 'an engaging emotional response to feel the difference between competing

8 Cf. L. Williams. 
moral sides as manifested through forward-moving storytelling' (244). Clark's prevarications about his extra-terrestrial identity and terrestrial purpose are synonymous with his affective morality, his uncertainty manifest in emotional responses to particular crises as well as to the unpredictability of his potentially monstrous body mirrored in the petroglyph of Naman's fiery gaze.

The camera also 'unconceals' villainy lurking within the increasingly fraught atmosphere of the gathering. Martha is distinguished from the other actors by occupying a unique 'axis of action' (Butler, 2009, $38-41)$, reflecting her revised identity in the series as the daughter of a prominent Metropolis corporate lawyer. Supporting the LuthorCorp project, Martha departs from her traditional role as the nurturing mother of the New Deal defender of the working class. As executive assistant to a man who also happens to be not-so-secretly attracted to her, Martha embodies conflicts between the rural and the urban, the family farm and corporate interests, heritage and progress. Her divided loyalties are symptomatic of the ways Smallville implicitly asks, to cite the title of Thomas Frank's book, What's the Matter with Kansas? How Conservatives Won the Heart of America (2004). Frank argues that

the Republican Party and the Bush administration have inverted turn of the century agrarian populism by calling upon the Midwestern cultural cache of honesty, innocence, and 'traditional' values to fuel culture wars regarding 'moral' issues [in order to] divert attention from the party's economic agenda which favors deregulation, privatization, and lower taxes for wealthier people, [...] goals diametrically opposed to those forwarded by early populism. (Kustritz, 4-5)

Jonathan, too, is enveloped in this paradox. His identity-carried over from Schneider's portrayal of good old boy Bo Duke in The Dukes of Hazzard-is compromised by the secrets he holds, including his knowledge of Martha's involvement in the LuthorCorp towers. Just as the historical discussion descends into politics and the fundamental antagonism between (Christian) idealism and (capitalist) materialism (jagodzinski, 176), Clark's descent into the caves and into his own history is impeded by the ideological concerns ranged around the dinner table. An implicit question this episode-and indeed the entire series-raises is 'what kind of ideological duty is the young Superman performing in the post-9/11 era of anxiety?' (jagodzinski, 174). While answers are not easily forthcoming in a series that 'parcels out incomplete pieces of closure' that 'always construct the foundations of new enigmas,' its modified soap 
opera style invites viewers to work out questions of morality along with Clark as he negotiates the vicissitudes of his super-teen life in a hybrid episodic and serial narrative form in which '[i]deological conflicts are never fully reconciled' (Butler, 1986, 55, 54). ${ }^{9}$

The dinner sequence also exemplifies how teen melodrama destabilizes the myth of Superman by exposing Clark to, as Miranda Banks claims, broader cultural crises in representations of masculinity. She argues that Clark typifies 'a new television hero who is motivated to action by enlightened dreams for an equal partner, emotionally fulfilling relationships and a sense of duty to his community' (18). Like the male protagonists of Beverly Hills 90210, Party of Five, Dawson's Creek and Roswell High, Clark departs from 'the shy, insecure, neurotic or effeminate teen males of the 1950s' cinema melodrama, paralysed by their emotions. Rather it is their willingness-often even eagerness-to be reflective and emote without losing control that sets them apart as a new type of hero' (22). The transgeneric television format, in which 'heroic violence resolves the action plotline in a single episode, but fails to resolve the continuing domestic melodrama,' allows temporary closure for the casual viewer but extends dedicated fan interest in the 'developing intricacies of personal relationships between recurring characters' (Shimpach, 36). Mittell notes that the integration of serial melodrama into genres like SF action 'has led to more fluid possibilities of gender identification and to the challenging of rigid stereotypes of gendered appeals' by addressing a 'wide range of viewers and [...] a spectrum of affective engagements within a single viewer of any gender identity' $(246,248)$. Within action/melodrama, the 'apparently hetero, white, male action hero' is 'increasingly depicted as under all manner of assault, a conflicted, besieged, unstable subject facing personal as well as geopolitical crises' (Shimpach, 31; cf. Duffy).

At the Kawatche Caves, geopolitics and identity politics are bound in the petroglyphs' depiction of an epic battle between Naman and his arch rival 'Sageeth.' Like 'a brother to Naman,' explains Kyla, Sageeth completes Naman. Superman's storied battles with Lex Luthor (Michael Rosenbaum) develop in a story world in which heroic action and villainy circulate within the emotional trauma of brother figures destined to be 'torn apart due to the larger circumstances dominating their lives' (Kohnen, 211). The caves' secrets are ground zero for 'retconning' a new Superman mythos that is, as Jes Battis observes, 'more interested in exploring what first brought these characters together rather than what will someday tear them apart' (50). The

9 Mittell calls this mixed narrative form 'Complex TV' (2015). 


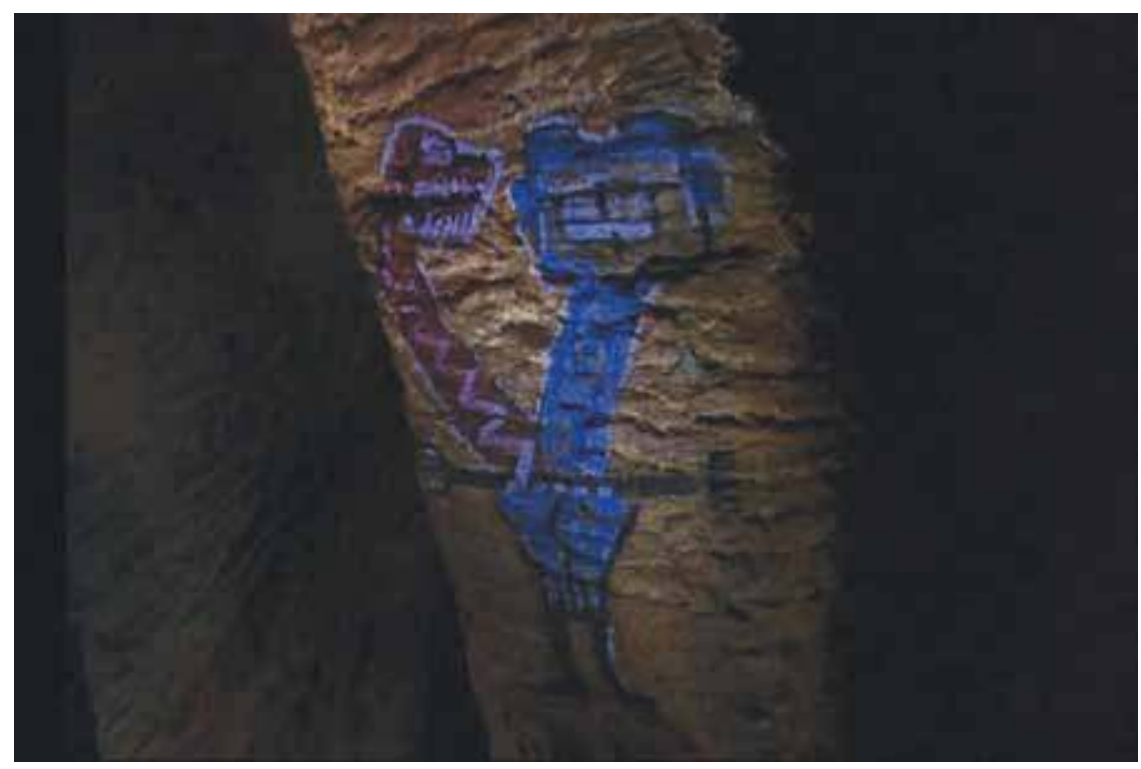

Figure 14. Smallville, 'Skinwalker'

(Warner Bros. Television, 2002).

Naman/Sageeth pairing reminds the viewer that identity formation for both young men unfolds within the private tribulations of teenage friendships and the external pressures of growing up mistrustful of parental figures. Like Clark, Lex's character negotiates the extraordinary demands of a televisual environment that subjects him to crises of identity on a weekly basis (Kohnen, 211). In a self-parodic moment in 'Skinwalker,' Clark confides in his friend about his feelings for Kyla. 'Have you ever wondered if you were destined to be with someone?' he asks. Lex replies, 'You're asking someone who's been fighting his destiny his entire life.' Lex's sense of destiny is motivated by his desire to safeguard the world from the clutches of his father's generation, a paradox that is never successfully resolved because he inherits his father's own 'superpower,' his penchant for corporate intrigue, a legacy that ultimately corrupts Lex and propels the conflicted Clark toward his destiny of becoming, as Dr. Fate puts it, the billionaire's 'ultimate opponent.'

In teen melodrama the kind of intradiegetic information conveyed by the enigmatic glances exchanged between the characters in the dinner scene is likewise evocative of, as Battis observes, 'an array of silences that actually come to define a whole constellation of identities' for Clark and Lex. The closeted nature of these 'two 
highly secretive and vulnerable men' (45-46, 46; cf. Kustritz) has not been lost upon Smallville's active online community. The characters' on-screen chemistry has been routinely interpreted as 'sexual desire, and "knowing"' in online 'slash' and 'shipper' forums like HoYay! (short for 'Homoeroticism, Yay!'), which tease out moments of queer spectatorship. The portmanteau name 'Clex' is thereby 'slashed' from the 'various looks, touches, or pieces of dialogue that fans declare undeniably queer' (Kohnen, 221, 212). At the same time, homoerotic desire is often sublimated into heteronormative triangulations of male competition for female characters. Clark, Lex and Lana are thus 'shipped' (i.e. 'relation-shipped') into 'Clexana' (Kohnen, 214). ${ }^{10}$ Analyzing Smallville forums on the interactive fan websites Television Without Pity (on which HoYay! emerged in November 2001 [Kustritz, 8]) and LiveJournal, Melanie Kohnen contends that female and male viewers who do not necessarily identify as gay demonstrate how 'seeing queerly is practiced [...] at a time in which cultural sexual norms are so hotly contested' (210). These assaults upon the straight Superman are apropos of the potentially volatile nature of identity politics within Smallville's melodramatic framework. 'Embodying and performing competing masculinities,' Shimpach relates, contemporary heroes in teen television drama form 'composite characters designed to attract various viewing positions together into a (larger) composite audience' (39). The queer gaze also encompasses the archaeological themes of the episode and the series as a whole. For the origin story of 'Clex' is also inscribed on the cave walls, the 'erotic and ideological' nature of their friendship visualized in the intertwined phallic imagery of the Naman/Sageeth ('Nameeth'?) petroglyph.

Seeing queerly raises the thematic and political stakes in Smallville. Kustritz relates that 'Superman's very omnipresence and familiarity also mean that his cultural force remains vulnerable to appropriation by fans and lay critics whose public discussion and amateur art forms may use Superman symbolism to construct radically different counter-claims about the nation and national identity' (8). Discussions by 'specialty in-groups with unique counter-knowledge' (9) of the subversive potential of gender-neutral, gender-transcendent and romantic homosexual relationships have opened Smallville's Superman to more equitable formations of citizenship and political engagement. In 'Skinwalker,' Clark uses his abilities to save Kyla from a cave-in caused by Lionel's excavation equipment, but his powers are otherwise 'closeted'

10 Other discussions of Smallville fan slash practices include Barker; Kustritz; and Shimpach, 42-43. 
and ineffectual against the real-world corporate menace to the caves and indigenous culture. Ultimately, Lex saves the day by preserving the caves from LuthorCorp bulldozers. Amazed by the petroglyphs, he exclaims, 'Incredible! These may be even more impressive than the caves at Lascaux.' Overstated perhaps, but Lex nevertheless wrests control of the caves from his father by supporting a local protest led by Willowbrook. Directing his resources towards having the caves declared a heritage site by the State Preservation Society, Lex in turn secures the government contract for their archaeological survey. In 'Skinwalker' archaeology is a mode of rescue that displaces Clark's traditional role as saviour, a role that is simultaneously being reconfigured within the queer thematics visualized in the archaeological figure of the Naman/ Sageeth petroglyph.

Though motivated by friendship, their fated rivalry is quickened nonetheless by information the future supervillain withholds from Clark. For Lex secretly possesses a Kryptonian artefact that fits exactly with a niche in the caves, an octagonal key that will eventually open a portal to the Fortress of Solitude in the Arctic ('Commencement,' 18 May 2005). Drawing connections between the strange artefact, the petroglyphs, the mutant phenomena in Smallville and Clark's secretive nature, Lex undertakes parallel ancient astronaut research into the identity of the alien visitor. In the third-season episode 'Talisman,' Lex develops a fatal theory about the caves. In a conversation with Clark, he observes that Naman 'could conquer the world. He could become a tyrant if no one kept him in check. So, I've been thinking ... anybody who'd be willing to fight him would have to be pretty brave. Clark, did it ever occur to you that the hero of the story is Sageeth?' While Clark is plagued by the ambivalent motives of Naman's messianic return, Lex is intoxicated by a myth that fuels his dangerously narcissistic mission to safeguard the world from both his father's tyrannical hold on America and alien threats to security.

Mirrored in this fascinating drama of a fractious friendship-and the televisual leap forward in dismantling the fortress of rigid heterosexuality that Superman traditionally safeguards-is Clark's impossible love for the Native girl. Kyla is a sacrificial victim who dies defending the caves and Clark's secret identity, which she correctly gleans from the petroglyphs. Her tragic death-she 'skinwalks' into a wolf, confronts Lionel, and is mortally wounded in her escape-furnishes a cathartic conclusion to the young couple's forbidden love; but killing her off allows Clark to perform the tricky manoeuvre of inhabiting the myth of Naman while disavowing the Native other, who represents the double threat of a mutant terrorist and the monstrous feminine. His role in the 
Kawatche dispute ultimately sanctions the colonial myth he is reluctant to adopt for himself. ${ }^{11}$

In this regard, 'Skinwalker' opens a third interest, another way of thinking about conflicts that cannot be closeted within the caves' origin story. The episode engages immediate geopolitics through Clark's conflicted friendship with Lana, who lingers on the margins of his affair with Kyla. Just as Kyla is unavailable to Clark because of her Native and monstrous status, Lana is unavailable in a genre in which true love is forbidden to the protagonist, in this case until Clark masters his powers and is mature enough to commit to the responsibilities of being both Superman and Lois Lane's (Erica Durance) life partner. At this moment in the series Lana is dating the former quarterback of the Smallville Crows, Whitney Fordman (Eric Johnson), who after graduation joins the Marines to fight terrorist threats against American interests. The final scene of 'Skinwalker' sets up new dramatic and ideological tensions: just minutes after Kyla's death, Lana breaks the news to Clark that Whitney is missing in action while stationed in Indonesia. Clark's is the first shoulder she cries on. The scene sets up the next episode, 'Visage' (14 January 2003), which takes as its subject the return of soldiers suffering with PTSD. While the show cannot address directly assaults upon military heroism at a time when flag-draped caskets were beginning to arrive on American soil, it does so indirectly through Clark's struggle to reconcile his ambiguous status as a saviour and an alien invader in relation to Whitney's career as a war veteran.

As a football star and fallen soldier, Whitney incarnates the kind of normative heroism that is irresistible to the home-coming queen Lana but withheld from the perforce retiring Clark. The ideological potential of the Whiney/Lana/Clark triad is amplified, however, through a potentially subversive form of lesbian spectatorship. Some backstory is required. The first-season episode 'X-Ray' (6 November 2001), which introduces Clark to his new ability to see through objects (including Lana's towel in the locker room), explores the nature of friendships among girls organized in a hierarchy of beauty and popularity. The mousey Tina Greer (Lizzy Caplan), who is secretly a shape-shifting meteor freak, becomes jealous of Lana's 'perfect life,' and plots to kill and replace her. Clark foils the plan and Tina is committed to Smallville's psychiatric hospital, Belle Reve. In 'Visage,' Tina concludes that she is actually in

11 The dominant culture's appropriation of Kawatche heritage continues in the third-season episode 'Talisman' (5 May 2004), which involves a Kawatche youth who mistakenly claims the Naman identity for himself after temporarily acquiring Clark's powers. 
love with Lana. She escapes and assumes Whitney's identity. But overly sensitive to Lana's emotional needs, the war hero is a suspiciously perfect partner for Lana. When Clark circumvents Tina's plot to marry Lana, the shape-shifter impersonates Lana's new saviour, who reveals 'his' love for her. Enveloped in the simmering lesbian implications of the storyline and the effeminization of these all-American heroes, Whitney's image becomes entangled in the threatening world of meteor freaks that envelopes Clark's own ontological struggles as a superpowered alien living secretly among humanity. As Kustritz relates, 'Tina's abilities and the war in "Indonesia" present clear parallels with post-9/11 fears regarding the possibility of an enemy capable of penetrating American borders, infiltrating the country, undetected' (7). Just as 'Clex' vouchsafes the inefficacy of masculine heroism in teen melodrama (Shimpach, 31), the gender-bending implications of Whitney's return further assail the heteronormative order encompassing Superman and the American military-football complex. Circulating alongside the kinds of SF military films examined in 'Battling Babylon,' Smallville occasions through the dramas surrounding Whitney's death and Clark's interventions in Kawatche culture an oblique emotional and politically charged commentary on the contemporary alien invasion of the Middle East: the narratives of salvation that validate the periodic return to the cradle of civilization are sublimated into Clark's conflicted feelings about his own cultural origins in the battle to possess and control Native North American cultural heritage.

The Kawatche Caves remain an important touchstone for Clark's evolution in subsequent seasons. To this end, the producers resurrected another artefact from the Superman franchise to help Clark: Christopher Reeve, whose 'star persona functions forcefully as a legitimizing force' in the series (Ndalianis, 2011, 76). ${ }^{12}$ Reeve plays Paleo-SETI investigator Dr. Virgil Swann, who founded at the time of the meteor shower a secret society of wealthy socialites (including Lionel Luthor) called 'Veritas,' an organization devoted to investigating the prophecy of the return of an extra-terrestrial figure known as 'The Traveller.' In the second-season episode 'Rosetta' (25 February 2003), the caves come back into play by downloading the Kryptonian language into Clark's consciousness when he inserts the octagonal key (recovered from Lex by Martha Kent ['Insurgence,' 21 January 2003]) into the niche on the wall. Accidentally burning a Kryptonian symbol on his barn door,

12 The season-two DVD release includes the short feature 'Christopher Reeve: The Man of Steel,' which commemorates Reeve's contribution to the role and his passing of the torch to Tom Welling. 
Clark attracts the attention of Swann, who shares with his protégé a cryptic message broadcast from Clark's spaceship: 'This is Kal-El of Krypton, our infant son and our last hope. Please protect him and deliver him from evil.' The message also holds a potentially sinister meaning for Clark: 'On this third planet from this star Sol you will be a god among men. They are a flawed race. Rule them with strength. This is where your greatness lies.' Sent in the form of a prayer, the transmission from his Kryptonian father Jor-El (voiced by Terence Stamp) echoes the Naman legend, which the ever-sensitive Clark misinterprets as his destiny to conquer. ${ }^{13}$ Reeve-as-Swann invites Clark to consider the nature of power, morality and responsibility in a world where choices seem preordained and the Naman/Sageeth dynamic has the potential to become inverted-both palpable sources of anxiety for the superhero in training. As an alien invader, Clark must continually, melodramatically engage his threatening difference in a decade-long struggle to understand what it means to be a defender of truth, justice and ... other stuff.

Leaping ahead to the final two seasons, Clark's maturation into a journalist at the Daily Planet and his burgeoning attraction to Lois Lane take place against a background of black book projects designed to harness and manipulate the abilities of the young superheroes gathering around Clark. In this phase of Clark's bildung, Smallville leverages the cultural capital of Superman mythology against the kinds of paranoid politics that compromise the very American Way that Clark is being groomed to defend. A benchmark moment in terms of Smallville's archaeo-politics is the two-part episode 'Absolute Justice' in season nine. Retconning the history of the Justice Society of America to align temporally with the Smallville universe, the episode recounts the JSA's passing into obscurity in the 1970s after its members refused to cooperate with the government's black ops organization 'Checkmate.' Illustrative of Smallville's rich DC Comics intertext, ${ }^{14}$ these golden age characters resurface to help the next generation embrace their vocational potential in a world sliding once again into the dangerous polarizations of power that delimited the JSA's activities during the Cold War. In the episode, Dr. Fate teleports Clark to Carter Hall's abandoned JSA museum. In a kind of comic book archaeology, Clark rummages through the dusty artefacts of the forgotten organization. He regards Flash's Mercury

13 On Clark's guilt and its connection to Christian morality see Banks, 24-25; jagodzinski, 179-86; and Kozloff.

14 According to Smallville Wiki approximately 60 DC Comics characters appear in the series. http://smallville.wikia.com/wiki/Absolute_Justice. 


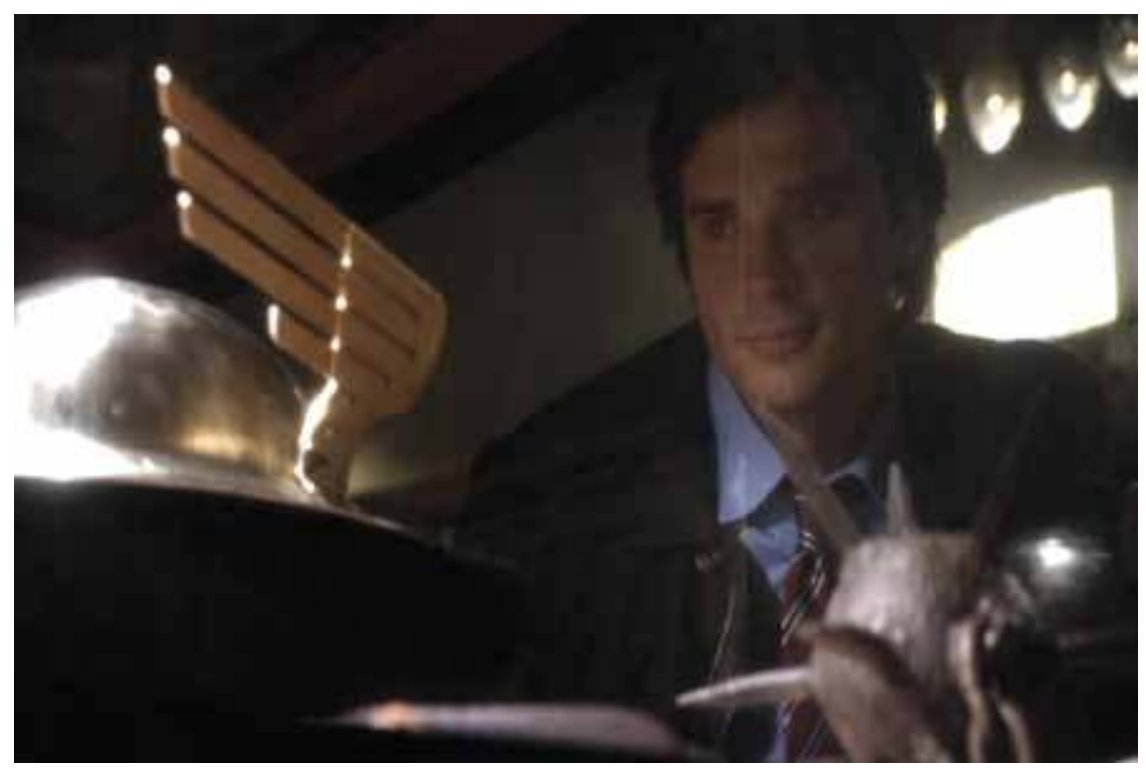

Figure 15. Smallville, 'Absolute Justice'

(Warner Bros. Television, 2010).

helmet, Green Lantern's power battery, Hourman's hourglass and Mr. Terrific's 'Fair Play' weight belt. He lingers over Hawkgirl's mace and cracked helmet, a reminder of the fatal blow that killed Hall's beloved wife, Shayera. Framing Clark within the display case and then gazing upwards at a painting of the JSA team ranged around their boardroom table creates visual and emotional continuity between viewers, Clark and the defunct JSA project, nostalgic moments that resist within the culture of superheroism the politics of difference from which Smallville garners its storylines (cf. Huq).

As in 'Skinwalker,' the final seasons of Smallville engage political themes through melodrama. In 'Ultimate Justice,' Dr. Fate tells Lois that 'You are the one he will need; he is the one you will need [...] The saviour, the one who will heal us all, the sentient power.' In the first episode of the final season, 'Lazarus' (24 September 2010), Lois accepts a promotion to the Daily Planet's African desk because she is afraid that a girlfriend will distract Clark from his greater calling. Concerned for her safety, the ever-suffering Clark accepts her decision with outward equanimity. The lovers are at an impasse. At once a sign of heroic stoicism, Superman has traditionally been wary of the kryptonite of romantic attraction and female agency (Farghaly, vii-xiv, 2013b). As Umberto Eco unequivocally relates in his essay 'The Myth 
of Superman,' marriage with Lois is a 'step toward his death' (18; cf. Collins). But in a television series that furnishes its diverse audience with strong female characters who, like its male protagonist, are empowered by their emotions, Smallville's hybrid action/SF/melodrama format clears a path for Clark and Lois to escape the genealogical snares threatening to mire the post-9/11 Superman in conservative gender politics. Karin Hirmer contends that as 'a moral center, the All-American Girl for the All-American Hero,' Smallville's Lois Lane is 'largely involved in Clark's eventual "becoming"' $(250,252)$. Nadine Farghaly also points out that Lois's journey of self-individuation parallels Clark's, enabling her 'to help create Earth's greatest superhero' (296, 2013a). Lois is thereby instrumental in resolving the problematic origin story scripted in the Kawatche petroglyphs. By demanding equal partnership with Naman, she tips the scales in the fight against Sageeth.

In the episode 'Shield' (1 October 2010), archaeology furnishes a melodramatic context in which to reconcile romantic fatalism with audience expectations for gender equality. The episode sees Lois in Egypt covering a story on the discovery of a cache of artefacts dedicated to the goddess Isis. In the teaser Lois enters a tent and looks longingly at a papyrus record of the Egyptian queen and her husband Osiris. The camera refocuses on a shadowy figure outside the door. 'They were star crossed lovers.' The camera racks to a low-angle shot of Carter Hall stepping into the dusky light. 'I guess you never know what fate has in store for you.' Michael Shanks's persona as Stargate SG-1's intrepid Daniel Jackson authorizes Hall's sovereignty in an Orientalized domestic mise-en-scene of veiled women serving tea and bearing washing water. In this environment the archaeologist relates the story of Isis and Osiris, of the love that inspired the ancient queen to brave the terrors of the underworld in search of her husband. The Hall-mark of Hawkman's own eternal romantic cycle of reincarnation with and separation from Shayera, the Egyptian myth helps Lois put aside her personal fears and embrace her destiny as Clark's partner. 'With every great relationship comes a great burden,' Hall says, 'and the strength to carry it [...] He can't do it without you. You're his Shayera.' By bringing Lois to the emotional precipice, Hawkman offers a hopeful, romantic resolution to the political discord that destroyed his golden age dream of a better world.

The trope of 'star crossed lovers' intersects with the larger story arc unfolding in season ten. The secondary narrative in 'Shield' concerns Jor-El's warning to Clark that an apocalypse is at hand, that a 'dark force' (i.e. Darkseid) is rising with the power to turn his son's self-doubts against him, rendering the Kryptonian the ultimate weapon 


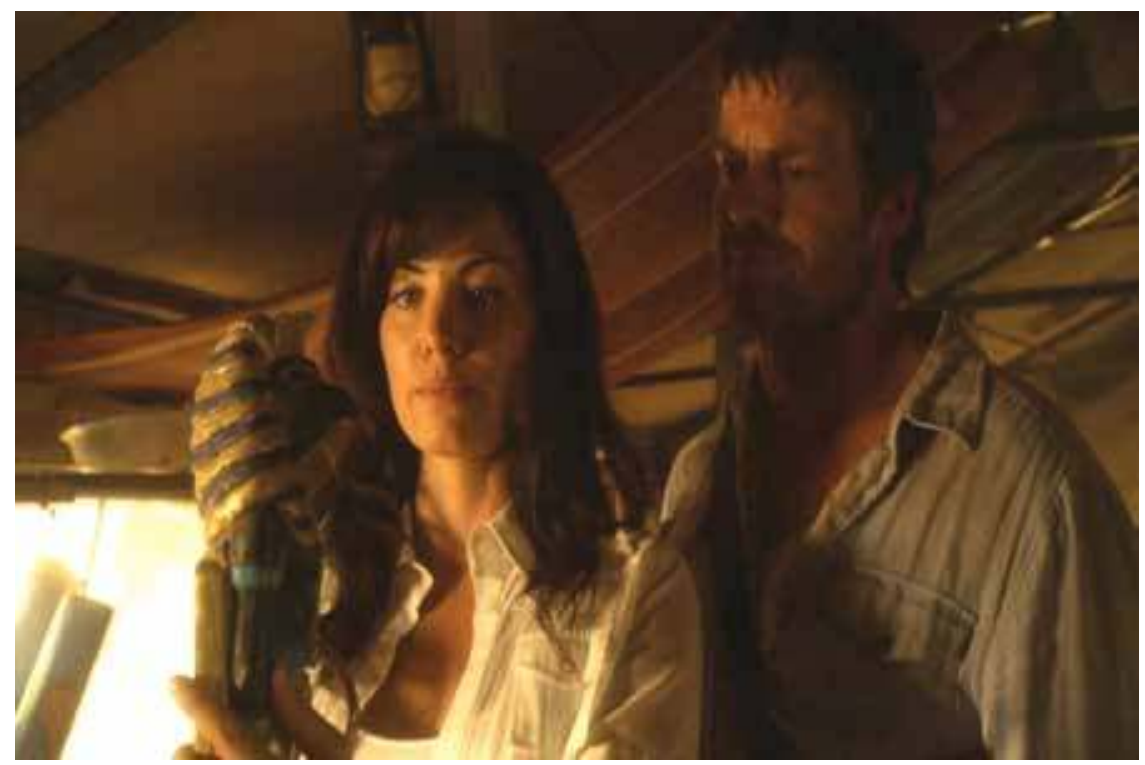

Figure 16. Smallville, 'Shield' (Warner Bros. Television, 2010).

against his adoptive home. In an atmosphere of rising paranoia, the secret work of Checkmate garners constitutional legitimacy with the establishment of the Department of Domestic Security, which is tasked to enforce the new Vigilante Registration Act. An obvious analogue of the Department of Homeland Security and the Patriot Act, the DDS is accorded extraordinary powers of surveillance, rendition and interrogation (cf. Cole; Hart; and Schulhofer). Its first victim is Oliver Queen (aka 'Green Arrow,' played by Justin Hartley), who registers only to be detained and waterboarded in an attempt to learn the secret identities of his colleagues ('Patriot,' 19 November 2010). These tensions reach critical momentum in the final episode before the mid-season break, 'Icarus' (10 December 2010). In an episode in which Daily Planet employees are being screened for weapons, Clark proposes to Lois. Lois admires her engagement ring in front of a threat advisory notice. DDS agents ransack offices, kick in the front door of the Kent farm, and arrest Clark's friends without warrant or charge. Daily Planet editor and vigilante sympathizer Tess Mercer (Cassidy Freeman) is warned by cub reporter Cat Grant (Keri Lynn Pratt) that 'If you don't get with the majority agenda soon, somebody's going to notice.' Under control of the DDS, television becomes a mass media platform for spreading fear and inciting violence against superheroes. Darkseid's henchman, DDS chief Lt. Gen. Slade Wilson (Michael Hogan), issues a call to arms: 


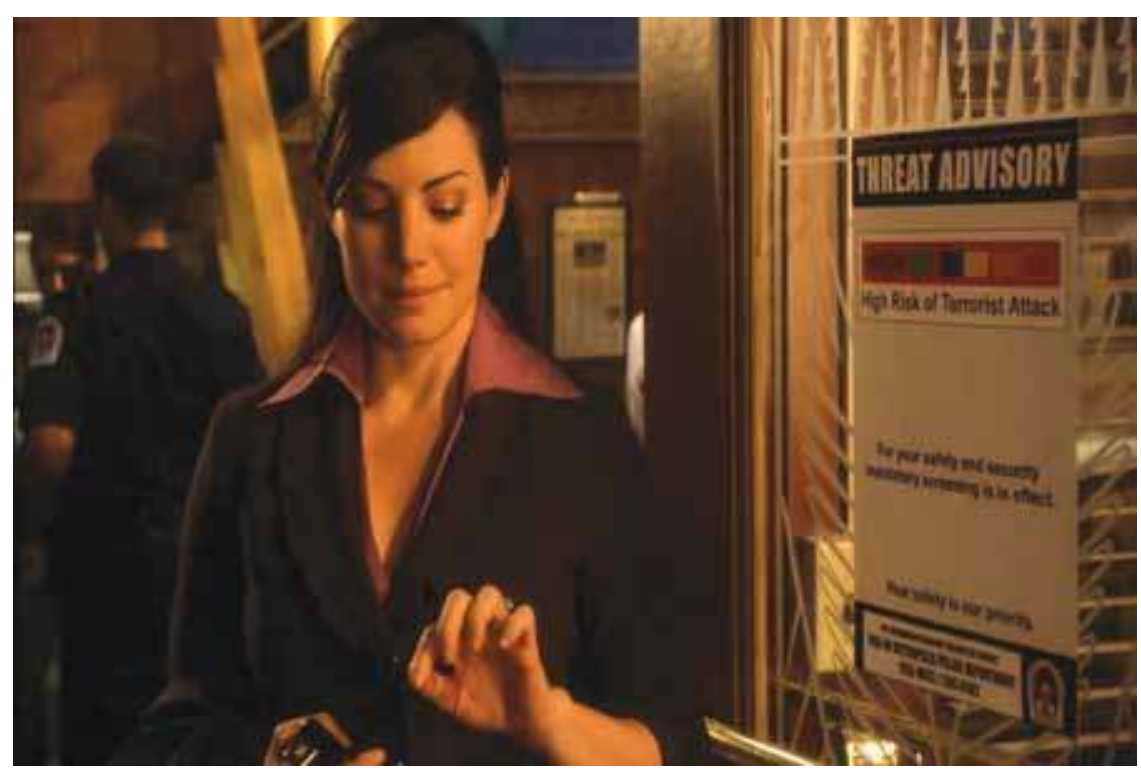

Figure 17. Smallville, 'Icarus' (Warner Bros. Television, 2010).

'Too many civilians have been left feeling unsafe in their own homes. Too many people have suffered, while too few vigilantes have been brought to justice. It's time these terrorists paid for their crimes.' Critical of the ways news media manufactures consent for aggressive foreign policies and national security, Smallville issues an implicit warning against governmental incursions upon the very liberties supposedly targeted by terrorist organizations (Leone and Anrig, 7-8).

In 'Icarus,' Carter Hall undertakes one last mission as Hawkman: to save the world from Darkseid by saving Lois and Clark's relationship. In the episode, Slade Wilson captures Lois after discovering her searching his office for evidence of Darkseid's scheme to brainwash the American people. Hawkman rescues Lois but is stabbed in the back during the escape. Embraced in his flaming wings, they fall to the streets below. Dying, Hawkman affirms the revitalizing power of romance contained in the imagery of their fall, the immolation of Cupid and Icarus. Clark and Lois exchange a knowing glance when Hall with his final breath says, 'You hold on to her, because there has to be a balance, Clark. We can't do what we have to do with an emptiness in our heart [...] I'm sorry I won't be there to help you fight the darkness, but you have all the help you need.' Though Hall's death-bed speech encodes romantic attraction within the gendered binary of feeling/action, it nevertheless affirms Lois's new destiny to fight injustice through active political and 


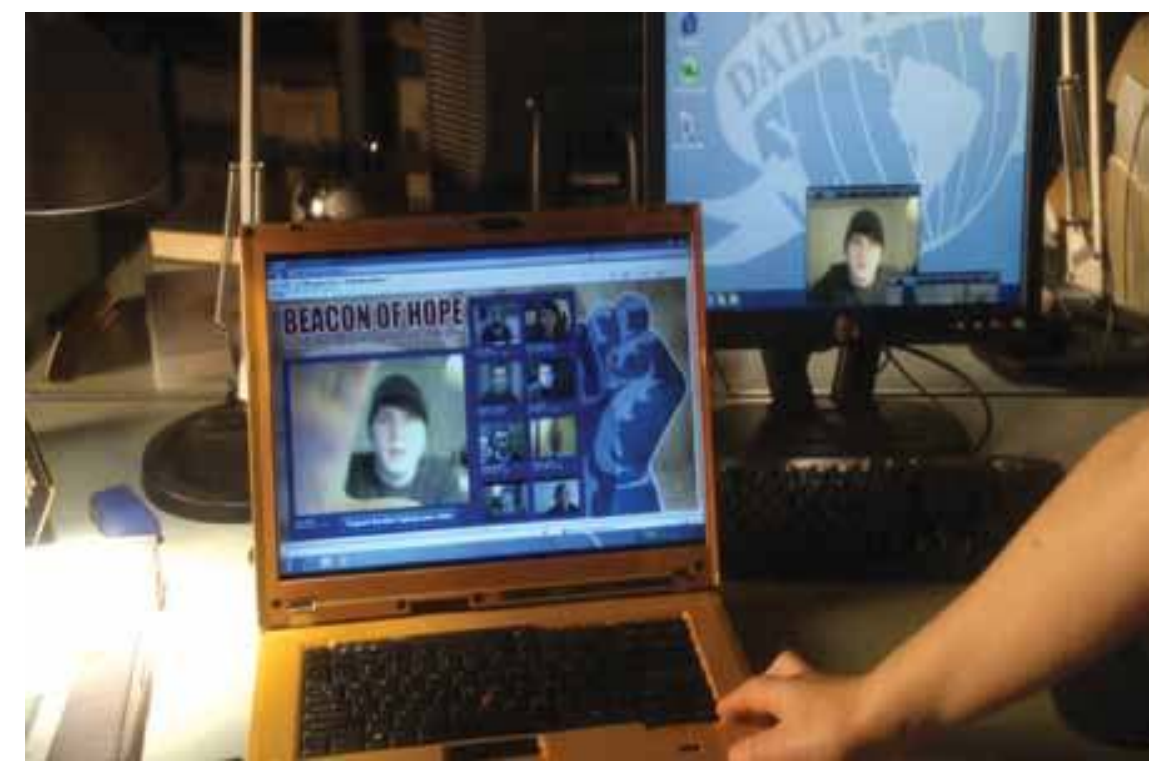

Figure 18. Smallville, 'Beacon' (Warner Bros. Television, 2010).

civic engagement alongside her partner. In a gesture that pays homage to Smallville's active online community, Lois directs her vocational talents towards rallying support for vigilantes in print and social media in a plebiscite to decide the fate of the VRA ('Beacon,' 11 February 2011). The episode features Skype conversations of people supporting heroes as role models of responsible citizenship. The VRA is voted down in a show of solidarity that is instrumental in bolstering Clark's confidence so that he can resist Darkseid's corrupting influence. Empowered by the support of Lois and the community of citizens willing to set aside their fears of difference, Clark musters the courage to fly-cue the John Williams Superman theme-and catapults up, up and away to repel the planet Apokalips, the fiery version of Nibiru sent by Darkseid on a collision course with Earth ('Finale,' 13 May 2011).

However spectacular and cathartic, the preordained conclusion of Clark's journey prompts dedicated viewers to parse the ellipsis in Clark's class presidency speech, the hesitation between 'truth and justice' and the 'American Way.' For the much-anticipated image of Superman policing the skies is certainly problematic for a series whose protagonist is grounded in real-world problems of corporate power, gender equity, civil rights and sexual preference in dialogue with its fan base. Series endings are often unsatisfactory, and in the finale Clark is simply returned to his native comic book habitat. His high school friend Chloe 


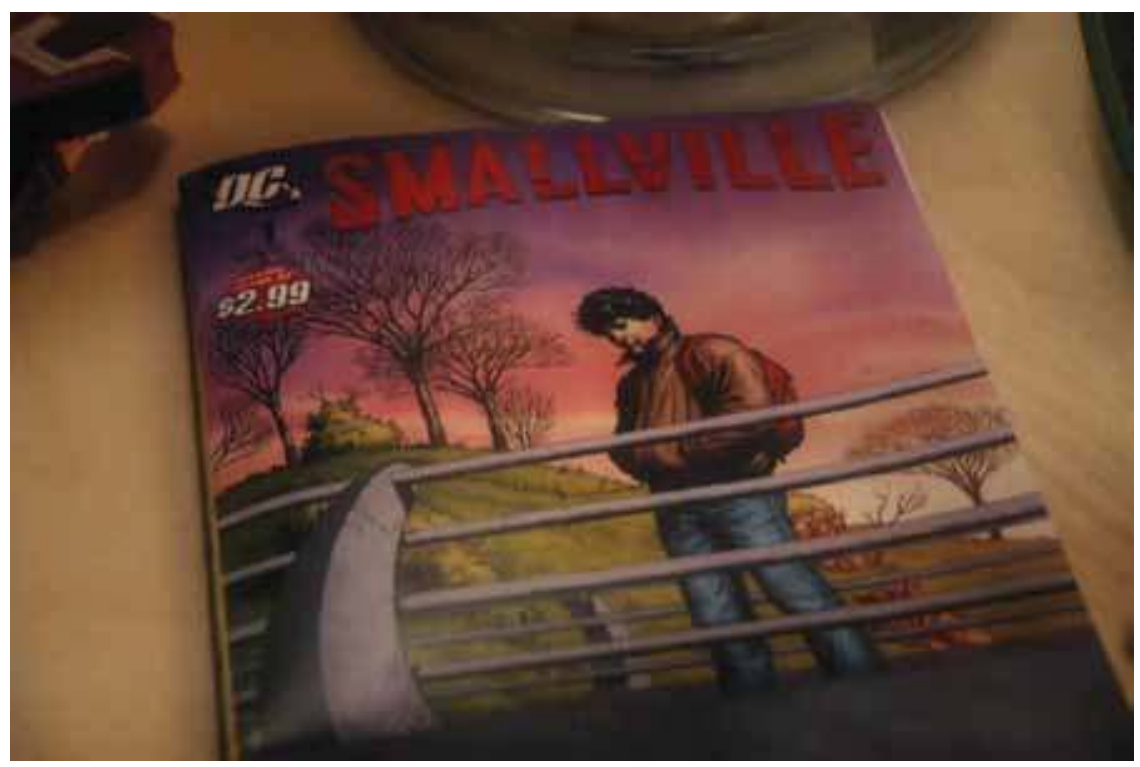

Figure 19. Smallville, 'Finale' (Warner Bros. Television, 2011).

Sullivan (Allison Mack) reads an issue of DC's Smallville comic to her child at bedtime, a cute product placement advertisement for the DC/ WB's bimonthly comic released between 2003 and 2004. But the way Smallville raises questions about the nature of responsible citizenship through media archaeology of its popular culture hero makes it difficult to reconcile Smallville's Clark Kent with his comic book progenitor. And we must remember, too, that any monument to the American Way in Smallville bears the scars of Kyla's sacrifice of her life and her heritage to satisfy both the ontological demands of the Superman franchise and the epistemological tautology of ancient astronaut speculation from which the series remodels its protagonist. If, as Otto Friedrich puts it, 'One of the odd paradoxes about Superman [...] [is] that while he is a hero of nostalgia, the constant changes in his character keep destroying the qualities that make him an object of nostalgia' (74), then Smallville's contribution to Superman lore is that it demands rigorous examination of the nature of heroism at the nexus of adolescent dramas of individuation and civic engagement.

The final section of this study, 'Cyborg Sites,' entertains similar questions about origins and endings in Ronald Moore's Battlestar Galactica and Ridley Scott's Prometheus. Both narratives are structured on a search for a mythical home world by following archaeological breadcrumbs scattered across the cosmos; both trouble origins through the cyborgs 
along for the ride. In each, material culture is a sign system for understanding the shared, embodied experience of materiality in time. Like Smallville, these SFFTV artefacts manufacture 'mythical narrative[s] of perpetual self-renewal' (Hantke, 2012, 389) for franchises that ultimately cannot reconcile desires for stable futures with the politics of origin. For the cyborg is always wary of such human endeavours. 


\section{Part 3}

\section{Cyborg Sites: The Case of A.I. Artificial Intelligence}

Perhaps the SF of this era of cybernetics and hyperreality will only be able to attempt to 'artificially' resurrect the 'historical' worlds of the past, trying to reconstruct in vitro and down to its tiniest details the various episodes of bygone days: events, persons, defunct ideologies-all now empty of meaning and of their original essence, but hypnotic with retrospective truth.

Jean Baudrillard ${ }^{1}$

The ones who made us are always looking for the ones who made them.

Gigolo Joe

In her discussion of 2001: A Space Odyssey, Zoë Sofia argues that the enigmatic appearance of the Star Child marks the completion of an evolutionary life cycle that began with humanity's first encounter with technology and culminates in an embodied fusion with it. A 'biomechanism, a luminous creature of special effects technologies, a cyborg capable of living unaided in space,' the embryonic astronaut, she says, is a curious amalgamation of material science and political mediation, a "special effect" of a cultural dreamwork which displaces attention from the tools of extermination and onto the fetal signifier of extinction itself' $(52,54)$. Having joined the waltz of time that began with Moon-Watcher's euphoric bone toss across time and space, it is unclear

1 Baudrillard, 1991, 310. 
whether this being conceived by the forces that delivered David Bowman beyond the infinite has returned to save or destroy its birthplace, or has some other, altogether unfathomable alien purpose. Suspending discrete chronometric categories of past, present and future, the cyborg actor is instead a figure for contemplating the (often destructive) epistemological directives of our technocratic culture.

From a disciplinary perspective, Stanford archaeologist Michael Shanks also appreciates the cyborg's composite identity in the organic, material and social worlds. Like the Star Child, the cyborg is a poignant signifier of mutability. The 'decay of the artefact,' he asserts, 'is a token of the human condition. The fragment, the mutilated and incomplete thing from the past, brings a sense of life struggling with time: death and decay await us all, people and objects alike. In common we have our materiality' (Pearson and Shanks, 93). This syncretic view of a life cycle that envelopes things and people raises, he says, the haunting 'spectre of the cyborg,' the 'epistemological threat [...] [that if] the object world is collapsed into the social world [...] it might appear that objective standards of truth are lost and relativism results' (98). The archaeologist asserts, 'We have always been cyborgs,' a revision of Donna Haraway's radical position that 'we are cyborgs' (150)

rooted in the argument and evidence for the coevolution of culture and biology, that for as long as we have been our human species, and probably before that, (material) culture and biology have been part of the same evolutionary process. Given also the duality of structure, the way an action such as making is distributed through socio-cultural structures, past and future, people have always been embroiled in mixtures of material and immaterial forms and systems. With respect therefore to both people and things, we should adopt a relational, distributed ontology. Connections, internal relations, make an artifact or person what they are; we find ourselves in others. People have always been prosthetic beings, sharing their agency with others, with things and processes beyond them. We have always been cyborgs-hybrid beings, humanmachines. (Olsen et al., 191)

Shanks's reflexive archaeological programme thereby extends the cyborg debate from engineering, biopower, environmentalism, animal rights and gender politics to the material and historical conditions in which these technological and social issues circulate.

This introduction to 'Cyborg Sites' takes the form of a case study: an examination of the collapse of the organic and the material in Steven 
Spielberg's A.I. Artificial Intelligence (2001), a reading that exposes the director's outwardly nostalgic remediation of the Pinocchio myth ${ }^{2}$ to the kinds of critical questions Shanks asks about the shared life cycle encompassing people and objects. The story chronicles the travails of David, an artificial being who wants to be made into a real boy so that his mother will return his (programmed) love for her. The film's tag line 'His love is real, but he is not' encapsulates the central dilemma for a feeling machine. David is positioned at the heart of ontological debates about the nature of reality in an age of advanced bio-medical and reproductive technology falling inexorably into an apocalyptic future in which humanity is survived and remembered by its post-human offspring, who excavate in the far-flung future the ruined mise-enscene of the film and the mise-en-abyme of David's idyllic memories of his mother.

The sense of déjà vu evoked by Spielberg's cyborg returning to his birthplace arises in part from A.I.'s origin story. After decades of wanting to adapt into a feature film Brian Aldiss's story 'Supertoys Last All Sumer Long' (1968), for which Kubrick bought the rights in 1983 (Loren, 211), Kubrick asked Spielberg in 1995 to complete the project. ${ }^{3}$ Kubrick's main obstacle was that cinematic technology lagged behind his vision of a realistic cyborg character. Kubrick's legacy to Spielberg, whose Jurassic Park (1993) convinced the elder director that an artificial actor was possible, is a film that deals explicitly with the problems of what happens when technology catches up with our dreams, when film is itself symptomatic of the cascading social trauma A.I. explores through the trials of David and his cyborg friends. Like 2001, the bio-material figure of the cyborg in A.I. articulates complex relationships between memory and extinction. A.I. chronicles two extermination events, two ways of experiencing archaeological time. The first is through the artificial boy himself, who represents the end of fertility in a world collapsing into environmental unsustainability. We experience with David the imagined joys and the real horrors of artificial people in a world whose social structures are delimited by its strictures on biological reproduction. We are then abruptly cast like David Bowman into a 2,000-year proleptic leap into a world in which we are survived by artificial life forms who glean an ironic past through the artificial boy's memory and his interaction with his 'mother,' whom the aliens clone from a surviving strand of

2 Cf. Morrissey on Spielberg's adaptation of the Pinocchio story.

3 Elaborate concept drawings by Chris Baker and facsimiles of Kubrick's production notes and treatments have recently been made available in a folio volume (Harlan and Struthers). 
her hair. In the short resurrection scene with which the film concludes, the narrative folds back onto itself as we watch, like Bowman regarding his own death bed, the imagined incarnations of our future selves rummaging among the shards of their long-forgotten origins, which is to say our imminent future stored in the memories of artificial beings.

These distinct epochs pivot upon a geographically and historically specific image of ruin. Released in June 2001, the film is itself an archaeological record of the future it documents fictionally. Flyover scenes of the ruined Twin Towers rising out of a flooded and uninhabitable Eastern Seaboard are the dystopic analogue of cyborg struggles for actualization. While the visual reference of the WTC in ruins just a few months prior to $9 / 11$ is entirely coincidental with the attacks, it is, like the beached Statue of Liberty in Planet of the Apes, a prognostic image, an archaeology of the future. The towers are poignant reminders of the entropic forces that consign the lessons of global sprawl to the watery depths. A.I. makes us remember (and in a sense pre-remember) through the figures of David and the Love Mecha Gigolo Joe (Jude Law) that this site of corporate control is a beacon sent from a post-apocalyptic future that draws humans and objects together, the cyborg world looming just beyond the horizon. Like the Forbidden Zone in Planet of the Apes, the Restricted Zone for Mechas holds the truth about the origins of a species born out of the disasters wrought by global capitalism. Though drowned-and later frozen-the Twin Towers remain perfect mirrors of each other, indifferent and closed off from the globalized world order from which they were conceived, a perfect singularity that holds in the balance David's faith in his uniqueness and the fatal knowledge that he is one of the many simulacral boys available to fulfil Monica Swinton's (Frances O'Connor) emotional void. The site of origin is the end of a worldview that David dissimulates and ultimately survives physically and emotionally as a gift to the archaeologists of the future, the Super Mechas. From these ruins the co-evolution of biological and artificial life radiates: the Twin Towers are an ironic Ellis Island through which cyborgs emerge as un-naturalized citizens.

The geopolitical complexion of David's manufacture is dramatized in the film's second act, which concerns his quest to become a real boy after Monica abandons him in the woods. Accompanied by Gigolo Joe, who chaperones the child through the world of experience and human-Mecha relations, David's voyage is an odyssey that leads him back to his birthplace, Dr. Hobby's (William Hurt) android factory, Cybertronics in Manhattan. Never dissuaded from his desire to be realwhich seems to be an unforeseen consequence of his programming as a mother-loving son-David is an innocent who cannot look directly 
or intelligibly like Gigolo Joe upon the cruelties latent in his function as a surrogate child. Instead, like a 'real' boy, David internalizes the oppressive nature of human attachments in his own desires for his mother to reciprocate his unconditional love for her. From an archaeological perspective, two related scenes expose David to what Despina Kakoudaki characterizes as the 'nihilistic tendencies' devolving from David's ontological dilemma that he is manufactured but psychologically indistinguishable from a real boy (186). His crisis epitomizes the tension between what she calls the 'paranoid' and 'performative' models of cyborg narrative:

If paranoia inspires storylines that depend on stable definitions of human and nonhuman and showcase the disruptions that emerge when one does not police these definitions adequately, in stories that engage forms of performativity the search to define the human appears as a more ambiguous and open-ended process that often returns to insights about the arbitrariness of distinctions. (175)

In A.I. these storylines merge at a site-specific location. The group stumbles across an uncanny scene: a midden heap of robotic parts left to bait runaway Mechas for cannon fodder in Lord Johnson-Johnson's (Brendan Gleeson) carnival show, 'Flesh Fair.' In one of the film's most pitiful sequences, outmoded Mechas rummage through cast-off appendages, looking for prosthetic replacements for their worn bodies. Here David is exposed to the social as well as material conditions of his kind. Images of fear, slavery and service to human needs and desires are cast onto artificial others: nannies and doctors, construction workers and cooks. As a child, David cannot reconcile his manufacture with their fragmentary existence, their parody of assembly-line production, this anti-teleology of progress that is literally in his cybernetic DNA but incompatible with his faith in the superiority of humans that governs his insistent sense of his own uniqueness as a loving son. Fittingly, it is here that he encounters Gigolo Joe, a character defined by his very name for a human need that has outlasted, it seems, human ability. Like humans, Mechas are subject to a murderous symbolic order that seeks perfection beyond death. As a visible sign of human entropy cast into terms of the cyborg other, the cybernetic boneyard attempts but ultimately fails to maintain the distinction between object and subject. As Michael Shanks reminds us, our performances of selfhood reveal that 'in common we have our materiality' (1998, 19).

The material politics of the film are most affective in the scene of androids helping one another survive by scavenging. Acting according 
to what appears to be their own desire to save each other beyond the dictates of programmed service to humans bears the hallmark of a species evolving towards self-individuation, an ironic genesis at the site of decay that serves the sinister purpose of gathering subjects for torture and dismemberment at Flesh Fair. The ultimate scavenger of society's detritus, Lord Johnson-Johnson is a scrap dealer who orchestrates a spectacle of marginality from the margins, a sensational paratextual arena of the politics of replication far away from the tranquil domestic rituals of the Swintons' comfortable suburban life. The point behind these 'grotesquely dramatic enactments of abjection' is to 'maintain the boundaries of the human, [to] separate the non-human where it threatens to compromise these borders' (Loren, 224). But David's presence-his performance of childhood innocence-ultimately undermines the social iniquities that Flesh Fair purports to address. The crowd (mis)recognizes David as a child, which allows the party to escape, dispersing the cyborg thereafter into the social world. The David simulation has at this moment obliterated the original by standing in for all children. In this regard, the carnival is transformed into an exhibition, a freak show that shares its genealogy with World's Fairs and expositions of technology. In his backward-looking desire to recover the human from the machine, Lord Johnson-Johnson ironically orchestrates a pageant of material progress from which the cyborg may recognise, claim and ultimately reject its own origins.

This exhibitionary sensibility resurfaces when the friends fly to Cybertronics headquarters. In the laboratory of Dr. Hobby, David encounters himself, one of many identical artificial boys created in the image of Dr. Hobby's lost son for every couple who has lost theirs. This has disastrous consequences for David's psyche, which cannot reconcile his hard-wired love for his mother with the ontological condition of replication. When David destroys David in a re-enactment of Cain's murder of Abel to secure his mother's love for himself, he unsuccessfully tries to escape the entropic logic of the Twin Towers that still stand as the ruling paradigm of his purpose and identity. David has come to the point in his existential journey in which he is confronted, like many people, with the realization that 'the danger of human-likeness revolves around what the copy reveals: that there is no certainty in the original' (Kakoudaki, 185). David murdering David by striking off his head with a lamp is an inherently futile attempt at self-actualization reminiscent of Flesh Fair's entertaining destruction of objects that threaten Lord Johnson-Johnson's paranoid definition of (the organic) self. In the case of A.I. this dismemberment precipitates David's self-murder by throwing 
himself into the ocean encircling Cybertronics and the Twin Towers. David's suicide marks the limits of his struggle to imagine utopian otherness in a world in which the reality principle has become overrun by its own simulations. The 'personal' tragedy for David is that love itself is a simulation, such that the object of his affection, his mother, can only be returned to him as a figment of simulation technology. Jumping into the watery oblivion represents the failure of the symbolic order to transcend the horror of replication that he, unlike real people, must accept as a condition of his life.

The third act, which features the return of the Super Mechas to the frozen wasteland of New York City, their awakening of David and Teddy, and the reanimation of Monica, shifts from one version of the future to another, from one SF fabula to another. For an audience perhaps as traumatized as the attendees of Flesh Fair by the film's spectacles of child abuse, the wistfully hopeful fairy tale extended to David in the final act is nostalgic at best and sentimental at worst. After hearing the long-awaited words 'I love you' from his mother, David falls asleep to Ben Kingsley's soothing voiceover, a promise that he is drifting 'to that place where dreams are born.' With their advanced cloning technology, the Super Mechas rescue David from the frozen symbolic order only to re-establish the utopian myth of transformation incarnate in the Pinocchio story. Spielberg's sadly comforting, yet ultimately misremembered past conjured from David's fairy tale dreams of maternal devotion holds out two distinct conclusions, two discrete interpretations that correspond in broad strokes with the futures of simulation propounded by Jean Baudrillard and Donna Haraway. In 'Simulacra and Science Fiction,' Baudrillard argues that the era of hyperreality signals the 'end of SF.' In the cyber age

it is the real which has become the pretext of the model in a world governed by the principle of simulation. And, paradoxically, it is the real which has become our true utopia-but a utopia that is no longer a possibility, a utopia we can do no more than dream about, like a lost object [...] We can no longer imagine other universes; and the gift of transcendence has been taken from us as well. $(311,310)$

The Super Mechas, yearning for their own origins, entrust their desires for historical certainty in their human forebears. The cultural conditions in which the referent is lost to nostalgia in a sea of hyper-mediated signs is the malaise the Super Mechas share with David. Their 'lost object' is humanity itself, whose reality principle lay in a half-remembered 
fairy tale, the imagined powers of the Blue Fairy refracted through the tangled circuitry of a cyber boy's child-like mind.

But if, like Lord Johnson-Johnson, Baudrillard attempts to close the door on the cyborg future, then Haraway opens another onto a new frontier beyond the awful apocalyptic telos of the West's escalating dominations of abstract individualism' (150-51) that the fearful figure of loss of human agency holds for Baudrillard. According to Istvan Csicsery-Ronay, for Haraway SF affords 'the necessary hopefulness that comes with knowing that neither the initial conditions (the origin) nor the outcome (the apocalypse) of any process, no matter how highly rationalized, can be determined' $(1991,394)$. This perspective also informs the cyborg archaeologists' reading of the bygone Anthropocene. As in 2001 (and Battlestar Galactica), the appearance of these cyborg beings is the climax of a vast home voyage, a nostos. Their interpretation of what they uncover is inseparable from the material and technological conditions of their very composition. Instead of Baudrillardian harbingers of apocalypse they appear as emancipatory figures, drawing from David traces of a hope that seems to have survived as a condition of his cyborg identity. Immortality - the denial of death-that fuels the human desire for progress is moot for them. While interested in origins, they are beyond death, implying that they are not beholden to myths of origin and can thereby, as Haraway states in her 'Manifesto,' thrive 'outside salvation history' (66) and the totalizing mythology that 'legitimates the patriarchal, capitalist, heterosexist quest for reunion with a Mother Nature it was alienated from at The Origin' (Csicsery-Ronay, 1991, 397).

These post-human beings embody what is for Baudrillard and Haraway SF's social vocation, communication (Csicsery-Ronay, 1991, 389). They are in fact rendered as communication. They encounter in David a version of humanity that has as its lost origin the emotional investment in sharing, a reiteration of cyborg compassion enacted at Lord Johnson-Johnson's midden site. Clearly nostalgic for a lost age survived by an artefact crafted to fulfil a human need, the Super Mechas are spellbound by David's utopian drives. They retain the hopeless wish to commune with beings displaced by the ersatz experiences conjured from the boy's programming. Their desire for the lost humans-'certainly human beings must be the key to the mysteries of existence'-is articulated in a manner of speech that is physically awkward for beings who retain only animated skeuomorphic traces of human facial features. The process of recollection-here through archaeological re-collectionis always contingent and fluid. The critique of human relationships in the global capitalist state in the final scenes is framed by archaeologists of the future, who, like biological television sets, communicate through 


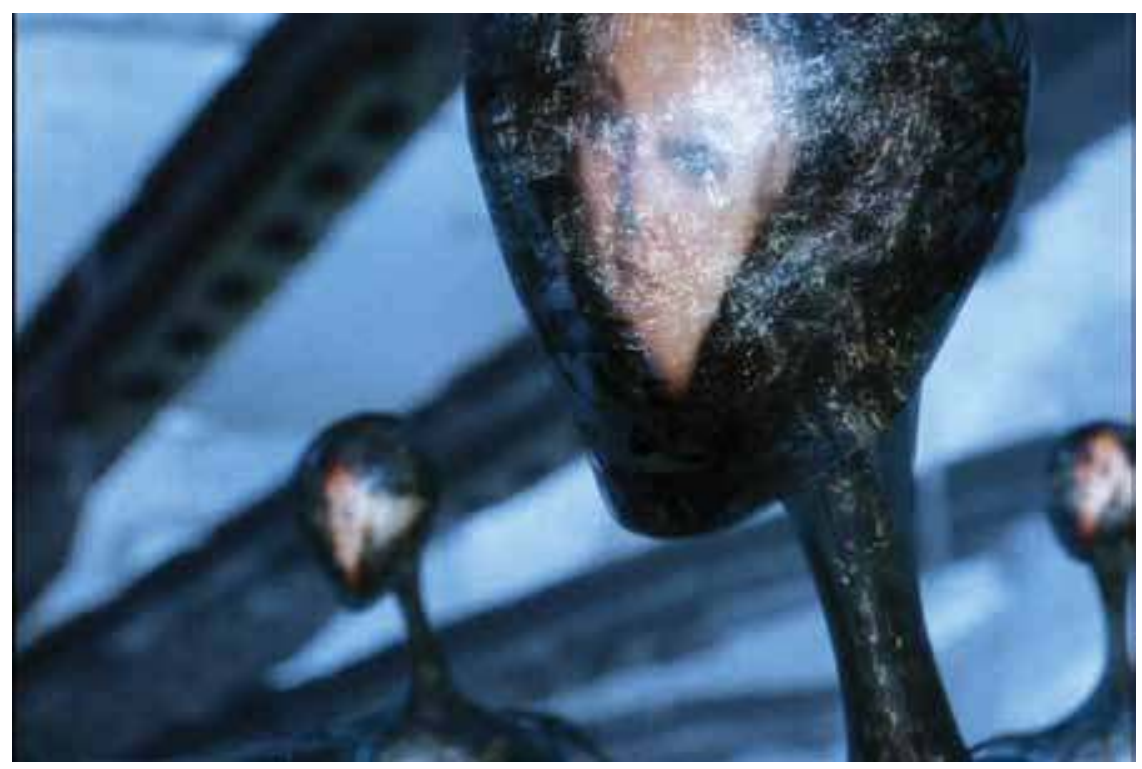

Figure 20. A.I. Artificial Intelligence (Warner Bros., 2001).

images and sounds projected onto and through their bodies. Community is created when these aliens join hands and share their knowledge in a way that replicates in kind through cinematic imagery the familial logic programmed into-but ultimately withheld from-David. The Super Mechas are a network, an assemblage in a new set of cultural and technological relations: the dreams of human connection are realized in these beings, the dream of David's purpose to love his mother. The film thereby returns the future to the 'precession' of simulacra and cleanses it of the horrors it once held for their cyborg ancestors.

Ultimately the film does not and cannot offer any definitive answer as to what these future artificial people learn from their excavations of a material world coeval with David's memories and dreams. All we truly know lies within the diegetic realm of the film wherein Gigolo Joe's prophetic words come true: 'We are suffering for the mistakes they made because, when the end comes, all that will be left is us.' Can the Super Mechas understand the irony of David's idyll? Do they watch with pity or detached interest? While answers are not readily forthcoming, it seems clear that their empathetic abilities forecast the revolutionary energy Haraway ascribes to the cyborg. For Spielberg's cyborgs are also filmmakers who produce from David's memories a short feature characterized by 'retold stories [...] that reverse and displace the hierarchical dualisms of naturalized identities [...] [by subverting the] central myths 
of origin of Western culture' (175). The Super Mechas embody if they do not explicitly name the 'condition of freedom from the illegitimate categories of "nature" (race, gender, species, kingdom) - a freedom that can only emerge with the destruction of those rationalities and of the mythologies of essential identity' (Csicsery-Ronay, 1991, 396). While certainly revisionist, the cyborg history in A.I. transcends the destructive mythologies of essentialism incarnate in origins by exposing origins not just to their apocalyptic finale but to a utopian frontier in which apocalypse is a revolutionary rather than world-ending force. A.I. realizes Michael Shanks's prognostication that archaeology is the preeminent science in the cyborg age, because the cyborg cannot dissociate object and subject. The Super Mechas offer a version of cyborg storytelling that questions the binaries of the real and unreal, the self and other, gesturing towards a narrative model that, as Lisa Yaszek relates, 'marshals other representational strategies that undermine the tragic or ironically detached tendencies of postmodern writing itself, replacing them with narrative trajectories that end toward a certain cautious hopefulness' (2002, 15).

It is certainly arguable that the Super Mechas fall entirely within the purview of Haraway's cyborg canon, yet they do exhibit a genealogical tendency towards the transformation of subject/object into an archaeological practice that challenges even as it aesthetically mirrors the political instabilities of the world they observe through David. David is a found object lost in time by aliens whose physicality, which is the very source of David's anxieties about the nature of reality, is their triumph over the discourse of objectification. Having evolved beyond the historical and material conditions that make fairy tales necessary forms of narrative closure for David-and for we human spectators of our future selves-Spielberg's archaeologists accord partial liberation from David's decidedly human tragedy, his fatal attraction to origins and ends.

In the chapters that follow, the cyborg offspring of space-faring humanity-namely the Cylons and another David-likewise embark on existential journeys through archaeological investigations of their origins in human technology, excavations that expose the material conditions of the cyborg birth to the politics of simulation in which we are constantly remaking and unmaking ourselves. Like those in A.I., archaeological expeditions in Battlestar Galactica and Prometheus uncover ironic origins from which to create alternate archaeologies of the future, which is to say, disruptive histories of our current geopolitical investments in apocalyptic teleology and technology. 


\section{Chapter 7}

\section{Battlestar Galactica}

There are those who believe that life here began out there, far across the universe, with tribes of humans who may have been the forefathers of the Egyptians, or the Toltecs, or the Mayans [...] Some believe that there may yet be brothers of man who even now fight to survive somewhere beyond the heavens.

Opening narration, Battlestar Galactica (1978-79)

What is crucial to such a vision of the future is the belief that we must not only change the narratives of our histories, but transform our sense of what it means to live, to be, in other times and different spaces, both human and historical.

Homi Bhabha ${ }^{1}$

The opening sequences of the Battlestar Galactica miniseries are steeped in dramatic irony (2003-09; 8 December 2003). On the very day the eponymous Colonial vessel is scheduled to be decommissioned and turned into a Cylon War museum, 'humanity's children' destroy Armistice Station and decimate the Twelve Colonies. The first shot aboard Galactica is evocative of this irony. In an elaborate three-and-ahalf-minute continuous take, the audience is taken on a video tour of the battlestar. We join a news crew documenting a group of dignitaries being led by a Cylon sleeper agent, Aaron Doral (Matthew Bennett). Doral calls attention to Galactica's gritty, old-fashioned functionality, to things that seem 'antiquated to modern eyes, phones with chords, awkward manual

A version of this chapter was originally published as 'Does all this have to happen again? Excavating Heritage in Battlestar Galactica' in Science Fiction Film and Television 7.1 (2014), 1-29.

1 Bhabha, 256. 
valves, computers that barely deserve the name.' Galactica is, he says, 'a reminder of a time when we were so frightened by our enemies that we literally looked backward for protection.' The clunky artefact of the Cylon Wars contrasts sharply with the sleek CGI Cylon centurions and the ethereal back-lit, runway model aura of Model Six (Tricia Helfer) on Armistice Station. The viewer is thus positioned within this long take at a critical moment of temporal fragmentation, signalled by the material and televisual conditions of the antagonists' distinct environments.

Foregrounding the materiality of $B S G^{\prime}$ s mise-en-scene, the sequence also alludes to the ways the show registers political tension through historical discourse. Appearing three times in the shot, Commander William Adama (Edward James Olmos) plays a crucial role in this meta-historical spectacle. He practises a speech for the decommissioning ceremony, an event that also marks his retirement. 'The Cylon War is long over, yet we must not forget the reasons why,' he begins, before being interrupted by Kara 'Starbuck' Thrace (Katee Sackhoff) jogging through the crowded passageways. After a short exchange, he starts again, but the camera pans to a new point of interest before we can hear any more. He reappears twice more in the shot; twice more he repeats the phrase. It is significant that Adama cannot answer the question he raises about remembrance on the day his ship is due to become a heritage site. The 'reasons why' hang ominously over the miniseries and provide an ethical context for the episodes that follow. Later at the ceremony, he initially frames his speech within well-worn patriotic platitudes; 'The Cylon War is long over,' he says, 'yet we must not forget the reasons why so many sacrificed so much in the cause of freedom.' The commander pauses at this point. Haunted by the memory of a son lost in the service, he continues off-script:

Sometimes the cost is too high. You know, when we fought the Cylons, we did it to save ourselves from extinction. But we never answered the question 'Why?' Why are we as a people worth saving? We still commit murder because of greed and spite and jealousy, and we still visit all of our sins upon our children. We refuse to accept responsibility for anything that we've done, like we did with the Cylons. We decided to play God, create life. And when that life turned against us, we comforted ourselves in the knowledge that it really wasn't our fault, not really. You cannot play God then wash your hands of the things that you've created. Sooner or later, the day comes when you can't hide from the things that you've done any more. 
Adama's last act as a battlestar commander is a surprising one. He and his ship are relics of the war, but as a matter of public record Adama troubles Galactica's conscription into the flagship of Colonial heritage. After the Cylon attack, humanity's refugees will 'look backward' for protection in Galactica's guns, but their survival will also require the battlestar-museum to negotiate its embattled history with the Cylons.

This chapter argues that BSG's central story arc of finding Earth is deeply immured in the material conditions and politics of remembrance. While reminiscent of the epic home voyages of Exodus ${ }^{2}$ and the Odysseyand equally reminiscent of the original series' search for the lost 13th tribe taken from Mormon beliefs and history-the fabula of Galactica's journey is also an exploration through the space-time of archaeological sites. On the verge of a diaspora, the crew of Galactica and its Cylon antagonists are poised at a moment of cultural transformation, in which, to borrow from Homi Bhabha, the 'natural(ized), unifying discourse of nation, peoples, or authentic folk tradition, those embedded myths of culture's particularity, cannot be readily referenced' (439). Material artefacts serve a complex diegetic purpose in BSG. At once chapters in the story of the home voyage, they also signal the deeper cultural codes and ideological conditions embedded within the heritage beliefs that the characters must navigate in their difficult journey to peaceful co-existence.

This journey will require new schema for interpreting the archaeological remains that line the route to Earth. While executive producer Ronald Moore is bound by the constraints imposed by a medium that requires the obfuscation of certain details in order to spin out the story arc over four seasons, there is nonetheless a coherence in obfuscation that I argue is broadly archaeological in nature. In $B S G$, archaeological sites are places of assembly, contestation and ultimately critical reflection on the dangerous antagonisms and imperial politics that have brought humanity to the brink of extinction. Cylons and humans alike search for their origins, identity and even survival among the shards of material history. As a mode of cultural production with ideological commitments constitutive of the issues of culpability raised by Adama, archaeology plays a crucial role in both the physical and ethical dimensions of the journey to Earth. BSG creates through archaeological contestation the possibility of a future that is critical of the pernicious and partial chronotopes of progress

2 Resisting the comparison to Exodus, Grace Dillon argues that the original $B S G$ and Galactica 1980 are better understood through diaspora theory. She contends that the shows' portrayal of an embattled people seeking and settling upon the 'promised land' (17) is an elaborate allegory of Regan-era economic imperialism. 
and heritage exemplified in turning Galactica into a Cylon War museum (Liedl; Rizvi, 197), an act that perpetuates through commemoration the simmering hostility between the races. And if Moore has been successful in his plan to 'comment on things that are happening in today's society, from the war against terror to the question of what happens to people in the face of an unimaginable catastrophe' (qtd. in Bassom, 12), ${ }^{3}$ then $B S G^{\prime}$ 's archaeological imagination is not simply a means to reanimate the mytho-religious environment of the original series, but a way of exposing it to the real-world geopolitical tensions that impress the $B S G$ reboot with contemporary relevance for its viewership.

The miniseries concludes with Adama announcing his plan to search for the distant ancestor of humanity described in the Sacred Scrolls, the enigmatic 'Thirteenth Tribe' who emigrated from Kobol and settled on Earth some 2,000 years before the remaining tribes left to form the Twelve Colonies (10 December 2003). Like many Colonials, Adama thinks that Earth is a myth, but draws upon the scriptural narrative in order to give the survivors hope of a friendly destination (E. Silverman, 1991, 192). The irony of Galactica's museumification is actualized in the fleet's exodus into the depths of their mythic past. But here, too, irony bites, for what they discover completely undermines all sense of their origins. With the help of a rebel Cylon faction, a joint archaeological expedition finds in Earth's irradiated soil material proof of their common ancestry, their common humanity in their shared materiality. Sifting through the detritus of the Thirteenth Tribe, each race is left to ponder its purpose and identity as agents of the kind of imperialist power that has led to cataclysms past and present. Over the course of the painful journey to Earth, Colonials and Cylons come to appreciate the artefacts they encounter as footprints of shared, bio-material existence. In this way, BSG patiently exposes an 'archaeology of the future,' a utopian possibility latent in humanity's rediscovery of its deep-seated hybrid history with the Cylons.

This sense of material, cultural and historical interconnection is signalled in a phrase repeated by humans and Cylons alike, 'All this has happened before, and all this will happen again. ${ }^{4}$ These words are spoken first by the Model Two Cylon known as Leoben Conoy (Callum

3 The numerous readings of $B S G^{\prime}$ s engagement with $9 / 11$ and the war on terror include Dinello; Erickson; Johnson-Lewis; Leaver, 2008; McHenry; Melançon; Mulligan; Ott; Peters; Pinedo; and Rawle.

4 E.g. 'Flesh and Bone' (25 February 2005), 'The Hand of God' (11 March 2005), 'Home: Part 2' (26 August 2005), 'Razor' (24 November 2007), 'Revelations' (13 June 2008), 'No Exit' (13 February 2009) and 'Daybreak: Part 2, 3' (20 March 2009). 
Keith Rennie) in 'Flesh and Bone' (25 February 2005). Focusing on Kara's interrogation and torture of the captured Cylon, who claims to have planted a nuclear warhead somewhere in the fleet, the episode is a shocking reminder of CIA waterboarding of Al-Qaeda suspects and the dehumanisation of prisoners at Abu Ghraib (Bassom, 74; cf. Johnson-Lewis, 24-25; Kind, 123-24; and Leaver, 2012, 133-34). Its grisly scenario notwithstanding, the episode represents the most intimate encounter between Cylons and Colonials to date in the series. As a torturer, Kara seeks truth by exposing the Cylon to his own physicality. She is astonished by what she finds, a grotesque parody of human weakness that feels pain and humiliation, has hunger and bleeds. If 'you cut him open,' she casually observes, 'there's blood, guts, the whole thing.' Her dawning sense of their mutual fragility-she herself is nursing a broken leg-disrupts the formidable version of the evil machine-like 'other' she expects to find in the interrogation room. She becomes 'unbalanced' (Sharp, 71) as a consequence. The audience, too, is positioned within the torture, vis-à-vis a frontal shot taken from inside the water bucket into which Leoben's head is thrust. The camera frames the moment within the very medium of torture, a disturbing perspective that compels the audience to bear witness to a cruel act. Disrupting the viewers' normative cinematic relation to the subject, the camera manipulates any stable sympathies we might have for Colonial humanity, which is to say the biological side of the cyborg divide.

Torture thus performs a critical cultural function. It establishes boundaries of inclusion and exclusion, civilization and savagery. But the barbarity of torture always threatens to destabilize and invert these binaries. Kara accuses Leoben of destroying her civilization, aware of the paradox that humans 'frakked up' by creating and then enslaving the Cylons in the first place. The problematic and ultimately self-referential logic of torturing a thing-in this case an artefact from humanity's history-raises a pertinent question about the ways we acquire knowledge: what can objects signify beyond the possibilities of truth offered by the interrogator?

Leoben's torture, then, may be appreciated as an archaeological performance that connects contemporary images of war with finding the truth. Like torture, archaeology is a mode of truth-seeking that responds to the mutability of material existence. Sympathies emerge between archaeologist and artefact, between human and Cylon. ${ }^{5}$ In 'Flesh and Bone' we observe an individual Cylon struggling for being in time, an

5 Matthew Gumpert, 144-46, also explores the unstable nature of the human/Cylon binary in materialist terms. 
alien concern for the virtually immortal cyborg. Having ventured beyond the range of his resurrection ship renders acute Leoben's longing for spiritual transcendence beyond his physical existence. At this moment he is, like his interrogators, a material being defined through entropy. ${ }^{6}$ We see in Leoben the first instance of how, as Lewis Call relates, 'Death establishes the possibility of meaning' for the Cylons (85). And also for the Colonials, who begin, like Kara, to question the wisdom of received narratives of the material world. Both a meta-commentary on the war on terror and the construction of the alien other, 'Flesh and Bone' destabilizes through archaeological imagery the object/human categories upon which such distinctions are constructed.

Bringing things and people into symmetry is the first step towards dismantling the categories of difference so deeply embedded in the Colonialist worldview. Exposing Cylon materiality to human decay effects an amazing reversal. The tortured Leoben penetrates the torturer's hard exterior, her own inscrutable materiality. 'I look at you now,' he says, 'I don't see Kara Thrace. I see an angel blazing with the light of God, an angel eager to lead her people home [...] You will find Kobol, the birthplace of us all. Kobol will lead you to Earth.' These words amaze her, for she is unprepared for the Cylon to recognize her own religious struggles. The empathetic bond between torturer and tortured collapses the object world into the social, allowing Leoben to expose in Kara's imagination the prospect of inclusive and flexible narratives of origins for both races.

President Laura Roslin (Mary McDowell), the secular leader of 'her people,' however defends entrenched binary distinctions. She reminds Kara that the Cylon is 'a machine. And you don't keep a deadly machine around when it kills your people and threatens your future.' Roslin cannot accept a future defined by Cylon subjectivity, an irony that unfolds in season two when she herself leads her followers on an archaeological expedition to Kobol with the help of another Cylon prisoner, Sharon Valerie (Grace Park). The manner of Leoben's execution-which

6 The finality of Leoben's death foreshadows the future of the Cylon race itself. After the destruction of the Resurrection Hub, the leader of the Cylon rebellion, the Six known as Natalie, states, 'We began to realise that for our existence to hold any value, it must end. To live meaningful lives, we must die and not return. The one human flaw that you spend your lifetimes distressing over, mortality, is the one thing, well, it's the one thing that makes you whole' ('Guess What's Coming to Dinner?' 16 May 2008). Lewis Call argues that she is 'dying in the Heideggerian sense: she has been comporting herself towards death, and she has been open to opportunities for authenticity' (102). 


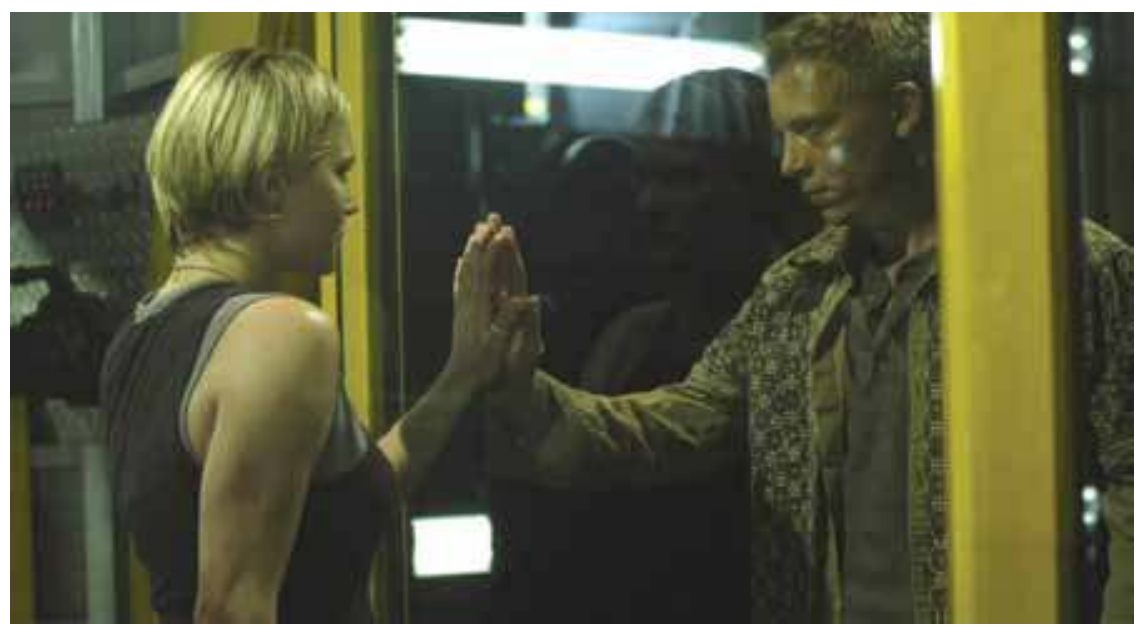

Figure 21. Battlestar Galactica, 'Flesh and Bone' (Universal Studios Home Entertainment, 2005).

she invents on the spot for Cylon war criminals-re-inscribes his status as an unwanted thing: 'flushing' the Cylon into the vacuum of space. Kara explains to Roslin that Leoben is not afraid of death, but afraid, like all people of faith, that his soul will not find God. Resigned to his fate, Leoben places his hand on the glass partition of the airlock. Kara responds in kind. Hands join momentarily in a gesture of prayer, then he is destroyed. The glass mirrors the frontal shot of the torture scene, situating torturer and tortured in a position of mutual sympathy. Replacing the objective views of the camera and water, the window renders transparent the deep-seated distinctions between object/person, origin/future and alien/kindred.

Kara's ostensibly contradictory acts of torture and communion challenge Roslin's executive power to preserve exclusive categories of difference. She repeats this interrogative performance privately at a makeshift shrine to the gods of Kobol that she tends in her locker. It is significant that she keeps these votive figurines close to her. As reproductions of primitivistic representations of the gods of the ancient, quasi-mythical homeworld, these fetishized artefacts stand in for the personal relationship she has just established with Leoben. Kara is uncertain about the status of the Cylon's soul, but she nevertheless asks her gods to 'please take care of it.' Holding the promise of meaning in space and time for both parties, these artefacts resonate with the transformative experiences of the interrogation room and the promise that she will find Kobol, the home of Cylons and Colonials alike. Yet 
this disturbing sense of equilibrium also encodes and echoes privileged notions of antiquity for the viewer. The Etruscan-looking figurines signify an a priori value lingering behind and before the technological culture embodied by the Cylons. Part of $B S G^{\prime}$ 's fascination for its audience is its ability to draw viewers into the diegetic search for origins survived by its archaeological mise-en-scene. Kara's locker is, in fact, only one of several private collections stowed aboard the museum-ship. Adama's quarters, for example, are saturated with historical memorabilia of the vanished colonies. His many books, statues and old furniture occupy the same space as his navy paraphernalia, a model ship, cutlasses and even a samurai helmet evocative of a Cylon head, a subtle connection between our own imperial past and the colonial wars depicted in the series.

Privy to the torture of Leoben, the audience, like Kara, can no longer enjoy the privileged position of coding the Cylon as a static object of repetition or of unfeeling programming. In the episodes that follow, recognisable archaeological sites continue to disrupt these cultural categories of human and material. The dawning sense of interconnected existence in 'Flesh and Bone'-the troubling figure of the cyborg that emerges when perceived dualisms keeping things and people apart collapse-is crucial for the next phase of the archaeological journey: Kara's search among the ruins of Caprica for clues to the direction to Earth.

The opening 'teaser' for the first-season finale ('Kobol's Last Gleaming: Part 1,' 25 March 2005) presents a series of pairings. Adama and Lee (Jamie Bamber) spar in the boxing ring; the father knocks down the son. Kara and Gaius Baltar (James Callis) are having sex, which ends badly when she cries out Lee's name; 'Virtual' Six (i.e., Baltar's former Cylon lover who appears to him in visions) is deeply wounded by the betrayal. Sharon 'Boomer' Valerie (hereafter 'Boomer') suspects she is a Cylon sleeper agent, and considers shooting herself. Stranded on Caprica after the attacks, Karl 'Helo' Agathon (Tahmoh Penikett) shoots the Model Eight masquerading as Boomer sent to seduce him (hereafter 'Sharon'); wounded, Sharon reveals that she is pregnant with his child and wants to defect to Galactica to raise it.

Father and son, lovers, friends, allies, Cylon and human are bound to each other in conflict. In his podcast commentary, Moore relates that this is his favourite teaser of the first season, because it reflects the physical and psychological battles developing between the principal characters (Moore, 2005). These antagonisms are crucial in the search for Earth. Unforeseen and largely unconscious sympathies develop between the Cylons and Colonials depicted in the teaser. Once again, archaeology as praxis and critical idiom offers a way of framing these relationships, the 


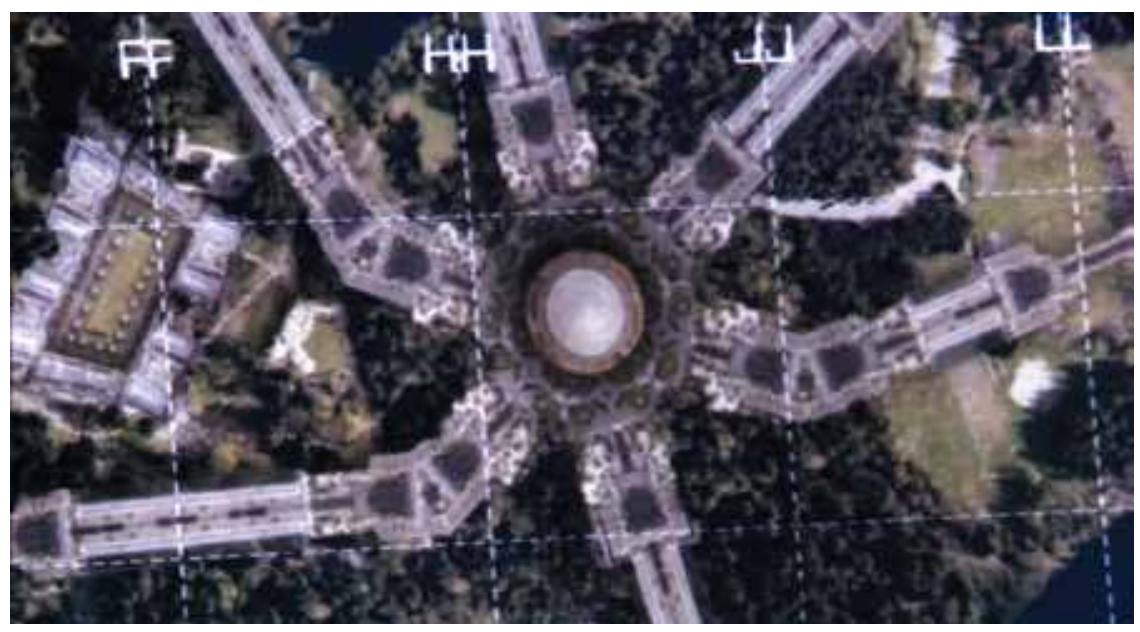

Figure 22. Battlestar Galactica, 'Kobol's Last Gleaming: Part 1' (Universal Studios Home Entertainment, 2005).

evolution of the home-journey narrative, and the critique of privileged notions of origins that $B S G$ progressively undermines. On a scouting mission for supplies, Boomer locates a planet that Roslin identifies from reconnaissance photos as the Kobol of myth and scripture. The president sees in the photo of ruins an inhabited city with features identical to the 'Forum' in Caprica City. She literally cannot see the site as it is, only as a simulacrum, a manifestation of her desire to claim the aura of origins filtered through the Sacred Scrolls and an architectural reproduction at the Colonial capital. Acting under the misplaced belief that humanity will be welcomed by its ancestors, she envisions Earth as a version of the mythic Kobol, the land 'where gods and men lived in paradise until the exodus of the Thirteen Tribes.' Ironically, her conviction is the product of the kind of repetition and simulation that Colonials ascribe to the machine world of the Cylons. The irony deepens when she echoes Leoben's own words by telling Kara, 'We are playing our part in a story that is repeated again and again throughout eternity.' Convinced that 'Earth is real,' Roslin persuades Kara to return to Caprica to retrieve the Arrow of Apollo from the archaeological museum, the artefact that will, according to the Sacred Scrolls, unlock the Tomb of Athena on Kobol and reveal the route of the Thirteenth Tribe to Earth.

On Caprica, Kara finds the museum in ruins ('Kobol's Last Gleaming: Part 2,' 1 April 2005). She picks her way through toppled statuary and broken display cases. Colonial heritage is literally under attack. In this episode, the emerging archaeological motifs are certainly topical, for 


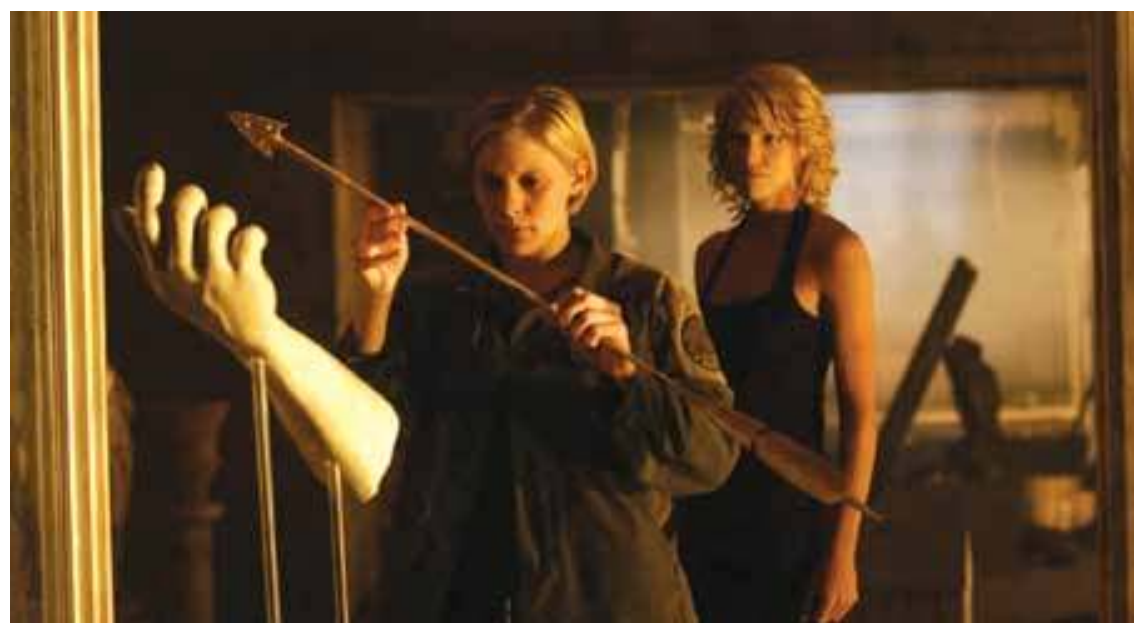

Figure 23. Battlestar Galactica, 'Kobol's Last Gleaming: Part 2' (Universal Studios Home Entertainment, 2005).

the battle over history and heritage at this site clearly references the bombing and looting of the Baghdad Museum in April 2003. In BSG, Colonial heritage is similarly embattled. Kara enters the bombed-out museum, shoots herself with anti-radiation medication and then shoots the display case containing the Arrow of Apollo. The Colonials steal their own history by exposing it, as it were, to the poisonous atmosphere of imperial war. The artefact is unlocked from its hermetic seal and rejoins the world of struggle and symbolic exchange. Enter Six, who appears over Kara's shoulder, the new guardian of heritage. In the still above, the artefact is framed in a deep focus shot that layers the antique hand, Kara holding the arrow, and Six in a series of strong parallel lines. A sense of continuity and contestation in time is established in the frame, with the arrow literally and figuratively changing hands. The battle for history ensues, moreover, in brutal hand to hand combat for possession of the arrow, which is to say, its continued meanings for the future: the Cylons, too, need it for their own, parallel search for Earth. The Arrow of Apollo is a sign of common heritage and interconnected history that, like the bombing and looting of the Baghdad Museum, dissolves into conflict between rival claimants.

The fight is, however, oddly intimate. The intimacy of boxers, of a father and son sparring in the ring ... or of lovers. After a series of rapid cuts of Six dashing around the room-Six is showing off her physical superiority to a terrified, hunted Kara-in the end, Kara tackles her and they fall together through a hole in the floor, crushing the Cylon. They 
lie embracing among the broken statuary. At this very moment Helo and Sharon arrive. Another piece of a larger puzzle emerges at this contested heritage site. The Arrow, a weapon that Kara jabs at Six, now points the way to the future, the human-Cylon child growing within Sharon. The arrow is now a compass that will lead both sides to a hybrid future beyond their embattled history.

Similar convergences are occurring simultaneously on Kobol. A survey expedition from Galactica unwittingly jumps into the middle of a Cylon armada and crashes near the ruins photographed by Boomer ('Kobol's Last Gleaming: Part 2'). The site offers both visual relief from the closed spaces of the ships, and a perspective of the deep historical time the Colonials are tracing on their journey to Earth. With gestures towards the eighteenth-century picturesque ruin tradition, the extreme long shot of the temple ruins is-with the aid of computer imagingcoeval with the primordial landscape suggested by the swamp in the foreground and, in the background, the vertical repetition of the structure by the mountains.

The visual layering of the establishing shot of the temple is indicative of the dynamic nature of visual perception and its manipulation in $B S G$. The scene cuts to Virtual Six rescuing Baltar from the burning Raptor. Filmed as she often is in high-key and strong back-lighting, she interrupts the normative environment, representing a kind of mythic extra-diegetic time and space coeval with the ruins, an embodied zeitgeist. At this moment she immerses Baltar in the Cylons' perceptual experience of what in BSG mythology is known as 'projection,' the fabrication of desired spaces and realities, like a kind of built-in holo-deck. Similar to the Super Mechas in A.I., Cylons are by their very nature meta-filmic, for their sense of identity is shaped directly within the conventions of visual culture. Their ability to disrupt time and space, which is integral to the televisual feel of $B S G$, also invests the archaeological terrain with historical meaning. Virtual Six tells Baltar that he has been chosen by God to 'survive and serve His purpose.' The angelic figure shares with her former lover a projected vision of the temple. He, like Roslin, 'recognizes the place,' sees instead of ruins the temple as it might have been millennia ago. Baltar and Roslin experience the same vision of a simulation based on the model on Caprica, the very building in which Kara is battling Six for the Arrow of Apollo. The ruins on Kobol are extant with those on Caprica. Both sites mark the cycles of holocaust endured and propagated by each race. In ruination, both hold clues to a new beginning. In the temple (also known as the Opera House) Virtual Six shows Baltar a projection of Helo and Sharon's child, Hera (Iliana Gomez-Martinez). While the Christian imagery is unmistakable-Virtual 
Six is dressed in angelic white and bathed in a heavenly glow that envelops the child-messiah - the vision is as mundane and material as a child in a crib. Hera is the answer to Adama's question of shared liability for the violent cycles of time. As the fleet draws closer to Earth, Hera becomes the Rosetta Stone for translating a new hybrid beginning, and a new way of understanding the interconnected nature of the material past over which each race is fighting.

By the second season of $B S G$, Roslin and Adama have reached an impasse over the route to take, which is to say, the ways material history is interpreted. One third of the fleet jumps away with Roslin to search on Kobol for the Tomb of Athena, forcing Adama to make the difficult decision to reunite the 'family' of humanity on Roslin's archaeological expedition ('Home: Parts 1, 2,' 19, 26 August 2005). On Kobol, Baltar's revelation of the child intersects with Sharon's role in the series. She becomes not simply the mother of the hybrid future, but is herself the map to this end. Claiming to 'know more about your religion than you do,' she warns Roslin that her kind will soon descend on the tomb. Sharon assumes the dual sense of her name, 'sharing' knowledge and, like Charon of classical mythology, crossing between worlds. She will be rewarded ultimately for guiding the party with acceptance back into the fleet, where she receives the call sign 'Athena' from the Raptor pilots. At this point, however, she is forbidden to enter the tomb that bears her new name and new hybrid life aboard Galactica. She remains the enemy, a thing to be used, a kind of military asset. Played by an actress of Korean descent, Sharon, moreover, is a figure of typage, who invokes the fear of the cyborg incarnate in, as Eve Bennett argues, far-Orientalist configurations of technophobia (26-31)..$^{7}$

Inside the tomb, the low-key lighting creates mysterious shadowy effects upon a ring of broken classical statuary. Stepping into the gloom, Kara murmurs, 'this is where it all began.' Reiterating the classical iconography of the Caprica Museum, the site represents a familiar chapter in the story of the rise of Western civilisation. Like leaving their guide outside, the very act of 'discovery' — of being the first race to find the tomb-reinforces categories of inclusion and exclusion. Discovery is a form of dispossession, typifying what anthropologist Johannes Fabian famously calls 'the denial of coevalness' (31) to the

7 Bennett also observes that Sharon and Boomer are also coded within the Orientalist 'Madame Butterfly' trope of sacrificial victim (34-38). Nadine McKnight similarly argues that $B S G$ is guilty of reproducing and replicating black stereotypes, such as black mysticism and the threat of sexual violence, most notably in the characterization of Elosha and Simon. 


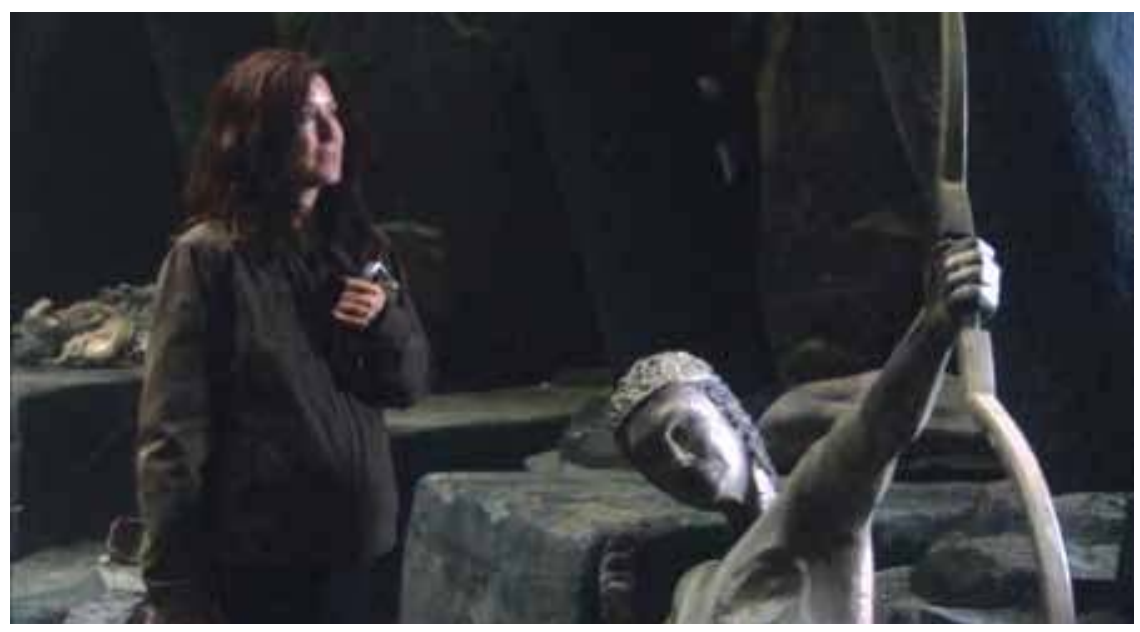

Figure 24. Battlestar Galactica, 'Home: Part 2'

(Universal Studios Home Entertainment, 2006).

colonial other. Finding the tomb and the way to Earth unites the fleet by affirming its mytho-religious identity, but this only accentuates the political antagonisms that have limited their historical understanding. For this sacralized space is actually a technological device constructed by ancient Cylons, a cyborg site activated by the Arrow of Apollo, revealing its real purpose as a planetarium that projects-in cinematographic Cylon fashion-the constellations surrounding Earth over a stone circle and, beyond, the Ionian Nebula that will give the fleet its new bearings. Seeing these familiar objects and patterns is comforting, yet the knowledge garnered from this classical site-and its pretence of a privileged historical timeline-will also have to be dismantled. For Apollo's arrow directs the Colonial fleet to the nuclear legacy of the Thirteenth Tribe. The lesson that humans and Cylons must work collectively to understand the nature of their hybrid history remains hidden in the rubble of what each side still considers its special destiny to survive at the cost of the extinction of the other.

This glimmering sense of intertwined histories and fate in the seriesand the prejudices and horror that the cyborg figure still inspires in its human participants-intensifies on the next leg of the archaeological journey, the discovery on the Algae Planet of the Temple of Jupiter, or, in Cylon lore, the Temple of the Final Five ('The Eye of Jupiter,' 15 December 2006, and 'Rapture,' 21 January 2007). At this point in the $B S G$ saga, the colony of New Caprica has been abandoned and the fleet has renewed the search for Earth. The next major stand-off with 
the Cylons is a winner-take-all battle for the temple and possession of its artefact, the 'Eye of Jupiter,' which is said to hold further secrets about the location of Earth. The Cylons are led by the Model Three D'Anna Biers (Lucy Lawless). Like Roslin, she is convinced that she has a special destiny. Hers is a parallel quest for the truth of her Cylon origins, the forbidden knowledge of the 'Final Five' progenitors of the humanoid Cylon race.

Just like the Temple of Athena, the Temple of Jupiter/Final Five is actually a technological beacon left by the Cylons after their exodus from Kobol, a site which now contains information about the Final Five, who stopped here to 'pray' for guidance on their journey to the Twelve Colonies. The Eye of Jupiter mandala inside-a kind of bull's eye of concentric circles-is a figure for knowledge based on 'seeing straight.' But sight is as contested as the site itself. The Colonials are frustrated and grasp at meanings that linger tantalizingly close. Galen Tyrol's (Aaron Douglas) reverential caress of the mandala betokens the kind of fetishization that resists intelligibility. The elaborate lighting inside the temple creates a sense of cathedral-like immensity and wonder. Artificial light projected from the top of the chamber draws the eye upward to a CGI vaulted ceiling, creating chiaroscuro effects around the central pillar, the light of knowledge veiled in shadowy mystery. The lighting scheme reflects the action. Whereas the Colonials are now united in their appreciation of the temple's significance if not its meaning, the Cylons have become divided. Model One, 'Brother' John Cavil (Dean Stockwell), is prepared to kill D'Anna in order to guard its message from his peers, that the Final Five, the sole survivors of the holocaust on Earth, hold the secret that Cylons and humans share a common ancestry. Just as New Caprica and the pretence of living in peace crumbled, the utopia of Cylon democratic consensus fails under the pressures of Cavil's own imperialist politics and the resistance this breeds in characters like Sharon, D'Anna, Caprica Six, Natalie and, moreover, the Centurions and Raiders who are developing self-awareness and individual identities through their experiences. The humanoid Cylons have quickly created their own 'Cylon problem' through their burgeoning imperialistic culture and politics.

On the Algae Planet, the archaeological path folds in on itself, revealing the deepening complexity and interpenetration of human and Cylon affairs. As Janice Liedl states, the 'race for Earth is not just one for survival, but an evolving dialectic between rival groups for control of contested destinies arising out of their claims on history' (205). Both races are fated to be at the site when the sun goes nova, which reveals the way to Earth to the Colonial and Cylon fleets. 'The nova is the Eye of Jupiter,' remarks Galen, which aligns with the Ionian System revealed 


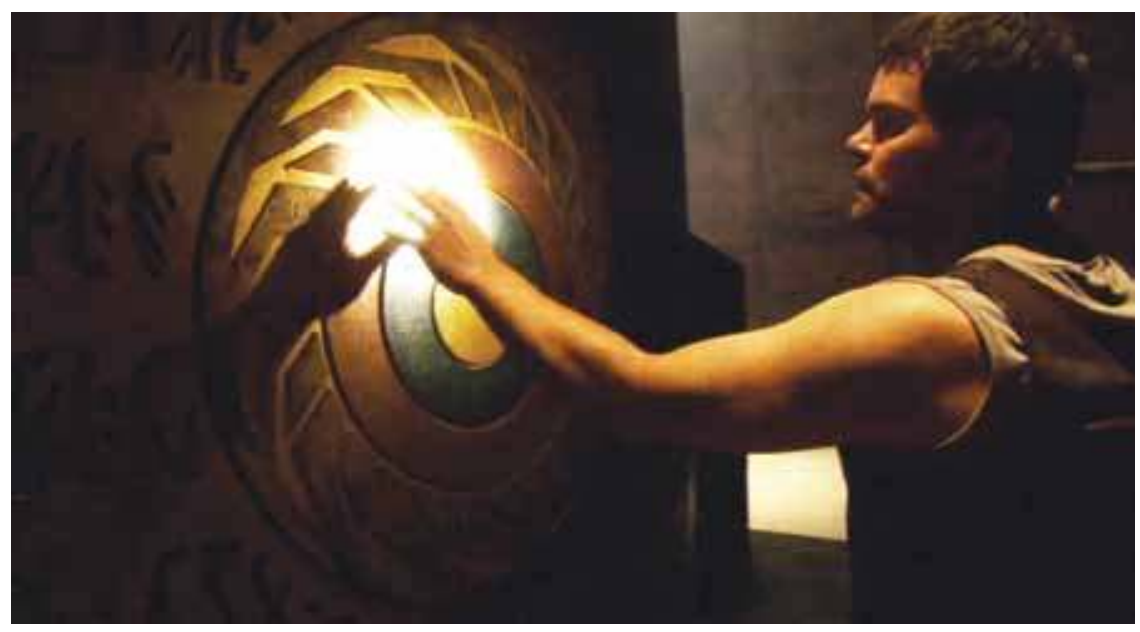

Figure 25. Battlestar Galactica, 'The Eye of Jupiter' (Universal Studios Home Entertainment, 2008).

at the Temple of Athena. But the experience also has a special mystical meaning for D'Anna. She steps into the nova's light cast through the temple, which reveals to her a projection of the Opera House, and therein the luminous figures of the Final Five. As an artefact, the Eye of Jupiter is not a figure of enlightenment, but an actual light source that registers within D'Anna's televisual Cylon perception the deeper truth that the Final Five live indistinguishably among the human population. And so, on the verge of unveiling this secret, the Colonials and Cylons begin the final leg of the race to Earth. A race both species are destined to lose.

Two important archaeological moments remain, the discovery of the two Earths, the two ends, the results of two kinds of choices: the nuked colony of the Thirteenth Tribe and the pristine planet the characters of $B S G$ name after the idea of the world they have been chasing. On the first 'older' Earth, they do not find a new beginning at the end of their travails, nor a quasi-mystical encounter with distant ancestors. The fleet's progress has led them to the end of progress, to the place where they began, in ruins, another site of apocalypse. Instead of encountering welcoming embraces, the characters stumble through the overexposed irradiated landscape of hollow archways and twisted metal reminders of Hiroshima or the WTC, a parody of civilization ('Revelations,' 13 June 2008, and 'Sometimes a Great Notion,' 6 January 2009). The moment of discovery shatters any lingering sense of privileged destiny for either race. Archaeological expeditions turn up humanoid Cylon bones and Centurion-like faceplates. The inference is devastatingly clear: the 


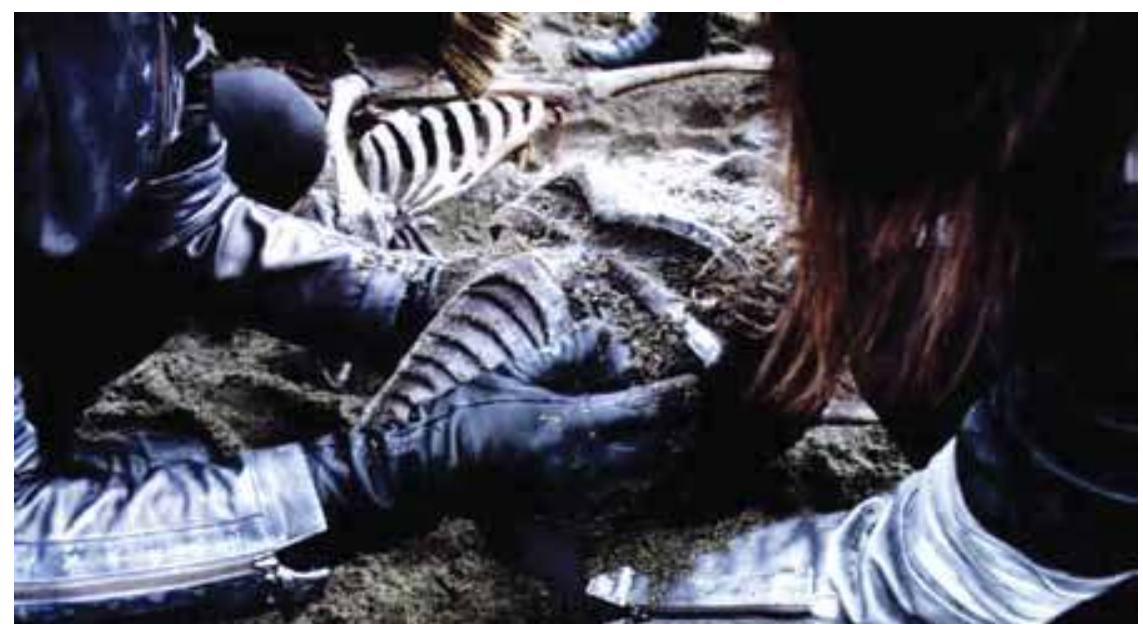

Figure 26. Battlestar Galactica, 'Sometimes a Great Notion' (Universal Studios Home Entertainment, 2009).

Thirteenth Tribe were Cylons, who created their own machines, which in turn rebelled and laid waste to their masters. All this has happened before, and happened again. The end of the line is the knowledge that human and Cylon, creator and created, are bound in a chain of life and destruction.

The joint expedition reveals a common history that completely challenges the historical timeline that the leaders of both sides were struggling to maintain. Long establishing shots over the desolate terrain cut to a series of close-ups of characters digging in the ground, unearthing bits and pieces of expired life, children's toys, musical instruments, a watch. These ordinary objects resonate with the life lived beneath the grand archaeological narratives stored up in places like the Caprica Museum. Here Cylons went to the beach, played guitars, owned businesses, loved and were loved. Four of the Final Five find artefacts. Touching them sparks projections of their former lives. For the Cylons, material traces of the past come fully equipped with narratives. Galen passes a trench containing Cylon remains, establishing continuity with a startling 'find' of his own: his incineration shadow left on a wall, from which he projects his last moments there. He was buying an avocado at a market. Samuel Anders (Michael Trucco) finds a guitar neck, recalls playing it. Tory Foster (Rekha Sharma) remembers the song he wrote for her. Saul Tigh (Michael Hogan) finds a safety deposit box, and sees his wife Ellen (Kate Vernon) lying in the rubble of the bank and realizes that she is the last member of the Final Five. 
The archaeological imagination in $B S G$ merges at this juncture with the show's implicit postcolonial critique of the relationships between the Colonials and the Cylons dating back to 'Flesh and Bone.' The archaeological record on Earth seems like the punch line of a bad joke, but it also offers new routes beyond the old imperial narratives constructed by both races. The archaeological materials gathered on Caprica, Kobol and the Algae Planet are ideological texts that are open to scrutiny. We see here that archaeology is a powerful tool to dismantle dominant histories, to render, in the words of archaeologist Praveena Gullapalli, the 'colonizercolonized dichotomies problematic' (35). She argues that the 'assessment of archaeology as a viable and reliable way of understanding and investigating the past is best exemplified in discussions over contentious sites' (48). Earth clearly fits this paradigm, for its history of contestation lies just below the surface of the terrain into which rival groups had been battling to stake their claims.

This new archaeological evidence requires new sensitivities to the heterogeneity of historical experience gathered here. As leader of the rebel Cylons, D'Anna is forced to negotiate peace with the Colonial forces. Like them, she initially resists, in Gullapalli's words, 'the multiplicity of experiences, both past and present' (37) that binds Cylons and Colonials. But the archaeological discoveries on Earth unite 'groups with different ideologies and perceptions whose actions mirror the multiplicity of self-interests that they embodied' (37). Through their own burgeoning civil war, the Cylons have become heterogeneous, casting off their identity in model numbers and, after the destruction of the 'Resurrection Hub' ('The Hub,' 6 June 2008), the kind of mechanical reproduction that arrests their bodies in time. They are inserted into the temporal flow along with their human antagonists, and like true cyborgs, join humanity in the experience of entropy.

For Kara, these issues play out at another gravesite: her own. Her mortal remains are physical proof that she has been here before (i.e., that she travelled to Earth when she passed through the vortex in 'Maelstrom' [4 March 2007]). The grave is another archaeological site that challenges linear progress. The SF topos of time travel merges with the archaeological conceit of communion with the dead. Indeed, this is the ultimate archaeological site, for she accomplishes what humans and Cylons alike are seeking all along: their own face in the archaeological record. Of course the knowledge gleaned from this (crash) site is ironic and completely disappointing. For it is endemic of how these discoveries have shattered illusions of causality between human and Cylon, and raises deeper and more pressing questions of identity. As Kara says to Leoben, 'If that's me lying there, then what am I?' Her body itself is the 
intimate witness of the disastrous cycles of human conflict. The desire to plant roots in Earth now becomes the need to search for routes to a new Earth beyond the pale of human/Cylon conflict.

The fascinating and confusing interpenetration of Cylon and human history, culture, belief systems and psychology has, by the mid-point of the fourth season, now fallen into place. The battle for survival for humans and Cylons comes down to a war between those who accept Cylon-human hybridity and the Cylons who follow Cavil's desires to extinguish humanity and live in a machine-ruled universe. Each position depends, however, on the survival of the child Hera, who holds for Cavil the secrets to resurrection and, for the rebel Cylons, proof of natural conception with their human partners. The final assault on the Cylon colony is fought for a principle, the salvation of a child, the embodied future of both races. The battle is won, the child is saved from Cavil's operating table, destinies and prophecies merge, and the fleet jumps blindly away to a new planet they will name Earth ('Daybreak: Parts 1, 2,' 13, 30 March 2009).

This version of Earth is the prize earned for accepting postcolonial hybridity. But there is one more archaeological challenge remaining. For this world is inhabited by, in Baltar's words, an 'early ritualistic tribal society.' Adama surveys them through field glasses from a hilltop, a telephoto point-of-view shot, another ideological sight-line. Hidden behind their panoptic technology, 'Doc' Coddle (Donnelly Rhodes) relates that he found a burial site and has determined that the aboriginals are genetically compatible mates. The polemical archaeological issue of disturbing indigenous burials aside, humanity will survive by interbreeding with the natives. The characters are poised on the precipice of another moment of cultural transformation. Adama dismisses the natives as 'tribal, without language even.' Lee counters that 'we can give them that, we can give them the best part of ourselves.' This utterance is problematic given the disastrous results of ratiocination explored on the journey. Lee has forgotten that such impositions led to their near extinction several times over. He fails to recognize that this Garden of Eden already has a history, a past that he is willing to conscript into humanity's new heritage.

Lee also makes an interesting and outwardly contradictory proposition: to abandon technology and begin again. He proposes that 'We break the cycle. We leave it all behind and start over.' Material culture may be abandoned, but Earth will nonetheless become a constructed Paradise founded on principles like teaching the locals civilization. As Ronald Moore relates in his podcast commentary (2009), Lee's plan mimics Cortez scuttling his ships, binding the conquistadors to their colonial 


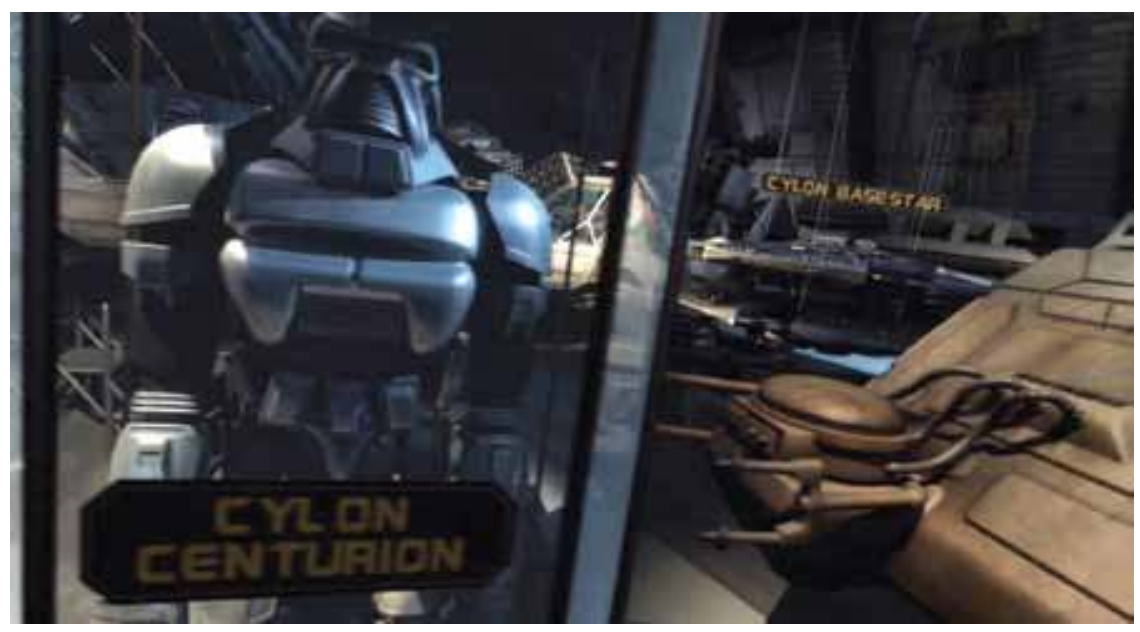

Figure 27. Battlestar Galactica, 'Daybreak: Part 2, 3' (Universal Studios Home Entertainment, 2009).

enterprise. The Galactica-museum-which still preserves the glassed-in Cylon Centurion in the launch bay-is driven into the sun in a gesture of apotheosis, a foundational moment in the colony's burgeoning mythology. The new colony presents, as Grace Dillon relates, 'a dispersed people in exile that nevertheless has the power to colonize the host they encounter. Doing so effects the transformation of collective memory and myth' (17). And so, the seeds of a new cycle of violence are sown.

Kara's final conversation with Lee confirms this future, this implied end. Aware that she died on old Earth and has been reincarnated in order to bring the fleet to this place (Butler and Winston), she asks him what he wants to do. The deep focus and warm golden tones of the grassy 'African' savanna signal departure from the cramped physical and psychological interiors of the space-faring vessels. He answers that he longs to explore, to climb the mountains and cross the oceans. The colonial cartographical imagination cannot be incinerated with Galactica. The outwardly un-SF-like act of destroying technology paradoxically opens the territory for exploration and settlement. Space exploration simply shifts focus to a single world. And this new beginning has a historical function, what John Rieder calls the 'anthropologist's fantasy' of relegating native 'others' to the colonizers' past. Lee's desire to start over requires a stable theory of origins that can be bracketed off in time and projected meaningfully into the future. This historical narrative enables a host of other 'imperial fantasies' of appropriation on Earth: the racial fantasy of superiority/inferiority, the discoverer's fantasy 
of claiming empty lands, and the missionary fantasy of correcting indigenous beliefs (30-31). ${ }^{8}$ Indeed, the ideological positioning suggested by the telephoto shot of the aboriginals is reiterated throughout the settlement process, a series of high-angle shots over vast virgin territory teeming with vegetable and animal life, the building blocks of civilization. Baltar finds a spot to farm. The pristine ground is ripe for planting future history. Of all the characters, only Galen will remove himself from history altogether. He chooses to settle on the 'northern islands' where it is cold and unpopulated. Like Frankenstein's creation, he will suffer through isolation the sins of his race and bear the stain of difference in solitude. End of line for Galen.

While Rieder focuses on SF narratives composed during the heyday of Western colonialism in the late nineteenth and early twentieth centuries, his model is entirely apropos of the neoimperialist themes explored in $B S G$. $B S G^{\prime}$ 's ultimate failure to dramatize its own premise is, arguably, the show's most poignant critique: that SF television cannot contrive a future beyond destructive narratives of progress. The audience jumps away from the fleet to the present-to the future history of $B S G$-and lands in a crowded metropolitan street easily recognisable as Times Square. Time itself is the message. Virtual Six and Virtual Baltar are on hand, proverbial angels on the shoulders of none other than Ronald Moore, who is reading National Geographic, a publication with a long history of manufacturing exotic scientific subjects for Western consumption. The series ends much like it began, with an ironic meta-textual commentary on the current state of affairs. Six reads from the magazine, a story about a recent archaeological discovery in Tanzania of the fossilized remains of a young woman speculated to be 'Mitochondrial Eve,' the most recent common ancestor of all living humans. The ground zero for the terrorist attacks in 2001-which is also the conceptual ground zero for the reimagined $B S G$ - overlays the historical, primitive, virgin territories of the National Geographic metier. Reading the bones of Hera as the fossilized 'Eve' is clearly wrong. Baltar 'gives the punch line' (Call, 110) that she lived with her 'Cylon mother and human father.' Yet, the scientific misidentification bears the ironic truth that $B S G$ has been exploring but ultimately fails to dismantle at every juncture: that imperial regimes inevitably create and reproduce disastrous histories from stable points of origin. $B S G^{\prime}$ s potentially subversive narrative premise-of challenging the archaeo-capitalist notions of progress that have led humans and Cylons to their end-simply folds back into tried-and-true imperial

8 Cf. Patricia Kerslake's examination of SF's generic coding of aliens as colonial 'other' (passim). 
patterns incarnate in the image of Eve descending from the heavens as the mother of a new race, or, in the final meta-historical moments of watching our own present unfold in New York City, the scientific search for Mitochondrial Eve, the excavated fossil dedicated to re-scripting time into monomyths of origins. As Matthew Gumpert relates, the 'spectre of the miraculous child whose coming will usher in a new era is a figure from our past, not our future: a sign of the pervasive nostalgia underlying the apocalyptic futurism of $B S G^{\prime}$ (153).

We are left with Six's observation, 'consumerism, decadence, technology run amok, remind you of anything?' 'All of this has happened before,' she says. 'But the question remains,' interjects Baltar, 'does this all have to happen again?' The audience is left with a question that hearkens back to Adama's speech. The city streets furnish an answer as deterministic as the Prophecies of Pithia. The camera in the last scene pans away from a beggar, contrasting an ugly image of despair and poverty with the artificial beauty of the city and shops where she begs. The camera focuses on televised pictures of the 2005 Robotics Expo in Aichi, Japan, which featured the sexy 'actroid' DER 01. She is posted on electronic billboards, the sea of replicative technology at Times Square, the robotic artefact of our future, or, in the mythology of $B S G$, the reincarnation of our distant ancestor, the android Eve. The television screens are a self-reflexive commentary on the $B S G$ saga as a television spectacle, and a meta-textual comment on the show's central theme: that we have sacrificed our own 'humanity' to the cause of material progress and cosmetic immortality, the pretence of arresting death for the privileged few in this cybernetic field of dreams.

While Katie Moylan advocates quite rightly that $B S G$ never fully retreats from its 'military project' enough to offer substantial cultural critique (67), as a popular cultural document BSG nonetheless invites attentive viewers to question the historical paradigms that support entrenched militaristic and imperialist ideologies of Western culture. The space opera closes with Jimi Hendrix's song 'All Along the Watchtower' emanating from the street person's boom box. 'There must be some kinda way outta here' is the desperate hope that closes the circle on Adama's question of responsibility. Galactica's final jump to Earth is programmed by this song, this musical code, this promise of a fresh start. BSG holds this promise out to us. But the question remains, what versions of heritage are we willing to sacrifice along the way? For historical discourse is often itself a major barrier to transcending the destructive singularities represented by Cylons and humans, of how, in Homi Bhabha's words, 'in signifying the present, something comes to be repeated, relocated and translated in the name of tradition, in the guise of a pastness that 
is not necessarily a faithful sign of historical memory but a strategy of representing authority in terms of the artifice of the archaic' (35). The final moments of Battlestar Galactica suggest that the ruling ideologies of economic, cultural and ethnic difference cannot be so easily cast-like the relics of the Cylon War-into the sun. 


\section{Chapter 8}

\section{Prometheus}

\section{Building Better Worlds}

Weyland Industries corporate motto

Big things have small beginnings.

Lawrence of Arabia

In concert with the 2012 TED conference in Long Beach, California, the creative agency Ignition Interactive launched an elaborate marketing campaign to promote the release of Prometheus (2012), Ridley's Scott's pseudo-prequel to Alien (1979). In a virtual TED talk delivered from the year 2023, the CEO of Weyland Industries, Peter Weyland (Guy Pearce), discusses his company's breakthroughs in artificial intelligence. The talk concludes with an invitation to visit his corporate website, which unlocks Prometheus media to 'investors,' including information about 'Project Genesis,' an interstellar expedition to investigate archaeological evidence supporting the intelligent design theory of humankind. ${ }^{1}$ The campaign also featured a full-page advertisement in the Wall Street Journal and a video for the company's latest android, the David $8 .^{2}$ Altogether, the advertising strategy immerses fans in the Prometheus backstory by blurring, in the words of Creative Director Chris Eyerman, 'the boundaries between content and marketing, fiction and reality, story and game $[\ldots]$ to the point of invisibility, creating a holistic narrative experience that entertains and engages regardless of platform' (Karpel). In her review of the film, however, Vivian Sobchack argues that

1 The talk was uploaded on 28 February 2012 to the official TED site (Sancton). For more information about the viral campaign see Eisenberg and Karpel.

2 Https://www.weylandindustries.com/david. 
the disconnect between the anticipation generated by the trailers, website, and viral marketing' and the 'extremely confusing, illogical, and disjointed plotting, and weakly conceived characters who act implausibly' is symptomatic of the Herculean task Scott set for himself: to build a better world from the materials and corporate expectations of a highly successful franchise. Prometheus is caught in its own almost inescapable double bind' between 'the filmmaker's desire and demand for originality and $[\ldots]$ a huge parasitic franchise and stifling mythology' $(2012,33)$. Her assessment is rooted in Roland Barthes's injunction that the

very end of myth is to immobilize the world [...] [E]very day and everywhere, man is stopped by myths, referred by them to this motionless prototype which [...] stifles him in the manner of a huge parasite and assigns to his activity the narrow limits within which he is allowed to suffer without upsetting the world. (Qtd. in Sobchack, 2012, 32)

Invoking Barthes's 'huge parasite' is significant in the context of a franchise whose central fascination is a huge parasite of its own: the iconic face-hugging Xenomorph, whose plastic life cycle is a compelling metaphor for the potentially protean franchise mythology augured by the Prometheus marketeers. Sobchack contends that despite its narrative shortcomings, Prometheus is 'quite coherent as an allegory of the film's own struggle to pay respect to yet reject its own origins' (34), an observation that invites us to peer beyond the dialectical dead end of Barthean mythology to a space inhabited by another creature who plays a pivotal role in the promotional material and in the film: the David 8 android played by Michael Fassbender. No mere repetition of the devious Ash [Ian Holm] or Bishop [Lance Henriksen] in the first film and its sequel' (34), the film's protagonist departs from the model company servant by disrupting, like HAL or his Cylon counterparts, anthropocentric control of the archaeological record. In this context, David's role in the search for humanity's 'Engineers' and his secret genetic experiments with their parasitic bio-technology introduce a potentially novel cyborg mythology into the Alien franchise and a more opened-ended appreciation of the film as an allegory of its Promethean struggle to square origins with originality.

To this end, Scott attempts what is for Barthes the impossible task of vanquishing 'myth from the inside' (qtd. in Sobchack, 2012, 34), a project that begins with the promotional materials' intertextual-which is to say parasitic-relationship with another film, David Lean's Lawrence of Arabia (1962). Weyland's TED talk, which is ostensibly about the 
future of artificial people in deep space exploration, pays homage to the figure of Lawrence promulgated by Lean. He opens with an anecdote from the film: 'T.E. Lawrence, eponymously of Arabia but very much an Englishman, favoured pinching a burning match between his fingers to put it out. When asked by his colleague William Potter to reveal his trick [...] Lawrence just smiled and said "The trick, Potter, is not minding it hurts."' Weyland likens the 'fire that danced at the end of that match' to Prometheus's gift to 'mankind,' the spark of technological innovation from which sprang stone tools and gunpowder, combustion engines and nuclear weapons, fusion and ultimately 'cybernetic individuals, who in just a few short years,' he says, 'will be completely indistinguishable from us, which leads to an obvious conclusion: we are the gods now.' Visual cues support his titanic solipsism. The video opens with a low-angle reverse shot of Weyland entering a massive stadium, arms raised in salute like a boxer in a title fight. Camera drones project his image onto enormous screens broadcasting Twitter feeds from 76 million online viewers. The cost of claiming divine power-Lawrence's singed fingers, the Titan's eternal agony-is implied in the scopophilic low-angle shots of Weyland at the centre of the adulating crowd, a clear reference to Leni Riefenstahl's fetishization of Adolf Hitler and Nazi ideology in Triumph of the Will (1935). 'My ambition,' he asserts, 'is unlimited, and I will settle for nothing short of greatness, or I will die trying,' a plot spoiler redolent with the corporate expectations to which the twentyfirst-century Prometheus holds his cybernetic progeny accountable.

If the 2023 TED conference marks the unofficial launch of David, a being for whom 'not minding it hurts' implies rather ominous motives underpinning Weyland's need to 'change the world,' the marketing symbology of the David 8 advertisement, 'Happy Birthday, David,' raises pertinent questions about the integrity of a corporate culture mirrored in the monstrous appetite of the Xenomorph. Weyland Industries unveils its new model android through the ambivalent imagery of unwrapping a present or unpacking merchandise, the opening of a sarcophagus or a birth from an industrial womb. The white circulatory fluid that routinely erupts from dismembered androids in the Alien films is injected like mother's milk into David's naked body. ${ }^{3}$ Preschoolish music and a soft-spoken male inquisitor complete the parodic nativity. Asked 'What can you do, David?' the eager and earnest android replies, 'I can do almost anything that could possibly be asked of me.' David's child-like sense of wonder and trust in corporate authority resonates in unsettling

3 Milk is in fact a key ingredient in the special effects cocktail (Fordham, $58)$. 
images of replication. David plays chess with David and paints a figurine of a man in a suit, crafty forms of intelligence and mimicry that simultaneously forecast the fragility of the human/machine binary promoted in the advertisement. Asked 'What do you think about?' David's response 'children playing, angels, robots' implies his sense of ontological separation from created beings and their materiality, an assertion of individuation freighted with the sinister S.S. imagery imparted by cybernetic skulls flanking the decidedly Aryan figure cut by Fassbender. With a slight sigh he relates that he can carry out directives that his 'human counterparts might find distressing or unethical.' Prompted to speak for himself, David expresses his 'gratitude towards the people who created me.' But what form will his gratitude assume in a film whose title references the rebellion of created beings against their gods? What kind of 'better world' can the Weyland Corporation build with and even for its artificial people? 'Happy Birthday, David' thus promises to reinvigorate the Alien universe by developing a backstory for cybernetic individuals raised from Weyland's industrial sarcophagi, and in the process an alternative history for a franchise that casts the future of human labour relations in the monstrous form of the Xenomorph.

For a film whose title invokes the SF uber-myth of Prometheus/ Frankenstein, the intertextual relationship with Lawrence of Arabia adds an unexpected dimension to the cyborg question introduced in the promotional material. If Lawrence is the genealogical lynchpin joining Weyland to the Greek titan, the myth of Lawrence also connects Weyland to the future through David, who adopts his creator's cinematic tastes. Early in the film, David watches the very scene from Lawrence of Arabia that Weyland references in his TED talk. David styles his hair like Peter O'Toole's, mimicking the actor's inflections in front of a vanity mirror as he does so: 'The trick, William Potter, is not minding that it hurts.' That this android, whom Weyland introduces to the Prometheus crew as 'the closest thing to a son [he] will ever have,' so closely resembles Lean's protagonist warrants investigation of the connections between David's adolescent gestures of individuation and the megalomania of a 'father' who finances a trillion-dollar archaeological mission to look upon the face of God. Lawrence of Arabia is, I contend, a mythic threshold through which David enters Prometheus's meta-performance of its struggle with its parasitic franchise mythology. Whereas Weyland appears to accept unreservedly the romantic image of Lawrence for his own plan to 'change the world,' David's emulation articulates a more nuanced understanding of the paradoxes Lawrence embodies as a servant of the British Empire and leader of the Arab Revolt, a legendary figure born from the complex 
nexus of archaeology, military conflict and entertainment explored in 'Battling Babylon.'

As a film buff himself, David develops self-awareness in relation to the symbolic medium that he as a technological being is uniquely equipped to appreciate. Initially, David filters his experiences of the desert world of LV_233, the destination of the Prometheus expedition, through Lean's lens. He invests his hopes for a meaningful contribution to the mission in a mediatized appreciation of barren places. But like Lawrence, whose fascination with the desert and its peoples is systematically eroded by the imperial machinations of General Allenby's expeditionary force and Prince Feisal's promotion of Hashemite nationalism, David becomes discomfited by the meta-filmic space bequeathed to him by his 'father.' In a film shot entirely with 3-D cameras (Wong), his vision matures, rather, in the stereoscopic environment that Scott carefully constructs around the particular anxieties of individuation confronting the android servant. Sobchack's observation that the director uses '3-D unobtrusively, and thus effectively' (32) gestures towards stereoscopic space as an alternative mode of storytelling for a protagonist eager to free himself from his creator's parasitic attachment to evolutionary typology. Out of David's struggles with the worldview Weyland promotes through his uncritical admiration of Lawrence 'of' Arabia, a new myth of origin for the franchise emerges like the birth of the alien life form.

A short genealogy of the Lawrence myth is necessary to contextualize the manner in which the polyvalent figure of Lawrence as an archaeologist and military commander, and as an enigmatic outsider and a celebrity, filters into David's cybernetic psyche. The recurrent references to Lawrence in the viral campaign and in the film underscore how Lawrence as an archaeologist-cum-spy gathered and produced particular kinds of intelligence in the geographical and historical milieu with which he is eponymously remembered. The genesis of Lawrence's activities in the Middle East lay in a version of 'The Great Game' playing out before the outbreak of World War I. Along with Near Eastern archaeologists Gertrude Bell and Leonard Woolley 'of Ur,' Lawrence was recruited as a secret agent to monitor German activities in Palestine by the Keeper of the Ashmolean Museum and wartime Deputy Director of the Arab Bureau, D.G. Hogarth (Satia, 24-39). Hogarth's excavations at Carchemish, which Lawrence joined in 1911, were the base of operations for gathering intelligence on the construction of the Berlin-Baghdad railway line, which he and his Arab combatants famously sabotaged during the war. At Hogarth's recommendation, the Palestine Exploration Fund hired Lawrence and Woolley in 1913 to map 
the Israelite exodus across the uncharted Wilderness of Zin on the Sinai Peninsula, a topographical expedition that would be crucial for planning the defence of the Suez Canal. At the outbreak of the war, Lawrence was assigned to the British War Office's Geographical Section and then dispatched in 1916 to implement the Arab Revolt plan. Together the 'Oxford Four,' relates Tobias Richter, used their 'knowledge gained as part of their archaeological explorations-geographical expertise, language skills, and personal contacts-to foster essentially imperialist agendas during the war' (225).

In Orientalism, Edward Said offers an illuminating reading of the convergence between archaeology and espionage in the myth of Lawrence adopted by David Lean and Ridley Scott. In his analysis of the Englishman's best-selling memoir of the Arab Revolt, Seven Pillars of Wisdom: A Triumph (1935), Said contends that Lawrence introduces a 'new dialectic' in Orientalist discourse by conflating the knowledgegathering paradigms of the archaeologist with the political aspirations of the Colonial Office, a new mode of representing the Orient and its peoples at the intersection of 'vision' and 'narrative.' Through Lawrence, '[k]nowledge of the Orient' leveraged for the war effort is 'directly translated into activity, and the results give rise to new currents of thought and action in the Orient.' Promising to destabilize the panoptic vision of the archaeologist who 'surveys the Orient from above, with the aim of getting hold of the whole sprawling panorama before himculture, religion, mind, history, society' (239), the new imperial strategy 'will require from the White Man a new assertion of control, this time not as the author of a scholarly work on the Orient but as the maker of contemporary history' (238). But the Orientalist cannot easily escape the synchronic vision of the Arab world he propagated as a scholar. The central conceit of Lawrence's memoir is that his monumental effort to draw the Arabs into the purview of modernity collapsed into a 'powerful sense of failure and betrayal' (241). Lawrence's 'vision' thereby 'became the very symbol of Oriental trouble: Lawrence, in short, had assumed responsibility for the Orient by interspersing his knowing experience between the reader and history [...] All the events putatively ascribed to the historical Arab Revolt are reduced finally to Lawrence's experiences on its behalf' (243). For Said, the tension between (narrative) diachrony and (visual) synchrony is the very essence of the Lawrence myth, the synthesis of a dialectic in which Lawrence's experiences stand in for the epic failure of the rebellion. In short, the myth of Lawrence is a huge Barthean parasite in the history of Orientalism.

What is pertinent for the present analysis is not the fairness or accuracy of Said's assessment of Lawrence's controversial place in history, but the 
distinction he draws between vision and narrative in the Englishman's representation of his role in the Arab Revolt. If as an archaeologist and a military commander Lawrence becomes in Said's words 'a figure of Oriental history, indistinguishable from it, its shaper, its characteristic sign for the West' (238), then the manner in which the figure of Lawrence of Arabia circulates within the popular imaginary as a stage and screen celebrity is also of vital importance for understanding his lingering influence in Scott's film. While Said does not consider Lawrence's earliest expositor, the American journalist and adventurer Lowell Thomas, who in the words of Lyon Macfie 'created one of the most powerful orientalist images ever created' (82), nor Lean's multi-Oscar-winning film, his dialectical model of vision and narrative gives rise to new currents of thought and action in David's own ontological engagement with the popular cultural image of Lawrence promoted by Thomas and Lean.

Thomas's treatment of Lawrence's activities in the Near East unfolds unproblematically within the spatial purview of the Orientalist. Assembled from a stock of still images and moving pictures gathered from his travels in the Levant-including records of his time with General Allenby in Palestine and his two-week sojourn with Prince Feisal and Lawrence in April 1918-Thomas presented 'With Allenby in Palestine and the Conquest of Holy Arabia' to New York audiences in March 1919, and then in London the following year under the new banner 'With Allenby in Palestine and Lawrence of Arabia.' Illustrated with 240 lantern slides and some 30 film clips (including the first aerial photography of archaeological sites in Egypt and Jordan) and accompanied by Levantine music and oriental dance routines (Hodson, 27-44), the show's central conceit is the British liberation of the East from the Turks, a modern-day crusade with Lawrence playing the leading role of white knight (Macfie, 83). Thomas neatly evades the problem of imperial politics by directing action and the possibility for change into a closed system of spectatorship at the interstices of vaudeville, tourism and the Western literary canon. A progenitor of the reductionist and revisionist TED brand of infotainment championed by Weyland, Thomas's show transforms Lawrence into, in his own words, a 'kind of matinee idol' (qtd. in Anderegg, 283).

And it is 'precisely as a matinee idol,' contends Michael Anderegg, 'that Lawrence returns to the screen [...] in Lawrence of Arabia' (283-84). The film responds to several critical biographical studies of Lawrence published after World War II, the most infamous being Richard Aldington's Lawrence of Arabia, A Biographical Inquiry (1955), which attributes Lawrence's 'sense of failure and betrayal' to an underlying crisis of personality characterized by 'his angst over his own illegitimacy, his hybrid British national identity, and his reported sadomasochism and 
homosexuality' (Patterson, 159). ${ }^{4}$ Lean sublimates the film's political matter into the story of Lawrence's dissolution, rendering the failure of the rebellion through the emptying 'desert' of the protagonist's psyche. Unlike Said's syncretic figure of Lawrence as the still centre of the failed English attempt to drag the Orient into the modern era, or Thomas's shining image of Lawrence as the hero of medieval chivalry, Lean translates the dialectics of vision and narrative into the cinematic process itself, such that, as Anderegg observes, the 'formal properties' of the film 'reflect the thematics of the fable' (296). The desert is the co-star and its spectacular and mercurial representation becomes the spatial analogue of Lawrence's psychological breakdown under the (narrative) rigours of leading the revolt.

In her examination of Lawrence's 'person-environment interaction' with the desert, Christina Kennedy observes that two distinct conceptions of the desert correspond with the ambiguities of Lawrence's character. The first half of film presents a version of the idealist protagonist promoted by Thomas. Lawrence enters his role through the 'catalyst' of the desert, which transforms the archaeologist and map-maker into an intrepid agent. 'Originally,' she says, the desert is a 'clean, heroic landscape full of challenge and beauty where Lawrence is alone or with allies or friends. Panoramic shots show the scale of the landscape. In medium-range shots, Lean makes extensive use of triangular composition-reflecting the forms in the landscape and indicating stability. Modern technology is largely absent' (166). But following the capture of Aqaba, Lawrence begins to succumb to his own myth as liberator. His relationship with the desert sours as a result, becoming 'a metaphor for the capitulation of the Arab nations to British hegemony that, ostensibly, represents progress' (162). In the second half of the movie

the desert is decentered from the narrative and, importantly, it loses its beauty. There are few panoramic shots, and those mostly of retreating armies or massacres. The narrative focus shifts to battles and destruction. Modern technology is more in evidence. Triangular composition is gone. Vertical and diagonal lines meet at odd angles, giving a sense of instability and chaos. $(166)^{5}$

4 Studies of Lawrence's sexual politics include Mack; Mengay; and K. Silverman, 1992.

5 Caton (95-99) details how these thematic shifts are also a product of the 'material contradictions' (95) of moving from Jordan to Spain, and the necessity of narrowing the camera focus to accommodate the new topography. 
It is significant that the film resumes after the intermission with the appearance of Lowell Thomas's alter ego, American journalist Jackson Bentley (Arthur Kennedy). Prompted by Prince Feisal (Alec Guinness) to account for his interest in Lawrence, Bentley responds, 'I'm looking for a hero,' a telling assertion at a moment when heroic action has reached its zenith and is thereby ripe for mythologizing. The film thus takes as a central issue the problematic image of Lawrence engendered by Thomas and, as Anderegg argues, the intensely self-conscious way [Lawrence] acts out his heroic role. Lawrence simultaneously performs as a hero and watches himself performing,' complicating 'the categories of actor, role, and identity' (296). For a film that is ostensibly about Lawrence's own ambivalent relationship with myth-making, the notion of 'vision' in the cinematic sense is more flexible than that to which Said accords the Orientalist's memoir. Resisting panoptic control, the desert is a touchstone for Lawrence's quest for personal freedom, an impulse shared by one of his big fans, David, who begins to challenge his scripted role on the Prometheus expedition through his critical appreciation of Lean's film.

If Weyland fancies himself a Lawrencian prophet of revolutionary change, then David identifies with the other Lawrence, the misunderstood soul buffeted by the caprice of the Arabian theatre. In the closing chapters of Seven Pillars of Wisdom, Lawrence recalls the sensation of his 'detached self always eying the performance from the wings in criticism' (561). David also inhabits this ambiguous (spatial) position: initially adopting Weyland's admiration for Lawrence, David's experiences aboard Prometheus also leave him critical of his performance, which is to say his vocational programming. And it is precisely as the author of a rebellion of his own that David introduces a potentially novel cyborg mythology to the Alien franchise. Like Lawrence's mutable relationship with the desert in Lean's film, the metier for David's evolution is the space he inhabits, in this case an alternative stereoscopic environment in which to contemplate the fundamental questions of cyborg existence. The film's formal properties reflect the thematics of an emergent cyborg fable.

The majestic opening title sequence intimates the potential for stereoscopic photography to translate space into an alternative narrative field. The Engineer spacecraft/camera plunges through the cloud cover to reveal the monochromatic cobalt patina representing the elemental forces of the world in its infancy, the rugged mountains, steaming volcanoes (shot in location at Mount Hekla in Iceland), glacier-scarred plateaus and imposing cataracts (Dettifoss, Iceland). The sublime and estranging perspective draws us backward to the point of origin of our species rendered as technological mediation, a documentary imposition 
on free, uncharted space similar to the 'Dawn of Man' sequence in 2001. Marc Streitenfeld's haunting musical score facilitates this transformation. A simple horn melody and drum beat squire the ship's passage through the atmosphere; then, like the diegetic electronic notes that alert Moon-Watcher to the presence of the monolith, alternating tones fold into the orchestration like sonic echoes of the digital hum that pervades Vangelis's futuristic score in Blade Runner. ${ }^{6}$ Rising out of these musical nods to Kubrick and to Scott's second SF film, the Prometheus theme invites the audience to behold Scott's version of the dawn of time in the form of the Engineer's (Daniel James) ritual sacrifice. He swallows a vial of black fluid and immediately convulses as his body is torn apart at the molecular level then falls into the cascade below. The moment of creation signals a rupture in the visual field, a shift from primordial beauty to a microscopic, clinical 3-D animation of ruptured DNA nucleotides swirling in the tumbling water and reforming into new helical structures. The camera then 'pulls back to reveal myriad cells undergoing mitosis [...] depicting the birth of life on Earth' (Fordham, 39). Refracting the ancient astronaut premise of intelligent design through sublime aesthetics and scientific process introduces one of the film's major themes: creation as an act of pollution, which, as evidenced by Moon-Watcher's first kill or Lawrence's military campaign in pristine environments, forecasts the destructive frontier mentality underpinning Weyland's corporate motto 'building better worlds.' Referencing Scott Bukatman's 'The Artificial Infinite: On Special Effects and the Sublime' (1999), Nicholas Brinded considers how 'science fiction cinema as a repository of the modern romantic sublime' in films like 2001, Blade Runner and Prometheus recasts American exceptionalist rhetoric into 'dramatic landscape shots that involve the viewer in sublime vistas' (231). The immersive experience of stereoscopic sublimity is constitutive of the technological mastery of space and its temporalities. The aesthetic measure of space is thus an important thematic aspect of a film that explores the relationship between creation and colonization through the 'promise of rejuvenation' (Brinded, 234) that the characters are eager to find in the archaeological record left by the alien creators.

Millions of years later, archaeologists Elizabeth Shaw (Noomi Rapace) and her husband Charlie Holloway (Logan Marshall-Green) uncover the material remains of the primal scene, a petroglyph depicting a group of people worshipping a giant being pointing to a constellation, which the archaeologists infer is a 'star map' to the location of the Engineers'

6 Cf. Kreindler on sound design. Decker (74-111) provides a reading of similarities in plot and theme between Blade Runner and Prometheus. 
homeworld. Shot at the Old Man of Storr rock formation on the Isle of Skye, the filming site itself marks the ideological nature of romantic aesthetics. Tapping into the 'primal, mysterious and earthy' aura of the Scottish Highlands, Prometheus contributes to the flattening effect of the transnational tourist and film industries, what John Marmysz calls the 'myth of Scotland as nowhere in particular' (30). In Prometheus, the 'picturesque and awe-inspiring' aerial views of the geological fixture that inspired the local legend of the Storr giant pointing to the heavens are co-opted as the point of origin for the film's own mythic concerns. Both 'ancient and futuristic all at once' (34), the site is a chronotopic threshold through which the film industry exerts technological mastery over 'ancient' terrain. Prometheus thus renders 'traces of past mythology' into sublime sources for decidedly 'monolithic' conceptions of space. Through the contemporary myth of ancient astronaut speculation, Prometheus reconfigures the 'myth of Scotland as nowhere in particular' into symbolic terrain upon which to introduce the myth of Lawrence that David adopts during his mission to help his master colonize the future.

The following scene presents David onboard the Prometheus. He appears through laterally opening doors, an SF device that alludes to the visual vocabulary of the stage. The actor enters into his role throughindeed as-stereoscopic space, emerging from the 'backstage' of the positive parallax plane to the zero parallax space of centre stage. In a film whose theatrical self-referentiality combines with stereoscopic effects to disrupt the 'artificial construction of the fourth wall,' the potential for a liberating cyborg mythology resides in situ in the 'thick palpable screen spaces where the boundaries between the film's objects and the viewer's bodies are unclear' (M. Ross, 63, 13). David moves 'stage left' to the hyper-sleep pod containing Dr. Elizabeth Shaw. He monitors her dreams and memories through a HUD 'neuro-visor,' one of the many futuristic screen configurations that point to the film's 'thematic concerns with technology, interfaces, cyberspace, and the boundaries between the real and the virtual' (Purse, 2005, 153). He watches residual image-traces of Shaw's childhood, when she as a motherless girl plied her archaeologist father for information about the after-life. David is drawn to Shaw, whose dream-world provides a spectatorial, philosophical, emotional and technological framework through which he begins to formulate questions about his own origins, ends and purpose. Spying creates an unsettling intimacy between the pair. Crucially, the archaeologist's very name is a direct allusion to the identity Lawrence assumed after the war, when he joined the Royal Tank Corps in 1925 as Private Thomas Edward Shaw (having served under the pseudonym Private John Hume Ross in the RAF from 1922). Cast onto the electronic display of the neuro-visor, 
David's silhouette is superimposed momentarily on the dream image, suggesting that she is dreaming of him, too. Through her, he dreams himself. The implication is that David is developing a psychology and, like Lean's Lawrence, an alter ego from spying. This scene reveals that as a technological being, David is beginning to experience agency within the haptic play of stereoscopic space. Like Lawrence's immersion in Lean's deep focus Panavision photography, David confronts his own identity as a simulated person whose imagination and material reality are, in Aneta Stojnić's words, the 'two pillars supporting every possibility for historical transformation' (51).

David's first activities aboard Prometheus are indicative of the Lawrence/Shaw intertext. As well as the expedition's custodian, he is an archaeologist. He spends his time learning Proto-Indo European, the presumed language of the Engineers, by repeating 'Schleicher's Fable,' an invented text that serves as a touchstone for reconstructing the language and its pronunciation. But the content of the fable-a story about a sheep and a horse whose empathy for each other's service to humans causes them to recognize and confront their own identity as slavescomments on labour relations aboard Prometheus. As an intelligent and emotional being, David becomes increasingly self-aware through his dawning understanding of the disparity between himself and the crew, a disparity that he connects to Lawrence's prevailing sense of isolation in Lean's film. In his solitude, David watches Lawrence of Arabia on a curved projection wall-an exaggeration of the CinemaScope screen used to correct the aspect ratio while providing the sensation of threedimensionality (Belton, 1992, 201) - and dyes his hair while imitating O'Toole's inflections. The camera tracks across the film, replicating for the audience David's own viewing experience of what amounts to Scott's stereoscopic restoration of the 1962 film. These three moments in the first act of Prometheus - the origins of life, archaeological (re)discovery, and David's duties and entertainment predilections-are defining elements in David's character as an Orientalist, a lover of Lean's film, a keeper of the crew and a spy. While the questions 'What can you do?' and 'What do you think about?' are answered explicitly in relation to the mission objectives, the real answers lie in the mirror world David constructs around himself.

Having reached the secret destination LV_233, David revives the crew and they assemble for Weyland's holographic briefing recorded in the year 2091. Supposedly dead after the two-year voyage, the briefing forms a continuum with his TED talk. As the creator of artificial people, Weyland introduces himself through the myth borne vocatively by the ship and its mission. 'There's a man sitting with you today,' he says, 
His name is David. He is the closest thing to a son I will ever have. Unfortunately, he's not human. He will never grow old. He will never die. And yet he is unable to appreciate these remarkable gifts, for that would require the one thing that David will never have: a soul. I have spent my entire lifetime contemplating the questions Where do we come from? What is our purpose? What happens when we die? [...] The titan Prometheus wanted to give mankind equal footing with the gods. For that he was cast from Olympus [...] [T] he time has finally come for his return.

Motivated ostensibly by Weyland's philosophical inquiry into the mysteries of life, the central tension in the film is the relevance of these questions to an artificial person whose creator denies him a soul. The bastard progeny sits in rapt attention while Shaw and Holloway brief the crew on the secret objective to find their creators, the Engineers depicted on the various 'star maps' discovered at ancient sites around the world. ${ }^{7}$ Challenged by the biologist Millburn (Rafe Spall) to disprove 500 years of evolutionary theory, Shaw responds that faith guides her inference. It is, she says, 'what I choose to believe,' a direct quotation from her dream about her father's faith in the after-life. The scene ends with a cut to a perplexed David, who seems to realize that the mission and by implication his very existence is based on a figment. As a repository of what Sherryl Vint terms the 'embodied subjectivity' of the post-human subject, David is a material site for reassessing 'currently dominant constructions of the social' $(2007,21)$, a corporeal signifier of his father's unbounded corporate ambition and narcissism, and, moreover, the unstable fantasies originating in Shaw's loss of her mother. Born from these two fractured psyches, and desirous of severing his umbilical connection to the corporate 'mother'-from Freud's 'biology as destiny' —David begins some creative myth-making of his own and in the process becomes unbound to the Promethean will of Weyland.

Similar to Lawrence's ambivalent relationship with the desert, David comes to 'signify new forms of exclusions' by inhabiting 'new spaces of freedom' (Vint, 2007, 21). These spaces are manifest in the desert environment of LV_233. The descent of Prometheus in the next scene mirrors the activities of the Engineers in the opening sequence. The diminutive ship banks into rolling cloudscapes, then passes over sweeping mountains and valleys of the primal world below. The

7 The Project Genesis page on the Weyland website displays pictorial representations of the Engineers being worshipped at all the ancient astronaut hot spots, including Nazca, Palenque, Babylon and the Valley of the Kings. 
Prometheus theme rises once again, immersing the audience in the sublime prospect unfolding before the crew. The filming location is a crucial point of contact between Scott's and Lean's conceptualization of character in relation to desert spaces. Aerial photography for the entry was taken from a helicopter over the Wadi Rum desert in Jordan (Fordham, 41), the historic site where Lean filmed Lawrence's march to Aqaba. The Seven Pillars rock formation (so named by the Lawrence tourist industry and not after the Quran quotation from which Lawrence takes the title of his memoir) completes the mise-en-scene. Breaking through the clouds, the crew comment on the expansive waste below. David enigmatically offers, 'There is nothing in the desert, and no man needs nothing.' When the physician Ford (Kate Dickie) demands an explanation, David replies that the phrase is just something from a film I like.' This direct quotation of Lawrence of Arabia carries a surprising revelation of aesthetic sensibility for an artificial person, an emotional response to the rugged beauty filtered through David's appreciation of Lean's cinematography.

At once a mark of individuation, the phrase also invites reflection on the politics of the mission. Spoken by Prince Feisal, the full quotation undermines Lawrence's aesthetic claims upon Arabia. 'I think you are another of these desert-loving English-Doughty, Stanhope, Gordon of Khartoum. No Arab loves the desert. We love water and green trees. There is nothing in the desert. No man needs nothing.' In Lean's film, these words convey Feisal's suspicion of British imperial interests in terms similar to Said's. But here, quoted selectively, the double negative conveys a special meaning for David, who literally is no man. Set apart by his status as an artificial person, his attraction to the desert of LV_233 as an archaeologist and admirer of Lean's epic film offers David a potentially transcendent space in which to explore his burgeoning sense of purpose and identity. If, as Scott Bukatman observes, the 'precise function of science fiction, in many ways, is to create the boundless infinite stuff of sublime experience, and thus to produce a sense of transcendence beyond human finitudes' $(1999,256)$, then David is the consummate spectator of the SF special effects unfolding all around him. His aesthetic appreciation of the sublime transforms the desert of LV_233 into a transcendent space wherein he begins to heed the insistent call of his own soul.

But like Lawrence, the seeds of David's disillusionment are also sown in the territory he finds so invigorating. This is manifest in his tense relationship with Holloway, who delights in teasing David for his human pretensions. It is significant that an archaeologist is most disturbed by David's encroachments on biological reality. Similar to the Colonials in Battlestar Galactica, Holloway cannot reconcile the objective nature of 
time that David embodies as the latest artifice of human design with his professional appreciation of time's passage through material culture. The future that David anticipates for himself in the desert is incommensurate with Holloway's long-awaited encounter with humanity's creators. Preparing to enter the toxic environment outside the ship. Holloway (whose name suggests an empty reading of Donna Haraway's 'Cyborg Manifesto') makes a flippant inquiry: 'David, why you wearing a suit, man? [...] You don't breathe, remember, so why wear a suit?' Of course, he does not need it: no man needs nothing. And David, like Lawrence, is well-adapted to this environment. The exchange that follows conveys the horrors of difference that David will in turn visit upon Holloway:

David: 'I was designed like this because you people are more comfortable interacting with your own kind.'

Holloway: 'Making you guys pretty close.'

David: 'Not too close I hope.'

As an artificial person created in a man's image, David's future is prescribed within the generic history of his kind. The very title of the film connects him to Mary Shelley's industrial creation myth of Frankenstein, the work whose anxieties about the mechanization of social relationships set the terms for the debate about the 'co-evolution of Homo sapiens and Robo Sapiens' (Kim and Kim, 316). The unnamed creature embodies the asymmetrical power relations that 'are the basis for the construction of otherness that will become one of the central motives in the cyborg myth' (Yaszek, 2002, 50). At this critical moment, the anticipation of actualizing a dream hard-wired into his programming and stamped onto his physical features is deflated and trumped by Holloway's privileged sense of destiny on LV_233. In forcing David to articulate and thereby acknowledge his difference, the android begins to open critical distance between himself and his creators ('you people,' 'your own kind') in the very terms with which Holloway sets David apart. Whereas Shelley's cyborg is initially and irreparably severed from the social order through physical monstrosity, the handsome David is forced by Holloway to question the viability of the cultural myths and performances that shape his existence. Akin to a spiritual crisis, the 'cyborg is rather uncertain about its own status' (Smelik, 2010b, 94). Disassociated from the kind in whose image he was created, David becomes unkind, a killer in fact, who chooses Holloway as the first subject for his Promethean design to create life of his own and, in the process, render the soul a redundant sign of human ascendancy.

The anxiety of David's uncertain status inflects his parallel 
archaeological activities, his mission to deliver Weyland, who is secretly in cryo-stasis aboard Prometheus, to the Engineers, and a secret agenda of his own connected to his struggle to liberate himself from the prejudices of his human colleagues. While his motivations are never fully explained in the film, they are clearly connected to his discovery of and experimentation with Engineer bio-technology, a version of the black fluid the Engineer imbibes in the opening sequence. The expedition enters a conical structure that turns out to be a hangar bay for the Engineer 'juggernauts.' David lags behind the group to examine cuneiform inscriptions on a control panel that activates a holographic recording with Sanskrit voicings of the Engineers fleeing some unseen danger (Wong). The holographic shadows pass through David's body. David reacts physically, almost ecstatically to the sensation, as if he were touched by grace. It turns out that the ship is a temple of sorts dedicated to the Xenomorph, which the Engineers depict in a Christ-like crucifixion on a frieze in a chamber lined with amphorae of the fluid. Clues to David's agenda are revealed in the iconography of what may very well be the Engineers' own myth of origin. Are the Engineers looking for the ones who made them? If so, David continues their mission: like Ash in Alien, who under classified company orders to collect a sample of the alien life form allows the infected Kane (John Hurt) to enter the Nostromo, David secretes an amphora aboard the Prometheus and sets to work in his laboratory.

Another important intertextual moment with Lawrence of Arabia occurs during his examination of the unctuous liquid. Peering into a drop on the tip of his forefinger, which bears in its swirls the Weyland logo, David says, 'Big things have small beginnings.' In the context of Lean's film, this line refers to Lawrence's involvement in the Arab Revolt articulated by Mr. Dryden (Claude Rains), the fictional head of the Arab Bureau modelled on Hogarth. In this context, though, the android has embarked upon his own revolt against the establishment whose proprietary brand he bears. In the desert world of LV_233, David finds inspiration to forge an alternate future independent of the human evolutionary path. The transforming characteristics of the fluid on organic DNA is the medium for David's own will to power, of unshackling himself from Weyland's thrall and becoming a god himself. The 'small beginning' of his rebellion is infecting the clearest object of his subjugation, Holloway, who takes out his frustration in finding the Engineers dead on David. The archaeologist's impossible desire to 'meet his maker' is for him reason enough to belittle what he and his kind have created in their own image. Holloway wants to know why the Engineers created humanity, a question that also fuels David's need 
to understand his purpose as a sentient artificial being. For David, the bio-mechanical engineering of humanity and androids suggests parity in their shared material genealogy. His exchange with Holloway draws out the philosophical and ideological concerns of artificial people as a second race:

David: 'Why do you think your people made me?'

Holloway: 'We made you because we could.'

David: 'Could you imagine how disappointing it would be to hear that from your creator?'

Holloway (laughing): 'I guess it's a good thing you can't be disappointed.'

David (laughing in return): 'It's wonderful actually. May I ask you something? [...] How far would you go to get what you came all this way for-to get your answers? What would you be willing to do?' Holloway: 'Anything and everything.'

David: 'That's worth drinking to, I imagine.'

Harbouring the bitterness of his failed mission to meet his makers, the archaeologist relegates David to the status of tool or experiment. Holloway's naked assertion of power and his own hubris are all the evidence David needs to continue the Engineers' programme of genetic manipulation. He contaminates the drink he pours for Holloway, setting off a chain of mutations. Holloway impregnates Shaw, Shaw gives birth to an alien foetus (the 'trilobite'), which grows into a giant trilobite which in turn 'face-hugs' a surviving Engineer, from whose body emerges the 'deacon,' a prototype of H.R. Giger's Xenomorph, complete with a snatching set of inner teeth. His alter ego Shaw becomes the surrogate for David's line of cyborg progeny: David in turn becomes the surrogate father for the Alien franchise by fulfilling what may be the Engineers' own quest: to recreate or honour their own god/origin in the shape of the Xenomorph.

Like the cycles of human/Cylon creation in Battlestar Galactica, Prometheus reimagines through David's experiments an alternate history for biological and synthetic life. A fluidic medium for surprising forms of creation and procreation, the black fluid is also a spatial analogue of progressive SF cinematic storytelling. Scott Bukatman's examination of the relationship between identity and digital morphing is fruitful for locating a cyborg narrative within the thematics of Alien mythology. Bukatman observes that around virtual reality and morphing images of reality, identity, and history are put up for grabs by a mutability so apparently radical that these categories appear to be superseded, 
even obliterated [...] [M]orphing holds out the promise of endless transformation and the opportunity to freely make, unmake, and remake one's self.' Morphing disrupts discrete categories of space and time by presenting a 'condensed performance of vision,' which is to say, an 'enhanced temporality' that 'also enacts a performance of memory, yielding further self-(re)generation' (2003, 133-34). With morphological interventions into normative spatial experience, history too becomes an open signifier of fluid identity politics. David's experiments with new life forms are an extension of his emulation of the mercurial figure of Lawrence in Lean's film and the contradictory historical myths he as an Orientalist and military commander embodies. David's meta-morphic creations function on the one hand within the Alien franchise like his own David 8 type, as a physical and "cultural "double" [that] enacts our own greedy and effortless consumerism' (Sobchack, 1999, xii). But these disruptions are also 'meta-phoric' in their 'historically substitutive activity' (xiii). The possibility for embodied forms of subjectivity beyond biological reproduction and heteronormative sexual relations opens up, as Lisa Yaszek observes in her reading of Scott's replicants in Blade Runner, 'the possibility of new, non-Oedipal ones as well' (2002, 147). That the infertile Elizabeth Shaw, whose very name collapses the myths of Frankenstein and Lawrence, is the vessel and incubator for David's 'child' potentially circumvents his Oedipal relationship with Weyland. David inseminating through laboratory processes Shaw, who vocatively carries the unstable historical image David bears, represents a kind of self-replication, a mode of cyborgian continuity and futurity that usurps Weyland's factory-line replication of Davids (and the kind of horror that compels Spielberg's own David to stave in David's head with a floor lamp). A frank exchange between Shaw and David, who have developed a grotesque intimacy through her impregnation, articulates how disruptions to sexual subjectivity posit new forms of agency for a being freighted with fulfilling the impossible dreams of the father:

Shaw: 'What happens when Weyland's not around to program you any more?'

David: 'I suppose I'll be free.'

Shaw: 'Is that what you want?'

David: 'Want? Not a concept I'm familiar with. That being said, doesn't everyone want their parents dead?'

The irony of David's quotation 'No man needs nothing' assumes its full meaning here. If we read this statement as an expression of his desire for freedom from his human programmer, then David as an archaeologist 
is not so much discovering his origins like his human counterparts, but rewriting their genetic code.

But David still has his other parents to deal with, the Engineers themselves. David's petition to the surviving Engineer (Ian Whyte) on Weyland's behalf is answered with a murderous rampage. The reason why the Engineer decides to kill Weyland is not explained, but the Frankenstein intertext would seem to suggest that, in Stephanie Smith's reading, 'the creator loathes his creation so much that the creator actively seeks his creation's demise' (67). With their cache of black fluid, which Captain Janek (Idris Elba) presumes is a bioweapon of mass destruction, the Engineers have in their plans to return to Earth with the fluid revealed if not the reason for destroying what they created a simple will and ability to do so. They make and unmake us, to echo Holloway's words, 'because they could.' Dying from the Engineer's blow, Weyland utters his last words 'There is nothing' to the extra-diegetic leitmotif that played when David spoke the line during the descent to LV_223. That no man needs nothing is a pun on the way an android's search for individuation has replaced the original, just as the black parasitic fluid renders the original untenable. Weyland's dying words are a testament to David's triumph. To a degree, of course, because David's own Promethean desires fall just as short as his maker's. If he thinks he needs nothing, he ultimately requires Dr. Shaw's help after the Engineer, in a comic gesture and homage to Ash in Alien, rips off the android's head. The act is at once the denouement and a commentary on the competing agendas jostling in the microcosm of corporate society onboard the Prometheus. The film ends with Shaw and the decapitated android flying one of the juggernauts in the direction of the Engineer's homeworld. The archaeological mission to revisit the origins of life and time continues with Lawrence's alter ego Shaw and her disciple David 'heading off' on another galactic road trip. Captained by two failed Lawrences, whose breaks with their personal and corporate mythologies open the franchise to a potentially novel post-archaeological and post-apocalyptic future, the new Prometheus expedition just might have lighted out for another shot at a truly original sequel, which is to say an alternate prequel to Alien.

If Prometheus ultimately fails to break radically from the parasite of franchise mythology, the film does gesture towards a cyborg subjectivity beyond recycled myths of biological or mechanical reproduction. Like Lawrence of Arabia, the formal properties of the film reflect the thematics of the fable: the plastic computer generated environments David inhabits are analogous to the fungible futures David tries to create for himself and potentially for his kind. Roger Beebe observes that the narratives that we tell about an emergent posthuman cultural 
formation' are contingent upon 'the new cinematic narrative forms that are produced under and bespeak this new cultural formation' (160). If David is the author of a new species, which is continually shifting shape and eluding the confines of its control systems, his subjectivity most directly and fully emerges within the CGI worlds he encounters aboard the alien spacecraft. David's discovery of the juggernaut bridge is a pivotal moment, a potential rupture with the historical paradigms infecting his manufacture and programming. Alone and having severed communications with the crew, David discovers the very point of origin of Alien, a version of the chamber where Kane discovers the 'Space Jockey' and the Xenomorph egg clutch. Here David triggers a hologram of the Engineers on the bridge preparing to leave LV_233 with their cargo of black fluid. In one of the film's most spectacular moments he activates the Engineers' version of the star map, a lambent stereoscopic 'orrery.' With the Prometheus theme resonating in the compartment, David immerses himself in the dense matrix of visual technology. Like the audience's encounter with Lawrence entering the depth of the desert (or David Bowman's journey through the infinite in 2001), this sublime moment invites the spectator to inhabit as much as watch the film. ${ }^{8}$

If Lean's Lawrence found purpose and inspiration in the cleanliness of a pre-technological world, David works in the opposite direction, locating beauty in the technological sublime. Combining narrative strategies with stereoscopic visuality provides a 'meta-visual account of how embodied vision might function' (M. Ross, 43). For David, the effect and the mode of production are one and the same: the manifestation of the star map is a chronotopic threshold for the cyborg's cognitive mapping and, moreover, emergent spirituality. For the technology that carries death to Earth holds the utopian promise of an artificial soul, the dawning sense of his own 'cosmic connectedness' (Bukatman, 2003, 105). Stereoscopic imagery is a fitting medium for cyborg dreams of emancipation. Echoing the opening scene of the Engineer's sacrifice, David swims in fluidic stereoscopic space, the awesome grandeur of the universe collapsed into kinetic bands of DNA, planets and galaxies. Similar to Lawrence's shadow-dance in the desert when he receives his white robes from Sherif Ali (Omar Sharif), David dances in his new luminescent cobalt coat, the artefactual gift from the future. In this moment, David, like the audience in the opening sequence, encounters aesthetics proprioceptively as an effect of the technological system of 3-D imaging (Richmond, 6-9). In contrast to the spectacular thrills generally associated with the medium, the floating aspects of mise-en-scene 


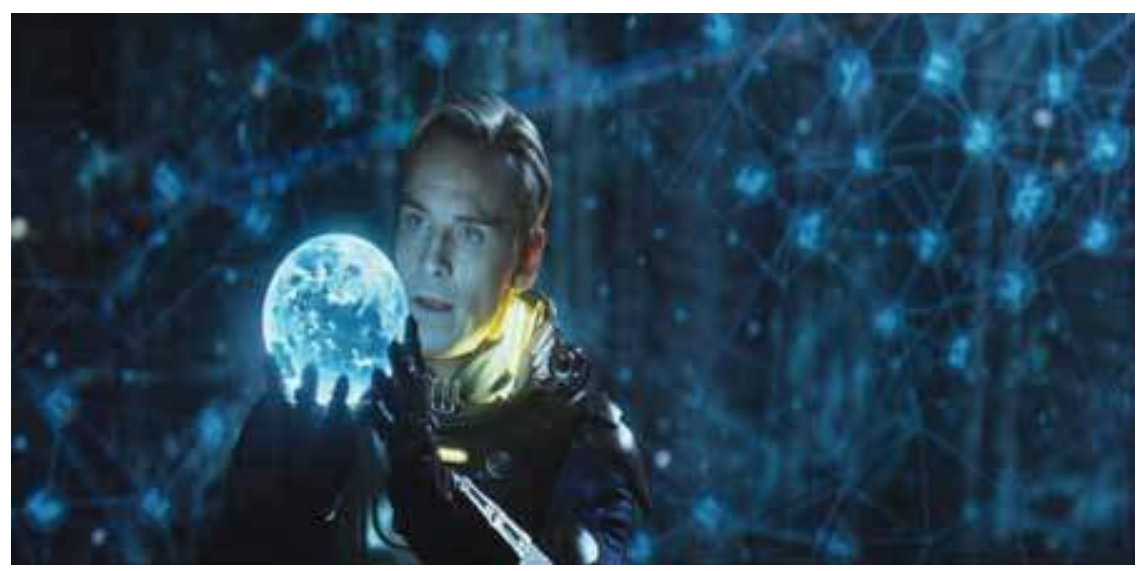

Figure 28. Prometheus (Twentieth Century Fox, 2012).

impart an altogether different impact, a kind of lyricism and awe' (Klinger, 2013, 191). In this environment, David broadens his emotional intelligence through his sensory experience of the Engineers' embodied technology. For David stereoscopic space is diegetic: a spatial distortion that he shares with the audience. ${ }^{9}$ Breaking down the perceptual space between screen and viewer, stereoscopic cinema promotes what Miriam Ross calls 'hyper-haptic' experience for the audience (18-46): 'rather than finding distance from the screen and a sense of mastery over the images, we consider and reconfigure our bodily placement in relation to the screen content' (24). By collapsing the scopic distance between the viewer and subject, Scott invites us for a time to feel, in Bukatman's words, David's 'extended encounter with the sublime, rehearsing (and hyberbolizing) the filmic spectator's own response' (1999, 259-60). In this fashion, stereoscopic space functions like the meta-filmic perceptual apparatus of the Cylons, who translate their desires for transcendence into environments and experiences that they share with each other and occasionally manifest for Baltar and, through him, the audience.

In a surprising gesture, David plucks the Earth from the centre of the orrery. He regards the planet with awe and a sense of possession, enjoying the privileged view of the Engineers. Holding the whole world in his hands, David experiences a Promethean moment of creation. For an archaeologist, the orrery is the ultimate artefact: a map of origins connecting early civilizations to their future through a cyborg '[c]onsciousness, which perceives space and experiences duration,

9 See Fordham for techniques used to make the orrery. 
makes the self and the universe at once' (Bukatman, 2003, 136). Like the desert in Lawrence of Arabia, the orrery opens possibilities for an alternative narrative register that supersedes the galactic mapping and colonial imagery of the Weyland website. Prometheus thus offers glimpses into an alternative future for the franchise in the ongoing SF cinematic project of destabilizing, like 2001 did for its generation, the present through the experience of the artificial sublime. The cyborg body enters a fluidic narrative field that visually disrupts the Alien origin story. At this exultant moment the new-born Dave slips the controls of programmed memory to discover-like the replicants in Blade Runner - that 'reality can be morphed' (137). For a brief moment, the viewer and David are confronted with the possibility that it is the world that morphs and not the body' (138).

The conclusion of the film supports this reading. David and Shaw lift off from the planet to Shaw's voiceover of her report to Earth. But unlike Ripley, she does not embark upon a homeward course, does not fall asleep to become absorbed back into the company. Having given birth to an alien life form herself, she is also a cyborg, suggesting a co-evolutionary future alongside her artificial companion. The search for origins has given birth to a potentially viable cyborg myth for a franchise poised to reimagine how we construct intelligences around objects deemed historical. Like the Cylons, David opens up fissures and troubles this relationship by asking questions and demanding answers of his creators, demands for reciprocation that trouble the easy othering and binary of us and them, subject and object, biology and materiality. While the Cylons create a space to cohabitate with their Colonial brethren, this is not the end of their story, for the coalition invites attentive viewers to reconsider the history and co-evolutionary path of power and technological ascendancy that will bring them once again to the precipice of nuclear annihilation. David's future has yet to be written and so remains a potential avenue in SFFTV to continue to examine critically the ways we graft the production of knowledge into corporate dreams of colonizing the future.

Whatever surprises the future-past of Alien might have in store, the biggest disappointment of Prometheus may be that the film is ultimately an allegory of an android's failure to find an equitable station in the future, an ending foreclosed by the parasitic imagery of the franchise with which Scott leaves the viewer: a version of the Xenomorph erupts from the belly of the Engineer, unleashed upon the future by a disaffected cyborg from the very DNA of his creators. We are also left to ponder what role a headless android might play in shaping his future and that of the franchise. While these questions remain to be answered 
in a potential sequel, I suggest that these closing images of monstrosity and disincorporation offer an oblique yet apropos commentary on recent events in the cradle of civilization, the desert from which the film's allegory of creation accrues so much of its aesthetic and historical imagery. David and Shaw's envoy to meet their makers is a fitting envoi to the archaeological themes of the film and to the present examination of archaeology and geopolitics in contemporary SFFTV.

Writing at the end of the 1990s, Steven Caton makes the interesting observation that old films like Lawrence of Arabia have a surprisingly durable shelf life. He recalls his experience of watching the 1989 restoration, which was still playing in repertory cinema houses during the First Gulf War. He argues that two aspects of the 'film's anthropology'-its historical material and its aesthetic content-were still relevant for the critical appreciation of ongoing political affairs in the Middle East. He offers a 'speculative reading of the film as allegory of the First Gulf War' (194-99; cf. Hodson, 128), a reading that recognizes the fairly facile identification of 'Stormin' Norman Schwartzkopf with Lawrence (a comparison the general himself makes in his memoirs [194]), but is more interested in the particular narratives about the Gulf War that the comparison spawns, especially in relation to the bilateral issue of war atrocities. This reading dovetails Lawrence's 'revenge' upon the Turks after they slaughtered the villagers of Tafas with the issue of civilian deaths in a new era of 'intelligent' warfare. For Caton, Lawrence's massacre of the Turkish column, the 'climax of Lawrence's journey into his heart of darkness' (196), resonates with one of the grisliest televised images to emerge from the war: the so-called 'Highway of Death,' the firebombed Kuwaiti road carrying Iraqi civilians fleeing from the allied advance, a controversy that could never be fully settled because of the tight rein on a press relegated to reproducing the official rhetoric of the campaign handed out during briefings. Filtered through the dehumanizing experiences and culpability of Lawrence, Caton concludes that it was, sadly, as though this movie spoke more honestly and painfully of this war than any representations of it emanating from the government or the press' (198). If the film is both an artefact of an imperial imagination and a critique of the hegemonic system that produced the myth of Lawrence, it continues to have 'moral relevance to our colonialist involvement in the Middle East today' (199).

Similar comments could no doubt be raised about the 50th anniversary $4 \mathrm{~K}$ restoration released in 2012 in the context of the ongoing efforts against al-Qaeda and the new challenges to global security arising out of the Arab Spring. Released in the same year as Prometheus and the outbreak of the civil war in Syria, Lean's film is an uncanny testament 
to the forever war in the Middle East. Us watching David watching Lawrence is a contemporary metaphor for reflecting upon our latest return to the birthplace of civilization. David's immersion in the stereoscopic restoration of Lawrence of Arabia affords a glimpse into the future of East/West relations as yet another incarnation of the tension between vision and narrative formulated by Edward Said. In this sense, Prometheus offers material for contemplating the latest phase of the myth of the eternal return not explicitly as an allegory of contemporary events, but as a cluster of images that prompt questions about the relevance of SF as a symbolic medium for considering relationships between material culture, progress and politics. The present study concludes with an envoi that considers how Prometheus as an SF film artefact helps us to reflect upon real-world uses of 3-D cinema in the symbolic war on heritage currently raging in the cradle of civilization. 


\section{Envoi}

'These ruins that are behind me, they are idols and statues that people in the past used to worship instead of Allah. The Prophet Muhammed took down idols with his bare hands when he went into Mecca. We were ordered by our prophet to take down idols and destroy them, and the companions of the prophet did this after this time, when they conquered countries.'

Anonymous ISIS soldier ${ }^{1}$

[The iconoclasts'] rage to destroy images rose precisely because they sensed this omnipotence of simulacra, this facility they have of effacing God from the consciousness of men, and the overwhelming, destructive truth which they suggest: that ultimately there has never been any God, that only the simulacrum exists, indeed that God himself has only ever been his own simulacrum.

Jean Baudrillard ${ }^{2}$

As I compose this on St. Patrick's Day of 2017, Iraqi and coalition forces are poised to recapture the city of Mosul, the last major ISIS stronghold in northeastern Iraq. Over the past few weeks, the army has painstakingly reclaimed much of the eastern section of the city. The timing of the offensive is coincidental yet significant for the role of archaeological remains in the struggle to establish an Islamic caliphate. Nearly two years ago to the day, ISIS released a video documenting their vandalism of the Mosul museum (26 February 2015). ${ }^{3}$ The horrified world watched

1 Translation taken from Winsor.

2 Baudrillard, 1983, 8.

3 Https://www.youtube.com/watch?v=_KELYkEklgU. 
ISIS fighters laying waste to artefacts gathered from the Assyrian cities of Nineveh, Nimrud and Khorsabad, as well as the ancient city of Hatra. The video's coup de grâce is a soldier drilling into the face of a winged, human-headed bull known as a lamassu. The videographer employs a split screen to juxtapose a photograph of the artefact being excavated in the mid-nineteenth century with a contemporary image of the object in situ at the Nimrud complex on the outskirts of Mosul. An Arabic caption scrolling across screen completes the triptych: 'These idols and statues are not from the era of the prophet (pray to him, peace be upon him) and his companions, but (rather) are inventions from the servants of satan. ${ }^{4}$ The sentence is passed and the lamassu is beheaded.

The choreographic effects of slow motion photography, staccato and montage editing, and background singing overlaying the sounds of battle are integral to the iconoclastic message. While a pale comparison to the kinds of artefact and monument destruction choreographed by Michael Bay in his Transformers films-how could actual demolition compete with the rolling fireballs of Hollywood action blockbusters?- the Islamic State hijacked in kind the visual vocabulary of Bay's brand of state-sponsored violence. In this asymmetrical war, global audiences are confronted with a low-budget but equally high-concept war film with the power to outrage and inspire (cf. Parkin).

Liberated by Iraqi forces, the ravaged museum forms a grotesque book-end to the looting of the Baghdad Museum in April 2003. It seems that ISIS learned an important lesson from what was incidental (though predictable) damage to archaeological remains during the Second Gulf War. A weaponized expression of fundamentalist Sunni ideology, smashing artefacts has another, far more cynical objective. Iconoclasm inflates black market prices and promotes a cottage industry in looting from which ISIS levies taxes. Looting and destruction thus conspire in a global network in which Western buyers help finance the caliphate. Bearing witness to the 'general exchange of all cultures' (Baudrillard, 2010, 102), these ravaged 'beach-heads of globalization' (Coulter, 5) are attractive, highly valued terrorist targets and commodities.

Toppled, smashed and humiliated, the statues are, furthermore, destroyed in a manner suggestive of an execution, a parody of the snuff videos prepared for world-wide distribution by militant fundamentalists. These gruesome exhibitions of ISIS resolve emerge as perhaps an inevitable and predictable response to the fatal history of Western intervention in the region. Parodying and exploiting the symbolic value of archaeology as a science of shared origins, the iconoclastic impulses of

4 My thanks to Jeanette Greven for the translation. 
ISIS pay homage to the power of archaeology to generate authentic signs of the West. The outrage of Western civilization at artefact destruction is a version of the outrage expressed by fundamentalist revolutionaries who understand their value as symbolic capital. While the brutality of the attacks on the museum may be interpreted as a vestigial expression of a primitive mentality, the logic of iconoclasm has a remarkably postmodern significance: to recognize, in Baudrillard's terms, the mighty reality of the simulacrum, the god of global monoculture that equates sanitised Hollywood images of war and violence with democratic legitimacy.

While SFFTV has yet to respond to the war against ISIS-as Tripp Reed's Manticore did for the looting of the Baghdad Museum-the West has nonetheless prepared a swift and proportionate response to a particular ISIS attack: the systematic looting and destruction of the UNESCO World Heritage site of Palmyra, which was overrun by ISIS forces in May 2015. In October, ISIS blew up the triumphal arch of Septimius Severus, a cornerstone feature of the Silk Road oasis that joined an immense colonnade spanning more than one kilometre in length (the Temple of Bel was also demolished in the same year). ${ }^{5}$ In one of a growing list of UNESCO press releases, Director-General Irina Bokova condemned the action within the very rhetoric of world heritage that makes these sites irresistible targets for ISIS. She states that this

new destruction shows how terrified by history and culture the extremists are, because understanding the past undermines and delegitimizes the pretexts they use to justify these crimes and exposes them as expressions of pure hatred and ignorance. Palmyra symbolizes everything that extremists abhor; cultural diversity, intercultural dialogue, the encounter of different peoples in this centre of trading between Europe and Asia. ${ }^{6}$

In terms reminiscent of George W. Bush's admonition that al-Qaeda attacked the World Trade Center because it 'hates freedom,' Bokova ennobles Palmyra as a prototype of globalist harmony. Her clarion call

5 It is also the site of another particularly calculated act of violence, the beheading in August 2015 of the 82-year-old head of antiquities in Palmyra, Dr. Khaled al-Asaad. Photos of his body hung on a colonnade in the central square were published with a sign outlining the charges against him, which included fealty to the Syrian president Bashar al-Assad, maintaining contact with senior regime intelligence and security officials, and managing Palmyra's collection of 'idols' (Shaheen and Black).

6 Http://en.unesco.org/news/director-general-condemns-destruction-archtriumph-palmyra-extremists-are-terrified-history (5 October 2015). 
to a new theatre of war ignores the underlying social and political injustices fuelling the civil war against Syria's president and his allies (as I revise this Bashar al-Assad with Russian complicity unleashed sarin gas on the town of Khan Shaykhun). She continues,

Despite their relentless crimes, extremists will never be able to erase history, nor silence the memory of this site that embodies the unity and identity of the Syrian people. Each new destruction should spur us to share knowledge of the significance of this heritage in museums, schools or the media. This is an important part of safeguarding the city and of the global fight against the cultural cleansing underway in the Middle East. I commend teachers, journalists, associations, and professionals in the field of culture, as well as members of the public, who are helping transmit the story of Palmyra to future generations.

The manner of perpetuating Palmyra's memory is critical to her message. In lieu of archaeological fieldwork, which has been suspended in Syria since the civil war began in 2011, documentation is key for heritage preservation. She affirms UNESCO's determination in 'establishing networks to link the thousands of experts in Syria and abroad working to transmit this heritage, notably with the help of modern technology.' Digital photography, the medium of disseminating ISIS propaganda, is a countermeasure to the Islamic State's programme of erasure. Several virtual preservation initiatives are underway, including the creation of stereoscopic models from crowdsource data. Images taken from archives, the internet and even tourist photographs are being used to replicate cheaply sites targeted for looting and destruction in war zones (Spanò).

A decidedly science fictional logic has taken root in the cultural heritage industry's programme to perpetuate a desired future, an irony evidenced by the highly publicized efforts to synthesize the Arch of Septimius Severus by the Oxford-based Institute for Digital Archaeology in conjunction with researchers from Oxford and Harvard Universities and Dubai's Museum of the Future. As its name suggests, the organization is dedicated to preserving heritage through a form of digital counter-insurgency. Carved by robots out of Carrara marble, the 12-ton, one-third scale replica is, in the words of the institute's director Roger Michel, 'a symbol of defiance against terrorists erasing the Middle East's pre-Islamic history' (qtd. in T. Williams, 1). Michel is also on record as stating, 'My intention is to show Islamic State that anything they can blow up we can rebuild exactly as it was before, and rebuild it again and again. We will use technology to disempower Isis' (2). This 
questionable assertion-that a reproduction, and even a reproduction of a reproduction ad infinitum, can stand in for the original-demonstrates that these quasi-archaeological objectives are thoroughly invested in the symbolic work of nation-states. Present and tangible, the arch accrues authenticity in relation to the performances of authenticity made possible on this new 'beach-head' opened up against ISIS. Digital replication is the latest salvo in an 'assault of postmodern warfare' (Bergstein, 38).

In the case of the triumphal arch-whose origin as a monument to the Roman conquest of Persia seems to have been overwritten in the 3-D printing process-the scaled-down model of intercultural dialogue has gone on a world tour. The replica was unveiled first in Trafalgar Square in April 2016, and then in New York City in September. While the symbolism of the exhibition site in London is sympathetic with the commemoration of England's own imperial victory at Trafalgar (and of the stockpile of Egyptian artefacts that Nelson confiscated as war booty from the French), the second ceremony in the U.S. creates new histories for the replica that are entirely in accord with the Institute for Digital Archaeology's 'other' motive for artefact simulation. The promotional material on the Institute's website celebrates the arch's admission into New York City's pantheon of democratic icons. ${ }^{7}$ Entitled 'A Bridge Over Troubled Water,' the second exhibition has a theme song to commemorate what Mayor William De Blasio calls a 'powerful act of solidarity with all those lost and hurt in Syria.' The arch also commemorates the 35th anniversary of Simon and Garfunkle's 1981 reunion concert in Central Park. The Institute posts photos of performers paying homage to the folk duo on a small stage fronting the arch. The display has since moved twice more: to Dubai for the World Government Summit in February 2017, and then in March to Florence for the G7 Summit, where it currently resides in the Piazza della Signoria alongside the reproduction of Michelangelo's David. ${ }^{8}$ After the tour the arch will be repatriated to Palmyra, perhaps to become an ISIS target, thereby endowing the replica with immediate historical value.

I suspect that many archaeologists are suspicious of the political agendas served by 3-D salvation, if only in the theoretical sense that archaeology is by its very nature dedicated to studying ruination as a process. It is in these terms that Anne Pyburn, the Director of the Center for Archaeology in the Public Interest at Indiana University,

7 See Institute for Digital Archaeology website, http://digitalarchaeology.org. uk/new-york-city/.

8 Http://www.theflorentine.net/news/2017/03/arch-palmyra-installed-g7-off/ (9 March 2017). 
responds to the digital archive project with a degree of alacrity. For the idea of replication is an ideological intervention into the historical life of things, a programme that aligns archaeology with the economics of 'the tourist industry and the preservation industry and the projects of nation states,' wherein artefacts are in danger of becoming 'renewable resources' in a system of 'disaster capitalism' $(229,227,230)$. In the case of the triumphal arch, replication manufactures value for the object alongside 'stakeholder' desires to 'reify the status quo in the present by constructing a primordial pedigree for it' (228). This is especially problematic in the war against ISIS, for monuments also bear witness to local histories of violence, histories that are in danger of erasure through paradigms of world heritage that protect sites and objects determined to have 'outstanding universal value' (Kalman, 1). Pyburn warns that the cultural heritage industry too often imposes preservation schemes that 'can alienate people from their resources, making them vulnerable to predatory organizations' (Pyburn, 226).

It is in this sense, then, that Prometheus offers an oblique commentary on the simulacral war on terror. In an article in the New York Times, journalist Kamel Daoud expresses a popular response to ISIS when he argues that the organization 'seeks to negate and destroy any evidence of the passing of time, in Palmyra and elsewhere.' ISIS, he says, 'tries to extend the desert's domain: to replace walls with sand, to flatten out landscape, to return to a vacuum so as to start history all over again' (qtd. in Bergstein, 14). The reference to the desert brings us full circle to Ridley Scott's remediation of Lawrence of Arabia, to a film whose artificial protagonist reminds us that all deserts-all places seemingly devoid of symbolic context-bear the marks and traces of time, and that erasure is always part of the historical context. David's ironic recitation of Prince Feisal's axiom 'no man needs nothing' resists the forces that seek to collapse diversity through replication, to reduce the world, as Baudrillard famously puts it, to 'the desert of the real' $(1983,2)$. Born out of a postmodern need to generate origins through simulation, the cyborg is an emergent figure of time. Like the lamassu, David is beheaded as a sign of the iconoclastic principles of his human compatriots to preserve stable myths of human origins; yet David nonetheless liberates through his genetic experiments a new cyborg life form as his artefactual gift to the future, one that clearly does not respect its origins and resists the impulse to put the head back on the broken thing, which is to say, to extend the symbolic life of objects with the cement provided by powerful corporate structures like Weyland Industries and UNESCO.

Through David, Prometheus exposes the contradictory logic of the phoney triumphal arch. As an objective manifestation of our dreams for 
a perfect past, the simulation attempts to conceal the scars of imposed origins. For all her scientific training, for all her faith in the gods of origin, Elizabeth Shaw can only—and honestly—conclude, 'we were so wrong.' If David's experiences shed light on the iconoclastic impulses of ISIS, they also reflect the iconodulist demands of UNESCO, which artificially suture through simulation material culture to the flow of life. Like the failures of Lean's Lawrence, ISIS and the Institute for Digital Archaeology fail to bring antiquity into a new narrative, and instead relegate the past into metonymic images of ritualistic dis(re)memberment that reaffirm the cultural and monetary value of origins through the seemingly endless morphology of perpetuation. Prometheus asks us through the figure of an artificial person to meditate on the manner in which our preservation instincts sacrifice the future in the quest for authentic pasts. Until we can envision a future beyond them, we remain trapped in the circular logic of Fredric Jameson's prescient aphorism: that SF's 'deepest vocation is to bring home, in local and determinate ways and with a fullness of concrete detail, our constitutional inability to imagine Utopia itself' (289). 


\section{Works Cited}

ABC Good Morning America. 18 April 2003. http://www.mediaresearch. org/cyberalerts/2003/cyb20030421.asp.

Abu Dhabi TV. 16 April 2003. http://www.baghdadmuseum.org/looting/ pages/menews030416cl8.htm.

Agnew, Neville and Janet Bridgland, eds. Of the Past, for the Future: Integrating Archaeology and Conservation (Los Angeles: Getty Conservation Institute, 2006).

Aiken, Stuart C. and Leo E. Zonn, eds. Place, Power, Situation and Spectacle: A Geography of Film (Lanham, Maryland: Rowman \& Littlefield, 1994).

Aldington, Richard. Lawrence of Arabia: A Biographical Inquiry (Westport, CT: Greenwood Press, 1955).

Aldiss, Brian. Supertoys Last All Summer Long: And Other Stories of Future Time (New York: St. Martin's Press, 1969).

Andén-Papadopoulos, Kari. 'US Soldiers Imaging the Iraq War on YouTube.' Popular Communication 7.1 (2009), 17-27.

Anderegg, Michael A. 'Lawrence of Arabia: The Man, the Myth, the Movie.' Michigan Quarterly Review 21.2 (1982), 281-300.

Andersson, Pia. 'Alternative Archaeology: Many Pasts in Our Present.' Numen 59 (2012), 125-37.

Andrews, Rena. 'Blade Runner Needs Sharpening.' Review of Blade Runner (Denver Post, 25 June 1982), 6 (qtd. in Kerman, 1997a, 248).

Aronstein, Susan. "Not Exactly a Knight": Arthurian Narrative and Recuperative Politics in the Indiana Jones Trilogy.' Society for Cinema and Media Studies 34.4 (1995), 3-30.

Arrighi, Giovanni. 'Hegemony Unravelling I.' New Left Review 32 (2005), 23-80.

'Art Loss in Iraq.' IFAR Journal 6 (2003), 30-62.

Aston, James and John Walliss, eds. Small Screen Revelations: Apocalypse in Contemporary Television (Sheffield: Sheffield Phoenix Press, 2013).

Aydin, Mustafa and Çağri Erhan, eds. Turkish-American Relations: Past, Present, and Future (London: Routledge, 2004).

Bahrani, Zainab. 'The Fall of Babylon.' In Polk and Schuster, 2005, 214-16.

-. 'Babylon: A Case Study in the Military Occupation of an Archaeological Site.' In Agnew and Bridgland, 2006, 240-46.

—. 'The Battle for Babylon.' In Stone and Bajjaly, 2008, 165-72. 
Banks, Miranda J. 'A Boy for all Planets: Roswell, Smallville and the Teen Male Melodrama.' In Davis and Dickinson, 2004, 17-28.

Baram, Amatzia. Culture, History, and Ideology in the Formation of Ba'thist Iraq, 1968-89 (New York: St. Martin's Press, 1991).

Barker, Cory. "Chlark" Versus "Clois": Shippers, Anti-Fans and Anti-Fan Fans.' In Barker et al., 2014, 174-92.

- et al., eds. Mapping Smallville: Critical Essays on the Series and Its Characters (Jefferson, NC: McFarland Press, 2014).

Bassom, David. Battlestar Galactica: The Official Companion, Season One (London: Titan Books, 2005).

Battis, Jes. 'The Kryptonite Closet: Silence and Queer Secrecy in Smallville.' In Geraghty, 2011, 45-64.

Baudrillard, Jean. Simulations (New York: Semiotext[e], 1983).

-. 'Simulacra and Science Fiction.' Trans., Arthur B. Evans. Science Fiction Studies 18.3 (1991), 309-13.

-. Symbolic Exchange and Death. Trans., Iain Hamilton Grant (London: Sage, 1993a).

-. The Transparency of Evil: Essays on Extreme Phenomena. Trans., James Benedict (London: Verso, 1993b).

- Fragments: Cool Memories III, 1991-95. Trans., Emily Agar (New York: Verso, 1997).

-. 'The Ecstasy of Communication.' Trans., John Johnston. In Foster, 1998, 126-34.

-. The Spirit of Terrorism and Requiem for the Twin Towers. Trans., Chris Turner (New York: Verso, 2002).

- . 'Our Society's Judgment and Punishment.' Trans., Laura Nyssola. International Journal of Baudrillard Studies 3.2 (2006). http://www.ubishops. ca/baudrillardstudies/vol3_2/jb_soc.htm.

—. The Agony of Power (New York: Semiotext[e], 2010).

Bauer, Alexander A. et al. 'When Theory, Practice, and Policy Collide, or Why Do Archaeologists Support Cultural Property Claims?' In Hamilakis and Duke, 2007, 45-58.

Beebe, Roger Warren. 'After Arnold: Narratives of the Posthuman Cinema.' In Sobchack, 1999, 159-79.

Beeler, Stan. 'Stargate $S G-1$ and the Quest for the Perfect Science Fiction Premise.' In Telotte, 2008, 267-82.

- 'From Comic Book to Bildungsroman: Smallville, Narrative, and the Education of a Young Hero.' In Geraghty, 2011, 3-24.

- and Lisa Dickson, eds. Reading Stargate SG-1 (New York: Tauris, 2006).

Bell, Laura. 'Military and the Movies.' University Observer (no date). http:// www.universityobserver.ie/film-tv-otwo/military-and-the-movies.

Belton, John. Widescreen Cinema (Cambridge, MA: Harvard University Press, 1992).

Benko, Georges and Ulf Strohmayer, eds. Space and Social Theory: Interpreting Modernity and Postmodernity (Oxford: Blackwell, 1997).

Bennett, Eve. 'Techno-Butterfly: Orientalism Old and New in Battlestar Galactica.' Science Fiction Film and Television 5.1 (2012), 23-46. 
Berenger, Ralph D., ed. Global Media Go to War: Role of News and Entertainment Media During the 2003 Iraq War (Spokane, WA: Marquette Books, 2004).

Bergstein, Mary. 'Palmyra and Palmyra: Look on These Stones, Ye Mighty, and Despair.' Action: A Journal of Humanities and the Classics 24.2 (2016), 13-38.

Bernbeck, Reinhard. 'Structural Violence in Archaeology.' Archaeologies 4.3 (2008), 390-98.

- and Susan Pollock. 'The Political Economy of Archaeological Practice and the Production of Heritage in the Middle East.' In Meskell and Preucel, 2006, 335-52.

Bernhardsson, Magnus T. Reclaiming a Plundered Past: Archaeology and Nation Building in Modern Iraq (Austin, TX: University of Texas Press, 2007).

Bhabha, Homi. The Location of Culture (London: Routledge, 1994).

Biber, Katherine. 'The Emperor's New Clones: Indiana Jones and Masculinity in Reagan's America.' Australia and New Zealand American Studies Association 14.2 (1995), 67-86.

Birkenstein, Jeff et al., eds. Reframing 9/11: Film, Popular Culture and the 'War on Terror' (New York: Continuum, 2010).

Bishop, Rebecca. “Several Exceptional Forms of Primates": Simian Cinema.' Science Fiction Studies 35.2 (2008), 238-50.

Biskind, Peter. Seeing Is Believing: How Hollywood Taught Us to Stop Worrying and Love the Fifties (New York: Pantheon Books, 1983).

Bogdanos, Matthew. The Thieves of Baghdad: One Marine's Passion for Ancient Civilizations and the Journey to Recover the World's Greatest Stolen Treasures (New York: Bloomsbury, 2005).

Boggs, Carl and Tom Pollard. The Hollywood War Machine: U.S. Militarism and Popular Culture (Boulder, CO: Paradigm Publishers, 2007).

Booker, Keith M. Monsters, Mushroom Clouds, and the Cold War: American Science Fiction and the Roots of Postmodernism, 1946-1964 (Westport, CN: Greenwood Press, 2001).

Bragard, Véronique et al., eds. Portraying 9/11: Essays on Representations in Comics, Literature, Film and Theatre (Jefferson, NC: McFarland, 2011).

Brake, Mark. Alien Life Imagined: Communicating the Science and Culture of Astrobiology (Cambridge: Cambridge University Press, 2013).

Brinded, Nicholas. 'Exceptionalist Discourse and the Colonization of Sublime Spaces: Alfonzo Cuarón's Gravity, Ridley Scott's Prometheus and Thomas Cole's The Oxbow.' European Journal of American Culture 33.3 (2014), 223-36.

Brunsdon, Charlotte. 'Crossroads: Notes on Soap Opera.' Screen 22.4 (1981), 32-37.

Buerger, Michael E., Karen E. Gardner, Bernard H. Levin and John A. Jackson. 'Incorporating Local Police Agencies into a National Intelligence Network.' Futures Working Group White Paper 1.1 (July 2008).

Bukatman, Scott. 'The Artificial Infinite: On Special Effects and the Sublime.' In Khun, 1999, 249-75.

-, ed. Matters of Gravity: Special Effects and Supermen in the 20th Century (Durham, NC: Duke University Press, 2003). 
Butler, Anthea D. and Diane Winston. 'A Vagina Ain't a Halo: Gender and Religion in Saving Grace and Battlestar Galactica.' In Winston, 2009, 259-88.

Butler, Jeremy G. 'Notes on the Soap Opera Apparatus: Televisual Style and "As the World Turns."' Cinema Journal 25.3 (1986), 53-70.

—. Television Style (New York: Routledge, 2009).

Caldwell, John Thornton. Televisuality: Style, Crisis, and Authority in American Television (New Brunswick, NJ: Rutgers University Press, 1995).

Call, Lewis. 'Death, Sex and the Cylon: Living Authentically on Battlestar Galactica.' Science Fiction Film and Television 5.1 (2012), 85-113.

Campion, Nicholas. 'The 2012 Mayan Calendar Prophecies in the Context of the Western Millenarian Tradition.' Proceedings of the International Symposium on Archaeoastronomy 278 (2011), 249-54.

Cantwell, Ann-Marie E. et al., eds. Ethics and Anthropology: Facing Future Issues in Human Biology, Globalism, and Cultural Property (New York: New York Academy of Sciences, 2000).

Carlson, John B. 'Anticipating The Maya Apocalypse: What Might the Ancient Day-Keepers have Envisioned for December 21, 2012?' Archaeoastronomy: The Journal of Astronomy in Culture 24 (2011a), 143-82.

-. 'The Maya Calendar and 2012 Phenomenon Studies: An Introduction.' Archaeoastronomy: 24 (2011b), 1-7.

Carruthers, Susan. 'Limited Engagement: The Iraq War on Film.' In Lucia, 2016, 438-53.

Caton, Steven C. Lawrence of Arabia: A Film's Anthropology (Berkeley, CA: University of California Press, 1999).

Chapman, Jeannie. 'Making the Millennialist Mainstream: How Television Covered the Apocalyptic Predictions of Harold Camping.' In Aston and Walliss, 2013, 39-58.

Charles, Alec. 'Extraordinary Renditions: Reflection upon the War on Terror in British and American Screen Science Fiction.' Historia Actual Online 22 (2010), 117-24.

Cheung, Floyd D. 'Imagining Danger, Imagining Nation: Postcolonial Discourse in Rising Sun and Stargate.' Jouvert 2.2 (1998), 1-13.

Chilton, Elizabeth S., ed. Material Meanings: Critical Approaches to the Interpretation of Material Culture (Salt Lake City: University of Utah Press, 1999).

Ciecko, Anne. 'Digital Territories and States of Independence: Jordan's Film Scenes.' Afterimage 36.5 (2009), 3-6.

Clack, Timothy and Marcus Brittain, eds. Archaeology and the Media (Walnut Creek, CA: Left Coast Press, 2007).

Clarke, Arthur C. 2001: A Space Odyssey (New York: New American Library, 1968).

Coe, Michael. The Maya (London: Thames and Hudson, 1966).

Cole, David. 'What Bush Wants to Hear.' In Leone and Anrig, 2007, 51-66.

Collignon, Fabienne. 'Silo Psychosis.' CTheory (2011). ctheory.net/ silo-psychosis.

Collins, Margo. 'Domesticity Deferred: Lois Lane, Clark Kent, and the Absence of Superman in Smallville.' In Farghaly, 2013b, 261-78. 
Cornea, Christine. Science Fiction Cinema: Between Fantasy and Reality (Edinburgh: Edinburgh University Press, 2007).

Coulter, Gerry. 'Baudrillard on Terrorism and War in Times of Hyper-Mobility.' International Journal of Safety and Security in Tourism/Hospitality 1.13 (2010), $1-10$.

Cowan, Douglas E. Sacred Space: The Quest for Transcendence in Science Fiction Film and Television (Waco, TX: Baylor University Press, 2010).

Cowie, Elizabeth. Recording Reality, Desiring the Real (Minneapolis: University of Minnesota Press, 2011).

Csicsery-Ronay, Istvan, Jr. 'The SF of Theory: Baudrillard and Haraway.' Science Fiction Studies 18.3 (1991), 387-404.

—. 'Science Fiction and Empire.' Science Fiction Studies 30 (2003), 231-45.

Dalby, Simon. 'Warrior Geopolitics: Gladiator, Black Hawk Dawn, and The Kingdom of Heaven.' Political Geography 27.4 (2008), 439-55.

Davidson, Joe. 'Michael Bay Has Military Play BIG Role in Transformers 2: Revenge of the Fallen.' Scorecard Review (23 June 2009). thescorecardreview.com/ news/2009/06/24/michael-bay-has-military-play-big-role-in-transformersrevenge-of-the-fallen/4053.

Davies, Paul. The Eerie Silence: Renewing Our Search for Alien Intelligence (New York: Mariner Books, 2011).

Davis, Doug. 'Science Fiction Narratives of Mass Destruction and the Politics of National Security.' In Hassler and Wilcox, 2008, 145-56.

Davis, Glyn and Kay Dickinson, eds. Teen TV: Genre, Consumption, Identity (London: British Film Institute, 2004).

Debrix, Francois. Tabloid Terror: War, Culture, and Geopolitics (New York: Routledge, 2007).

Decker, Mark T. Industrial Society and the Science Fiction Blockbuster: Social Critique in Films of Lucas, Scott and Cameron (Jefferson, NC: McFarland, 2016).

Denison, Rayna. 'It's a Bird? It's a Plane! No, It's DVD: Superman, Smallville, and the Production (of) Melodrama.' In Gordon et al., 2007, 160-79.

DeRosa, Aaron. 'September 11 and Cold War Nostalgia.' In Bragard et al., $2011,58-72$.

Derrida, Jacques. 'Des tours de Babel.' In Kamuf and Rottenberg, 191-225.

Díaz-Andreu, Margarita. A World History of Nineteenth-Century Archaeology (Oxford: Oxford University Press, 2007).

- and Timothy Champion, eds. Nationalism and Archaeology in Europe (London: University College of London Press, 1996).

Dillon, Grace L. 'Diaspora Narrative in Battlestar Galactica.' Science Fiction Film and Television 5.1 (2012), 1-21.

Dinello, Daniel. 'The Wretched of New Caprica.' In Steiff and Tamplin, 2008, 185-200.

Dixon, Wheeler Winston, ed. Film and Television After 9/11 (Carbondale, IL: Southern Illinois University Press, 2004).

-. Lost in the Fifties: Recovering Phantom Hollywood (Carbondale, IL: Southern Illinois University Press, 2005).

Dodds, Klaus. 'Hollywood and the Popular Geopolitics of the War on Terror.' Third World Quarterly 28 (2008), 1621-37. 
Dover, Julia. 'The Imitation Game: Paralysis and Response in Fritz Lang's Metropolis and Contemporary Critiques of Technology.' In Minden and Bachmann, 2000, 272-87.

Duffy, Michael S. 'Sacrifice or Salvation? Smallville's Heroic Survival amid Changing Television Trends.' In Geraghty, 2011, 153-71.

Duncan, Jody. 'Heavy Metal.' Cinefex: The Journal of Cinematic Illusions 119 (2009), 88-118.

Eberl, Jason T., ed. Battlestar Galactica and Philosophy: Knowledge Here Begins Out There (Malden, MA: Blackwell, 2008).

Eco, Umberto. 'The Myth of Superman.' Diacritics 2.1 (1972), 14-22.

Eisenberg, Erich. 'Prometheus Viral Reveals Stunning New Image.' Cinema Blend (6 March 2012). http://www.cinemablend.com/new/PrometheusViral-Reveals-Stunning-Image-29828.html.

Elrod, P.N. and Roxanne Conrad, eds. Stepping Through the Stargate: Science, Archaeology and the Military in Stargate SG-1 (Dallas, TX: Banbella Books, 2004).

Emberling, Geoff. 'Archaeologists and the Military in Iraq, 2003-2008: Compromise or Contribution?' Archaeologies: Journal of the World Archaeological Congress 4.3, 445-59.

Erickson, Christian. 'Counter-Terror Culture: Ambiguity, Subversion, or Legitimization.' Security Dialogue 38.2 (2007), 197-214.

Fabian, Johannes. Time and the Other: How Anthropology Makes Its Object (New York: Columbia University Press, 1983).

Fagan, Brian M. The Rape of the Nile: Tomb Robbers, Tourists, and Archaeologists in Egypt, rev. ed. (Boulder, CO: Westview Press, 2004).

-. Return to Babylon: Travelers, Archaeologists, and Monuments in Mesopotamia, rev. ed. (Boulder, CO: University Press of Colorado, 2007).

Fagan, Garrett G., ed. Archaeological Fantasies: How Pseudoarchaeology Misrepresents the Past and Misleads the Public (New York: Routledge, 2006).

—. 'Diagnosing Pseudoarchaeology.' In G. Fagan, 2006, 23-46.

- and Kenneth L. Feder. 'Crusading Against Straw Men: An Alternative View of Alternative Archaeologies: Response to Holtorf (2005).' World Archaeology 38.4 (2006), 718-29.

Farghaly, Nadine. 'Attachment Disorder and Smallville: How an Army Brat Saved Superman.' In Farghaly, 2013a, 279-99.

- ed. Examining Lois Lane: The Scoop on Superman's Sweetheart (Lanham, UK: The Scarecrow Press, 2013b).

Feder, Kenneth L. 'Skeptics, Fence Sitters, and True Believers: Student Acceptance of an Improbable Prehistory.' In G. Fagan, 2006, 71-95.

-. Encyclopedia of Dubious Archaeology: From Atlantis to the Walam Olam (Oxford: Greenwood, 2010).

-. Frauds, Myths, and Mysteries: Science and Pseudoscience in Archaeology, 8th ed. (New York: McGraw-Hill, 2014).

Feinberg, Scott. 'Toronto 2011: Megan Fox Talks Life After "Transformers" [...] Reveals Surprising "Archaeologist" Aspiration.' Hollywood Reporter (11 September 2011). http://Www.hollywoodreporter.com/race/toronto2011-megan-fox-talks-233865. 
Fisher, Jaime and Barbara Mennel, eds. Spatial Turns: Space, Place, and Mobility in German Literary and Visual Culture (Amsterdam: Rodopi, 2010).

Flanagan, Martin. “Get Ready for Rush Hour": The Chronotope in Action.' In Tasker, 2004, 103-18.

Flemming, N.C. 'The Attraction of Non-Rational Archaeological Hypotheses: The Individual and Sociological Factors.' In G. Fagan, 2006, 47-70.

Fordham, Joe. 'Prometheus: Alien Genesis.' Cinefex 130 (July 2012), 32-62.

Fortin, David T. Architecture and Science-Fiction Film: Philip K. Dick and the Spectacle of Home (Farnham, UK: Ashgate Press, 2011).

Foster, Hal, ed. The Anti-Aesthetic: Essays of Postmodern Culture (Port Townsend, WA: Bay Press, 1998).

Foucault, Michel. The Archaeology of Knowledge (New York: Pantheon, 1972).

Fouladi, Shahriar. 'Smallville: Super Puberty and the Monstrous Superhero.' In Gray II and Kaklamanidou, 2011, 161-78.

Frank, Thomas. What's the Matter with Kansas? How Conservatives Won the Heart of America (New York: Henry Holt and Co., 2004).

Freedman, Carl. The Incomplete Projects: Marxism, Modernity, and the Politics of Culture (Middletown, CT: Wesleyan University Press, 2002).

Friedman, Lester D. Citizen Spielberg (Chicago, IL: University of Illinois Press, 2006).

Friedrich, Otto. 'Up, Up and Awaaay!' Time (14 March 1998), 66-74.

Fritze, Ronald H. False Knowledge, Fake Science and Pseudo-Religions (London: Reaktion Books, 2009).

Galtung, Johan. 'Violence, Peace and Peace Research.' Journal of Peace Research 6.3 (1969), 167-91.

—. 'Cultural Violence.' Journal of Peace Research 27.3 (1990), 291-305.

- and Tord Høivik. 'Structural and Direct Violence. A Note on Operationalization.' Journal of Peace Research 8.1 (1971), 73-76.

Gannon, Charles E. Rumors of War and Infernal Machines: Technomilitary AgendaSetting in American and British Speculative Fiction (Liverpool: Liverpool University Press, 2003).

Garcia, Frank and Mark Phillips. Science Fiction Television Series, 1990-2004: Histories, Casts and Credits for 58 Shows (Jefferson, NC: McFarland, 2009).

Garen, Micah and Carleton and Marie-Hélène. 'Erasing the Past: Looting the Archaeological Sites in Southern Iraq.' In Polk and Schuster, 15-19.

Genosko, Gary. 'The Spirit of Symbolic Exchange: Jean Baudrillard's 9/11.' International Journal of Baudrillard Studies 3.1 (2006). http://www.ubishops. ca/baudrillardstudies/vol3_1/genosko.htm.

George, Susan A. Gendering Science Fiction Films: Invaders from the Suburbs (New York: Palgrave Macmillan, 2013).

Geraghty, Lincoln. American Science Fiction Film and Television (New York: Berg, 2009).

-, ed. The Smallville Chronicles (Toronto, ON: Scarecrow Press, 2011).

Gershoni, Israel and James P. Jankowski. Egypt, Islam, and the Arabs: The Search for Egyptian Nationhood, 1900-1930 (New York: Oxford University Press, 1987). 
Gibson, William. Burning Chrome (Author essay). http://www.harpercollins. ca/author/authorExtra.aspx?authorID $=256928$ isbn $13=9780060539825 \&$ displayType=bookessay.

Gnecco, Cristóbal and Tracy Ireland. 'Ethical Archaeologies: The Politics of Social Justice.' In González-Ruibal and Moshenska, 2015, v-vi.

Gomel, Elana. Postmodern Science Fiction and Temporal Imagination (London: Continuum Literary Studies, 2010).

González-Ruibal, Alfredo and Gabriel Moshenska, eds. Ethics and the Archaeology of Violence (New York: Springer, 2015).

Goode, James. 'Archaeology and Diplomacy in the Republic of Turkey, 1919-39.' In Mustafa Aydin and Çağri Erhan, 2004, 49-65.

Gordon, Ian. 'Superman on the Set: The Market, Nostalgia and Television Audiences.' In Jancovich and Lyons, 2003, 148-62.

- Mark Jancovich and Matthew P. McAllister, eds. Film and Comic Books (Jackson, MS: University Press of Mississippi, 2007).

Gosden, Chris. 'The Past and Foreign Countries: Colonial and Post-Colonial Archaeology and Anthropology.' In Meskell and Preucel, 2006, 161-78.

Grajeda, Tony. 'Picturing Torture: Gulf Wars Past and Present.' In Martin and Petro, 2006, 206-36.

Gray II, Richard J. and Betty Kaklamanidou, eds. The 21st Century Superhero: Essays on Gender, Genre and Globalization in Film (Jefferson, SC: McFarland, 2011).

Gregory, Derek. 'Lacan and Geography: The Production of Space Revisited.' In Benko and Strohmayer, 1997, 203-31.

-. The Colonial Present: Afghanistan, Palestine, Iraq (Malden, MA: Blackwell, 2004).

Grünschloss, Andreas. "Ancient Astronaut" Narrations: A Popular Discourse on Our Religious Past.' Marburg Journal of Religion 11.1 (2006), 1-25.

Gullapalli, Praveena. 'Heterogeneous Encounters: Colonial Histories and Archaeological Experiences.' In Liebmann and Rizvi, 2008, 35-52.

Gumpert, Matthew. 'Hybridity's End.' In Potter and Marshall, 2008, $143-55$.

Gunning, Tom. The Films of Fritz Lang: Allegories of Vision and Modernity (London: BFI, 2000).

Hagopian, Patrick. 'The Abu Ghraib Photographs and the State of America: Defining Images.' In Purbrick, 2007, 13-45.

Hales, Peter Bacon. Atomic Spaces: Living on the Manhattan Project (Champaign, IL: University of Illinois Press, 1997).

Hamilakis, Yannis. 'Iraq: Stewardship and the Record: An Ethical Crisis for Archaeology.' Public Archaeology 3 (2003), 104-11.

-. 'The Fragments of Modernity and the Archaeologies of the Future.' Modernism/Modernity 11.1 (2004), 55-59.

- 'Whose World and Whose Archaeology? The Colonial Present and the Return of the Political.' Archaeologies 1.2 (2005), 94-101.

-. 'From Ethics to Politics.' In Hamilakis and Duke, 2007, 15-40.

-. "The "War on Terror" and the Military-Archaeology Complex: Iraq, Ethics, and Neo-Colonialism.' Archaeologies 5.1 (2009), 39-65. 
- and Philip Duke, eds. Archaeology and Capitalism: From Ethics to Politics (Walnut Creek, CA: Left Coast Press, 2007).

Hantke, Steffen. 'Bush's America and the Return of Cold War Science Fiction: Alien Invasion in Invasion, Threshold, and Surface.' Journal of Popular Film and Television 38.3 (2010), 143-51.

-. 'Exit Strategies: Narrative Closure and Political Allegory in Lost and Battlestar Galactica.' Zeitschrift für Anglistik und Amerikanistik: A Quarterly of Language, Literature and Culture 60.4 (2012), 375-90.

Haraway, Donna. Simians, Cyborgs and Women: The Reinvention of Nature (New York: Routledge, 1991).

Harlan, Jan and Jane M. Struthers, eds. A.I. Artificial Intelligence: From Stanley Kubrick to Steven Spielberg: The Vision Behind the Film (London: Thames and Hudson, 2009).

Harrison, Rodney. 'Surface Assemblages: Towards an Archaeology in and of the Present.' Archaeological Dialogues 18.2 (2011), 141-61.

Harrold, Francis B. and Raymond Eve, eds. Cult Archaeology and Creationism: Understanding Pseudoscientific Beliefs About the Past, rev. ed. (Iowa City, IA: University of Iowa Press, 1995).

Hart, Gary. 'The Absent Congress.' In Leone and Anrig, 2007, 67-86.

Hassan, Fekri A. 'Memorabilia: Archaeological Materiality and National Identity in Egypt.' In Meskell, 1998, 200-16.

Hassler, Donald M. and Clyde Wilcox, eds. New Boundaries in Political Science Fiction (Columbia, SC: University of South Carolina Press, 2008).

Hendershot, Cyndy. Anti-Communism and Popular Culture in Mid-Century America (Jefferson, NC: McFarland, 2002).

Hirmer, Karin. 'Smallville's Lois Lane: From New Woman to Female Hero.' In Farghaly, 2013b, 235-60.

Hiscock, Peter. 'Cinema, Supernatural Archaeology, and the Hidden Human Past.' NUMEN 59 (2012), 156-77.

Hodder, Ian. Reading the Past: Current Interpretive Archaeology (Cambridge: Cambridge University Press, 1986).

- and Scott Hudson. Reading the Past: Current Approaches to Interpretation in Archaeology (New York: Cambridge University Press, 2003).

Hodson, Joel C. Lawrence of Arabia and American Culture: The Making of a Transatlantic Legend (Westport, CT: Greenwood Press, 1995).

Holloway, David. Cultures of the War on Terror: Empire, Ideology, and the Remaking of 9/11 (Montreal, QC, and Kingston, ON: McGill-Queen's University Press, 2008).

Holtorf, Cornelius. 'Beyond Crusades: How (Not) to Engage with Alternative Archaeologies.' World Archaeologies 37.4 (2005), 544-51.

-. Archaeology Is a Brand! The Meaning of Archaeology in Contemporary Popular Culture (Oxford, UK: Archaeopress, 2007).

Hoopes, John W. 'New Age Sympathies and Scholarly Complicities: The History and Promotion of 2012 Mythology.' Archaeoastronomy: The Journal of Astronomy in Culture 24 (2011a), 183-205.

-. 'A Critical History of 2012 Mythology.' Proceedings of the International Symposium on Archaeoastronomy 278 (2011b), 240-48. 
Hunner, John. 'Reinventing Los Alamos: Code Switching and Suburbia at America's Atomic City.' In Zeman and Amundson, 2004, 33-48.

Hunter, Edward. Brain-Washing in Red China: The Calculated Destruction of Men's Minds (New York: Vanguard Press, 1951).

Huq, Aziz, 'The New Counterterrorism: Investigating Terror, Investigating Muslims.' In Leone and Anrig, 2007, 167-85.

Huyssen, Andreas. 'The Vamp and the Machine: Fritz Lang's Metropolis.' In Minden and Bachmann, 2000, 198-216.

Izard, Ralph and Jay Perkins, eds. Lessons from Ground Zero: Media Response to Terror (Edison, NJ: Transaction Publishers, 2010).

Jackson, Kathy Merlock. 'Screaming Her Way into the Hearts of Post-9/11 Audiences: Dakota Fanning as Child Star.' In Morgan, 2009, 209-20.

Jacobs, Steven. 'Panoptic Paranoia and Phantasmagoria: Fritz Lang's Nocturnal City.' In Fisher and Mennel, 2010, 381-95.

Jafar, Ali. 'Jordan Hosts "Transformers" Shoot.' http://variety.com/2009/ film/features/jordan-hosts-transformers-shoot-1117999584.

jagodzinski, jan. Television and Youth Culture: Televised Paranoia (New York: Palgrave Macmillan, 2008).

James, Edward and Farah Mendlesohn, eds. Parliament of Dreams: Conferring on Babylon 5 (UK: Science Fiction Foundation, 1998).

Jameson, Fredric. Archaeologies of the Future: The Desire Called Utopia and Other Science Fictions (New York: Verso, 2005).

Jancovich, Mark. 'Re-Examining the 1950s Invasion Narratives.' In Redmond, 2004, 325-36.

- and James Lyons, eds. Quality Popular Television: Cult TV, the Industry and the Fans (London: British Film Institute, 2003).

Joffe, Alexander H. 'Museum Madness in Baghdad.' The Middle East Quarterly 11.2 (2004), 31-43.

Johnson, Matthew. Archaeological Theory: An Introduction, 2nd ed. (Malden, MA: Wiley-Blackwell, 2010).

Johnson-Lewis, Ericka. 'Torture, Terrorism, and Other Aspects of Human Nature.' In Potter and Marshall, 2008, 27-39.

Johnson-Smith, Jan. American Science Fiction TV: Star Trek, Stargate and Beyond (Middleton, CT: Wesleyan University Press, 2005).

Johnston, Keith M. Science Fiction Film: A Critical Introduction (New York: Berg, 2011).

Jones, Cary M. 'Smallville's Version of Superman.' Jump Cut: A Review of Contemporary Media 48 (Winter 2006). http://ejumpcut.org/archive/ jc48.2006/SmallvilleFans/.

'Jordan Signs Cinema Pact with USC.' http://news.usc.edu/20532/JordanSigns-Cinema-Pact-With-USC.

Kakoudaki, Despina. Anatomy of a Robot: Literature, Cinema, and the Cultural Work of Artificial People (New Brunswick, NJ: Rutgers University Press, 2014).

Kalman, Harold. 'Destruction, Mitigation, and Reconciliation of Cultural Heritage.' International Journal of Heritage Studies 23.6 (2017), 1-18.

Kamuf, Peggy and Elizabeth G. Rottenberg. Psyche: Inventions of the Other, vol. 1 (Stanford University Press, 2007), 191-225. 
Karpel, Ari. 'Behind the Innovative Social/Content-Driven Campaign for "Prometheus"' (26 June 2012). https://www.fastcocreate.com/1680976/ behind-the-innovative-socialcontent-driven-campaign-for-prometheus.

Kaveney, Roz and Jennifer Stoy, eds. Battlestar Galactica: Investigating Flesh, Spirit and Steel (London: Taurus, 2010).

Kennedy, Christina B. 'The Myth of Heroism: Man and Desert in Lawrence of Arabia.' In Aitken and Zonn, 1994, 161-79.

Kerman, Judith B., ed. Retrofitting Blade Runner: Issues in Ridley Scott's Blade Runner and Philip K. Dick's Do Androids Dream of Electric Sheep (Madison, WI: University of Wisconsin Press, 1997a).

Kerslake, Patricia. Science Fiction and Empire (Liverpool: Liverpool University Press, 2007).

Khatib, Lina. Filming the Modern Middle East: Politics in the Cinemas of Hollywood and the Arab World (London: Tauris Books, 2006).

Khun, Annette. Alien Zone II: The Spaces of Science Fiction Cinema (New York: Verso, 1999).

Kienscherf, Markus. US Domestic and International Regimes of Security: Pacifying the Globe, Securing the Homeland (New York: Routledge, 2013).

Kim, Min-Sun and Eun-Joo Kim. 'Humanoid Robots as "The Cultural Other": Are We Able to Love Our Creations?' AI and Society 28 (2013), 309-18.

Kind, Amy. 'You Can't Rape a Machine.' In Steiff and Tamplin, 2008, 117-28.

King, Geoff. Spectacular Narratives (London: Tauris, 2000).

-. 'Spectacle, Narrative, and the Spectacular Hollywood Blockbuster.' In Stringer, 2003, 114-27.

-, ed. The Spectacle of the Real: From Hollywood to Reality TV and Beyond (Portland, OR: Intellect Books, 2005).

—. '“Just like a Movie" ?: 9/11 and Hollywood Spectacle.' In King, 2005, 47-57.

Klein, Norman. 'Building Blade Runner.' Social Text 28 (1991), 147-52.

Klinger, Barbara. Melodrama and Meaning: History, Culture, and the Films of Douglas Sirk (Bloomington, IN: Indiana University Press, 1991).

- 'Beyond Cheap Thrills: 3D Cinema Today, the Parallax Debates and the "Pop-Out."' Public 24.37 (2013), 186-99.

Kodrich, Kris and Sweety Law. 'U.S. and British Press Coverage of the Search for Iraq's Mysterious and Missing Weapons of Mass Destruction.' In Berenger, 2004, 189-202.

Kohl, Philip L. and Clare Fawcett, eds. Nationalism, Politics, and the Practice of Archaeology (New York: Cambridge University Press, 1995).

Kohnen, Melanie E.S. 'The Adventures of a Repressed Farm Boy and the Billionaire Who Loves Him: Queer Spectatorship in Smallville Fandom.' In Ross and Stein, 2008, 207-23.

Kolker, Robert, ed. Stanley Kubrick's 2001: A Space Odyssey: New Essays (Oxford: Oxford University Press, 2006).

Kosso, Peter. 'The Epistemology of Archaeology.' In G. Fagan, 2006, 3-22.

Kozloff, Sarah. 'Superman as Saviour: Christian Allegory in the Superman Movies.' Journal of Popular Film and Television 9.2 (1981), 78-82. 
Kreindler, Sarv. 'Sound Design for Deep Space: Audio, Androids and Aliens on Prometheus.' Creative Planet Network (20 September 2012). http://www. creativeplanetnetwork.com/news/news-articles/sound-design-deep-spaceaudio-androids-and-aliens-prometheus/405112.

Kulle, Daniel. 'Bodies as Unreliable Signifiers: The Inconsistency of Smallville's Character Construction.' In Barker et al., 2014, 145-60.

Kustritz, Anne. 'Smallville's Sexual Symbolism: From Queer Repression to Fans' Queered Expressions.' Refractory: A Journal of Entertainment Media (14 October 2005). http://refractory.unimelb.edu.au/2005/10/14/ smallville\%E2\% 80\%99s-sexual-symbolism-from-queer-repression-tofans \%E2\% $\% 0 \% 99$-queered-expressions-anne-kustritz/.

Lacy, Mark. 'War, Cinema, and Moral Anxiety.' Alternatives 28 (2003), 611-36.

Landon, Brooks. 'Diegetic or Digital? The Convergence of Science-Fiction Literature and Science-Fiction Film in Hypermedia.' In Khun, 1999, 31-49.

Landy, Marcia. 'The Cinematographic Brain in 2001: A Space Odyssey.' In Kolker, 2006, 87-104.

Lavery, David, ed. The Essential Cult TV Reader (Lawrence, KY: University Press of Kentucky, 2010).

Lawrence, T.E. Seven Pillars of Wisdom: A Triumph (London: Jonathan Cape, 1935).

Leaver, Tama. “Humanity's Children": Constructing and Confronting the Cylons.' In Eberl, 2008, 169-80.

-. Artificial Culture: Identity, Technology, and Bodies (New York: Routledge, 2012).

Leonard, Garry. 'Technically Human: Kubrick's Monolith and Heidegger's Propriative Event.' Film Criticism 36.1 (2011), 44-67.

Leone, Richard C. and Greg Anrig, Jr., eds. Liberty Under Attack: Reclaiming Our Freedoms in an Age of Terror (New York: Public Affairs, 2007).

Lepselter, Susan. 'Why Rachel Isn't Buried at Her Grave: Ghosts, UFOs, and a Place in the West.' In Rosenberg and Harding, 2005, 255-80.

Liebmann, Matthew and Uzma Z. Rizvi. Archaeology and the Postcolonial Critique (Lanham, MD: Altamira Press, 2008).

Liedl, Janice. 'The Battle for History in Battlestar Galactica.' In Wright and Austin, 2010, 289-307.

Linder-Linsley, Sue E. 'Exploring the Archaeology of Stargate SG-1: From Childhood Westerns to Interstellar Imagination.' In Elrod and Conrad, 2004, 37-50.

Löfflmann, Georg. 'Hollywood, the Pentagon, and the Cinematic Production of National Security.' Critical Studies on Security 1.3 (2013), 280-94.

'The Long Shadows of 9/11: Science Fiction, Thrillers, and the War on Terror.' Special issue, Cinema Journal 51.1 (Fall 2011).

Loren, Scott. 'Mechanical Humanity, or How I Learned to Stop Worrying and Love the Android: The Posthuman Subject in 2001: A Space Odyssey and Artificial Intelligence: A.I. In Rhodes, 2007, 211-31. 
Lovata, Troy. 'Curious Archaeology: The Process of Assembling a Fringe Prehistory.' Public Archaeology 4 (2005), 266-75.

-. Inauthentic Archaeologies: Public Uses and Abuses of the Past (Walnut Creek, CA: Left Coast Press, 2007).

Lucia, Cynthia et al., eds. American Film History: Selected Readings, 1960 to Present (Malden, MA: Wiley Blackwell, 2016).

Luckhurst, Roger. Science Fiction (Malden, MA: Polity, 2005).

Luke, Christina and Morag M. Kersel. U.S. Cultural Diplomacy and Archaeology: Soft Power, Hard Heritage (New York: Routledge, 2013).

MacCabe, Colin et al., eds. True to the Spirit: Film Adaptation and the Question of Fidelity (Oxford: Oxford University Press, 2011).

Macfie, Alexander Lyon. 'Representations of Lawrence of Arabia.' Journal of Postcolonial Writing 43.1 (2007), 77-87.

Mack, John E. A Prince of Our Disorder: The Life of T. E. Lawrence (Boston: Little, Brown, 1976).

Malamud, Margaret. 'Pyramids in Las Vegas and in Outer Space: Ancient Egypt in Twentieth-Century American Architecture and Film.' Journal of Popular Culture 34.1 (2000), 31-47.

Maltby, Robert. Hollywood Cinema, 2nd ed. (Oxford: Blackwell, 2003).

Marmysz, John. 'The Myth of Scotland as Nowhere in Particular.' International Journal of Scottish Theatre and Screen 7.1 (2014), 28-44.

Martin, Andrew and Patrice Petro, eds. Rethinking Global Security: Media, Popular Culture, and the 'War on Terror' (New Brunswick, NJ: Rutgers University Press, 2006).

Masco, Joseph. 'A Notebook on Desert Modernism: From the Nevada Test Site to Liberace's Two-Hundred-Pound Suit.' In Rosenberg and Harding, 2005, 19-50.

Masters, Cristina. 'Bodies of Technology.' International Feminist Journal of Politics 7.1 (2005), 112-32.

Matthews, Melvin E., Jr. Hostile Aliens, Hollywood and Today's News: 1950 s Science Fiction Films and 9/11 (New York: Algora, 2007).

McBride, Joseph. Steven Spielberg: A Biography (Jackson: University of Mississippi Press, 2011).

McClean, Silo. Digital Storytelling: The Narrative Power of Visual Effects in Film (Cambridge, MA: MIT Press, 2007).

McGeough, Kevin M. 'Victorian Archaeologies, Anthropologies and Adventures in the Final Frontier: Modes of Nineteenth-Century Scientific Exploration and Display in Star Trek.' Science Fiction Film and Television 9.4 (2016), 229-52.

McHale, Brian. Postmodern Fiction (New York: Routledge, 1987).

McHenry, Bryan. 'Weapons of Mass Salvation.' In Steiff and Tamplin, 2008, 221-32.

McKnight, Nadine. 'Black Markets and Black Mystics: Racial Shorthand in Battlestar Galactica.' Science Fiction Film and Television 5.1 (2012), 47-66.

Melançon, Louis. 'Secrets and Lies: Balancing Security and Democracy in the Colonial Fleet.' In Steiff and Tamplin, 2008, 211-20. 
Melley, Timothy. Empire of Conspiracy (Ithaca, NY: Cornell University Press, 2000).

-. 'Brain Warfare: The Covert Sphere, Terrorism, and the Legacy of the Cold War.' Grey Room 45 (2011), 18-41.

Mengay, David. 'Arabian Rites: T. E. Lawrence's Seven Pillars of Wisdom and the Erotics of Empire.' Genre 27 (Winter 1994), 395-416.

Merriman, Nick, ed. Public Archaeology (New York: Routledge, 2004).

Meskell, Lynn, ed. Archaeology Under Fire: Nationalism, Politics, and Heritage in the Eastern Mediterranean and Middle East (New York: Routledge Press, 1998).

-. 'The Practice and Politics of Archaeology in Egypt.' In Cantwell, 2000, 146-70.

-. 'Sites of Violence: Terrorism, Tourism, and Heritage in the Archaeological Present.' In Meskell and Pels, 2005, 123-46.

- and P. Pels, eds. Embedding Ethics (New York: Berg, 2005).

- and Robert W. Preucel, eds. A Companion to Social Archaeology (New York: Blackwell, 2006).

Mindon, Michael and Holger Bachmann, eds. Fritz Lang's Metropolis: Visions of Technology and Fear (Rochester, NY: Camden House, 2000).

Mirrlees, Tanner. Global Entertainment Media: Between Cultural Imperialism and Cultural Globalization (New York: Routledge, 2013).

Mirzoeff, Nicholas. Watching Babylon: The War in Iraq and Global Visual Culture (New York: Routledge, 2005).

—. 'Invisible Empire: Visual Culture, Embodied Spectacle, and Abu Ghraib.' Radical History Review 95 (2006), 21-44.

Mitchell, Timothy. Colonising Egypt (Berkeley: University of California Press, 1988).

Mittell, Jason. Complex TV: The Poetics of Contemporary Television Storytelling (New York: New York University Press, 2015).

Monahan, Brian A. The Shock of the News: Media Coverage and the Making of 9/11 (New York: New York University Press, 2010).

Moore, Ronald. 'Kobol's Last Gleaming: Part l' (DVD podcast commentary). Battlestar Galactica Season 1 (Universal Studios Home Entertainment, 2005).

-. 'Daybreak: Part 2, 3' (DVD Podcast Commentary). Battlestar Galactica Season 4 (Universal Studios Home Entertainment, 2009).

Morgan, Matthew J., ed. The Impact of 9/11 on the Media, Arts and Entertainment: The Day That Changed Everything? (New York: Palgrave Macmillan, 2009).

Morris, Nigel. The Cinema of Steven Spielberg: Empire of Light (New York: Wallflower Press, 2007).

Morrissey, Thomas. 'Growing Nowhere: Pinocchio Subverted in Spielberg's A.I. Artificial Intelligence.' Extrapolation 45.3 (2004), 249-62.

Mourad, Tamima Orra. 'An Ethical Archaeology in the Near East: Confronting Empire, War and Colonization.' In Hamilakis and Duke, 2007, 151-67.

Moylan, Katie. "Nothing Is What It Appears to Be": Event Fidelity and Critique in Battlestar Galactica and Dollhouse.' Science Fiction Film and Television 5.1 (2012), 67-84. 
Mulligan, Rikk. 'The Cain Mutiny: Reflecting the Faces of Military Leadership in a Time of Fear.' In Potter and Marshall, 52-63.

Nacos, Brigitte et al. Selling Fear: Counterterrorism, the Media, and Public Opinion (Chicago, IL: University of Chicago Press, 2011).

Ndalianis, Angela. 'Stargate SG-1.' In Lavery, 2010, 237-82.

-. Science Fiction Experiences (Washington, DC: New Academia Publishing, 2011).

Nelson, Thomas Allen. Kubrick: Inside a Film Artist's Maze, expanded and rev. ed. (Bloomington, IN: Indiana University Press, 2000).

Nemeth, Erik. 'Collecting Cultural Intelligence: The Tactical Value of Cultural Property.' International Journal of Intelligence and CounterIntelligence 24 (2011), 217-38.

-. Cultural Security: Evaluating the Power of Culture in International Affairs (London: Imperial College Press, 2015).

Nicholas, George and Julie Hollowell. 'Ethical Challenges to a Postcolonial Archaeology: The Legacy of Scientific Colonialism.' In Hamilakis and Duke, 2007, 59-82.

North, Dan et al., eds. Special Effects: New Histories/Theories/Contexts (New York: Palgrave, 2015).

Olsen, Bjørnar, Michael Shanks, Timothy Webmoor and Christopher Witmore. Archaeology: The Discipline of Things (Berkeley, CA: University of California Press, 2012).

Ott, Brian L. '(Re)Framing Fear: Equipment for Living in a Post-9/11 World.' In Potter and Marshall, 2008, 13-26.

Parkin, Simon. 'How ISIS Hijacked Pop Culture: From Hollywood to Video Games.' The Guardian (29 January 2016). https://www.theguardian. com/world/2016/jan/29/how-isis-hijacked-pop-culture-from-hollywoodto-video-games.

Patterson, Alison. 'Indexing an Icon: T.E. Lawrence's Seven Pillars of Wisdom and David Lean's Lawrence of Arabia.' In MacCabe et al., 2011, 157-73.

Pearson, Mike and Michael Shanks. Theatre/Archaeology (New York: Routledge, 2001).

Peters, Ian M. 'Choosing Sides: Occupation or Resistance?' In Steiff and Tamplin, 2008, 201-10.

Piette, Adam. The Literary Cold War: 1945 to Vietnam (Edinburgh: Edinburgh University Press, 2009).

Pinedo, Isabel. 'Playing with Fire Without Getting Burned: Blowback Re-Imagined.' In Steiff and Tamplin, 2008, 173-84.

Polk, Milbry and Angela M.H. Schuster, eds. The Looting of the Iraq Museum, Baghdad: The Lost Legacy of Ancient Mesopotamia (New York: Harry N. Abrams, 2005).

Pollock, Susan. 'Archaeology Goes to War at the Newsstand.' In Pollock and Bernbeck, 2005, 78-96.

- and Catherine Lutz. 'Archaeology Deployed for the Gulf War.' Critique of Anthropology 14 (1994), 263-84.

- and Reinhard Bernbeck, eds. Archaeologies of the Middle East: Critical Perspectives (New York: Blackwell Publishing, 2005). 
Pope, Richard. 'Affects of the Gaze: Post-Oedipal Desire and the Traversal of Fantasy in Blade Runner.' Camera Obscura 25.1 (2010), 69-95.

Potter, Tiffany and C.W. Marshall, eds. Cylons in America: Critical Studies in Battlestar Galactica (New York: Continuum, 2008).

Power, Marcus and Andrew Crampton. 'Reel Geopolitics: Cinema-tographing Political Space.' Geopolitics 10.2 (2005), 193-203.

Preucel, Robert W. Archaeological Semiotics (Malden, MA: Blackwell, 2006).

Prince, Stephen. Firestorm: American Film in the Age of Terrorism (New York: Columbia University Press, 2009).

Purbrick, Louise, ed. Contested Spaces: Cultural Representations and the Histories of Conflict (New York: Palgrave Macmillan, 2007).

Purse, Lisa. 'The New Spatial Dynamics of the Bullet-Time Effect.' In King, 2005, 151-60.

-. Contemporary Action Cinema (Edinburgh: Edinburgh University Press, 2011).

Pyburn, K. Anne. 'Preservation as "Disaster Capitalism": The Downside of Site Rescue and the Complexity of Community Engagement.' Public Archaeology 13.1-3 (2014), 226-39.

Quay, Sara E. and Amy Damico, eds. September 11 in Popular Culture: A Guide (Santa Barbara, CA: Greenwood, 2010).

Randell, Karen. "It Was like a Movie": The Impossibility of Representation in Oliver Stone's World Trade Centre.' In Birkenstein et al., 2010, 141-52.

Rawle, Steven. 'Real-Imagining Terror in Battlestar Galactica: Negotiating Real and Fantasy in Battlestar Galactica's Political Metaphor.' In Kaveney and Stoy, 2010, 129-53.

Redmond, Sean, ed. Liquid Metal: The Science Fiction Film Reader (New York: Wallflower Press, 2004).

Reid, Donald Malcolm. 'Nationalizing the Pharaonic Past: Egyptology, Imperialism and Egyptian Nationalism, 1922-52.' In Gershoni and Jankowski, 1987, 127-49.

-. Whose Pharaohs?: Archaeology, Museums, and Egyptian National Identity from Napoleon to World War I (Berkeley: University of California Press, 2002).

Restall, Matthew and Amara Solari. 2012 and the End of the World: The Western Roots of the Maya Apocalypse (London: Rowman and Littlefield, 2011).

Reyes, Ian and Jason K. Smith. 'What They Don't Want You to Know About Planet X: Surviving 2012 and the Aesthetics of Conspiracy Rhetoric.' Communication Quarterly 64.4 (2014), 399-415.

Rhodes, Gary D., ed. Stanley Kubrick: Essays on His Films and Legacy (Jefferson, NC: McFarland, 2007).

Richmond, Scott C. Cinema's Bodily Illusions: Flying, Floating, and Hallucinating (Minneapolis, MN: University of Minnesota Press, 2016).

Richter, Jonas. 'Traces of the Gods: Ancient Astronauts as a Vision of Our Future.' Numen 59 (2012), 222-48.

Richter, Tobias. 'Espionage and Near Eastern Archaeology: A Historiographical Survey.' Public Archaeology 7.4 (2008), 212-40.

Rieder, John. Colonialism and the Emergence of Science Fiction (Middletown, CN: Wesleyan University Press, 2008). 
Rinzler, J.W. The Complete Making of Indiana Jones: The Definitive Story Behind All Four Films (New York: Ballantine Books, 2008).

Rizvi, Uzma Z. 'Conclusion: Archaeological Futures and the Postcolonial Critique.' In Liebmann and Rizvi, 2008, 197-203.

Robb, David L. Operation Hollywood: How the Pentagon Shapes and Censors the Movies (New York: Prometheus Books, 2004).

Robertson, Barbara. 'Weighty Matters.' Computer Graphics World 32.7 (July 2009), 20-29.

Roe, Annabelle Honess. Animated Documentary (New York: Palgrave Macmillan, 2013).

Rosenberg, Daniel and Susan Harding, eds. Histories of the Future (Durham, SC: Duke University Press, 2005).

Ross, Miriam. 3D Cinema: Optical Illusions and Tactile Experiences (New York: Palgrave Macmillan, 2015).

Ross, Sharon Marie and Louisa Ellen Stein, eds. Teen Television: Essays on Programming and Fandom (Jefferson, NC: McFarland, 2008).

Rush, Laurie, ed. Archaeology, Cultural Property, and the Military (Rochester, NY: Boydell Press, 2010).

- ' Military Archaeology in the US: A Complex Ethical Decision.' In Stone, 2011, 139-51.

-. 'Partnership Versus Guns: Military Advocacy of Peaceful Approaches for Cultural Property Protection.' In González-Ruibal and Moshenska, 2015, 181-98.

- and H. Wagner. 'Fort Drum Research Web.' www.drum.army.mil/ publicworks/pages/culturalresources.aspx.

Russell, John Malcolm. The Final Sack of Nineveh: The Discovery, Documentation, and Destruction of King Sennacherib's Throne Room at Nineveh, Iraq (New Haven: Yale University Press, 1998).

Sagan, Carl. 'Direct Contact among Galactic Civilizations by Relativistic Interstellar Spaceflight.' Planetary and Space Science 11.5 (1963), 485-98.

-. The Cosmic Connection: An Extraterrestrial Perspective (New York: Doubleday, 1973).

-. Boca's Brain: Reflections on the Romance of Science (New York: Random House, 1974).

- and I.S. Shklovski1. Intelligent Life in the Universe (San Francisco: Holden-Day, 1966).

Said, Edward. Orientalism (New York: Vintage Books, 1978).

-. Culture and Imperialism (New York: Vintage Books, 1993).

Sancton, Julian. 'TED Goes to the Movies' (22 March 2012). http:// www.bloomberg.com/bw/articles/2012-03-22/ted-goes-to-the-movieswith-prometheus-promotion.

Satia, Priya. Spies in Arabia: The Great War and the Cultural Foundations of Britain's Covert Empire in the Middle East (Oxford: Oxford University Press, 2008).

Scardera, Francis. 'Akwesasne-Where the Partridges Drum to Fort Drum: Consultation with Native Communities, an Evolving Process.' In Stone, 2011, 152-57. 
Schadla-Hall, Tim. 'The Comforts of Unreason: The Importance and Relevance of Alternative Archaeology.' In Merriman, 2004, 255-71.

Scham, Sandra. 'Disinheriting Heritage: Explorations in the Contentious History of Archaeology in the Middle East.' In Liebmann and Rizvi, 2008, 165-76.

Scheibach, Michael. Atomic Narratives and American Youth: Coming of Age with the Atom, 1945-1955 (Jefferson, NC: McFarland Press, 2003).

-, ed. 'In Case Atom Bombs Fall': An Anthology of Governmental Explanations, Instructions, and Warnings from the 1940s to 1960s (Jefferson, NC: McFarland Press, 2009).

Schulhofer, Stephen J. 'The Patriot Act and the Surveillance Society.' In Leone and Anrig, 2007, 123-47.

Scorer, James. " $\mathrm{X}$ " Never, Ever Marks the Spot: Latin American Lost Cities on Screen.' Iberoamericana 11.44 (2011), 101-16.

Seed, David. American Science Fiction and the Cold War: Literature and Film (Edinburgh: Edinburgh University Press, 1999a).

-, ed. Imagining Apocalypse: Studies in Cultural Crisis (New York: St. Martin's Press, 1999b).

-. Brainwashing: The Fictions of Mind Control: A Study of Novels and Films Since World War II (Kent, OH: Kent State University Press, 2004).

Shaheen, Kareem and Ian Black. 'Beheaded Syrian Archaeologist Refused to Lead ISIS to Hidden Palmyra Antiquities.' The Guardian (19 August 2015). https://WWw.theguardian.com/world/2015/aug/18/ isis-beheads-archaeologist-syria.

Shanks, Michael. Experiencing the Past: On the Character of Archaeology (New York: Routledge, 1991).

-. 'The Life of an Artifact in an Interpretive Archaeology.' Fennoscandia Archaeologica 25 (1998), 15-30.

-. The Archaeological Imagination (New York: Routledge, 2012).

Shapiro, Michael J. Cinematic Geopolitics (New York: Routledge, 2009).

Sharp, Patrick B. 'Starbuck as "American Amazon": Captivity Narrative and the Colonial Imagination in Battlestar Galactica.' Science Fiction Film and Television 3.1 (2010), 57-78.

Shaw, Wendy M.K. Possessors and Possessed: Museums, Archaeology, and the Visualization of History in the Late Ottoman Empire (Berkeley, CA: University of California Press, 2003).

Shimpach, Shawn. Television in Transition: The Life and Afterlife of the Narrative Action Hero (Malden, MA: Wiley-Blackwell, 2010).

Shohat, Ella and Robert Stam. Unthinking Eurocentrism: Multiculturalism and the Media (New York: Routledge, 1994).

Shoup, Daniel. 'Archaeology, Science Fiction, and Pop Culture.' Archaelog (17 May 2009) https://web.stanford.edu/dept/archaeology/cgi-bin/ $\operatorname{archaeolog} / ? \mathrm{p}=253$.

Silberman, Neil Asher. Between Past and Present: Archaeology, Ideology, and Nationalism in the Modern Middle East (New York: H. Holt, 1989).

- ' 'Promised Lands and Chosen Peoples: The Politics and Poetics of Archaeological Narrative.' In Kohl and Fawcett, 1995, 249-62. 
Silverman, Eric J. 'Adama's True Lie: Earth and the Problem of Knowledge.' In Eberl, 2008, 192-202.

Silverman, Kaja. 'Back to the Future.' Camera Obscura 9.3 (1991), 108-32.

-. Male Subjectivity at the Margins (New York: Routledge, 1992).

Simpson, Scott and Jessica Sheffield. 'Neocolonialism, Technology, and Myth in the Stargate Universe.' In Whitt and Perlich, 2008, 73-98.

Sitchin, Zecharia. The Twelfth Planet (New York: Stein and Day, 1976).

Sitler, Robert K. 'The 2012 Phenomenon: New Age Appropriation of an Ancient Mayan Calendar.' Nova Religio 9.3 (2006), 24-38.

Smelik, Anneke, ed. The Scientific Imaginary in Visual Culture (Göttingen: V\&R Unipress, 2010a).

—. 'Cinematic Fantasies of Becoming-Cyborg.' In Smelik, 2010b, 89-104.

Smith, Jeff. Film Criticism, the Cold War, and the Blacklist: Reading the Hollywood Reds (Berkeley, CA: University of California Press, 2014).

Smith, Stephanie. "AAn Empire O'er the Disentangled Doom": Captivity and the Re-Staging of Prometheus in the Twenty-First Century.' Science Fiction Film and Television 9.1 (2016), 55-72.

Smith, Stephen. "Furious Envy": Baudrillard and the Looting of Baghdad.' International Journal of Baudrillard Studies 3.2 (2006). http://www.ubishops. ca/baudrillardstudies/vol3_2/smith.htm.

Sobchack, Vivian. Screening Space: The American Science Fiction Film, 2nd enl. ed. (New Brunswick, NJ: Rutgers University Press, 1997).

-, ed. Meta-Morphing: Visual Transformation and the Culture of Quick-Change (Minneapolis, MN: University of Minnesota Press, 1999).

-. 'Between a Rock and a Hard Place: How Ridley Scott's Prometheus Deals with Impossible Expectations and Mythological Baggage.' Film Comment (July-August 2012), 30-34.

Sofia, Zoë. 'Exterminating Fetuses: Abortion, Disarmament, and the Sexo-Semiotics of Extraterrestrialism.' Diacritics 14.2 (1984), 47-59.

Sontag, Susan. 'The Imagination of Disaster.' In Redmond, 2004, 40-47.

Spanò, Antonia, Narges Hashemi and Sanaz Nourollahichatabi. 'ImageBased Models Using Crowdsourcing Strategies.' DigitCult: Scientific Journal on Digital Cultures 1.3 (2016), 65-79.

Starzmann, Maria Teresia, Susan Pollock and Reinhard Bernbeck. 'Imperial Inspections: Archaeology, War and Violence.' Archaeologies: Journal of the World Archaeological Congress 4.3 (2008), 353-55.

Steele, Caroline. 'Who Has Not Eaten Cherries with the Devil? Archaeology Under Challenge.' In Pollock and Bernbeck, 2005, 45-65.

Steiff, Josef and Tristan D. Tamplin, eds. Battlestar Galactica and Philosophy: Mission Accomplished or Mission Frakked Up? (Chicago, IL: Open Court, 2008).

Stojnić, Aneta. 'Cyborgs from Fiction to Reality: Marginalized Other or Privileged First?' Identities: Journal for Politics, Gender and Culture 10.1-2 (2013), 49-53.

Stone, Peter G. Cultural Heritage, Ethics, and the Military (Woodbridge, UK: Boydell Press, 2011).

- and Joanne Farchakh Bajjaly, eds. The Destruction of Cultural Heritage in Iraq (Woodbridge, Suffolk: Boydell and Brewer, 2008). 
Straczynski, J. Michael. 'The Profession of Science Fiction, 48: Approaching Babylon.' Foundation 64 (1995), 5-19.

Stringer, Julian, ed. Movie Blockbusters (New York: Routledge, 2003).

Takacs, Stacy. 'Monsters, Monsters Everywhere: Spooky TV and the Politics of Fear in Post-9/11 America.' Science Fiction Studies 36 (2009), 1-22.

Tasker, Yvonne, ed. Action and Adventure Cinema (New York: Routledge, 2004).

Teijgeler, René. 'Embedded Archaeology: An Exercise in Self-Reflection.' In Stone and Bajjaly, 2008, 173-82.

Telotte, J.P., ed. The Essential Science Fiction Television Reader (Lexington: University Press of Kentucky, 2008).

- and Gerald Duchovnay, eds. Science Fiction Film, Television, and Adaptation: Across the Screens (New York: Routledge, 2011).

Thomas, Julian. Archaeology and Modernity (New York: Routledge, 2004).

Tilley, Christopher, ed. Reading Material Culture: Structuralism, Hermeneutics, and Post-Structuralism (Oxford: Blackwell, 1990).

-. Material Culture and Text: The Art of Ambiguity (New York: Routledge, 1991).

-. Metaphor and Material Culture (Oxford: Blackwell, 1999).

Titus, Costandina. 'The Mushroom Cloud as Kitsch.' In Zeman and Amundson, 2004, 101-24.

Tomasulo, Frank P. 'Mr. Jones Goes to Washington: Myth and Religion in Raiders of the Lost Ark.' Quarterly Review of Film Studies (Fall 1982), 331-40.

Tryon, Chuck. 'Digital 3D, Technological Auteurism and the Rhetoric of Cinematic Revolution.' In North et al., 2015, 183-95.

Ucko, Peter J., ed. Theory in Archaeology: A World Perspective (London: Routledge, 1995).

Vint, Sherryl. Bodies of Tomorrow: Technology, Subjectivity, Science Fiction (Toronto: University of Toronto Press, 2007).

-. 'Babylon 5: Our First, Best Hope for Mature Science Fiction Television.' In Telotte, 2008, 247-65.

-. 'Simians, Subjectivity and Sociality: 2001: A Space Odyssey and Two Versions of Planet of the Apes.' Science Fiction Film and Television 2.2 (2009), 225-50.

-. 'Stargate $S G-1$ and the Visualization of the Imagination.' In Telotte and Duchovnay, 2011, 67-83.

Vizzini, Bryan E. 'Cold War Fears, Cold War Passions: Conservatives and Liberals Square Off in 1950s Science Fiction.' Quarterly Review of Film and Video 26.1 (2008), 28-39.

Von Däniken, Erich. Chariots of the Gods? Unsolved Mysteries of the Past (New York: Putnam, 1970).

Weaver-Hightower, Rebecca. 'Tomb Raider Archaeologists and the Exhumation of the US Neoimperial Cinematic Fantasy.' Journal of Popular Culture 47.1 (2014), 109-28.

Webster, David. 'The Mystique of the Ancient Maya.' In G. Fagan, 2006, 129-53.

Wee, Valerie. 'Teen Television and the WB Television Network.' In Ross and Stein, 2008, 43-60.

Wells, H.G. The War of the Worlds (New York: Tor, 1998). 
Whitesides, Kevin A. 'From Counterculture to Mainstream: 2012 Millennialism in Your Living Room.' In Aston and Walliss, 2013, 74-95.

- and John W. Hoopes. 'Seventies Dreams and 21st Century Realities: The Emergence of the 2012 Mythology.' Zeitschrift für Anomalistik 50 (2012), 50-74.

Whitt, David and John Perlich, eds. Siths, Slayers, Stargates, and Cyborgs: Modern Mythology in the New Millennium (New York: Peter Lang, 2008).

Williams, Linda. 'Mega-Melodrama! Vertical and Horizontal Suspensions of the "Classical."' Modern Drama 55.4 (2012), 523-43.

Williams, Tim. 'Syria: The Hurt and the Rebuilding.' Conservation and Management of Archaeological Sites (March 2016), 1-3.

Wilson, D. Harlan. 'Technomasculine Bodies and Vehicles of Desire: The Erotic Delirium of Michael Bay's Transformers.' Extrapolation 53.3 (2012), 347-64.

Winsor, Morgan. 'ISIS Destroys Iraqi Archaeological Site of Nimrud Near Mosul.' International Business Times (5 March 2015).

Winston, Diane, ed. Small Screen, Big Picture: Television and Lived Religion (Waco, TX: Baylor University Press, 2009).

Wolcott, James. 'Reborn on the Fourth of July.' New Yorker (15 July 1996), 79-80.

Wolfe, Gary. Evaporating Genres (Middletown, CT: Wesleyan University Press, 2011).

Wong, Bill. 'Prometheus Takes Flight with Cutting-Edge VFX Technology.' Electronic Design 60.7 (2012), 26-36.

Wood, Michael. 'The Pharaonic Past as a Component of Modern Egyptian Nationalism.' Journal of the American Research Center in Egypt 35 (1998), 179-96.

Wright, David C., Jr. and Allan W. Austin, eds. Space and Time: Essays on Visions of History in Science Fiction and Fantasy Television (Jefferson, NC: McFarland, 2010).

Yaszek, Lisa. The Self Wired: Technology and Subjectivity in Contemporary Narrative (New York: Routledge, 2002).

-. 'Shadows on the Cathode Ray Tube: Adapting Print Science Fiction for Television.' In Telotte and Duchovnay, 2011, 55-68.

Yu, Timothy. 'Oriental Cities, Postmodern Futures: Naked Lunch, Blade Runner, and Neuromancer.' Multi-Ethnic Literature of the United States 33.4 (2008), 45-71.

Yuen, Wong Kin. 'On the Edge of Spaces: Blade Runner, Ghost in the Shell, and Hong Kong's Cityscape.' Science Fiction Studies 27.1 (2000), 1-21.

Zeidler, James and Laurie Rush. 'In-Theatre Soldier Training through Cultural Heritage Playing Cards: A US Department of Defense Example.' In Rush, 2010, 73-85.

Zeman, Scott C. and Michael A. Amundson, eds. How We Learned to Stop Worrying and Love the Bomb (Boulder, CO: University Press of Colorado, 2004).

Zimmerman, Patricia. 'Soldiers of Fortune: Lucas, Spielberg, Indiana Jones, and Raiders of the Lost Ark.' Wide Angle 6.2 (1984), 34-39.

Žižek, Slavoj. Welcome to the Desert of the Real: Five Essays on September 11 and Related Dates (London: Verso, 2002). 


\section{Filmography}

2001: A Space Odyssey. Dir. Stanley Kubrick (MGM, 1968).

A.I. Artificial Intelligence. Dir. Steven Spielberg (Warner Bros., 2001).

Alien. Dir. Ridley Scott (Brandywine Productions, 1979).

Apocalypse Now. Dir. Francis Ford Coppola (Zoetrope Studios, 1979).

Armageddon. Dir. Michael Bay (Touchstone Pictures, 1998).

The Atomic Café. Dirs. Jayne Loader, Kevin Rafferty and Pierce Rafferty (The

Archives Project, 1982).

Battleship. Dir. Peter Berg (Universal Pictures, 2012).

Behind Enemy Lines. Dir. John Moore (Twentieth Century Fox, 2001).

Black Hawk Down. Dir. Ridley Scott (Revolution Studios, 2001).

Blade Runner. Dir. Ridley Scott (Warner Bros., 1982).

Chariots of the Gods. Dir. Harald Reinl (Terra Film, 1970).

Close Encounters of the Third Kind. Dir. Steven Spielberg (Julia Philips and

Michael Philips Productions, 1977).

Cloverfield. Dir. Matt Reeves (Paramount Pictures, 2008).

Collateral Damage. Dir. Andrew Davis (Warner Bros., 2002).

Cosmos. Dirs. Adrian Malone et al. (KCET, 1980).

The Day After. Dir. Nicholas Meyer (ABC Circle Films, 1983).

The Day After Tomorrow. Dir. Roland Emmerich (Lionsgate Films, 2004).

The Day the Earth Stood Still. Dir. Robert Wise (Twentieth Century Fox, 1951). The Day the Earth Stood Still. Dir. Scott Derrickson (Twentieth Century Fox, 2008).

Die Hard. Dir. John McTiernan (Twentieth Century Fox, 1988).

Earth vs. the Flying Saucers. Dir. Fred F. Sears (Clover Productions, 1956).

Ghosts of Abu Ghraib. Dir. Rory Kennedy (Moxie Firecracker Films, 2007).

The Green Berets. Dirs. Ray Kellogg and John Wayne (Batjac Productions, 1968).

The Incredible Shrinking Man. Dir. Jack Arnold (Universal International Pictures, 1957).

Independence Day. Dir. Roland Emmerich (Twentieth Century Fox, 1996). Indiana Jones and the Last Crusade. Dir. Steven Spielberg (Paramount Pictures, 1989).

Indiana Jones and the Kingdom of the Crystal Skull. Dir. Steven Spielberg (Paramount Pictures, 2008).

In the Valley of Elah. Dir. Paul Haggis (Warner Independent Pictures, 2007). Invaders from Mars. Dir. William Cameron Menzies (Edward L. Alperson Productions, 1953).

Invasion of the Body Snatchers. Dir. Don Siegel (Walter Wanger Productions, 1956).

Ironman. Dir. Jon Favreau (Marvel Studios, 2008).

Ironman 2. Dir. Jon Favreau (Marvel Studios, 2010).

Ironman 3. Dir. Shane Black (Marvel Studios, 2013).

It Came from Outer Space. Dir. Jack Arnold (Universal International Pictures, 1953).

Jaws. Dir. Steven Spielberg (Zanuck/Brown Productions, 1975). 
Jurassic Park. Dir. Steven Spielberg (Amblin Entertainment, 1993).

The Kingdom. Dir. Peter Berg (Universal Pictures, 2007).

King Kong. Dirs. Merian C. Cooper and Ernest B. Schoedsack (RKO Pictures, 1933).

Lawrence of Arabia. Dir. David Lean (Columbia Pictures, 1962).

Lions for Lambs. Dir. Robert Redford (Wildwood Enterprises, 2007).

Manticore. Dir. Tripp Reed (SyFy Pictures, 2005).

Metropolis. Dir. Fritz Lang (UFA, 1927).

The Omen. Dir. Richard Donner (Twentieth Century Fox, 1976).

Planet of the Apes. Dir. Franklin J. Schaffner (Twentieth Century Fox, 1968).

Prometheus. Dir. Ridley Scott (Twentieth Century Fox, 2012).

Raiders of the Lost Ark. Dir. Steven Spielberg (Paramount Pictures, 1981).

Rendition. Dir. Gavin Hood (New Line Cinema, 2007).

Speed. Dir. Jan de Bont (Twentieth Century Fox, 1994).

Stargate. Dir. Roland Emmerich (Canalt, 1994).

Star Trek: Into Darkness. Dir. J.J. Abrams (Paramount Pictures, 2013).

Star Wars. Dir. George Lucas (Lucasfilm Ltd, 1977).

Superman. Dir. Richard Donner (Dovemead Films, 1978).

Terminator 2: Judgment Day. Dir. James Cameron (Carolco Pictures, 1991).

Titanic. Dir. James Cameron (Twentieth Century Fox, 1997).

Transformers. Dir. Michael Bay (DreamWorks Pictures, 2007).

Transformers 2: Revenge of the Fallen. Dir. Michael Bay (DreamWorks SKG, 2009).

Triumph of the Will. Dir. Leni Riefenstahl (Leni Riefenstahl-Produktion, 1935).

The War of the Worlds. Dir. Byron Haskin (Paramount Pictures, 1953).

War of the Worlds. Dir. Steven Spielberg (Paramount Pictures, 2005).

We Were Soldiers. Dir. Randall Wallace (Icon Entertainment International, 2002).

\section{Television}

$7^{\text {th }}$ Heaven. Created by Brenda Hampton (Spelling Television, 1996-2007). Ancient Aliens (Prometheus Entertainment, 2009- ). Apocalypse How? Exec. Producer Bill Hunt (KPI, 2008).

Apocalypse Island. Dir. Edwin Barnhart (NFGTV, 2010).

Babylon 5. Created by J. Michael Straczynski (Babylonian Productions, 2004-08).

Battlestar Galactica. Created by Glen A. Larson (Glen A. Larson Productions, 1978-79).

Battlestar Galactica. Created by Glen A. Larson, Ronald D. Moore and David Eick (British Sky Broadcasting, 2004-09).

Beverly Hills 90210. Created by Darren Star (90210 Productions, 1990-2000). Buffy the Vampire Slayer. Created by Joss Whedon (Mutant Enemy, 1997-2003). Colony. Created by Ryan J. Condal and Carlton Cuse (Legendary Television, 2016-). 
Cosmos: A Personal Voyage. Created by Ann Druyan, Carl Sagan and Steven Soter (Public Broadcasting Service, 1980).

Countdown to Apocalypse. Exec. Producer Johnathan Koch (Asylum Entertainment, 2012).

Dawson's Creek. Created by Kevin Williamson (Outerbanks Entertainment, 1998-2003).

Decoding the Past: Doomsday 2012-The End of Days. Exec. Producer Michael Stiller (Morningstar Entertainment, 2007).

Decoding the Past: The Other Nostradamus. Dir. Mathilde Bitner (Authentic Entertainment, 2005).

The Dukes of Hazzard. Created by Gy Waldron (Lou Step Productions, 1979-85).

In Search of Ancient Astronauts. Created by Alan Landsburg (Alan Landsburg Productions, 1973).

Invasion. Created by Shaun Cassidy (Warner Bros. Television, 2005-06).

Judging Amy. Created by Amy Brenneman et al. (Barbara Hall/Joseph Stern Productions, 1999-2005).

The Lost Book of Nostradamus. Dir Kreg Lauterbach (1080 Entertainment, 2007).

Mayan Doomsday Prophecy. Dir. Kreg Lauterbach (Towers Productions, 2006).

Nostradamus 2012. Dir. Andy Picard (1080 Entertainment, 2009).

Party of Five. Created by Christopher Keyser and Amy Lippman (Columbia Pictures Television, 1994-2000).

Roswell High. Created by Jason Katims (Jason Katims Productions, 1999-2002).

Smallville. Created by Alfred Gough and Miles Millar (Warner Bros. Television, 2001-2011).

Stargate SG-1. Created by Brad Wright and Jonathan Glassner (Sony Pictures Television, 1997-2007).

Surface. Created by Jonas Pate and Josh Pate (NBC Universal Television, 2005-06).

Threshold. Created by Bragi F. Schut (Sky Television, 2005-06).

The Twilight Zone. Created by Rod Serling (Cayuga Productions, 1959-64).

$X$-Files. Created by Chris Carter (Ten Thirteen Productions, 1993-2002). 



\section{Index}

9/11 terrorist attack (WTC terrorist attack) 5-6, 13-14, 16, 17, 49, $50-51,113,138$ post-9/11 cinema 32-43, 38, 61, 72, 96 science fiction and militarism 19-30, 31-43, 60-61

2001: A Space Odyssey (Stanley

Kubrick) 1-3, 4, 10-13, 72, 74, $75,83,135,142,176,188$

Abel, Alfred 24

A.I. Artificial Intelligence (Steven

Spielberg) 17, 72, 135-44

Aldington, Richard 173-74

Aldiss, Brian 137

Alien (Ridley Scott) 18, 167, 169

'alien invasion' genre 64

'allegory lite' trend in cinema 32-43, 47

Ancient Aliens 15, 59, 73-81, 82-94, 104

ancient astronaut narrative 15 ,

$16,72,73-81,80,82-94$

Anderegg, Michael 173, 174, 175

Andersson, Pia 80

Andrews, Rena 23

Apatow, Judd 59

Apocalypse Now 35-36

archaeology

calculated destruction of antiquities 19-22, 34, 191-97

narrative of discovery and adventure 19-21 need for myths of origin 48-49

preservation of global heritage 20-21, 45-47

relationship between invasion of Iraq and archaeological stewardship 33-43, 47, 60 soft power initiatives 21-22, $31-32,61-62$

Armageddon 63

The Atomic Cafe 100

Babylon

symbolism of war and civilization 19-22, 30, 49-58

Tower of Babel symbolism 22-24, 29, 50-52

use as locus in SFFTV 23-30, $49-58$

Babylon 5 23, 28-30

Bahrani, Zainab 22-23

Baker, Chris 137n3

Bakhtin, Mikhail 83-84

Bambani, Ram 39

Bamber, Jamie 152

Banks, Miranda 121

Barthes, Roland 168

Battis, Jes 121, 122

Battleship 63

Battlestar Galactica (Ronald Moore) $17-18,133-34,142,144$, 145-66, 180-81

Baudrillard, Jean 13, 31, 34, 37, $38,57,111,135,141,142,191$, 193,196 
Bay, Michael, Transformers 2:

Revenge of the Fallen 13, 14-15, 16, 23, 30, 59-72, 83, 192

Beebe, Roger 185-86

Behind Enemy Lines 31

Bell, Gertrude 171

Bennett, Eve 156n7

Bennett, Matthew 145

Bernbeck, Reinhard 60, 61, 62, 110

Bhabha, Homi 145, 147, 165-66

Bishop, Lt. Col. Greg 63n4

Biskind, Peter 95

Black Hawk Down 31

Blade Runner (Ridley Scott) 4, 23 , 26-28, 29, 30, 176, 184

Blanchett, Cate 97

Bogdanos, Col. Matthew 33

The Thieves of Baghdad 34, 35

Boggs, Carl 64

Bokova, Irina 193-94

Bonaventura, Lorenze di 64

Booker, Keith 102

Botta, Émile 19

Brake, Mark 76

Brinded, Nicholas 176

Brittain, Marcus 84

Browder, Ben 55

Buffy the Vampire Slayer 113

Bukatman, Scott 176, 180, 183-84, 187

Burdick, Ben 38

Bush, George W. 71, 193

Caldwell, John 116

Call, Lewis 150

Callis, James 152

Campbell, Joseph 88

Carlson, John 89-90

Carruthers, Susan 40

Cassidey, Joanna 26

Caton, Steven 189

Chapman, Jeannie 93

Chariots of the Gods? (Erich Von

Däniken) 46, 77-78, 81,

95-96
Cheney, Dick 65

Cheung, Floyd 46-47

Childress, David 88, 90

Clack, Timothy 84

Clarke, Arthur C. 11-12

Cloverfield (Matt Reeves) 6

Coe, Michael 89

Collateral Damage 31

Collignon, Fabienne 103

Cooper, Merian 6

Cornea, Christine 6n5

Cowan, Douglas 48

Cruise, Tom 6

Csicsery-Ronay, Istvan 7, 10, 46, 142

cyborg themes 25-26, 135-44

Daoud, Kamel 196

The Day After 100

The Day After Tomorrow (Roland Emmerich) 6

The Day the Earth Stood Still 102

De Blasio, William 195

DeRosa, Aaron 101

Derrida, Jacques 22

Dickie, Kate 180

Dillon, Grace 147n2, 163

Dixon, Wheeler Winston 102-03

Donner, Richard 5

Douglas, Aaron 158

Durance, Erica 125

Earth vs. the Flying Saucers 102

Eco, Umberto 128-29

Elba, Idris 185

Emmerich, Roland The Day After Tomorrow 6 Independence Day 6n5

Stargate 13, 14, 16, 45, 47, 49, 50

Evans, Maurice 74

Eyerman, Chris 167

Fagan, Brian 42 Return to Babylon 19-20 
Fagan, Garrett 78, 79

Fahey, Jeff 37

Fanning, Dakota 6

Farghaly, Nadine 129

Fassbender, Michael 168

Feder, Kenneth 78, 79, 81

Feldman, Tamara 115

Flanagan, Martin 66-67

Flemming, N.C. 79

Ford, Harrison 27, 96

Fortin, David 23

Foucault, Michel 4

Fouladi, Shahriar 116

Fox, Megan 59

Frank, Thomas, What's the Matter with Kansas? 120

Freedman, Carl 2

Freeman, Cassidy 130

Freud, Sigmund 179

Fröhlich, Gustav 25

Galtung, Johan 60-61

Gannon, Charles 100

George, Heinrich 24

George, Jarvis W. 55

Geraghty, Lincoln, American

Science Fiction Film and

Television 6

Gibson, William 44

Giger, H.R. 183

Gleeson, Brendan 139

Gomel, Elana 83-84

González-Ruibal, Alfredo 66 Ethics and the Archaeology of Violence 61-62

Gough, Alfred 113

Gregory, Derek 59

Griaule, Marcel 77

Grünschloss, Andreas 80

Guinness, Alec 175

Gulf War films, emphasis on action-adventure rather than geopolitics 32-43

Gullapalli, Praveena 161

Gumpert, Matthew 165

Gunning, Tom 24, 25
Hales, Peter Bacon, Atomic Spaces 100

Hamilakis, Yannis 2, 8, 14, 20-21, 52-53

Hancock, Graham 85

Hantke, Steffen 102

Haraway, Donna 17, 136, 141, $142,143,144,181$

Harrison, Rodney 8

Hauer, Rutger 27-28

Helfer, Tricia 146

Helm, Brigitte 24

Henriksen, Lance 168

Heston, Charlton 74

Hiscock, Peter 73

Hogan, Michael 130-31, 160

Hogarth, D.G. 171-72

Hogg, James 26

Holm, Ian 168

Holtorf, Cornelius 9, 15, 80

Hoopes, John 89, 90

Humphries, Harry 63

Hunter, Edward 107

Hurt, John 182

Hurt, William 138

Hussein, Saddam 36, 38n10, 40, 52

In the Valley of Elah 32, 40nll

Independence Day (Roland

Emmerich) 6n5

Indiana Jones and the Kingdom of the

Crystal Skull (Steven Spielberg)

15-16, 94, 95-111

Invaders from Mars 102

Invasion of the Body Snatchers 102

Ironman franchise 63

It Came from Outer Space 102

James, Daniel 176

Jameson, Fredric 1, 4-5, 197

Johnson, Eric 125

Johnston, Keith, Science Fiction

Film 4

Jones, Cary 115

Judge, Christopher 55 
Kakoudaki, Despina 139

Kennedy, Arthur 175

Kennedy, Christina 174

Kennedy, Rory, The Ghosts of Abu Ghraib 40

Kersel, Morag 21, 53, 61, 62, 110,111

Khatib, Lina 66, 69-70 Filming the Modern Middle-East 66

Kienscherf, Markus 109

The Kingdom 32

Kingsley, Ben 141

Klein-Rogge, Rudolph 25

Kohnen, Melanie 123

Kosso, Peter 78-79

Kubrick, Stanley 76-77, 137n 3

2001: A Space Odyssey 1-3, $4,10-13,72,74,75,83$, $135,142,176,188$

Kulle, Daniel 114

Kustritz, Anne 123, 126

LaBeouf, Shia 59-60

Lacy, Mark 32n3

Landy, Marcia 2n3, 11-12

Lang, Fritz, Metropolis 23-26, 27, 29,30

Law, Jude 138

Lawrence of Arabia (David Lean) 167-90, 196, 197

Lawrence, T.E. 167-90

The Seven Pillars of Wisdom 18, 172, 175

Layard, Austen Henry 19

Lean, David, Lawrence of Arabia 167-90, 196, 197

Leonard, Garry 2

Liedl, Janice 158

Lions for Lambs 32

Löfflmann, Georg 63, 64

Lucas, George 95, 96, 99

Luckhurst, Roger 5-6

Luke, Christina 21, 53, 61, 62, 110,111
McBride, Joseph 96

McDowall, Roddy 74

McDowell, Mary 150

Macfie, Lyon 173

McGurk, Gary 28-29

McHale, Brian, Postmodernist Fiction 83n 3

Mack, Allison 132-33

McKnight, Nadine 156n7

Maltby, Robert 32

Manticore (Tripp Reed) 13-14, $16,30,33-43,47,66,72$

Marmysz, John 177

Marshall-Green, Logan 176

Masco, Joseph 103-04

Masterson, Chase 38

Mayan prophesies 89-93

Melley, Timothy 95, 101, 107-08

Meskell, Lynn 20

Metropolis (Fritz Lang) 23-26, $27,29,30$

Michel, Roger 194-95

military

cinema as medium for military self-promotion 63-64

interest in cinematic narrative of global political role 63-64

military-archaeology complex 31-43, 47, 60

Millar, Miles 113

Mirrlees, Tanner 62-63

Mirzoeff, Nicholas 30, 40 symbolism of Babylon 19, 21-23, 57

Watching Babylon 57

Mitchell, Timothy, Colonising Egypt 46

Mittell, Jason 119-20, 121

Moore, Ronald 147-48, 162-63, 164

Battlestar Galactica 17-18, 133-34, 142, 144, 145-66, $180-81$

Morton, Rob 115 
Moshenska, Gabriel 66 Ethics and the Archaeology of Violence 61-62

Moylan, Katie 165

Nelson, Thomas 12

Nemeth, Erik 97, 110-11

Netter, Douglas 28

O'Connor, Frances 138

O'Hare, Michael 28

Olmos, Edward James 146

The Omen 85

O'Toole, Peter 170

Park, Grace 150

Pearce, Guy 167

Pearson, Mike 9-10

Penikett, Tahmoh 152

Piette, Adam 103

Pine, Chris 82

Planet of the Apes (Franklin J.

Schaffner) 74-75, 83, 138

Pollard, Tom 64

Pope, Richard 27

Potter, William 169, 170

Pratt, Keri Lynn 130

Preucel, Robert 20

Prometheus (Ridley Scott) 18, 133-34, 144, 167-90, 196-97

Purse, Lisa 62, 71

Pyburn, Anne 195-96

Rains, Claude 182

Rapace, Noomi 176

Reed, Tripp, Manticore 13-14, 16, 30, 33-43, 193

Reeves, Matt, Cloverfield 6

Rendition 32

Rennie, Callum Keith 148-49

Reyes, Ian 91-92

Richter, Jonas 80

Richter, Tobias 172

Rieder, John 106, 163-64

Riefenstahl, Leni, Triumph of the Will 169
Ross, Miriam 187

Russell, John 35

Sackhoff, Katee 146

Sagan, Carl 75-77, 80

The Cosmic Connection 75-76

Cosmos 75

Said, Edward 172-73, 174, 180, 190

Culture and Imperialism 46

Orientalism 172

Schadla-Hall, Tim 80

Schaffner, Franklin J., Planet of the Apes 74-75, 83, 138

Schneider, John 116, 120

Schoedsack, Ernest, King Kong 6

Scott, Ridley 167-68

Alien 18, 167, 169

Blade Runner 4, 23, 26-28, 29, 30, 176, 184

Prometheus 18, 133-34, 144,

167-90, 196-97

Shanks, Michael 8-10, 16, 17, 44, $114,129,136-37,139,144$

Sharma, Rekha 160

Shelley, Mary, Frankenstein 181

Shimpach, Shawn 123

Shklovskii, I.S., Intelligent Life in the Universe 76

Shoup, Daniel 7

Silverman, Kaja 27

Sitchin, Zecharia, The Twelfth Planet 83

Smallville 16, 94, 111, 112-34

Smith, Jason 91-92

Smith, Stephanie 185

Smith, Stephen 31, 33-34

Sobchack, Vivian 82, 167-68, 171

Sofia, Zoë 135

Sontag, Susan 3-4

Spall, Rafe 179

Spielberg, Steven 42, 96, 104, 184

A.I. Artificial Intelligence 17, 72, 135-44

Close Encounters of the Third Kind 88 
Indiana Jones and the Kingdom of the Crystal Skull 15-16, 94, 95-111

Indiana Jones and the Last Crusade 65, 95

Jurassic Park 137

War of the Worlds 6-7

Stait, Brent 112

Star Trek 47

Star Trek: Into Darkness 82-83

Stargate (Roland Emmerich) 13, $14,16,45,47,49,50$

Stargate $S G-1 \quad 23,30,43,44-58$, 93

Stockwell, Dean 158

Straczynski, J. Michael 28

Strauss, Richard 11

Streitenfeld, Marc 176

Strub, Phil 63

Superman 85

Tahir, Faran 37

Tapping, Amanda 50

Telotte, J.P. 6, 18

Terminator 2: Judgement Day 100

Thomas, Lowell 173, 174-75

Titus, Constandina 100

Todd, Tony 55

Tootoosis, Gordon 115

Transformers 2: Revenge of the Fallen (Michael Bay) 13, 14-15, 16, 23, 30, 59-72, 83, 192
Trucco, Michael 160

Tsoukalos, Giorgio 82, 91, 92-93

Turturro, John 66, 68

Urban, Karl 82

Vernon, Kate 160

Vint, Sherryl 47, 74, 179

Von Däniken, Erich 90

Chariots of the Gods? 46, 77-78, 81, 95-96

Wayne, John, The Green Berets 40

We Were Soldiers 31

Webster, David 89

Welles, Orson 88-89, 94

Welling, Tom 112

Wells, H.G., The War of the Worlds 6, 88-89, 102

Whitesides, Kevin 89, 90

Wilson, Harlan 71

Wolcott, James 59

Wolfe, Gary 3, 4, 83-84

Woolley, Leonard 171-72

The $X$-Files 85

Yaszek, Lisa 144, 184

Young, Jonathan 88

Yu, Timothy 26

Žižek, Slavoj 5 



